\title{
Comparative metabolism of warfarin and acenocoumarol: stereoselectivity in oxidative and reductive biotransformation routes
}

Citation for published version (APA):

Hermans, J. J. R. M. (1993). Comparative metabolism of warfarin and acenocoumarol: stereoselectivity in oxidative and reductive biotransformation routes. [Doctoral Thesis, Maastricht University]. Rijksuniversiteit Limburg. https://doi.org/10.26481/dis.19921217jh

Document status and date:

Published: 01/01/1993

DOI:

10.26481/dis.19921217jh

Document Version:

Publisher's PDF, also known as Version of record

Please check the document version of this publication:

- A submitted manuscript is the version of the article upon submission and before peer-review. There can be important differences between the submitted version and the official published version of record.

People interested in the research are advised to contact the author for the final version of the publication, or visit the DOI to the publisher's website.

- The final author version and the galley proof are versions of the publication after peer review.

- The final published version features the final layout of the paper including the volume, issue and page numbers.

Link to publication

\footnotetext{
General rights rights.

- You may freely distribute the URL identifying the publication in the public portal. please follow below link for the End User Agreement:

www.umlib.nl/taverne-license

Take down policy

If you believe that this document breaches copyright please contact us at:

repository@maastrichtuniversity.nl

providing details and we will investigate your claim.
}

Copyright and moral rights for the publications made accessible in the public portal are retained by the authors and/or other copyright owners and it is a condition of accessing publications that users recognise and abide by the legal requirements associated with these

- Users may download and print one copy of any publication from the public portal for the purpose of private study or research.

- You may not further distribute the material or use it for any profit-making activity or commercial gain

If the publication is distributed under the terms of Article $25 \mathrm{fa}$ of the Dutch Copyright Act, indicated by the "Taverne" license above, 
COMPARATIVE METABOLISM OF WARFARIN AND ACENOCOUMAROL:

STEREOSELECTIVITY IN OXIDATIVE AND REDUCTIVE BIOTRANSFORMATION ROUTES 


\section{COMPARATIVE METABOLISM OF WARFARIN AND ACENOCOUMAROL: \\ STEREOSELECTIVITY IN OXIDATIVE AND REDUCTIVE BIOTRANSFORMATION ROUTES}

\section{PROEFSCHRIFT}

Ter verkrijging van de graad van doctor aan de Rijksuniversiteit Limburg te Maastricht op gezag van de Rector Magnificus, Prof. Mr. M.J. Cohen volgens het besluit van het College van Dekanen, in het openbaar te verdedigen op donderdag 17 december 1992 om 14.00 uur door

Johannes Jozef Robertus Maria Hermans 
Promotor: Prof. dr. H.A.J. Struijker Boudier

Co-promotor: Dr. H.H.W. Thijssen

Beoordelingscommissie: Prof. dr. P.J. Brombacher, voorzitter

Dr. P.J.A. Borm

Dr. K. Hamulyak

Dr. E. Maser, Philips Universităt, Marburg a/d Lahn, Duitsland

Prof, dr. H. Timmermans Vrije Universiteit, Amsterdam

CIP gegevens Koninklijke Bibliotheek. Den Haag

Hermans, Johannes Jozef Robertus Maria

Comparative metabolism of warfarin and acenocoumarol: stereoselectivity in oxidative and reductive biotransformation routes

Johannes Jozef Robertus Maria Hermans - (S.I. : s.m.). - ILL.

Proefschrift Maastricht - Met lit.opg. - Met samenvatting in het Nederlands ISBN 90-900 5646 - 7 geb.

Trefw.: Warfarine analoga/stereoselectiviteit/biotransformatie.

Lay-out-lithografie: Artpie, Kerkrade

Druk: Drukkerij Bakker. Merkelbeek

Bindwerk: M.v.d. Berg. Simpelveld 
Aan: mijn ouders 


\section{CONTENTS}

\section{Chapter 1}

General introduction 9

1.1 Stereochemical tems 9

1.2 Chirality in chemical-biological interactions 11

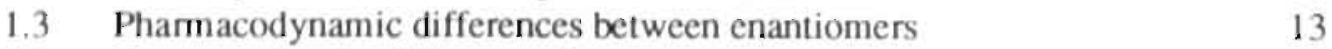

1.4 Phamacokinetic differences between enantiomers 15

1.4.1 Stereoselective uptake of drugs trough the gut wall 16

$\begin{array}{lll}\text { 1.4.2 Stereoselective tissue uptake } & 16\end{array}$

1.4.3 Stereoselective plasma protein binding $\quad 16$

$\begin{array}{lll}1.4 .4 & \text { Stereoselective renal clearance } & 17\end{array}$

1.4.5 Stereoselective metabolism 19

1.4.5a Substrate stereoselectivity $\quad 19$

$\begin{array}{ll}\text { 1.4.5b Product stereoselectivity } & 21\end{array}$

1.4.5c Chiral inversion $\quad 22$

1.4.5d Stereoselective first-pass metabolism 23

1.5 Siereochemical aspects in the phamacology of warfarin and acenocoumarol 23

1.5.1 Warfarin and acenocoumarol: general infonnation 24

1.5.2 The mechanism of action of 4-hydroxycoumarin anticoagulants 25

I.5.3 Clinical pharmacology of warfarin and acenocoumarol 27

1.5.4 Phamacokinetics of the enantiomers of warfarin and acenocoumarol 27

1.5.5 Biotransformation of the enantiomers of warfarin and acenocoumarol 30

1.5.6 Stereoselective drug-interactions with warfarin and acenocoumarol 31

1.5.6a Stereoselective interactions with the S-enantiomer 31

1.5.6b Stereoeselective interactions with the R-enantiomer 31

1.5.6c Non stereoselective interactions $\quad 32$

1.5.6d Other interactions 32

I.6 Aim of this thesis 32

1.7 Outline of this thesis $\quad 33$

1.8 References $\quad 34$ 


\section{CONTENTS}

\section{Chapter 2}

Enantioselective structure-pharmacokinetic relationships of ring substituted warfarin analogues in the rat.

2.1 Abstract

2.2 Introduction

2.3 Materials and methods $\quad 4.4$

2.4 Results 49

2.5 Discussion 51

2.6 References $\quad 54$

\section{Chapter 3}

Comparison of the rat liver microsomal metabolism of the enantiomers of warfarin and 4'-nitrowarfarin (acenocoumarol)

3.1 Abstract

3.2 Introduction

3.3 Materials and methods $\quad 58$

3.4 Results 63

$\begin{array}{lll}3.5 & \text { Discussion } & 75\end{array}$

$\begin{array}{lll}3.6 & \text { References } & 77\end{array}$

\section{Chapter 4}

Comparative biotransformation of warfarin analogues in human liver microsomes: 4'-substitution modifies cytochrome P450 isozyme selectivity

$\begin{array}{llr}4.1 \text { Abstract } & 80\end{array}$

$\begin{array}{lll}4.2 & \text { Introduction } & 81\end{array}$

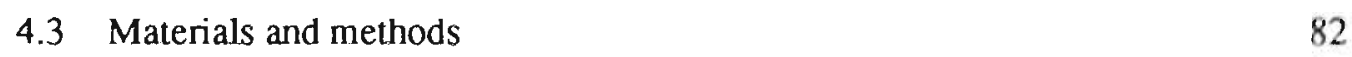

4.4 Results $\quad 84$

4.5 Discussion 91

4.6 References 95 


\section{CONTENTS}

\section{Chapter 5}

The in vitro ketone reduction of warfarin and analogues. Substrate stereeselectivity, product stereoselectivity and species differences.

5.1 Abstract

98

5.2 Introduction

5.3 Materials and methods

5.4 Results

5.5 Discussion

104

5.6 References

\section{Chapter 6}

Stereoselective acetonyl side chain reduction of warfarin and analogues: partial characterization of two cytosolic carbonyl reductases.

6.1 Abstraci

6.2 Introduction

6.3 Materials and methods

6.4 Results

6.5 Discussion

6.6 References

\section{Chapter 7}

General discussion

7.1 The basis of the pharmakokinetic differences of the enantioners of warlarin and acenocoumarol

7.2 Complexity of enantiomeric differences

7.3 Enantiomers as tools in biomedical science

7.4 Enatiomerically pure versus racemic drugs:

7.5 References

\section{Chapter 8}

Summary

$\begin{array}{lll}8.1 & \text { Summary } & 136\end{array}$

$\begin{array}{ll}8.2 \text { Samenvatting } & 138\end{array}$

Curriculum vitae $\quad 141$

Lijst van publicaties $\quad 142$

Full papers $\quad 142$

Abstracts $\quad 143$ 


\section{CHAPTER 1:}

\section{GENERAL INTRODUCTION}

\subsection{STEREOCHEMICAL TERMS:}

Three-dimensional structures, such as molecules, can exist as each others mirror images without being superimposable on each other. The property of an object or a molecule to have a non-identical mirror image is termed chirality (IUPAC, 1970). The term chirality is similar to 'handedness' and is derived from the Greek $\chi \varepsilon i \rho$. The phenomenon chirality is evident if two hands are considered: although the left and right hand appear identical, and can be considered each others mirror images, they are not superimposable. This has great implications since other chiral objects such as gloves may fit to one hand but not to the other.

Molecules that are each others mirror image but that are not superimposable are called enantiomers (enantios morphe: opposite shape) (IUPAC 1970, Waine 1988). Enantiomeric compounds mostly possess a chiral centre, but sometimes a chiral axis or plane. In most cases, chiral centres are tetravalent carbon atoms (figure 1.1) but amongst others, may also be nitrogen, phosphorus or sulphur. Enantiomers display virtually similar physico-chemical properties such as solubilities, boiling- and melting points. Compounds containing more than one chiral element are called diastereomers. Since diastereomers are not necessarily each others mirror image, they may possess quite different physico-chemical properties.

Pure enantiomers or chiral diastereomers possess optical activity, i.e. when a beam of plane-polarized light is transmitted through (a solution of) a chiral compound, the plane of polarization will be rotated. Enantiomers will rotate the polarization plane in the opposite direction than their enantiomeric counterparts. Optical activity is annotated (t) or d (dextrorotatory) when the polarization plane of the light is rotated to the right (clockwise) and $(-)$ or 1 (levorotatory) when the polarization plane is rotated to the left (counterclock wise). I/ 1 mixtures of the corresponding $(+)$ - and $(-)$ - enantiomers are racemates and do not possess optical activity. Optical activity of natural tartrate was first discovered by Jean-Baptiste Biot in 1815 (reviewed by Drayer 1988). However, it was Louis Pasteur in 1848, who related this phenomenon with molecular asymmetry, by comparing cristals of natural and synthetic tartrate (which is not optically active). Finally, Van 't Hoff and Le Bell postulated that this asymmetry was due to the presence of an asymmetrical carbon atom (i.e. a carbon atom to which four different groups are attached).

Optical rotation by a compound is not only dependent on its structure (although there is no clear structure-optical activity relationship) but also depends on its concentration, the solvent in which the compound is dissolved and the wavelength of the light with which optical activity is determined (Roberts and Caserio, 1977). Therefore, optical activity gives virtually no information on the three dimensional structure of the enantiomers. In order to obtain insight in the three dimensional structure of enantiomers, and to introduce a clear nomenclature, chiral molecules were originally chemically transformed to an arbitrarily chosen standard (+)-glyceraldehyde, which was assigned the D configuration by Fisher in 1919. 


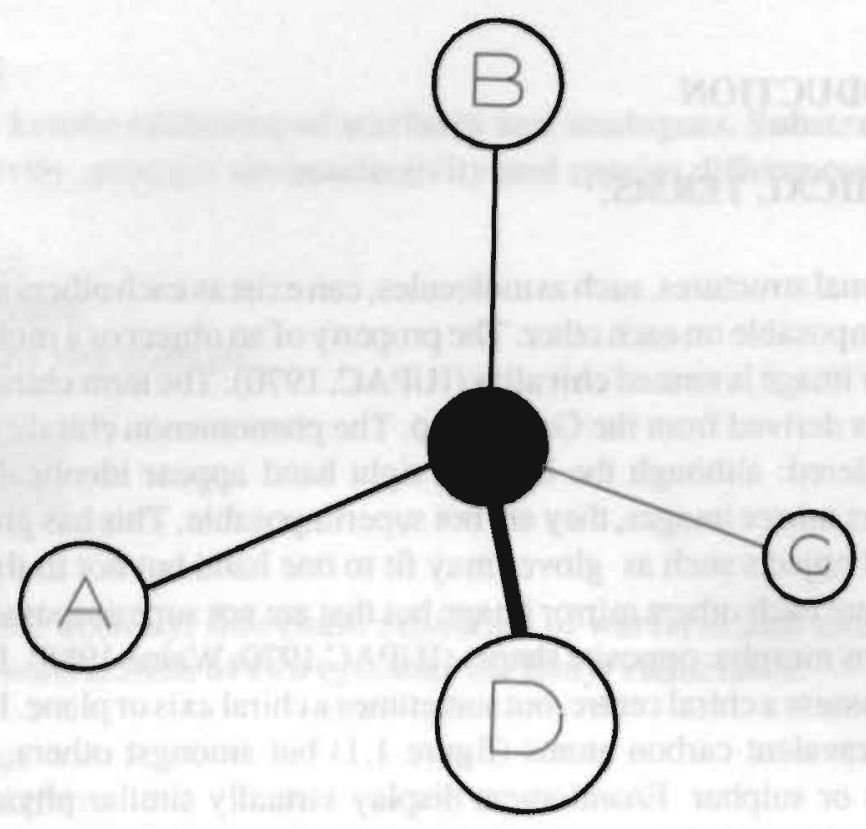

Figure 1.1: Representation of a chiral molecule. Groups A,B,C, and D represent four different atoms (or isotopes) or groups of atoms. The (carbon) atom to which these groups are attached is called an asymmetric (carbon) atom.

TABLE 1.1: Stereochemical terms in pharmacology.

Enantiomer a compound with a non-superimposable mirror image.

Chirality: the property of objects or molecules to be non-superimposable on their mirror image. Diastereomer. compounds containing more than one chiral element.

Eutomer: enantiomer with higher biological activity or affinity towards biomolecules than its counterpart.

Distomer: enantiomer with lower biological activity or aftinity towards biomolecules than its counterpart.

Eudismic ratio: quotient of the affinity/activity of the eutomer and the distomer.

Eudismic index: logarithm of the eudismic ratio. 
The opposite enantiomer was assigned the L configuration (not to be confused with the $\mathrm{d}$ and I prefices of optical activity). This Fisher Convention is still often used for naming (derivatives of) enantiomeric biological molecules such as sugars or amino acids. Since other techniques for determining the three-dimensional structure of molecules became available and because uniform conversion to (+)- or (-)-glyceraldehyde often is difficult, the RS Convention of Cahn, Ingold, and Prelog was introduced (Cahn et al, 1956).

This RS Convention implies that enantiomers are named on the basis of the rank order of the atoms or groups that are attached to a chiral centre. Rank orders are determined by sequence rules (atomic number, mass number in the case of isotopes, number of carbon atoms in alkanes, etc) as described by Cahn et al (1956) and the IUPAC (1970). The rank order numbers of the attached groups increase with decreasing priorities of the groups. If the group with the highest rank order number is positioned behind the plane of projection and the (other) rank order numbers increase clockwise, the enantiomers will have the R-(rectus; right) configuration. If the rank orders increase counterclockwise, the enantiomers will be assigned the S-(sinister; left) configuration. This nomenclature allows us to derive the three dimensional structure of enantiomers or diastereomers directly from their name and vice versa.

To date, the above discussed nomenclatures are all in use but the application of one single nomenclature for optical activity and one single nomenclature for absolute configurations would be beneficial as has been discussed by Simonyi et al (1989).

\subsection{CHIRALITY IN CHEMICAL-BIOLOGICAL INTERACTIONS:}

As has been stated above, apart from optical activity, enantiomers possess virtually identical physico-chemical properties. Nevertheless, large differences between enantiomers in their interaction with biological systems are often observed (reviews on this subject are given by Simonyi, 1984; Lam, 1988; Smith, 1989; and Maher and Johnson 1991). This is not surprising if it is realized that biological molecules are generally asymmetric. Firstly, the building blocks of macromolecules (amino acids and sugars) are chiral. Secondly, the threedimensional structure of macromolecules only allows the binding and interaction of ligands if specific spatial citeria are met. In fact, many hormones (for instance peptide hormones and steroids), neurotransmitters (such as (nor)adrenalin) and other regulating endogenous substances (e.g. prostaglandins) are chiral. However, for regulating biological compounds, chirality is not a rule: for instance, acetylcholine, dopamine, gamma-aminobutyric acid, serotonin, and histamine all are achiral. Nevertheless, their receptors display marked stereoselectivity towards chiral drugs (Simonyi, 1984).

It has been hypothetised (Mason. 1984: Mason, 1986; Waechtershauser, 1991) that homochirality of biological molecules in the prebiotic era arose from chemical synthesis on asymmetric mineral catalytic templates such as pyrite or quartz to form asymmetric amino acids and sugars. The amino acids then polymerized to form peptides that served as new, and more efficient chiral catalysts. 
Chirality of the resulting biomolecules can be considered the basis of the observed differences between enantiomers in their interaction with biological systems.

Already in 1933, Easson and Stedman proposed a model to explain the large differences in the biological activities of (+)- and (-)-adrenaline and in the miotic activities of some asymmetric urethanes (Easson and Stedman, 1933).
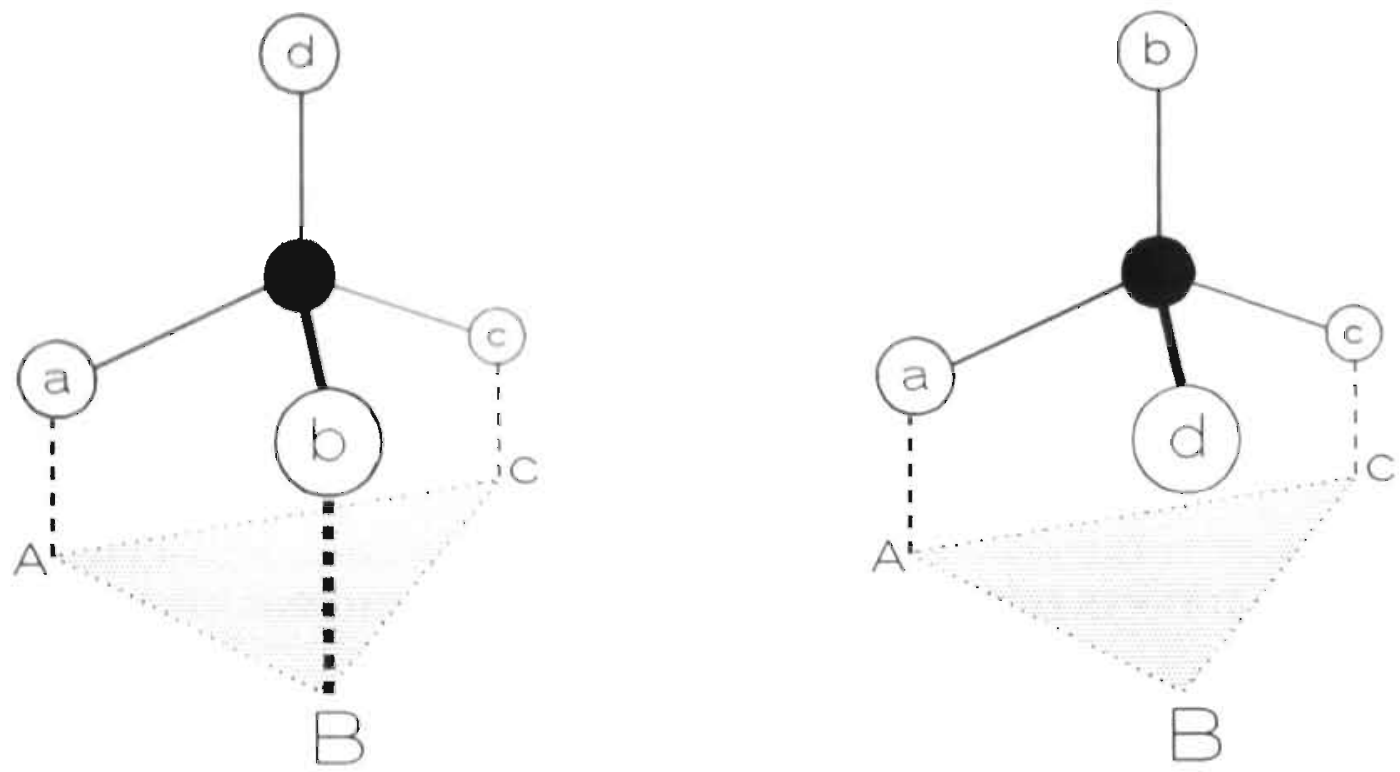

Figure 1.2: The three point allachement model proposed by Easson and Stedman (1933). An optimal fit of the ligands groups with the receptor is achieved when the ligand groups a, b. and c are able to bind to receptor groups A. B, and C respectively. For a chiral drug this is possible for only one enantiomer (left figure). Of the other enantiomer only two ligand groups can be attached to their corresponding receptor site (right figure).

Their three point attachement modei (figure 1.2) implies that in an optimal receptor ligand interaction, three ligand groups are important. In asymmetric molecules, only one of the enantiomers (the most active) will have the configuration that allows all three groups to interact with the receptor. In the case of the less active enantiomer however, maximally two 
groups interact with the receptor and thus the ligand-receptor interaction will be less effective.

From a pharmacological point of view, Rodrigues de Miranda (1975) and Lehman (1976. 1986) introduced the term eutomer for the most active enantiomer and the term distomer for the less active. The eudismic ratio is defined as the quotient of the affinity or activity of the eutomer and that of the distomer. The eudismic index is the logarithm of the eudismic ratio. The eudismic ratio will increase with the affinity of the eutomer. This relation was first given by Pfeiffer (1956) and demonstrates that the higher the affinity of the eutomer is, the more complementary the ligand-receptor interaction will be.

The fact that enantiomers have different biological properties has lead Arièns to the statement that racemic drugs are actually a mixture of two completely different drugs, with different pharmacological and toxicological properties, and that one of the enantiomers can be considered as isomeric ballast (Ariëns, 1984). An example, which is often cited to illustrate the importance of recognizing differences between enantiomers in their interaction with biological systems is thalidomide (Simonyi, 1984; Mason, 1984: de Camp, 1989; Williams. 1990; Lennard, 1991). This compound was initially used as a sedative; later it was shown to be teratogenic in humans. This prompted several investigators to study the teratogenicity of the thalidomide enantiomers. Fabro et al (1967) did not find any difference between the enantiomers and the racemate in teratogenic potency. However, closer inspection of these data by Simonyi revealed that the racemate was in fact twice as potent as teratogen as the individual enantiomers (Simonyi, 1984). Other studies reported that the teratogenicity of thalidomide may predominantly reside in the $S(-)$-enantiomer or metabolites thereof (Blaschke et al, 1979). As has been discussed by de Camp (1989), species and strain differences may play a role in the teratogenicity of thalidomide and its enantiomers. This example shows the complexity of enantiomeric interactions with biological systems.

In paragraphs 1.3 and 1.4, some examples of the differences between enantiomers on the pharmacodynamic (paragraph 1.3) as well as on the pharmacokinetic level (paragraph 1.4) will be given. The examples will demonstrate that enantiomers have different effects not only because of their distinct three dimensional structure, but also because of the large diversity of biomolecules with which they can or cannot interact.

\subsection{PHARMACODYNAMIC DIFFERENCES BETWEEN ENANTIOMERS:}

Phamacodynamics describes the effects of a compound on a biological system. Compounds elicit their effect by interaction with effector molecules (such as receptors, ion channels, and enzymes).

Differences between enantiomers (or stereoisomers) in their interaction with receptors are well documented (Ariëns et al, 1983; Jamali et al, 1989). These differences are the result of the different three-dimensional structures of the enantiomers in combination with the stereochemical requirements of the receptors with which the enantiomers interact (A riëns et 
al, 1983). Different interactions at the receptor level can occur because: 1) enantiomers have different affinities towards receptors 2) enantiomers have different intrinsic activities (maximal responses) or 3) enantiomers interact to various extents with different (sub)types of receptors.

Differences in affinities between enantiomers towards receptors are observed for fenoldopam, a dopamine agonist. The EC50 value of the R-enantiomer to relax norepinephrine contracted rabbit arterial segments is about 10 times lower than that of the Senantiomer (Ohlstein et al, 1984).

Another example of chiral ligands of which the enantiomers have different affinities towards receptors will be discussed for $\beta$-adrenoceptor ligands. Morris and Kaumann (1984) determined the affinities of the enantiomers of chiral $\beta$-adrenoceptor agonists (isoprenaline, adrenaline, and noradrenaline) partial agonists (prenalterol, practolol, alprenolol, and pindolol) and antagonists (atenolol, bupranolol, and propranol) towards $\beta_{1}$-receptors in calf heart and $\beta_{2}$-receptors in calf lung. In all cases, the affinity of the (-)-enantiomers was higher than the affinity of the (+)-enantiomers. However, the eudismic ratios observed for $\beta_{1}$-adrenoceptors were higher than those observed for the $\beta_{2}$-adrenoceptors. For instance, of the antagonists tested eudismic ratios for $\beta$,-receptors varied from 12 (atenolol) to 1450 (pindolol), whereas for $\beta_{2}$-receptors eudismic ratios varied from 6 (atenolol) to 200 (pindolol). These differences between $\beta_{1}$-and $\beta_{2}$-receptors could be partially attributed to the fact that $\beta_{2}$-receptors are more dependent on the lipophilicity of the ligands, so that the contribution to the binding to these receptors by factors different from the complementary 3 dimensional orientation of the ligand is relatively higher (El Tayar et al, 1988).

Different stereochemical demands between receptor subtypes are also shown for $\alpha_{1}$ - and $\alpha_{2}$-adrenergic receptors (reviewed by Ruffolo, 1983). It appears that $\alpha_{2}$-receptors are more sensitive for the three-dimensional structure of their ligands than $\alpha_{1}$-receptors. For instance, the $(-) /(+)$ enantiomeric activity ratio of noradrenaline is 107 for $\alpha_{1}$-receptors and 479 for $\alpha_{2}-$ receptors, whereas the RS/SR ratio of the diastereomeric compound $\alpha$-methylnoradrenaline is 60-fold for $\alpha_{1}$ - and 550-fold for $\alpha_{2}$-receptors (Ruffolo, 1983).

The different pharmacological effects of enantiomers are not only due to the different affinities that the enantiomers may have towards a variety of receptors, but may also be due to disparities in the intrinsic activities of the enantiomers when bound to a certain type of receptor. An example of this is 3-(3-hydroxyphenyl)-N-n-propylpiperidine (Hjorth et al, 1983). Bothenantiomeris are agonists for presynaptic dopaminergic receptors but at postsynaptic dopamine receptors, the S-enantiomer is an agonist, whereas the R-enantiomer is an antagonist. Different intrinsic activities are also observed for the enantiomers of dobutamine, which possesses both $\alpha$ - and $\beta$-adrenergic activity (Ruffolo, 1983). Bothenantiomers possess $\beta$-agonist activity, the (+)-enantiomer being the most potent. However, only the (-)enantiomer has significant $\alpha$-agonist activity which can be antagonized by the (+)-enantiomer. possessing only very weak partial agonist activity. 
As has been stated above, in some cases enantiomers or stereoisomers interact with different receptor (sub)types, resulting in differential effects. An example thereof is provided by labetolol, which actually is a diastereomeric compound. The mixture of the four diastereomers has $\alpha$-and $\beta$-adrenoceptor blocking activities. Brittain et al (1982) showed that in anaesthetized dogs and in isolated tissues, only the RR-diastereomer has significant $\beta_{1}$ - and $\beta_{2}$-blocking activity: of the other diastereomers 10-40 times higher doses are required. In contrast, the $\alpha_{1}$-blocking potency of labetolol resides in the SR-diastereomer, the other diastereomers being 5-20 times less potent. Of all diastereomers, only the RR-diastereomer is equally effective as antihypertensive as the mixture of the four stereoisomers (Gold et al, 1982).

All of the above considerations conceming enantiomer-receptor interactions (i.e. enantiomeric differences in affinity, intrinsic activity and in the selectivity towards specific biomolecules) also hold for chiral compounds that elicit an effect by enzyme inhibition or by modulation of ion channels. For example, the S-enantiomers of NSAIDs of the arylproprionic acid type display a higher affinity towards cyclooxygenases in vitro and are therefore effective as inhibitors of the prostaglandin synthesis at lower concentrations than their enantiomeric counterparts (Caldwell et el, 1988). Inhibition of different enzymes by enantiomers is for instance observed for the competitive monoamino oxidase inhibitor N[3-(2,4-dichlorophenoxy)propyl]- $\mathrm{N}$-methyl-3-butyn-2-amine (a clorgyline derivative). In rat liver mitochondria, the $\mathrm{R}$-enantiomer has a higher affinity towards monoaminooxidase $\mathrm{A}$, whereas the S-enantiomer has a higher affinity towards monoaminooxidase B (Dostert et al, 1992). Finally, the occurence of differences in the intrinsic activities of enantiomers is exemplified by the dihydropyridine BAY K 8644 . In rabbit heart and aorta, the $R(+)$-enantiomer of $B A Y$ $\mathrm{K} 8644$ is a calcium entry blocker; in contrast, the $\mathrm{S}(-)$-enantiomer activates calcium channels (Franckowiak et al, 1985).

\subsection{PHARMACOKINETIC DIFFERENCES BETWEEN ENANTIOMERS:}

Pharmacokinetics describes the fate of a compound in the body. This involves uptake, distribution (plasma protein binding and tissue uptake) and elimination (renal and biliary clearance and metabolism) processes. For all these processes, with the possible exception of biliary clearance, differences between enantiomers have been described (reviewed by Simonyi, 1984; Williams and Lee, 1985; Drayer et al, 1986; Ariëns and Wuis 1987; Lam, 1988: Tucker and Lennard, 1990; Campbell, 1990). The net effect of compounds is determined by their phamacodynamic properties as well as the concentration at which the compounds are present at their effector site. Therefore, stereoselectivity in pharmacokinetics is an important factor in determining the differential effects of enantiomers in biological systems.

In the next sections some examples of enantiomeric differences in the above described pharmacokinetic processes will be given. 


\subsubsection{Stereoselective uptake of drugs through the gut wall:}

Differences between enantiomers in their uptake after oral administration are relatively rare since most drugs enter cells by passive diffusion, which is dependent on the physicochemical properties (showing no differences between enantiomers) of the drug (Van Ginneken et al, 1983). Differences may, however, occur if facilitated or active transport is at stake. Thus, stereoselective resorption after oral intake is observed fordopa. Its L-enantiomer, which is used as antiparkinson drug, is taken up by active transport (probably by intestinal amino acid transporters) as well as by passive diffusion, whereas D-dopa is taken up by passive diffusion only (Wade et al, 1973). As a result, L-Dopa is absorbed more readily from the intestine than D-dopa. Another, more exireme difference in the intestinal uptake of enantiomers is observed for methotrexate. This chemotherapeutic drug is marketed as the $\mathbf{L}$ enantiomer. L-Methotrexate is extensively resorbed from the gut if applied orally; in contrast, resorption of the D-enantiomer is less than 3\% of the applied dose (Hendel and Brodthagen, 1984). This indicates a highly stereoselective transport of the L-enantiomer through the gut wall.

\subsubsection{Stereoselective tissue uptake:}

Stereoselectivity in tissue uptake is relatively seldom observed since tissue uptake is often attributable to physico-chemical properties of the compound. There are however some examples of differences between enantiomers in tissue distribution.

The $\beta$-adrenoceptor blocking agent atenolol is shown to be taken up by neurotransmitter vesicles by an active transport mechanism which can be inhibited by reserpine and (-)norepinephrine (Walle et al, 1988). This transport system is shown to be stereoselective since the uptake of $(-)$-atenolol is 5 fold greater than that of $(+)$-atenolol. A similar mechanism has been proposed for the enantiomers of propranolol (Walle et al, 1988); uptake of these $\beta$ adrenoceptor blocking agents in nerve endings may be of importance since it may account for a prolongation of their action after a single dose.

An example of stereoselective drug disposition, which is not dependent on stereoselective transport, is the NSAID ibuprofen. When racemic ibuprofen is given to Wistar rats for 7 days, the R-enantiomer of ibuprofen is found to be stored in fat tissue as the coenzyme A thioester, only trace amounts of the S-enantiomer are detected in fat tissue (Williams et al, 1986). Whether or not this has toxicological consequences is currently still under debate (Caldwell et al, 1988; Evans, 1992).

\subsubsection{Stereoselective plasma protein binding:}

Plasma protein binding is an important factor in pharmacokinetics since it has an impact on the (volume of) distribution and the clearance of drugs. For the binding of drugs to plasma 
proteins, differences between enantiomers are generally modest (Mueller, 1988; Lam, 1988; Campbell, 1990).

Drugs may bind to albumin (mainly acidic drugs), $\alpha_{1}$-acid glycoprotein (mainly basic drugs) or to both. An example of a basic drug that binds stereoselectively to plasma proteins is verapamil. The free fraction of its (+)-enantiomer is $6.5 \%$, whereas that of the (-)enantiomer is $11 \%$ (Eichelbaum et al, 1984). The stereoselectivity of the plasma protein binding of verapamil offers an explanation for the higher systemic clearance of the (-)enantiomer (table 1.2) of this high clearance drug. The uricosoric agent indacrinone offers an example of an acidic drug that binds stereoselectivity to plasma proteins. The free fraction of (+)-enantiomer is $0.9 \%$, whereas that of the (-)-enantiomer is only $0.3 \%$ (Drayer, 1988). Propranolol binds to both plasma proteins (although mainly to $\alpha_{1}$-acid glycoprotein) but with different stereoselectivity. In human plasma, the unbound fraction of (+)-propranolol is higher than that of (-)-propranolol (Walle et al, 1983). Using isolated $\alpha_{1}$-acid glycoprotein. the unbound fraction of the (+)-enantiomer of propranolol is higher than that of the (-)enantiomer. The inverse is observed for the binding of propranolol to isolated human albumin, for which the unbound fraction of the (-)- enantiomer is higher (Walle et al, 1983).

Albumin possesses two main non-overlapping binding sites (Sudlow et al, 1975). It is interesting to note that ligands bound to one of these two binding sites may influence the stereoselectivity of the other binding site and vice versa by allosteric interactions. Fitos et al (1990) showed that the binding of the enantiomers of a benzodiazepine derivative to immobilized human albumin is non-stereoselective. However, S-warfarin and the S-enantiomer of the benzodiazepine mutually increased the binding of each other, whereas bilirubin enhanced the binding of the R-enantiomer of the benzodiazepine.

In plasma protein binding, considerable species differences are observed (Mueller, 1988). For example, the free fraction of the R-enantiomer of the anticoagulant drug phenprocoumon is higher than that of the S-enantiomer in human, monkey, cat, dog, pig and horse. However, in the rat, mouse, guinea pig and the rabbit, the opposite is observed (Schmidt and Jaenchen, 1978).

\subsubsection{Stereoselective renal clearance:}

Stereoselective renal clearance is described for only a limited number of drugs. Often, stereoselectivity is attributable to enantiomeric differences in plasma protein binding (Tucker and Lennard, 1989). Stereoselectivity in the intrinsic renal clearance of drugs is expected only for compounds that are actively secreted in the kidney. This is indeed observed for the tubular secretion of some cationic compounds.

The antiarnhythmic drug disopyramide is subjected to active tubular secretion (Lima et al, 1985). The unbound renal clearance of the $\mathrm{S}$-enantiomer is shown to be twice as high as that of the R-enantiomer (Lima et al, 1985). Stereoselective renal clearance, in combination with stereoselective plasma protein binding and stereoselective metabolism are the basis of 
TABLE 1.2: Examples of stereoselective clearances in humans.

\begin{tabular}{|c|c|c|c|c|}
\hline \multirow[t]{2}{*}{ Drug } & \multirow{2}{*}{$\begin{array}{c}\text { admin. } \\
\text { route }\end{array}$} & \multicolumn{2}{|c|}{ Enantiomer } & \multirow[b]{2}{*}{ reference } \\
\hline & & $(+)$ & $\Leftrightarrow$ & \\
\hline \multirow[t]{2}{*}{ Nitrendipine } & p.o. & $241 / \min$ & $13 \mathrm{~V} / \mathrm{min}$ & Soons et al, 1990 \\
\hline & i.v. & $1.6 \mathrm{Vmin}$ & $1.5 \mathrm{~V} / \mathrm{min}$ & Soons, et al, 1990 \\
\hline Nimodipine & i.v. & $2.3 \mathrm{l} / \mathrm{min}$ & $2.2 \mathrm{~V} / \mathrm{min}$ & Sporckmann and Eichelbaum, 1991 \\
\hline \multirow[t]{2}{*}{ Verapamil } & p.o. & $1.71 / \mathrm{min}$ & $7.5 \mathrm{Vmin}$ & Vogelgesang et al, 1984 \\
\hline & i.v. & $0.8 \mathrm{~V} / \mathrm{min}$ & $1.4 \mathrm{~V} / \mathrm{min}$ & Eichelbaum et al, 1984 \\
\hline \multirow[t]{2}{*}{ Propranolol } & p.o. & $2.8 \mathrm{Vmin}$ & $2.0 \mathrm{~V} / \mathrm{min}$ & Ward et al, 1986 \\
\hline & i.v. & 1.2 Vmin & $1.0 \mathrm{~V} / \mathrm{min}$ & Paxton and Norris, 1984 \\
\hline \multirow{2}{*}{$\begin{array}{r}\text { Propafenone (EM) } \\
\text { (PM) }\end{array}$} & p.o. & $5.8 \mathrm{~V} / \mathrm{min}$ & $11 \mathrm{l} / \mathrm{min}$ & Gross and Korner, 1989 \\
\hline & p.o. & $0.3 \mathrm{l} / \mathrm{min}$ & $0.6 \mathrm{l} / \mathrm{min}$ & Gross and Korner, 1989 \\
\hline Mephenytoin (EM) & p.o. & $4.7 \mathrm{~V} / \mathrm{min}$ & $0.03 \mathrm{~L} / \mathrm{min}$ & Wedlund et al, 1985 \\
\hline$(\mathrm{PM})^{*}$ & p.o. & $0.03 \mathrm{1} / \mathrm{min}$ & $0.02 \mathrm{l} / \mathrm{min}$ & Wedlund et al, 1985 \\
\hline Phenprocoumon & p.o. & $18 \mathrm{ml} / \mathrm{kgd}$ & $14 \mathrm{ml} / \mathrm{kgd}$ & Jaenchen et al, 1976 \\
\hline Indoprofen & p.o. & $32 \mathrm{ml} / \mathrm{min}$ & $49 \mathrm{ml} / \mathrm{min}$ & Björkman, 1985 \\
\hline Pentobarbitone & p.o. & $40 \mathrm{ml} / \mathrm{min}$ & $32 \mathrm{ml} / \mathrm{min}$ & Cook et al, 1987 \\
\hline
\end{tabular}

EM: extensive metabolizers (of sparteine/debrisoquine in the case of propafenone).

PM: poor metabolizers

the different clearances of the enantiomers of disopyramide (Lima et al, 1985; table 1.2).

In man, the renal clearance of the S(-)-enantiomer of pindolol is about 1.3 times higher than that of the $\mathrm{R}(+)$-enantiomer (Campbell, 1990; Somogyi et al, 1992). despite the fact that pindolol enantiomers are bound to plasma proteins to equal extents (Campbell, 1990). Coadministration of cimetidine, an inhibitor of tubular organic cation transporters, decreases the renal clearance of pindolol stereoselectively: the renal clearance is reduced by $34 \%$ for R-pindolol versus $26 \%$ for the S-enantiomer, indicating stereoselectivity of the organic cation transporters in the tubule (Somogyi et al, 1992).

Stereoselective renal clearance is also observed for the antimalarial drug chloroquine, of which the (+)-enantiomer has a 1.6 times higher renal clearance, despite its stronger binding to plasma protein (Ofori-Adjei et al, 1986). 


\subsubsection{Stereoselective metabolism:}

In drug metabolism three types of stereoselectivity are observed: 1) substrate stereoselectivity i.e. the preferential metabolism of one of the enantiomers of a chiral substrate, 2) product stereoselectivity i.e. formation of a chiral product in enantiomeric excess and 3) chiral inversion i.e. the conversion from one enantiomer to the other.

All three types of stereoselective metabolism and some of their implications will be discussed below. Another complicating aspect which is of importance in the stereoselectivity of (drug) metabolism is the existence of genetic polymorphisms. Some implications of genetic polymorphisms in substrate- and product stereoselectivity will be put forward. Finally, stereoselectivity in first-passmetabolism will be discussed since first pass-metabolism is an important factor in determining the bioavailability of high clearance drugs when applied orally.

\subsection{5a Substrate stereoselectivity.}

Substrate stereoselectivity may occur because enantiomers have different affinities towards the metabolizing enzymes or because the catalytic activity of the metabolizing enzymes is higher for one of the enantiomers (Testa, 1988).

The racemic calcium antagonist felodipine is an example of a compound with stereoselective metabolism due to different affinities of the metabolizing enzyme(s) towards the enantiomers. Its enantiomers are oxidized by cytochrome $\mathbf{P} 450$ to their common pyridine metabolite. In human liver microsomes, the formation of this metabolite for both enantiomers has similar Vmax values (i.e. maximal reaction velocities, reflecting catalytic activity). However, the affinity of the R-enantiomer towards the metabolizing enzyme(s) is twice as high as that of the S-enantiomer. As a result, the intrinsic clearance, due to formation of this metabolite, is two times higher for the R-enantiomer (Eriksson et al, 1991). Since felodipine is a high clearance drug, which implies that its rate of elimination is determined by blood flow, this stereoselective metabolism has no effect on its systemic clearance. However, when felodipine is applied orally the bioavailability of the $\mathrm{S}$-enantiomer will be higher than that of the R-enantiomer, due to the more rapid first-pass metabolism (i.e. the metabolism of a compound during its passage from the gastrointestinal tract to the circulation) of this latter enantiomer. Felodipine may also serve as a clear example of species differences that may occur in stereoselective metabolism. The liver microsomal metabolism of felodipine is stereoselective for the R-enantiomer in man (as stated above), non-stereoselective in rat, whereas in dog liver microsomes stereoselectivity for the S-enantiomer is observed (Eriksson et al, 19.91).

Different catalytic activities of the metabolizing enzymes towards enantiomers may also be a cause of stereoselective metabolism. In man, the enantiomers of 4-hydroxypropranolol (an active metabolite of propranolol) are metabolized to their sulfate conjugates by 
cytosolic enzymes. In platelets both 4-hydroxypropranolol enantiomers are sulfated with similar $\mathrm{Km}$ values (i.e. dissociation constants of the enzyme-substrate complex), but the Vmax of the (+)-enantiomer is 5 times higher than that of the (-)-enantiomer (Walle and Walle, 1991). A similar phenomenon is observed for the glucuronidation of the enantiomers of the antibiotic ofloxacin in rat liver microsomes. This reaction appears to be carried out by the same isozyme but the Vmax value of the reaction for the S-enantiomer is 8 times higher than that of the R-enantiomer, whereas the affinities of the enantiomers are similar (Okazaki et al, 1991).

Sometimes, metabolizing enzymes display a catalytic activity to only one enantiomer, despite the fact that both enantiomers are able to bind to the enzyme. In that case one enantiomer is a substrate of the enzyme, whereas its enantiomeric counterpan is an inhibitor. In this respect, nicotine is a clear example. The natural S(-)-enantiomer of nicotine has been shown (Cundy et al, 1985) to be a competitive inhibitor (Ki about $60 \mu \mathrm{M})$ of an aromatic $\mathrm{N}$ methyltransferase whereas the $\mathrm{R}(+)$-enantiomer is a substrate of this enzyme ( $\mathrm{Km}$ about 10 $\mu \mathrm{M})$.

In the above examples, both enantiomers follow similar metabolic routes that account for a similar percentage of their total metabolic clearance. However, from enantiomers, different metabolites may be formed. Also, the metabolites that are formed, may contribute differently to the total metabolic clearance of the enantiomers. In addition, enantiomers may follow similar metabolic routes but the reactions are carried out by different isozymes with different enantioselectivities. Propranolol exemplifies a chiral drug of which the enantiomers follow metabolic routes to different extents. In man, both enantiomers undergo side chain hydroxylation, glucuronidation, as well as aromatic hydroxylation to the 4-hydroxy metabolite (Walle et al, 1984). However, of the metabolites, about $60 \%$ of the (+)-enantiomer versus 30 $\%$ of the (-)-enantiomer is recovered as 4-hydroxypropranolol, demonstrating that 4 hydroxylation is more important for the (+)- than for the (-)-enantiomer. This explains why quinidine, which is an inhibitor of the formation of 4-hydroxypropranolol, reduces the clearance of $(+)$-propranolol more than that of (-)-propranolol in man (Zhou et al, 1990). The above demonstrates that enantiomers may interact differently when other drugs are coadministered. This is because enantiomers may be metabolized by different combinations of enzymes or because enantiomers have different affinities to the enzymes. In the latter case, the enantiomer with the lowest affinity will be most sensitive for drug interactions at the metabolic level.

A clear example of different isozymes catalysing a similar reaction but with different enantioselectivities is observed in the metabolism of bufuralol. The main metabolite of this $\beta$-adrenoceptor blocking agent, 1'-hydroxybufuralol, is formed by two isozymes of the cytochrome P450 family: P450bufl and P450buf2 (Gut et al, 1986). The R/S ratio of the intrinsic formation clearance of 1'-hydroxybufuralol by P450bufl is about 5. P450buf2 shows an R/S ratio of only 1.3. As a result, the degree of stereoselectivity of 1'-hydroxylation will be determined by the ratio at which these two isozymes (in their active form) are present. 
Since P450buf1 is presumably related to P450 2D6 (Gut et al, 1986; Beaune and Guengerich, 1988) which is responsible for the sparteine/debrisoquine polymorphism, the activity ratios of these isozymes, and as a result the stereoselectivity of bufuralol 1'-hydroxylation, may vary considerably among subjects.

The anticonvulsant drug mephenytoin is an additional example of a compound of which the enantiomers are metabolized by different enzymes. This example clearly illustrates which implications this can have on the stereoselectivity of (metabolic) clearances. The metabolism (more specifically the 4'-hydroxylation) of mephenytoin is known to be controlled by a genetic polymorphism which is different from the sparteine/debrisoquine polymorphism (Guengerich, 1989). In extensive metabolizers (EM), a clear stereoselectivity (150 fold) for the clearance of the (+)-enantiomer is observed (table 1.2; Wedlund et al, 1989). In fact in EM, the (+)-enantiomer is a high clearance drug, whereas (-)-mephenytoin is a low clearance drug. In poor metabolizers (PM), the stereoselectivity in the clearance of mephenytoin is completely lost due to a marked reduction of the clearance of the (+)-enantiomer (table 1.2: Wedlund et al, 1989). This shows that if chiral drugs are metabolized by genetically polymorphic enzymes, the stereoselectivity of theirmetabolism may show large interindividual differences. Nevertheless, genetic polymorphisms do not always have an impact on the stereoselectivity of metabolic drug clearances. If both the polymorphic and the constitutive enzymes display similar enantioselectivities, no differences in the stereoselectivity of drug metabolism between EM and PM will be observed. This is for instance the case for the antiarrhythmic drug propafenone. The metabolism of this drug is controlled by the sparteine/ debrisoquine polymorphism (Siddoway et al, 1987; Kroemer et al, 1989). In EM, the clearance of propafenone is clearly stereoselective for the (-)-enantiomer (table 1.2, Gross and Komer, 1989). In PM however, this stereoselectivity is not altered since the clearance of both enantiomers is equally reduced.

The above examples demonstrate that the stereoselectivity of drug metabolism is a combination of the stereoselectivity of the metabolizing enzymes and the amount at which these enzymes are present (which may show large interindividual differences).

\subsection{5b Product stereoselectivity.}

Product stereoselectivity occurs if by metabolic conversion a chiral product is formed from an achiral substrate or if by metabolism an additional chiral centre is introduced in a chiral substrate. In the latter case a combination of product- and substrate stereoselectivity is possible.

An interesting example of product stereoselectivity is the 4-hydroxylation of debrisoquine. For the 4-hydroxylation of debrisoquine a genetic polymorphism is observed. In extensive metabolizers, the product formed is almost exclusively ( $>99 \%)$ in the Sconfiguration (Meese and Eichelbaum, 1986; Lennard et al, 1988). In contrast, in poor metabolizers, up to $20 \%$ of the 4 -hydroxydebrisoquine formed, is in the R-configuration (Meese and Eichelbaum 1986). 
To illustrate various aspects of product-and substrate stereoselectivity indrug metabolism and its complexity due to the involvement of multiple enzymes, one of the metabolic routes of the hypnotic agent hexobarbitone will be discussed in greater detail. The enantiomers of hexobarbitone are known to be eliminated stereoselectively in man due to stereoselective metabolism (Breimer et al, 1973). One of its metabolic pathways, 3'-hydroxylation (Vermeulen et al, 1983) introduces a second chiral centre. This reaction is under polymorphic control (Knodell et al, 1988). In microsomes from extensive metabolizers (EM) S-hexobarbitone is converted more rapidly to its 3'-hydroxy metabolite than R-hexobarbitone (Yasumori et al, 1990). In microsomes from poor metabolizers (PM), however, substrate stereoselectivity is lost due to a more drastic reduction of the 3'-hydroxylation of the S- than of the R-enantiomer. InEMmicrosomes, from $S$-hexobarbitone, the 3' $\beta$-hydroxy metabolite is formed in 8 fold excess over the $3^{\prime} \alpha$-hydroxy metabolite; this product stereoselectivity is completely absent in PM microsomes. From R-hexobarbitone, the $3^{\prime} \alpha$ metabolite is formed in 1.5 fold excess in EM microsomes, whereas in PM microsomes an inversion of product stereoselectivity is seen: 2.5 times more $3{ }^{\prime} \beta$ - than $3^{\prime} \alpha$-hydroxyhexobarbitone are formed (Yasumori et al, 1990). Once again, this demonstrates the role of the multiplicity of enzymes involved in the metabolism of a chiral substance in detormining substrato and product stcreuselectivity.

\subsection{5c Chiral inversion:}

A specific type of stereoselective metabolism is chiral inversion, i.e. the conversion from one enantiomer to the other. Well known examples of drugs for which chiral inversion plays an important role are derivatives of 2-arylpropionic acid. 2-Arylpropionic acids are an important group of NSAIDs. These compounds contain a chiral centre and from in vitro studies it is clear that the $\mathrm{S}(+)$-enantiomers are far more potent as inhibitors of the prostaglandin synthesis than the R(-)-enantiomers (Caldwell et al. 1988; Evans. 1992). However, when tested in vivo the stereoselectivity of their action is very markedly reduced. For instance, in vitro, S-ibuprofen is 165 times more effective than the R-enantiomer as inhibitor of the prostaglandin synthesis. In contrast, both enantiomers are approximately equipotent as analgetics (Adams et al, 1976). This apparent discrepancy is largely explained by the chiral inversion that is observed for 2-arylpropionic acids, which is highly selective for the transformation of R(-) in S(+)-enantiomers (Caldwell et al, 1988 and Evans, 1992). Inversion may be very rapid, as is for instance observed for fenoprofen in man (Rubin et al, 1985) and flunoxaprofen in rats (Iwakawa et al, 1991). On the other hand, some arylpropionic acids show very few inversion as is the case for indoprofen in man (Tamassia et al, 1984) and naproxen and carprofen in the rat (Iwakawa et al, 1991). Although the mechanism of this inversion is still not unambiguously determined, it may involve stereoselective conversion of the enantiomers to their acyl $\mathrm{CoA}$ esters and subsequent enzymatic epimerization (Caldwell et al, 1988; Evans, 1992; Tracy and Hall, 1992). 


\subsection{5d Stereoselective first-pass metabolism:}

First-pass metabolism is the metabolism of a compound during its passage from the gastro-intestinal tract to the circulation. First-pass metabolism has no effect on systemic parameters as $\mathrm{t}_{1 / 2}$ or the systemic clearance of enantiomers but determines their bioavailability when applied orally and thus the initial ratio at which the enantiomers will be present in plasma. This is most important for high clearance drugs.

Stereoselective first-pass metabolism of the calcium channel blocking agent verapamil has been shown to be the cause for the marked differences in plasma-concentration (of the racemate) effect relations after oral or iv administration (Eichelbaum, 1988). Plasma concentrations after oral administration must be 3 times higher than after iv administration to elicit the same effect (Eichelbaum et al, 1980). (-)-Verapamil is about 8-10 times more potent than (+)-verapamil with regard to its negative dromotropic effect. On the other hand the systemic and oral clearance of (-)-verapamil is subtantially higher (table 1.2; Vogelgesang et al 1984). Because of stereoselective first-pass metabolism the $(+) /(-)$ ratio of plasma verapamil concentrations is 5 after oral but only 2 after iv administration, explaining the observed discrepancies between plasma concentration effect relationships (Echizen et al, 1985). The reason of the stereoselectivity of the first-pass metabolism of verapamil probably is the higher affinity of the (-)-enantiomer towards the verapamil metabolizing enzymes (Kroemer et al, 1991).

Stereoselective first-pass metabolism is also observed for the dihydropyridine calcium antagonists nitrendipine (Soons et al, 1990) and nimodipine (Sporckmann and Eichelbaum. 1991). The systemic clearance of the latter compound is non-stereoselective (table 1.2), but because of first-pass metabolism, the bioavailability of the R-enantiomer after oral administration is $22 \%$ whereas that of the more potent S-enantiomer is only $3.5 \%$.

\section{STEREOCHEMICAL ASPECTS IN THE PHARMACOLOGY OF WARFARIN AND ACENOCOUMAROL:}

From the previous paragraphs it will be clear that differences between enantiomers in pharmacology are commonly observed and that enantiomeric differences occur at many levels in the pharmacodynamics and pharmacokinetics of chiral compounds.

Warfarin and some of its phenyl ring substituted analogues have been used as model compounds in this thesis to study the stereochemical aspects of their pharmacokinetics and biotransformation. Therefore, the second part of this introduction section will specifically deal with the stereochemical aspects of the pharmacology of warfarin and its 4'-nitro analogue acenocoumarol, which like warfarin is in use as oral anticoagulant. In paragraph 1.5.1 some general information of these drugs will be given. Their mode of action, pharmacokinetics and interactions with other drugs will be described in paragraphs 1.5 .2 to 1.5 .5 . Finally, in paragraphs 1.6 and 1.7 , the aim and outline of this thesis will be discussed. 


\subsubsection{Warfarin and acenocoumarol: general information.}

4-Hydroxycoumarins (figure 1.3) are widely used as oral anticoagulants in the treatment of thrombo-embolic disease and post-operative prevention of blood clotting. Furthermore, treatment with 4-hydroxycoumarins is proposed for reinfarction prevention after myocardial infarction (Jafri et al, 1992). In addition, 4-hydroxycoumarins are used as rodenticides.

In 1922, in North America, extensive bleeding of cattle that had consumed spoiled cloveroccured (Schofield, 1922). Later, in 1931, this was attributed to a depressed prothrombin level (Roderick, L.M., 1931). Campbell and Link (1941) isolated the active compound dicoumarol from sweet clover as the first coumarin anticoagulant.
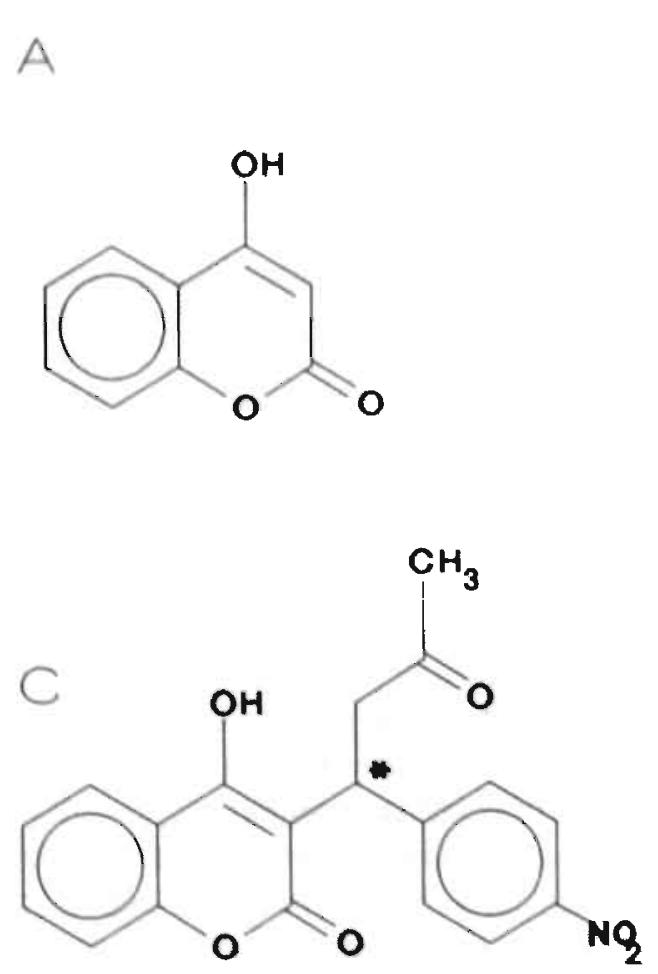
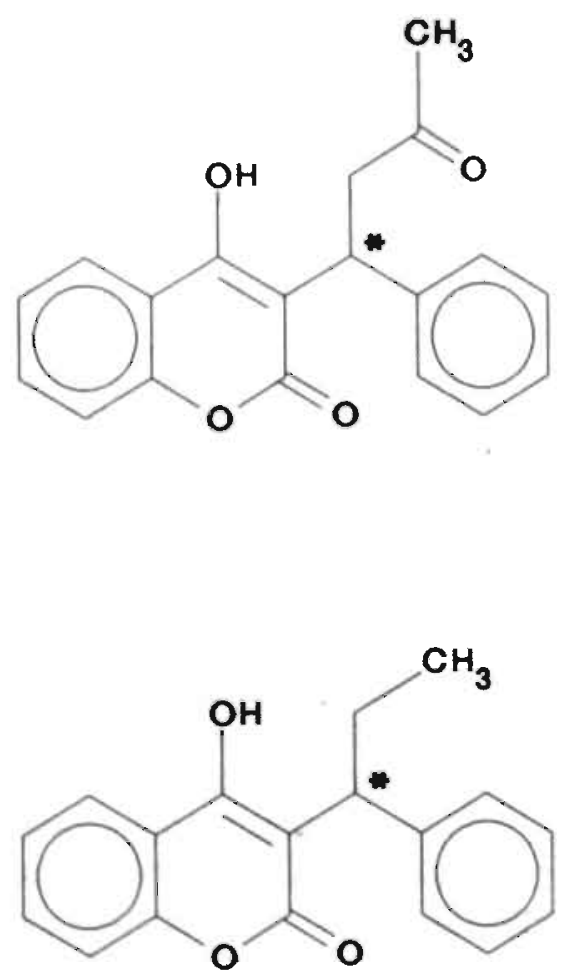

Figure 1.3: Structural formulas of 4-hydroxycournarin (A), warfarin (B), acenocoumarol (C). and phenprocoumon (D) 
Among the 4-hydroxycoumarins used as anticoagulants are warfarin, which is world wide the most extensively used, its 4'-nitro analogue acenocoumarol, and phenprocoumon (figure 1.3). These coumarins possess a chiral centre, which implies that two optically active enantiomers exist. West et al (1961) isolated the enantiomers of warfarin by cristallization of their quinidine and quinine salts and demonstrated that (-)-warfarin is related to $\$(-)-\beta$-caproic acid and therefore assigned the S-configuration to the (-)-enantiomer. In a later study by Wheeler and Trager (1977), the absolute configuration of the enantiomers of warfarin was confimed by X-ray crystallography. The same authors showed that (-)-acenocoumarol also has the S-configuration. Warfarin and acenocoumarol are weak acids due to the acidic 4hydroxy group of the coumarin moiety ( $\mathrm{pKa}$ values of about 4.8 ) that are protolysed at physiological $\mathrm{pH}$. In aequous solution, warfarin exists as an open ring form. In organic solution however warfarin can also be present as two cyclic diastereomeric hemiketals (Heimark and Trager, 1984). In addition, keto-enol tautomerism of the coumarin ring is possible (Vanhaelen, 1978).

\subsubsection{The mechanism of action of 4-hydroxycoumarin anticoagulants:}

The action of 4-hydroxycoumarins on blood coagulation is indirect and is due to their ability to decrease the regeneration of vitamin $\mathrm{K}$. The metabolism of vitamin $\mathrm{K}$ and the function of the vitamin have been reviewed by Olsen (1984) and Suttie (1987).

The hydroquinone of vitamin $\mathrm{K}$, next to molecular oxygen and carbon dioxide, serves as an obligatory cofactor for a microsomal carboxylase. This enzyme postiransiationally converts glutamyl residues of a number of protein precursors to gamma-carboxyglutanyl residues. Thereby, these proteins will become more negatively charged and will therefore be able to form complexes with calcium. The introduction of gamma-carboxyglutamyl residues is, among others, important for the activation of the plasma clotting factors II, VII, IX, and $\mathrm{X}$ and of the plasma proteins $\mathrm{C}$, and $\mathrm{S}$ that are involved in fibrinolysis and anticoagulation (Olsen, 1984: Suttie 1987). During the carboxylation reaction, the hydroquinone of vitamin $\mathrm{K}$ (figure 1.4) is converted to vitamin K 2,3-epoxide (Larson et al, 1981). This epoxide is subsequently converted to vitam in $\mathrm{K}$ by a dithiol-dependent reductase, which is located in the endoplasmatic reticulum (Zimmerman and Matschiner, 1974). Finally, vitamin K is reduced to its active form, the hydroquinone, by a dithiol dependent microsomal enzyme (Fasco and Principe, 1980 and 1982) and by NAD(P)H dependent enzymes, although the latter enzymes probably play only a minor role in the formation of vitamin $\mathrm{K}$ hydroquinone under physiological conditions (Wallin and Martin, 1985).

The microsomal dithiol dependent vitamin $\mathrm{K}$ and vitamin $\mathrm{K}$ epoxide reductase are possiby one and the same enzyme (Preusch and Suttie, 1984; Gardill and Suttie, 1990). The nature of the endogenous reductant of these reductase activities is still not unambiguously 
determined but reduced lipoic acid (Whitlon et al, 1978; Lee and Fasco, 1984) or thioredoxin (van Haarlem et al, 1987; Silverman and Nandi, 1988) are able to serve as reductant.

4-Hydroxycoumarins inhibit the reduction of vitamin $\mathrm{K}$-epoxide to vitamin $\mathrm{K}$ as well as the reduction of vitamin $\mathrm{K}$ to its hydroquinone. This has been demonstrated both in vitro, where 4-hydroxycoumarins are potent inhibitors of the microsomal dithiol-dependent reductases (Fasco et al, 1982) and in vivo, where accumulation of vitamin $\mathrm{K}$ epoxide is observed after application of a pharmacological dose of vitamin K to warfarin treated patients or volunteers (Choonara et al, 1985 and 1986b). Because the formation of the hydroquinone of vitamin $\mathrm{K}$ is inhibited, the synthesis of blood clotting factors will be hampered, and as a result, anticoagulation occurs.

It has been proposed (Silverman 1980, Fasco et al, 1983) that the dithiol-dependent enzyme(s) responsible for the reduction of vitamin $\mathrm{K}$ and its epoxide contain(s) two sulphhydryl groups that are oxidized to form a disulfide during reduction of the substrate. Later, the vitamin K 2,3 epoxide reductase was indeed shown to follow Ping-Pong kinetics and to shuitle between a reduced and an oxidized state (Hildebrandt et al, 1984). At high levels of dithiothreitol the extent of inhibition of the vitamin $\mathrm{K}$ epoxide reductase by warfarin is diminished (Zimmerman and Matschiner, 1974; Fasco er a', 1983). in the absence of reductant, the binding of warfarin to the dithiol dependent vitamin $\mathrm{K}$ and vitamin $\mathrm{K}$ 2,3-

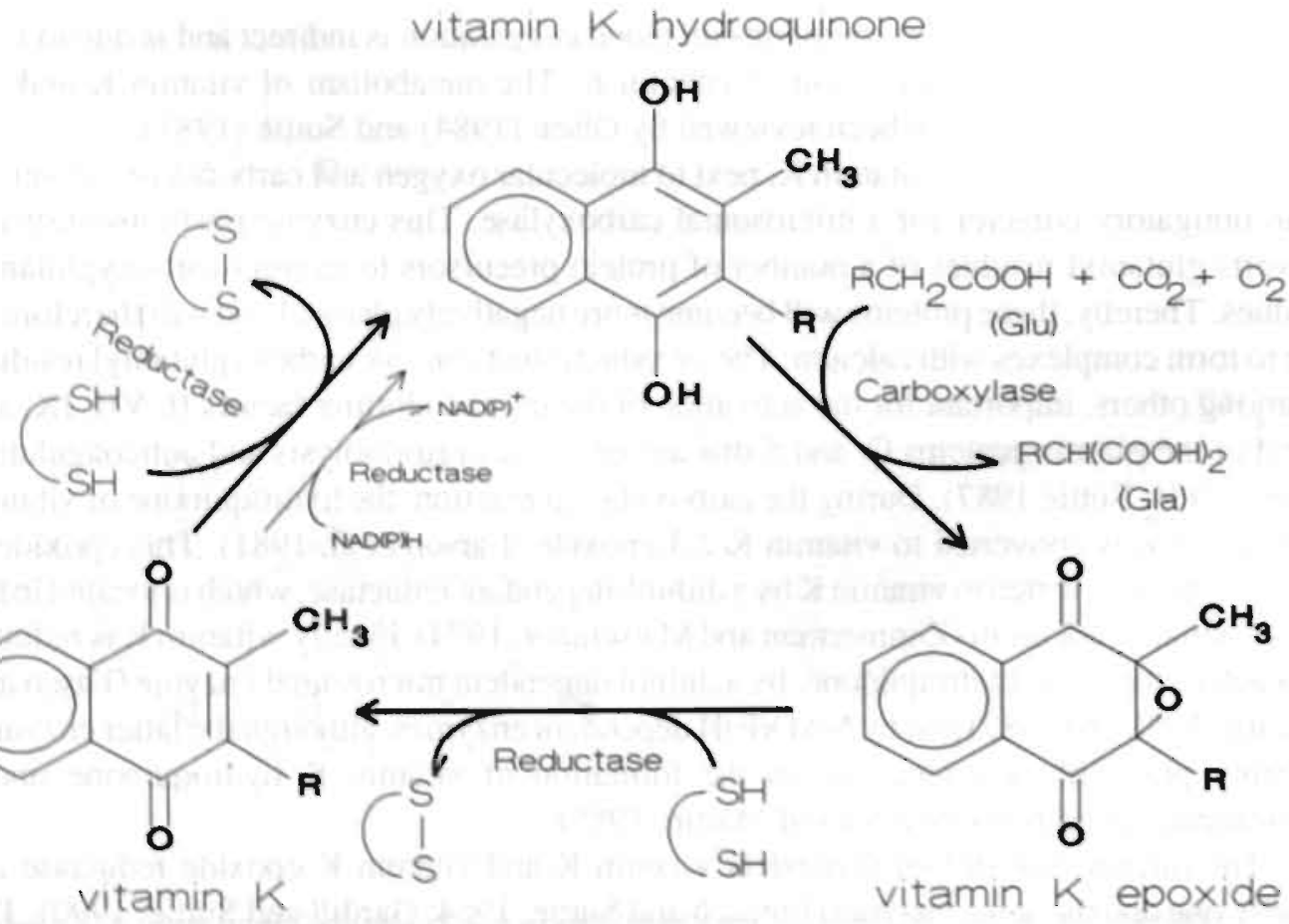

Figure 1.4: The vitamin K cycle. 
epoxide reductases is essentially irreversible, since washing of microsomes treated with warfarin does not diminish the inhibiting effect of warfarin on the reductases (Fasco an Principe, 1982). Therefore, a model has been proposed in which 4-hydroxycoumarins bind to the vitamin $\mathrm{K}$ epoxide reductase in the oxidized state (Fasco et al ${ }_{\text {. 1983), whereas vitamin }}$ $K$ epoxide binds to the enzyme in the reduced state. This model has been affirmed by Thijssen and Baars (1989), who showed the binding of ${ }^{14} \mathrm{C}$-warfarin to be shifted to the right by dithiothreitol. Nevertheless, the exact mechanism of the inhibition of the reduction of vitamin $\mathrm{K}$ and its epoxide by 4 -hydroxycoumarins at the enzyme level has still not yet been revealed. However, Silverman el al (1988), without presenting data, stated the inhibition by warfarin to be competitive for the reductant dithiothreitol.

\subsubsection{Clinical pharmacology of warfarin and acenocoumarol.}

4-Hydroxycoumarins have a narrow therapeutic range and large interindividual differences in the required dose are observed (Holford, 1986; Shetly et al, 1989). A clear relationship between the dose and the anticoagulant effects is still not known. Racemic acenocoumarol is more potent as anticoagulant than racemic warfarin. To obtain therapeutic anticoagulation (i.e. prothrombin complex activities of about $10 \%$ control values) total plasma concentrations of warfarin range from 1 to $10 \mu \mathrm{M}$ (Holford, 1986), whereas those of acenocoumarol range from 60 to $600 \mathrm{nM}$ (Thijssen et al, 1988b). Plasma-concentration anticoagulant effect curves for warfarin are steep (Holford, 1986). One of the reasons for this is that (at least in the rat) the dithiol dependent vitamin $\mathrm{K}$ epoxide reductase appears to have an overcapacity. At least $70-75 \%$ of its hepatic activity has to be eliminated before any clinical effect on clotting factor synthesis is observed (Mosterd and Thijssen, 1991 and 1992). Thus, a no-effect level for 4-hydroxycoumarins exists, which must be exceeded to have an anticoagulant effect.

In man and in the rat, the S-enantiomer of warfarin is about 2-5 times more potent as anticoagulant, than the R-enantiomer(Yacobi and Levi, 1974; Wingard et al, 1978; Fasco and Principe 1982; Choonara et al, 1986b). Conversely, $\mathrm{R}$-acenocoumarol is more potent than Sacenocournarol in man (Meinertz et al, 1978) and in the rat (Thijssen et al, 1985). However. if stereoselective clearance is dealt with, S-acenocoumarol is more potent than the $\mathrm{R}$ enantiomer (Thijssen et al 1985). Thijssen et al (1988) showed that the higher anticoagulant potency of the S-enantiomers in the rat is due to the slower release of the $\mathrm{S}$-enantiomers, when bound to the vitamin $\mathrm{K}$-epoxide reductase.

\subsubsection{Pharmacokinetics of the enantiomers of warfarin and acenocoumarol:}

When applied orally, warfarin and acenocoumarol are well and readily absorbed from the gastro-intestinal tract (Breckenridge and Orme 1973, Dieterle et al 1977. Thijssen ef al 1983, Gill et al 1989). Plasma peak concentrations are observed after about 1 to 4 hours. The absorption does not appear to be stereoselective. 
TABLE 1.3: Reported pharmacokinetic parameters of the enantiomers of warfarin and acenocoumarol in man.

\begin{tabular}{|c|c|c|c|c|}
\hline Warfarin & R. & s. & R/S & References \\
\hline \multirow[t]{7}{*}{$\mathrm{t} 1 / 2(\mathrm{~h})$} & 46 & 28 & 1.6 & Lewis et al 1974 \\
\hline & 46 & 32 & 1.4 & O'Reilly 1976 \\
\hline & 46 & 30 & 1.5 & Kelly and O'Malley 1979 \\
\hline & 33 & 22 & 1.5 & Banfield et al 1983 \\
\hline & 48 & 38 & 1.3 & Choonara et al 1986a \\
\hline & 44 & 33 & 1.3 & O'Reilly et al 1987 \\
\hline & 34 & 29 & 1.2 & Abernethy et al 1991 \\
\hline \multirow[t]{4}{*}{$\mathrm{Cl}(\mathrm{ml} / \mathrm{min})$} & 3.1 & 4.2 & 0.7 & Choonara et al 1986a \\
\hline & 2.2 & 3.3 & 0.7 & Choonara et al $1986 \mathrm{~b}$ \\
\hline & 2.5 & 3.6 & 0.7 & O'Reilly et al 1987 \\
\hline & 3.5 & 4.2 & 0.8 & Abernethy et al 1991 \\
\hline \multirow[t]{5}{*}{ Vd (I) } & 9.5 & 9.8 & 1.0 & Kelly and O'Malley 1979 \\
\hline & 11.2 & 11.2 & 1.0 & Banfield et al 1983 \\
\hline & 12.8 & 12.0 & 1.1 & Choonara et. al 1986a \\
\hline & 9.3 & 8.4 & 1.1 & O'Reilly et al 1987 \\
\hline & 9.8 & 9.8 & 1.0 & Abernethy et al 1991 \\
\hline \multirow[t]{4}{*}{$\mathrm{f}^{*}(\%)$} & 1.2 & 0.90 & 1.4 & Yacobi and Levi, 1977 \\
\hline & 0.49 & 0.44 & 1.1 & Banfieid et al 1983 \\
\hline & 0.85 & 0.50 & 1.7 & Toon and Trager 1984 \\
\hline & 0.86 & 0.73 & 1.1 & Abernethy at al 1991 \\
\hline Acenocoumarol & $\mathbf{R} \mathbf{*}^{*}$ & s- & R/S & References \\
\hline \multirow[t]{3}{*}{$11 / 2(h)$} & 11.5 & 1.1 & 10 & Thijssen et al, 1986 \\
\hline & 6.8 & 0.9 & 7.6 & Gill et al, 1988 \\
\hline & 7.1 & 1.6 & 4.4 & Gill et al, 1989 . \\
\hline \multirow[t]{3}{*}{$\mathrm{Cl}(\mathrm{ml} / \mathrm{min})$} & 35 & 496 & 0.1 & Thijssen et al, 1986 \\
\hline & 24 & 317 & 0.1 & Gill et al, 1988 \\
\hline & 24 & 225 & 0.1 & Gill et al, 1989 \\
\hline \multirow[t]{3}{*}{ Vd (1) } & 32 & 38 & 0.8 & Thijssen et al, 1986 \\
\hline & 16 & 23 & 0.6 & Gill et al, 1988 . \\
\hline & 15 & 31 & 0.5 & Gill et al, 1989 \\
\hline \multirow[t]{2}{*}{$\mathrm{r}(\%)$} & 1.8 & 2.0 & 0.9 & Godbillon et al, 1981 \\
\hline & 0.7 & 1.0 & 0.7 & Gill et al, 1988: \\
\hline
\end{tabular}

* $\mathrm{f}$ is the fraction of drug in the plasma which is not bound to plasma proteins. 
Warfarin and acenocoumarol are extensively bound to plasma protein. In humans Swarfarin is bound more tightly to plasma proteins than R-warfarin and as a result, the free fraction of the R-enantiomer is 1.1 to 1.7 times higher than that of the S-enantiomer (table 1.3). The contrary is observed in the case of acenocoumarol for which the R-enantiomer is more tightly bound; the free fraction of R-acenocoumarol is about 0.7 to 0.9 times that of Sacenocoumarol. In rats, however S-warfarin and S-acenocoumarol are more tighly bound to plasma proteins than the R-enantiomers (table 1.4). In rats, the free fraction of $\mathbf{R}$-warfarin is 1.6 times higher than that of S-warfarin, whereas the free fraction of $\mathrm{R}$-acenocoumarol is 1.1 times higher than that of S-acenocoumarol.

Both warfarin and acenocoumarol are eliminated stereoselectively. There are however, considerable species differences in the stereochemical course and speed of elimination. In man, S-warfarin is eliminated faster than $\mathrm{R}$-warfarin. The half-life of $\mathrm{R}$-warfarin in man is about 1.2 to 1.6 times higher than that of S-warfarin, and its clearance is about 0.7 to 0.8 times that of the S-enantiomer (table 1.3). In man, a qualitatively similar, but quantitatively more extreme stereoselectivity is also observed for the elimination of acenocoumarol. Halflives are reported to be $\mathbf{4 . 4}$ to 10 times higher for $\mathrm{R}$-acenocoumarol, whereas the clearance of R-acenocoumarol is about 10 times lower than that of S-acenocoumaroll (table 1.3).

Contrary to what is observed in man, $\mathrm{R}$-warfarin is eliminated faster than $\mathrm{S}$-warfarin in the rat. Haif-lifes of R-and S- warfarin are about 7.3 and 14 hours, whereas the clearance of the R-enantiomer is two times higher than that of S-warfarin. This inversion of stereoselectivity is not observed for acenocoumarol. In the rat, S-acenocoumarol is eliminated faster than Racenocoumarol but the difference between the enantiomers is less pronounced than in man. As in man, acenocoumarol enantiomers are eliminated substantially faster than the enantiomers of warfarin: clearances of $\mathrm{R}$ - and $\mathrm{S}$-acenocoumarol are about 10 and 90 times higher in man and about 10 and 70 times higher in rats (tables 1.3 and 1.4).

TABLE 1.4 Reported phamacokinetic parameters of the enantiomers of warfarin and acenocoumarol in rats.

\begin{tabular}{|c|c|c|c|c|c|}
\hline Wartarls & $\mathbf{R}$ & $\mathbf{S}$ & R/S & References & \\
\hline $1 / 2$ (b) & 7 & 14 & 0.5 & Yacobi and & Levy, 1974 \\
\hline $\mathrm{Cl}(\mathrm{m} / \mathrm{h})$ & 6.7 & 3.6 & 1.9 & . $\quad$ & * \\
\hline $\mathrm{Vd}(\mathrm{ml})$ & 64 & 63 & 10 & $"$ & " \\
\hline$f(\%)$ & 1.31 & 0.84 & 1.6 & Yacobi and & Levy, 197 \\
\hline Acenocoumarol & $\mathbf{R}$ & $\mathbf{s}$ & R/s & References & \\
\hline $11 / 2(h)$ & 1.6 & 0.4 & 4.0 & Thijssen et & al, 1985 \\
\hline $\mathrm{Cl}(\mathrm{m} / \mathrm{h})$ & 68 & 257 & 0.3 & $=\quad "$ & * \\
\hline Vd (ml) & 167 & 185 & 0.9 & $n \quad "$ & " \\
\hline$f(\%)$ & 16. & 1.4 & 1.1 & $=\quad-$ & " \\
\hline
\end{tabular}




\subsubsection{Biotransformation of the enantiomers of warfarin and acenocoumarol:}

In both man and rat warfarin and acenocoumarol have been shown to be eliminated mainly by biotransformation (Lewis et al, 1974, Toon et al 1986, Thijssen et al, 1986, Dieterle et al 1977, Thijssen and Baars 1987, Pohl et al 1976). Warfarin metabolites have been shown to have virtually no anticoagulant activity (Lewis et al 1973, Obaseki and Coker, 1987).

Various metabolic routes of warfarin have been described (figure 1.5). In man the main metabolites of R-warlarin are the RS alcohol (formed by reduction of the acetonyl side chain), 6-hydroxywarfarin and to a lesser extent 7- and 8-hydroxywarfarin. In contrast, the main metabolite of S-warfarin in man is the 7-hydroxy metabolite next to the 6-hydroxy metabolite, which is found in 2-4 times smaller quantities. (Lewis et al 1974; Banfield et al, 1983; Toon et al 1986; Niopas et al 1991: Abemethy et al, 1990). In the rat however, the main metabolites of both R- and S-warfarin are the 4'-, 6- and 7-hydroxy metabolites (Pohl et al 1976). In addition to the above described metabolites, small quantities of dehydrowarfarin, 9- and 10hydroxywarfarin (figure 1.5) and the SS, SR, and RR alcohols have been found in humans and rats (Lewis et al, 1974; Pohl et al, 1975; Abemethy et al, 1991; Pohl et al, 1976).

The enantiomers of acenocoumarol are mainly hydroxylated to their 7-and 6-hydroxy metabolites in man and in rat (Dieterle et al, 1977; Thijssen et al, 1986; Thijssen and Baars, 1987). In addition, the diastereomeric alcohols of acenocoumarol have been found in man. but information on the configurations of the alcohols was not given (Dieterle, 1977).

Figure 1.5: The biotransformation of warfarin and acenocoumarol.
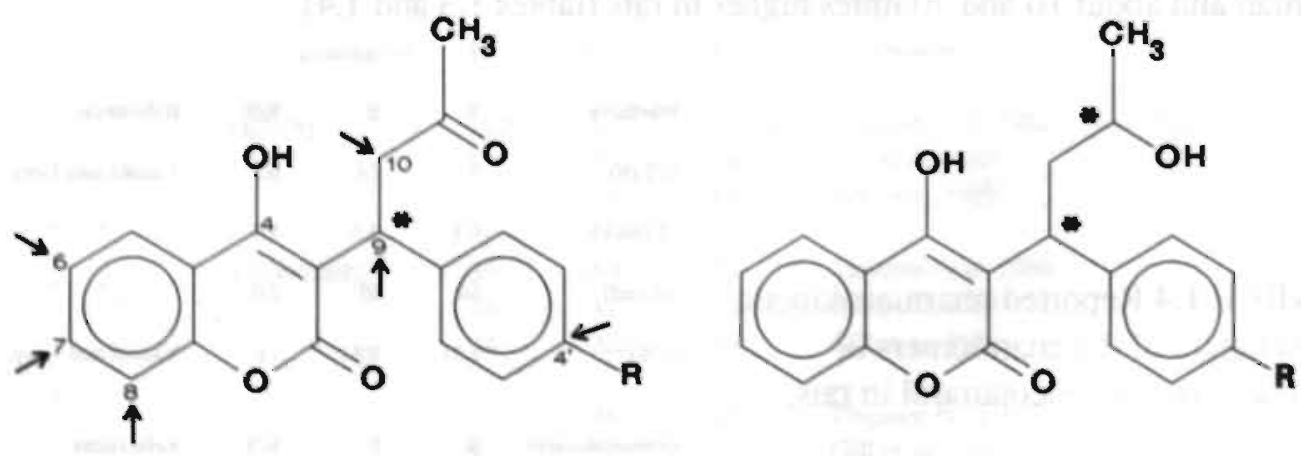

A) Arrows indicate bydroxylation sites of warfarin and acenocoumarol by cytochrome P450.

Dehydrowariarin possesses a double bond between $\mathrm{C} 9$ and $\mathrm{C} 10$

B) The diastereomeric alcohols, produced by reduction of the acetonyl side chain

*) Stereocentre 


\subsubsection{Stereoselective drug-interactions with warfarin and acenocoumarol.}

In man various interactions of drugs with warfarin have been described. These interactions occurboth at the pharmacodynamic and the pharmacokinetic level. Stereoselective interactions with the $\mathrm{S}$-enantiomer, the $\mathrm{R}$-enantiomer, as well as non-stereoselective interactions are found. For acenocoumarol, up till now, fewer interactions have been described.

In the next section, some drug-interactions with warfarin and acenocoumarol will be briefly discussed.

\subsection{6a Stereoselective interactions with the S-enantiomer:}

The anti-inflammatory drug phenylbutazone potentiates the anticoagulant activity of warfarin, without changing the clearance or elimination half life of the racemate. However. in a study in which the separated enantiomers of warfarin were given it was revealed that the clearance of the more potent S-enantiomer was markedly decreased, whereas that of the Renantiomer was increased by phenylbutazone (Lewis et al, 1974; Banfield et al 1983). This has been ascribed to the displacement of warfarin from albumin in combination with a decrease of the intrinsic clearance of S-warfarin. Because of the higher levels of unbound $R$ warfarin, the clearance of this enantiomer will be enhanced. On the other hand, the formation of the 6-and 7-hydroxy metabolites of S-warfarin has been shown to be markedly decreased upon coadministration of phenylbutazone, which explains the decreased intrinsic clearance of this enantiomer. The interaction of warfarin with phenylbutazone proves that it is necessary to evaluate the fate of the single enantiomers if racemic drugs are applied, since data on the racemate only may lead to substantial misinterpretation.

A similar stereoselective interaction with warfarin as that of phenylbutazone, is observed for the uricosuric agent sulfinpyrazone ( $O^{\prime}$ Reilly, 1982). This drug also enhances the clearance of the $\mathrm{R}$-enantiomer by displacement of the plasma protein binding sites (Toon and Trager 1984) but decreases the clearance of the S-enantiomer by inhibition of its oxidative metabolism (Toon et al, 1986). Sulfinpyrazone has also been reported to potentiate the anticoagulant effect of acenocoumarol (Michot et al, 1981).

Other compounds that potentiate the hypothrombinaemic response to racemic warfarin by inhibition of the metabolic clearance of the $\mathrm{S}$-enantiomer are the antibiotics metronidazole (O'Reilly 1976) and cotrimoxazole (O'Reilly 1980).

Phamacodynamic interactions with S-warfarin have been described for disulfiram (O'Reilly, 1981) and the blood lipid lowering compound clofibrate (Bjornsson et al, 1977). These compounds are without effect on the pharmacokinetics of S-warfarin but potentiated its anticoagulant effect.

\subsection{6b Stereoselective interactions with the R-enantiomer:}

The histamine $\mathrm{H} 2$ antagonist cimetidine is known to decraese the clearance of $\mathrm{R}$ - but not S-warfarin (Choonara et al 1986) by inhibition of the formation of the 6- and 7-hydroxy 
metabolites (Niopas et al, 1991). Cimetidine also decreases the clearance of R-acenocoumarol albeit only at relatively high doses (Thijssen et al, 1986; Gill et al, 1989). These interactions have been shown to increase the hypothrombinaemic response in some patients.

The calcium antagonist diltiazem, has been shown to decrease the clearance of $\mathbf{R}$ warfarin in man (Abemethy et al, 1991) by a decrease of the formation of the 6- and 8hydroxy metabolites of R-warfarin.

Other drugs that decrease the clearance of $\mathrm{R}$-warfarin are the antibiotic enoxacin , which inhibits the formation of the R-6-hydroxy metabolite (Toon et al, 1987), and the gastric hydrogen-potassium pump inhibitor omeprazole (Sutfin et al, 1989).

\subsection{6c Non stereoselective interactions:}

A non-stereoselective decrease of the clearance of warfarin has been described for the antiarrhythmic amiodarone (O'Reilly et al 1987); this has been attributed to a non-stereoselective inhibition of the metabolism of warfarin (Heimark et al, 1992).

Amiodarone is also shown to enhance the anticoagulant activity of acenocoumarol but information on the mechanism and on stereochemical aspects is lacking. (Pini at la, 1985; Fondevilla, 1988).

\subsection{6d Other interactions:}

The antiarrhythmic agent propafenone is known to potentiate the anticoagulant effect of warfarin by a decrease of its clearance but the stereochemistry has not been studied (Kates $\mathrm{et}$ al, 1987). Potentiation of the anticoagulant effect of warfarin, without information on the mechanism and stereoselectivity has been discribed for the antimalarial drug proguanil (Armstrong et al 1991) and the blood sugar lowering drug glibenclamide (Jassal 1991).

Finally, warfarin clearance is shown to be enhanced, probably by enzyme induction, by barbiturates, phenytoin, gluthetimide. rifampicin and griseofulvin (reviewed by Serlin and Breckenridge 1983). Some of these inductions involve one enantiomermainly, thus rifampcin induces particularly the metabolic clearance of R-warfarin (Heimark et al, 1987).

Enhancement of the clearance of racemic acenocoumarol in man has been described for pentobarbitone (K.roon et al, 1990).

\subsection{AIM OF THIS THESIS:}

The above paragraphs show that the enantiomers of warfarin and its 4'-nitro analogue acenocoumarol display clear differences in their pharmacokinetics and the stereoselectivity thereof. In addition, differences between species are observed (human and rat). Substitution of the 4'-hydrogen of wariarin by an amino or acetamido group was also shown to influence the rate and stereoselectivity of the elimination of the 4-hydroxycoumarin (Thijssen and Baars, 1983: Thijssen et al, 1985). This may point to an important role of the phenyl ring of 
warfarin in determining the stereochemical course of its pharmacokinetics.

To study whether this is indeed the case, the effect of phenyl ring substitution of warfarin on the stereochemical course of its pharmacokinetics has been investigated. Since no studies on the in vitro biotransformation of acenocoumarol have been conducted before, we compared the in vitro biotransformation of warfarin and acenocoumarol, in an attempt to explain the pharmacokinetic differences between these 4-hydroxycoumarins. Both the oxidative and reductive metabolism of these compounds have been investigated. The role of the multiplicity of enzymes in the differences in the (stereochemical course of the) metabolism of warfarin and acenocoumarol has been evaluated.

\subsection{OUTLINE OF THIS THESIS}

In chapter 2, the pharmacokinetics of various phenyl ring substituted warfarins in the rat will be described. In chapter 3 the stereochemical aspects of the rat liver microsomal cytochrome P450 mediated metabolism of acenocoumarol and warfarin will be compared and the effect of enzyme inducers, the cytochrome P450 inhibitor and antibodies raised to cytochromes $\mathrm{P} 450$ of the $3 \mathrm{~A}$ and $2 \mathrm{C}$ subfamily on the metabolism of both compounds will be discussed. Chapter 4 deals with the (stereochemical aspects of) human liver microsomal cytochrome P450 mediated metabolism of warfarin and acenocoumarol. In addition, the effect of some selected cytochrome P450 inhibiting drugs on their metabolism will be described.

In chapter 5 , stereochemical aspects of another metabolic route, reduction of the ketone group of warfarin and analogues and species differences in this metabolic route will be considered. Chapter 6 describes characteristics of two warfarin ketone reductases that have been partially purified from rabbit liver cytosol. Finally, in chapter 7 the experimental data of this thesis will be discussed and some considerations on the use of chiral drugs in pharmacology will be put forward. 
Choonara, A., Cholerton, S., Haynes, B.P., Breckenridge, A.M., and Park, B.K., 1986a, Stereoselective interaction between the R-enantiomer of warfarin and cimetidine. Br. J. clin. Pharmacol. 21: $271-277$.

Choonara, I.A., Haynes, B.P., Cholerton, S., Breckenridge, A.M., and Park, B.K., 1986b. Enantiomers of warfarin and vitamin Kl metabolism. Br. J. clin. Pharmacol. 22: 729-732.

Choonara, I.A., Scotı, A.K., Haynes, B.P., Cholerton, S., Breckenridge, A.M., and Park, B.K., 1985. Vitamin $\mathrm{K} 1$ metabolism in relation to pharmacodynamic response in anticoagulated patients. Br.J. clin. Pharmacol. 20: 643-648.

Cook, C.E., Seltzman, T.B., Tallent, C.R., Lorenzo, B., and Drayer, D.E., 1987. Pharmacokinetics of pentobarbital enantiomers as determined by enantioselective radioimmunoassay after administration of racemate to humans and rabbits. J. Pharmacol. Exp. Ther. 241: 779- 785.

Cundy. K.C.. Crooks, P.A., and Godin, C.S., 1985, Remarkable substrate-inhibitor properties of nicotine enantiomers towards a guinea pig lung aromatic azaheterocycle $\mathrm{N}$-methyltransferase. Biochem. Biophys. Res. Comm. 128: 312-316.

Dieterle. W., Faigle, J.W., Montigel, C., Sule, M., and Theobald, W., 1977, Biotransformation and pharmacokinetics of acenocoumarol (Sintrom) in man. Eur. J. Clin. Pharmacol. 11: 367. 375.

Dostert. P., O’Brien, E.M., Tipton, K.F., Meroni, M., Melloni, M., and Benedetti, M.S., 1992, Inhibition of monoamine oxidase by the R and $S$ enantiomers of N 3-(2,4-dichlorophenoxy) propy]-N-methyl-3-butyn-2-amine. Eur. J. Med. Chem. 27: 45-52.

Drayer, D.E., 1986, Pharmacodynamic and pharmacokinetic differences between drug enantiomers in humans: an overview. Clin. Pharmacol. Ther. 40: 125-133.

Drayer, D.E.. The early history of stereochemistry "in: Drug Stereochemistry. Analytical Methods and Pharmacology, pp: 1-31, eds Wainer, I.W., and Drayer, D.E., New York, 1988.

Eichelbaum, M., Mikus. G., and Vogelgesang, B., 1984, Pharmacokinetics of $(+),(-)$ and $( \pm)$-verapamil after intravenous administration. $B r, J$. clin. Pharmacol $17: 453-459$.

Eiçhelbaum. M.. 1988. Pharmacokinetic and pharmacodynamic consequences of stereoselective drug metabolism in man. Biochem. Pharmacol. 37: 93-96.

Eichelbaum, M.. Birkel, P.. Grube, E., Guetgemann U., and Somogyi, A., 1980, Effects of verapamil on PR intervals in relation to verapami! plasma levels following single i.v. and oral administration and during chronic treatment. Klin. Wochenschr. 58: 919-925.

Echizen. H., Vogelgesang. B., and Eichelbaum. M., 1985. Effects of d,I-verapamil on atrioventricular conduction in relation to its stereoselective first pass metabolism.Clin. Pharmacol. Ther. 38: $71-76$.

Eriksson, U.G., Lundahl, J.. Bäärnhielm, C., and Regårdh. C.G., 1991, Stereoselective metabolism of felodipine in liver microsomes from rat, dog, and human. Drug Metab. Dispos. 19: 889-894.

Evans, A.M., 1992, Enantioselective pharmacodynamics and pharmacokinetics of chiral nonsteroidal anti-inflammatory drugs. Eur. J. Clin. Pharmacol. 42: 237-256.

Fabro, S.. Smith, R.L., and Williams, R.T., 1967. Toxicity and teratogenicity of optical isomers of thalidomide. Nature 215: 269.

Fasco, M.J., Baker, F.D., and Fenton, J.W., 1976, Warfarin- stereochemical aspects of its metabolism by rat liver microsomes. Biochem. Pharmacol. 25: 2153-2!62,

Fasco, M.J.. Dymerski. P.P., Wos, J.D., and Kaminsky, L.S., 1978. A new warfarin metabolite: structure and function. J. Med. Chem. 21: 1054-1059. 
Fasco. M.J., Hildebrandt, E.F., and Suttie, J.W.. 1982, Evidence that warfarin anticoagulant action involves two distinct reductase activities. J. Biol. Chem. 257: 11210-11212.

Fasco, M.J., and Principe. L.M., 1980, Vitamin KI hydroquinone formation catalyzed by a microsomal reductase system. Biochem. Biophys. Res. Comm. 97: 1487-1492.

Fasco, M.J., and Principe, L.M., 1982, R- and S-warfarin inhibition of vitamin K and vitamin K 2,3epoxide reductase activities in the rat. J. Biol. Chem. 257: 4894-4901.

Fasco, M.J., Principe, L.M., Walsh. W.A., and Friedman, P.A., 1983, Warfarin inhibition of vitamin K-2.3-epoxide reductase in rat liver microsomes. Biochem. 22: 5655-5660.

Fitos. I., Visy, J.. Magyar. A., Kajtar. J., and Simonyi, M.. binding of 5-(o-chlorophenyl)-1.3-dihydro3-methyl-7-nitro-2H-1,4-benzodiazepin-2-one enantiomers to human serum albumin. Chirality 2: 161-166.

Fondevilla, C.. Meschengieser, S., and Lazzari, M.A.. 1988, Amiodarone potentiates acenocoumarin. Thromb. Res. 35: 203-208.

Franckowiak, G.. Bechem. M., Schramm, M.. and Thomas, G., 1985. The optical isomers of the 1.4 dihydropyridine BAY K 8644 show opposite effects on calcium channels. Eur. J Pharmacol. 114: $223-226$.

Gardill. S.L., and Suttie. J.W., 1990, Vitamin K epoxide and quinone reductase activities. Evidence for reduction by a common enzyme. Biochem. Pharmacol 40: 1055-1061.

Gill, T.S.. Hopkins. K.J.. Bottomley. J.. Gupta, S.K., and Rowland. M., 1989. Cimetidine-nicoumalone interaction in man: stereochemical considerations. Br. Journal of clin. Pharmacol. 27: 469. 474.

Gill. T.S.. Hokins. K.J., and Rowland. M.J.. 1988. Stereospecific assay of nicoumalone: application to pharmacokinetic studies in man. Br. J. clin. Pharmacol. 25: 591-598.

Van Ginneken, C.A.M. Rodrigues de Miranda, J.F., and Beld, A.J.. Stereoselectivity and drug distribution. In: Stereochemistry and Biological Activity of Drugs eds: Arièns, E.J.. Soudijn. W.. and Timmermans.P.B.M.W.M.. pp: 55-62. Blackwell Scientific Publications. Oxford. 1983.

Godbillon. J., Richard, J., Gerardin. A.. Meinertz. T.. Kasper. W.. and Jaenchen. E., 1981, Pharmacokinetics of the enantiomers of acenocoumarol in man. Br. J. Pharmacol. 12: 621-629.

Gold, E.H., Chang, W., Cohen, M., Baum, T., Ehrreich ، S., Johnson, G., Prioli, N., Sybertz, E.J., 1982. Synthesis and comparison of some cardiovascular properties of of the stereoisomers of labetolol. I Med Chem. 25: 1363-1370.

Gross, A.S., and Korner, B., 1989. Disposition of propafenone enantiomers in extensive and poor metabolizers of sparteine /debrisoquine. (Abstract) Naunyn Schmiedeberg's Arch. Pharmacol. 339 (Suppl): R 113.

Guengerich, F.P.. 1989. Polymorphisms of cytochrome P-450 in humans. TIPS 10: 107-109.

Gut, J., Catin. T., Dayer, P... Kronbach, T.,Zanger, U., and Meyer, U.A.., 1986, Debrisoquine/sparteinetype polymorphism of drug oxidation. Purification and characterization of two functionally different human liver cytochrome P-450 isozymes involved in impaired hydroxylation of the prototype substrate. J. Biol. Chem. 261: 11734-11743.

van Haarlem, L.J.M., Soute. B.A.M., and Vermeer. C.. 1987. Vitamin K-dependent carboxylase, - a possible role for thioredoxin in the reduction of vitamin $\mathrm{K}$ metabolites in liver. FEBS lett. 222: 353-357.

Heimark, L.D.. and Trager. W.F.. 1984. The preferred solution conformation of warfarin at the active site of cytochrome P-450 based on the CD spectral data. J. Med. Chem. 27: 1092-1095.

$$
\text { Ii }
$$


Heimark, L.D., Gibaldi, M., Trager, W.F.. O’Reilly. R.A., and Goulart, D.A., 1987. The mechanism of the warfarin rifampicin interaction in humans. Clin. Pharmacol.Ther. 42: 388-394.

Heimark. L.D., Wienkers, L., Kunze, K.. Gibaldi. M.. Eddy, A.C., Trager. W.F.. O' Reilly. R.A., and Goulart. D.A.. 1992. The mechanism of the interaction between amiodarone and warfarin in humans. Clin. Pharmacol. Ther 51: 398-407.

Hendel. J., and Brodthagen. H.. 1984. Entero-hepatic cycling of methotrexate estimated by use of the D-isomer as a reference marker. Eur. I. Clin. Pharmacol. 26: 103-107.

Hildebrandt. E.F.. Preusch. P.C., Patterson, J.L., and Suttic, J.W.. 1984, Solubilization and characterization of vitamin $\mathrm{K}$ epoxide reductase from normal and warfarin-resistant rat live microsomes. Arch. Biochem. Biophys. 228: 480-492.

Hjorth. S.. Carlsson, A., Clark, D., Svensson, K., Wikstrøm. H., Sanchez., D.. Linherg. P., Hacksell, U.. Arvidsson. L-E. Johansson. A., and Nilsson. J.G.L.. 1983. Central dopamine receptor agonist and antagonist actions of the enantiomers of 3-PPP. Psychopharmacol 81: 89-99.

Holford. N.H.G., 1986. Clinical pharmacokinetics and pharmacodynamics of warfarin. Understanding the dose-effect relationship. Clin. Pharmacokin. 11: 483-504.

IUPAC. 1970. Tentative rules for the nomenclature of organic chemistry. Section E. Fundamental Stereochemistry. J. Org. Chem. 35: 2849-2867Iwakawa. S.. Spahn. H.. Benet. L.Z., and Lin. E.T.. 1991. Stereoselective disposition of carprofen, flunoxaprofen and naproxen in rats. Drug Metab. Dispos. 19: 853-857.

Jafri, S.M., Gheorghiade. M.. and Goldstein S.. 1992. Oral anticoagulation for secondary prevention after myocardial infarction with special reference to the warfarin reinfarction study. Progr. Cardiovasc. Dis. 5: 317-324.

Jamali, F.. Mehvar. R., and Pasutto. F.M.. 1989. Enantioselective aspects of drug action and disposition: therapeutic pitfalls. I. Pharm. Sci. 78: 695-715.

Jamali, F.. 1988. Pharmacokinetics of enantiomers of chiral non-steroidal anti inflammatory drugs. Eur. I. Drug Metab. Pharmacokin. 13: 1-9.

Jassal. S.V.. Warfarin potentiated by glibenclamide. Br. Med I. 303: 789.

Keates, E.U., and Stone, R., 1984. The effect of d-timolol on intraocular pressure in patients with ocular hypertension. Am. J. Ophthalmot. 98: 73-78.

Kelly. J.G.. and O'Malley. K.O.. 1979. Clinical pharmacokinetics of oral anticoagulants.

Clin. Pharmacokin. 4: 1-15.

Knodell. R.G., Dubey. R.K.. Wilkinson. G.R.. and Guengerich. F.P.. 1988, Oxidative metabolism of hexobarbital in human liver: relationship to polymorphic S-mephenytoin 4-hydroxylation.

J. Pharmacol Exp. Ther. 245: 844-849.

Kroemer. H.K., Kihus. G.. Kronbach. T., Meyer, U.A., and Eichelbaum. M.D., 1989, In vitro characterization of the human cytochrome P-450 involved in polymorphic oxidation of propafenone. Clin. Pharmacol. Ther 45: 28-33.

Kroemer. H.K.. Echizen. H.. Heidemann. H.. and Eichelbaum, M.. 1992. Predictability of the in vivo metabolism of verapamil from in vitro data: contribution of individual metabolic pathways and stereoselective aspects. J. Pharmacol Exp. Ther. 260: 1052-1057.

Kroon C.. de Boer A.. Hoogkamer. J.F.W.. Schoemaker. H.C.. vd Meer. F.J.M., Edelbroek. P.M., and Cohen. A.F.. 1990. Detection of drug interactions, with single dose acenocoumarol: new screening method? Int. J. Clin. Pharmacol., Ther. Toxicol. 28: 355-360.

Lam. Y.W.F., 1988. Stereoselectivity: an issue of significant importance in clinical pharmacology. Pharmacother 8: 147-157. 
Larson, A.E., Friedman, P.A., and Suttie, J.W., 1981, Vitamin K-dependent carboxylase. -stochiometry of carboxylation and vitamin K 2,3-epoxide formation-J. Biol. Chem. 256: 11032-11035.

Lee, J.J., and Fasco. M.J.. 1984, Metabolism of vitamin K and vitamin K 2,3-epoxide via interaction with a common disulfide. Biochem. 23: 2246-2252.

Lehman, F.P.A., Rodrigues de Miranda, J.F., and Ariëns, E.J., 1976, Stereoselectivity and affinity in molecular pharmacology. In: Progress in drug research 20, pp 101-142, ed Jucker, E., BaselStuttgart.

Lehmann. F.P.A., 1986, Stereoisomerism and drug action. TIPS 7: 1-5.

Lennard. M.S., 1991, Clinical pharmacology through looking glass: reflections on the racemate vs enantiomer debate. Br. J. clin. Pharmacol. 31: 623-625.

Lennard, M.S., Tucker, G.T., Woods, H.F., Iyaun, A.O., and Eichelbaum, M., 1988, Stereoselective 4-hydroxylation of debrisoquine in Nigerians. Biochem. Pharmacol. 37: 97-98.

Lewis, R.J., Trager, W.F., Chan K.K.. Breckenridge, A., Orme, M., Rowland, M., and Schary, W.. 1974. Warfarin-stereochemical aspects of its metabolism and the interaction with phenylbutazone. J. Clin. Invest. 53: 1607-1617.

Lewis, R.J.. Trager. W.F.. Robinson. A.J., and Chan, K.K.. 1973, Warfarin metabolites: the anticoagulant activity and pharmacology of warfarin alcohols. J. Lab. Clin. Med. 81: 925-931.

Lima, J.J., Boudoulas, H., and Shields, B.J., 1985. Stereoselective pharmacokinetics of disopyramide enantiomers in mani. Drug Metab. Dispos. 13: 572-577.

Maher, T.J., and Johnson, D.A.., 1991, Review of chirality and its importance in pharmacology. Drug Devel. Res. 24: 149-156.

Mason, S., 1984, The left hand of nature. New Scientist 43: 10-14.

Mason, S., 1986, The origin of chirality in nature. TIPS 7: 20-23.

Meese, C.O., and Eichelbaum. M., 1986. Stereochemical aspects of polymorphic 4-hydrox ylation of debrisoquine in man (Abstrac1) . Naunyn Schmiedebergs Arch. Pharmacol. 332 (supl):R95.

Meineriz, T.. Kasper, W., Kahl, C., and Jaenchen, E.. 1978, Anticoagulant activity of the enantiomers of acenocoumarol, Br. J. clin. Pharmacol, 5: 187-188.

Michot. F., Holı, N.F., and Fontanilles. F., 1981, Uber die Beeinflussung der gerinnungshemmenden Wirkung von Acenocoumarol durch Sulfinpyrazon. Schweiz. Mediz. Wochenschr. 111: 255-260.

Morris, T.H., and Kaumann. A.J., 1984. Different steric characteristics of $\beta_{1}$ - and $\beta_{2}$-adrenoceptors. Naunyn-Schmiedeberg's Arch. Pharmacol. 327: 176-179.

Mosterd, J.J., and Thijssen. H.H.W.. 1991. The long term effects of the rodenticide, brodifacoum, on blood coagulation and vitamin $\mathrm{K}$ metabolism in rats. Br.J. Pharmacol.104: 531-535.

Mosterd. J.J., and Thijssen. H.H.W.. 1992, The relationship between the vitamin K cycle inhibition and the plasma anticoagulant response at steady-state $S$-warfarin conditions in the rat.

I. Pharmacol.Exp. Ther. 260: 1081-1085.

Mueller. W.E., Stereoselective plasma protein binding of drugs, in: Drug stereochemistry: analytical methods and pharmacology, eds: Wainer, I.W .. and Drayer, D.E., pp: 227-245. New York. 1988.

Mueller. W.E., and Wollert. U., 1975. High stereospecifity of the benzodiazepine binding site on human serum albumin. Studies with D- and L-oxazepam hemisuccinate. Mol. Pharmacol. 11: $52-60$. 
Nebert, D.W., Nelson, D.R., Coon, M.J., Estabrook, R.W., Feyereisen, R., Fuji-Kuriyama, Y., Gonzalez,F.J., Guengerich,F.P..Gunsalus, I.W.., Johnson, E.F., Loper, J.C., Sato, R., Waterman. M.R.. and Waxman, D.J., 1991. The P450 supergene family: update on new sequences, gene mapping, and recommended nomenclature. DNA Cell Biol. 10: 1-14.

Niopas. I., Toon, S., and Rowland, M., 1991, Further insight into the stereoselective interaction between warfarin and cimetidine in man. Br. J. clin. Pharmacol. 32: 508-511.

Obaseki, A.O.. and Coker, H.B., 1987. The anticoagulant activity of some selected warfarin analogues. J. Pharm. Pharmacol. 39: 142-144.

Ofori-Adjei, D., Ericsson, O., Lindstrom, B., Hermansson, J., Adjepon-Yamoah, K.., and Sioqvist, F., 1986. Enantioselective analysis of chloroquine and desethylchloroquine after oral administration of racemic chloroquine. Ther. Drug Monit. 8: 457-461.

Okazaki, O., Kurata, T., Hakusui, H., and Tachizawa, H., 1991, Stereoselective glucuronidation of ofloxacin in rat liver microsomes. Drug Metab. Dispos. 19: 376-379.

Olsen, R.E., 1984, The function and metabolism of vitamin K. Ann. Rev. Nutr. 4: 281-337.

O'Reilly, R.A., 1976, Stereoselective interaction of warfarin and metronidazole in man. New Engl. J. Medi.295: 354-357.

O'Reilly, R.A., 1980, Siereoselective interaction of trimethoprim-sulfamethoxazole with the seperated enantiomorphs of warfarin in man. New Engl. J. Med. 302: 33-35.

O'Reilly, R.A.. 1981, Dynamic interaction between disulfiram and separated enantiomorphs of racemic warfarin. Clin. Pharmacol. Ther. 29: 332-336.

O'Reilly, R.A.. 1982, Stereoselective interaction of sulfinpyrazone and its separated enantiomorphs in man. Circulation 65: 202-207.

O'Reilly, R.A.. Trager, W.F., Rettie. A.E.. and Goulart, D.A., 1987, Interaction of amiodarone with racemic warfarin and its separated enantiomorphs in humans. Clin. Pharmacol.Ther. 42:290294.

Paxton, J.W., and Norris, R.M., 1984. Propranolol disposition after acute myocardial infarction. Clin. Pharmacol. Ther. 36: 337-342.

Pfeiffer, C.C.. 1956, Optical isomerism and pharmacological action: a generalization. Science 124: 29 . 31.

Pini, M., Manotti. C., and Quintavalla, R., 1985, Interaction between amiodarone and acenocoumarin. Thromb. Haemost. 54: 549.

Pohl, L.H., Bales, R., and Trager. W.F., 1976. Warfarin: stereochemical aspects of its metabolism in vivo in the rat. Res. Comm. of Chem. Pathol. Pharmacoi. 15: 233-255.

Pohl, L.R., Nelson. S.D., Garland. W.A., and Trager, W.F., 1975, The rapid identification of a new metabolite of warfarin via a chemical ionization mass spectrometry ion doublel technique. Biomed. Mass Spectrom. 2: 23-30.

Preusch. P.C., and Suttie, J.W.. 1984, Relationship of DTT dependent microsomal vitamin K quinone and vitamin $\mathrm{K}$ epoxide reductases. Inhibition of epoxide reduction by vitamin $\mathrm{K}$ quinone. Bioch. Biophys. Acta 798: 141-143.

Rodrigues de Miranda. J.F., 1975, Specifity in drug-protein interaction (PhD Thesis).

Roberts.J.D., and Caserio, M.C., 1977. Basic principles of organic chemistry. Menlo Park, Cailifornia.

Rubin. A.. Knadler. M.P.. Ho, P.P.. Bechtol, L.D.. and Wolen, R.L.. 1985, Stereoselective inversion of (R)-fenoprofen to (S)-fenoprofen in humans. J. Pharm. Sci. 74: 82-84. 
Ruffolo, R.R..Stereoselectivity in adrenergic agonists and adrenergic blocking agents. In: Stereochemistry and Biological Activity of Drugs, Eds Ariëns, E.J.., Soudijn, E., and Timmermans.B.M.W.. pp: 103-125, Blackwell Scientific Publications, Oxford, 1983.

Schmidt. W., and Jaenchen, E., 1978, Species dependent stereospecific protein binding of the oral anticoagulant drug phenprocoumon. Experientia 34: 1323-1328.

Serlin, M.J., and Breckenridge, A.M., 1983, Drug interactions with warfarin. Drugs 25: 610-620.

Shetty. H.G.M., Fennerty, A.G., and Routledge,P.A.. 1989. Clinical pharmacokinetic considerations in the control of oral anticoagulant therapy. Clin. Pharmacokin. 16: 238-253.

Siddoway, L.A.. Thompson, K.A.. Mc Allister, C.B., Wang. T.. Wilkinson, G.R., Roden, D.M., and Woosly, R.L., 1987, Polymorphism of propafenone metabolism and disposition in man: clinical pharmacokinetic consequences. Circulation 4: 785-791.

Silverman, R.B., and Nandi, D.L., 1988, Reduced thioredoxin: a possible cofactor for vitamin K. epoxide reductase, further support for an active site disulfide. Biochem. Biophys. Res. Comm. 155: $1248-1254$.

Silverman, R.B., Mukharii, I., and Nandi, D.L.. 1988. Solubilization, partial purification, mechanism. and inactivation of vitamin $\mathrm{K}$ epoxide reductase. In: Current Advances in Vitamin $\mathrm{K} \mathrm{Re}$ search, ed Suttie J.W.. New York, pp: 65-74.

Simonyi. M., 1984, On chiral drug action. Med Res. Rev. 4:359-413.

Simonyi. M., Gal, J., and Testa, B.. 1989. Sign of the times: the need for a stereochemically informalive generic name system. TIPS 10:349-354.

Smith, D.F., 1989. The stereoslectivity of drug action. Pharmacol. Toxicol 65: 321-331.

Somogyi, A.A., Bochner, F., and Sallustio, B.C.. 1992. Stereoselective inhibition of pindolol renal clearance by cimetidine in humans. Clin. Pharmacol. Ther. 51: 379-387.

Sporckmann, K., and Eichelbaum, M.. 1991. Enantioselective disposition of R-and S-nimodipine after simultaneous oral and intravenous administration (Abstract). Naunyn-Scmiedebergs Arch. Pharmacol. 343: Ri24.

Sudlow. G.. Birkelt. D.J., and Wade, D.N., 1975. The characterization of two specific binding sites on human serum albumin. Mol. Pharmacol. 11: 824-832.

Sutfin. T. Balmer, K., Boström. H.. Eriksson, S., Höglund, P.„ and Paulssen, O., 1989, Stereoselective interaction of omeprazole with warfarin in healthy men. Ther. Drug. Mon. 11: 176-184.

Suttie, J.W., 1987. Recent advances in hepatic vitamin K metabolism and function. Hepatol. $7: 367$ 376.

El Tayar, N., Testa, B, van de Waterbeemd, H., Carrupt. P-A.. and Kaumann, A.J.. Influence of lipophilicity and chirality on the selectivity of ligands for $\beta_{1}$-and $\beta_{2}$-adrenoceptors. J. Pharm. Pharmacol. 40: 609-612.

Soons, P.A.. Roosemalen, M.C.M., and Breimer, D.D., 1990. Stereoselective pharmacokinetics of oral and intraveneous nitrendipine in healthy subjects (Abstract). Eur. J. Pharmacol. (Suppl. IUPHAR): 2283-2284.

Tamassia. V.. Jannuzo, M.G.. Moro, E., Stegnjaich. S.. Groppi. W.. and Nicolis, F.B., 1984, Pharmacokinetics of the enantiomers of indoprofen in man. Int. J. Clin. Pharmacol. Res. 4:223-230.

Testa, B., 1988. Substrate and product stereoselectivity in monooxygenase-mediated drug activation and inactivation. Biochem. Pharmacol. 37: 85-92. 
Thijssen, H.H.W., and Baars, L.G.M.., 1983. Active metabolites of acenocoumarol: do they contribute to the therapeutic effect. $B r . J$. clin. Pharmacol. 16:491-496.

Thijssen, H.H.W., and Baars. L.G.M.. 1987. The biliary excretion of acenocoumarol in the rat: stereochemical aspects. I. Pharmac. Pharmacol. 39: 655-657.

Thijssen. H.H.W.. and Baars. L.G.M., 1989. Microsomal warfarin binding and vitamin K-2.3-cpoxide reductase. Biochem. Pharmacol. 38: 1115-1120.

Thijssen. H.H.W., Baars. L.G.M.. and Drittij-Reijnders. M.J., 1985. Stereoselective aspects in the pharmacokinetics and pharmacodynamics of acenocoumarol and its amino- and acelamido derivatives in the rat. Drug Metab. Dispos. 13: 593-597.

Thijssen. H.H.W., Baars. L.G.M., and Vervoort-Peters, H.T.M., 1988, Vitamin K 2.3-epoxide reductase: the basis for stereoselectivity of 4-hydroxycoumarin anticoagulant. Br. J. Pharmacol. 95: 675-682.

Thijssen. H.H.W.. Hamulyak, K... and Willigers, H., 1988b, 4-Hydroxycoumarin oral anticoagulants: pharmacokinetics-response relationships. Thromb. Haemost, 60: 35-38.

Thijssen. H.H.W., Jansen, G.M.J., and Baars. L.G.M., 1986. Lack of effect of cimetidine on pharmacodynamics and kinetics of single oral doses of R-and S-acenocoumarol. Eur I. Clin Pharmacol. 30: 619-623.

Toon, S. Hopkins. K.J.. Garstang, F.M., Aarons, L.. Sedman, A., and Rowland. M.. 1987. Enoxacinwarfarin interaction: pharmacokinetic and stereochemical aspects. Clin. Pharmacol. Ther 42: $33-41$.

Toon, S., Lon.L.K., Gibaldi. M., Trager, W.F., O'Reilly. R.A., Motley.C.H.. andGoulart, D.A., 1986. The warfarin-sulfinpyrazone interaction: stereochemical considerations. Clin. Pharmaco! Ther. 39: 15-24.

Toon, S.. and Trager, W.F., 1984, Pharmacokinetic implications of stereoselective changes in plasmaprotein binding: warfarin/sulfinpyrazone. J. Pharm. Sci. 73: 1671-1673.

Tracy. T.S., and Hall. S.D.. 1992. Metabolic inversion of (R)-ibuprofen. Epimerization and hydrolysis of ibuprofenyl-coenzyme A. Drug Metah. Dispos. 20: 322-327.

Trager, W.F.. Lewis. R.J., and Garland, W.A.. 1970. Mass spectral analysis in the identification of human melabolites of warfarin. J. Med. Chem. 13: 1196-1204.

Tucker, G.T., and Lennard, M.S., 1989. Enantiomer specific pharmacokinetics. Pharmacol. Ther 45: 309-329.

Vanhaelen, M., and Vanhaelen-Fastré R., 1978, Stabilité des anticoagulants dérivés de l'hydroxy-4coumarine. II Structure des pricipaux produits de dégradation de la phenprocoumone. du clocoumarol, de la warfarine et de l'acénocoumarine. Pharm. Acta llelv. 53: 221-230.

Vermeulen. N.P.E.. Rietveld. C.T.. and Breimer. D.D., 1983, Disposition of hexobarbitone in healthy man: kinetics of parent drug and metabolites following oral administration. Br.J.clin. Pharmacol. 15: 459-465.

Vogelgesang. B.. Echizen. H., Schmidı. E.. and Eichelbaum. M.. 1984. Stereoselective first-pass metabolism of highly cleared drugs: studies of the bioavailability of 1 - and d-verapamil examined with a stable isotope technique. Br. J. clin. Pharmacol. 18: 733-740.

Waechtershauser, G.. 1991. Biomolecules: The origin of their optical activity. Med Hypoth. 36: 307-311.

Wade, D.N., Mearrick, P.T., and Morris, J.L., 1973. Active transport of L-Dopa in the intestine. Nature 242: 463-465. 
Wainer, I.W., and Marcotte, A.L., 1988, Stereochemical terms and concepts. in: Drug Stereochemistry, Analytical Methods and Pharmacology, eds Wainer, I.W, and Drayer, D.E. pp: 31-41, New York.

Walle, U.K., and Walle, T., 1991, Stereoselective sulfate conjugation of 4-hydroxypropranolol in humans: comparison of platelet and hepatic activity. Drug Metab. Dispos. 19: 838- 840.

Walle, U.K., Walle, T., Bai, S.A., and Olanoff, L.S., 1983, Stereoselective binding of propranolol to human plasma, al-acid glycoprotein and albumin. Clin. Pharmacol. Ther. 34: 718-723.

Walle, T., Webb, J.G., Bagwell, E.E., Walle, U.K., Daniell, H.B., and Gaffney, T.E., 1988, Stereoselective delivery and actions of beta receptor antagonists. Biochem. Pharmacol. 37:115-124.

Wallin, R., and Martin, L.F., 1985, Vitamin K-dependent carboxylation and vitamin K. metabolism in liver. Effects of warfarin. J. Clin. Invest. 76: 1879-1884.

Ward, S.. Branch, R.A., Walle, T., and Walle, U.K., 1986, Cosegregation of propranolol metabolism with the debrisoquine and mephenyioin polymorphisms. Pharmacologist 28: 137.

Wedlund, P.J., Aslanian, W.S., Jacqz,E., McAllister. C.B., Branch, R.A., and Wilkinson, G.R., 1985. Phenotypic differences in mephenytoin pharmacokinetics in normal subjects. J. Pharmacol. Exp. Ther. 234: 662-669.

West, B.D., Preis, S., Schroeder, C.H., and Link, K.P., 1961. Studies on the 4-hydroxycoumarins. XVII. The resolution and absolute configuration of warfarin. J. Am. Chem. Soc. 83: 26762679.

Wheeler, C.R., and Trager, N.F., 1979. Absolute configuration of acenocoumarin. J. Med. Chem. 22: 1122-1124.

Whitlon, D.S., Sadowski, J.A., and Suttie. J.W., 1978, Mechanism of coumanin action: significance of vitamin K epoxide reductase inhibition. Biochemistry 17: 1371-1377.

Williams, K.M., 1989. Chirality: pharmacokinetics and pharmacodynamics in 3 dimensions. Clin. Exp. Pharmacol. Physiol. 16: 465-470.

Williams, K., Day, R., Knihinicki, R., and Duffield, A., 1986, The stereochemical uptake of ibuprofen enantiomers into adipose tissue. Biochem. Pharmacol. 35: 3403-3405.

Williams, K., and Lee, E., 1985. Importance of drug enantiomers in clinical pharmacology. Drugs 30: 333-354.

Wingard, L.B., O'Reilly, R.A., and Levy, G., 1978, Pharmacokinetics of warfarin enantiomers: a search for intrasubject correlations. Clin. Pharmacol. Ther. 23: 212-217.

Yacobi, A., and Levy, G., 1974, Pharmacokinetics of the warfarin enantiomers in rats.J. Pharmacokin. Biopharm. 2: 239.255,

Yacobi, A., and Levy, G., 1977. Protein binding of warfarin enantiomers in serum of humans and rats. J. Pharmacokin. Biopharm. 5: 123-131.

Yasumori, T., Murayama, N., Yamazoe. Y., and Kato, R., 1990, Polymorphism in hydroxylation of mephenyioin and hexobarbital stereoisomers in relation to hepatic P-450 human-2. Clin.Pharmacol. Ther. 47: 313-322.

Zhou. H-H. Anthony, L.B., Roden, D.M., and Wood, A.J J., 1990, Quinidine reduces clearance of (+)propranolol more than (-)-propranolol through marked reduction in 4-hydroxylation. Clin. Pharmacol. Ther. 47: 686-693.

Zimmerrman. A.. and Matschiner. J.T., 1974, Biochemical basis of heriditary resistance to warfarin in the rat. Biochem. Pharmacol. 23: 1033-1040. 


\section{CHAPTER 2:}

\section{ENANTIOSELECTIVE STRUCTURE-PHARMACOKINETIC RELATIONSHIPS OF RING SUBSTITUTED WARFARIN ANALOGUES IN THE RAT.}

\subsection{ABSTRACT:}

The enantiomer specific pharmacokinetics of ring substituted warfarin analogues have been studied in the rat after the administration of $2 \mathrm{mg} / \mathrm{kg}$ of the racemates. The stereoselective differences observed are due to stereoselective plasma binding and stereoselective intrinsic hepatic clearance. Greater binding is observed for the S-enantiomers, except for the 2'-substituted analogues, where the Renantiomers are more tightly bound. The stereoselectivity of plasma protein binding ranges up to a factor of about 4 .

All substituted warfarins show a higher intrinsic clearance than warfarin. Enantiomer selectivity of the intrinsic clearance depends on the position of the substituent; warfarin and 3 -analogues show $R>S$; 4'- and 2'-substituted analogues show $S>R$. Exceptions to this generality are observed for 4'methoxy and 4'-methylwarfarin for which there are no differences between the enantiomers in the intrinsic clearances.

Adapted from: J. Pharm. Pharmacol. 42: 861-866, 1990, L.G.M. Baars, M.T. Schepers, J.J.R. Hermans, H.H.J. Dahlmans, and H.H.W. Thijssen.

\subsection{INTRODUCTION:}

Stereoselective differences in drug disposition and drug activity have received increasing attention as awareness has grown that pharmacokinetic and pharmacodynamic descriptions of a drug applied as a racemic mixture are meaningless unless the fate of the individual enantiomers is established (Ariëns, 1984; for reviews, see Walle and Walle, 1986; Evans et al, 1988: Tucker and Lennard, 1990). The closely related 4-hydroxycoumarin anticoagulants warfarin and acenocoumarol (4'-nitrowarfarin) are in use as racemic mixtures. The stereoselectivity of the pharmacokinetics and the pharmacodynamics of their enantiomers in man and rat has been widely studied (Breckenridge et al, 1973; Yacobi and Levy, 1974; Toon et al, 1986; Godbillon et al, 1981: Thijssen et al, 1985, 1986). In man the S-enantiomers of both compounds are eliminated more rapidly than the R-enantiomers; the differences are modest for the warfarin enantiomers but 10-20 fold for the enantiomers of acenocoumarol. The body clearance of the acenocoumarol enantiomers is at least 100 times that of R/S-warfarin (Godbillon et al, 1981: Thijssen et al, 1986). Those differences between warfarin and acenocoumarol are also observed in the rat. However, in the rat, R-warfarin is eliminated faster than S-warfarin. The stereoselectivity of acenocoumarol elimination in the rat is comparable to that of man, i.e. S-acenocoumarol is cleared 3-4 times faster (Thijssen et al, 1985). The effects of the introduction of the 4'-nitro substituent on clearance and stereoselectivity prompted us to investigate the disposition of a series of phenyl-substituted warfarin (figure 2.1) analogues in the rat. The compounds were administered as their racemates and 
the individual enantiomers were analyzed by a stereoselective HPLC procedure. Stereoselectivity in plasma protein binding was accounted for in the pharmacokinetic evaluation.

Figure 2.1: The structure of warfarin $(\mathrm{R}=\mathrm{H})$ and the ring substituted analogues. The chiral center is indicated by *.

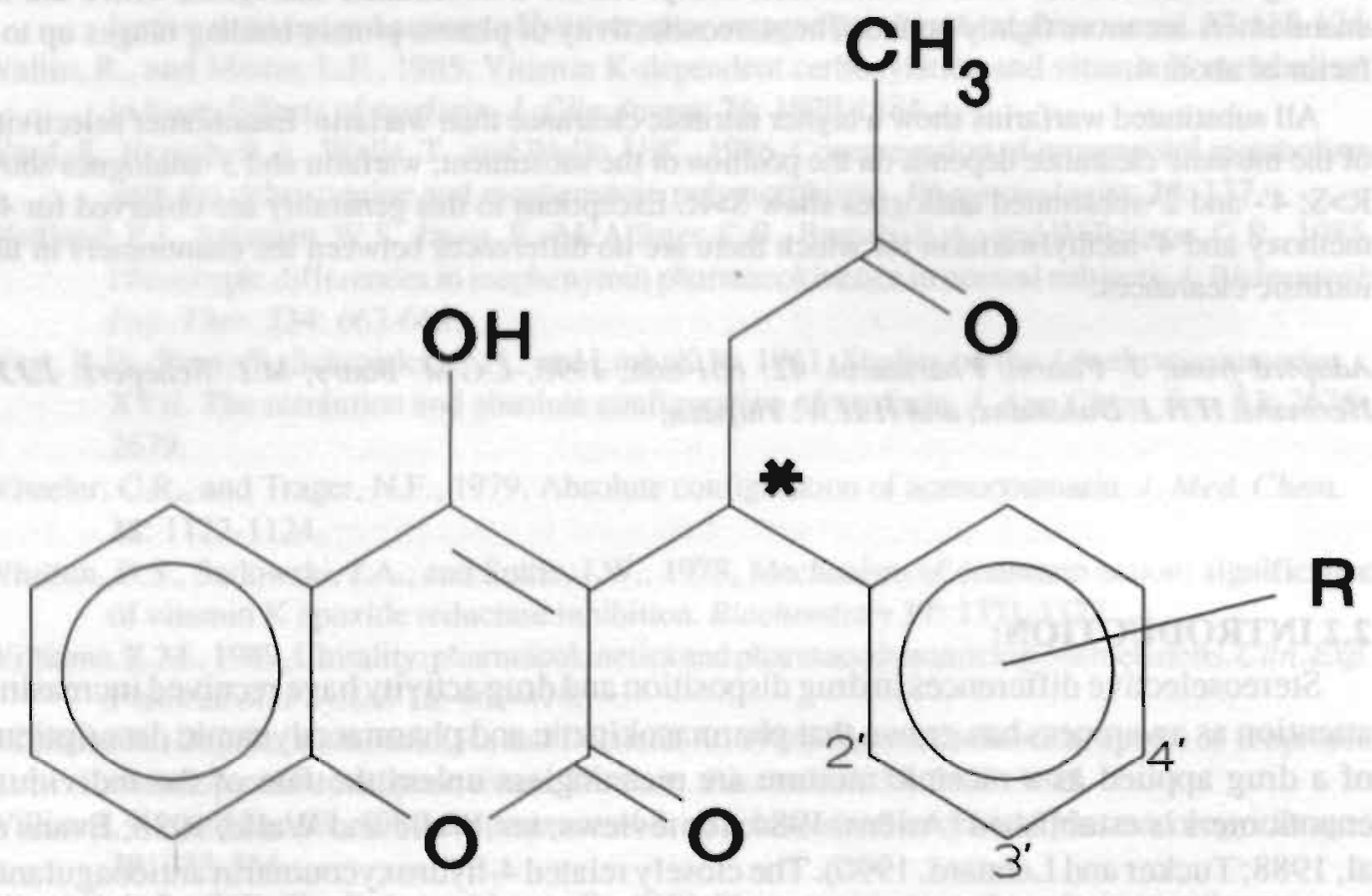

\subsection{MATERIALS AND METHODS:}

\section{Synthesis of warfarin analogues:}

Racemic warfarin was obtained from Sigma Chemicals (St. Louis, USA); racemic 4'chlorowarfarin was from Aldrich (Brussels, Belgium); racemic 4'-nitrowarfarin was a gift from Ciba-Geigy (Amhem, The Netherlands). Optically pure isomers of warfarin, 4'chlorowarfarin and 4'-nitrowarfarin were prepared by the method of West at al (1961). The purity of the enantiomers was tested by the formation of their t-BOC-L-proline diastereomers and subsequent analysis by HPLC (Lichrosorb Si60; n-hexane/ethylacetate/methanol 75/25/ 0.2 ) as described by Banfield and Rowland (1984) and proved to be higher than $97 \%$.

Phenyl ring substituted warfarin analogues were synthesized in our laboratory according to standard procedures. Briefly, substituted benzalacetones were prepared from the respective benzaldehydes by condensation with acetone under alkaline conditions in an ethanol-water 
mixture. The benzalacetones were purified by crystallization (TLC was used to monitor purity) and identified by mass spectrometry (GC-MS, Hewlett Packard 5995). Conjugation of the benzalacetone with 4-hydroxycoumarin via Michael additon was by refluxing an equimolar mixture of the reactants in methanol as described by Bush and Trager (1983). The compounds were purified by crystallization (TLC and HPLC were used for analysis). GCMS identification of the warfarins was performed after derivatization with diazomethane. The acidity (pKa) of the warfarins was estimated from the $\mathrm{pH}$-dependent change in UV absorption (at $272 \mathrm{~nm}$ ) of $10 \mu \mathrm{g} / \mathrm{ml}$ solutions in buffers ( $\mathrm{pH}$ range $2-11$, ionic strength $0.5 \mathrm{M}$ ).

\section{Drug analysis:}

Total drug concentrations, i.e. the $\mathbf{R}$ - and $\mathrm{S}$-enantiomer were assayed by reversed phase HPLC based on techniques described by Thijssen et al (1985). The eluent consisted of a mixture of acetonitrile and $0.1 \% \mathrm{v} / \mathrm{v} /$ acetic acid in water, brought to a pH of 5.0 to 5.2 with ammonia. For each compound the eluent was adapted for optimal resolution and sensitivity. The stationary phase consisted of a Chromspher C18 column 3x100 mm (Chrompack, Middelburg, the Netheriands). To $80 \mu$ plasma, $0.5 \mathrm{mi}$ of $0.1 \mathrm{M}$ sodium acetate buffer $(\mathrm{pH}=4,4)$ was added. The drugs were extracted by shaking the acidified plasma samples with $4 \mathrm{ml}$ of a $1 / 1(\mathrm{v} / \mathrm{v})$ mixture of methylene chlloride and petroleum ether (boling range 40-60 C). Before extraction, one of the enantiomers of either warfarin, 4'-chlorowarfarin, or 4'nitrowarfarin was added as internal standard. The choice depended on the chromatographic behaviour in relation to the compound to be assayed. Following evaporation of the organic phase, the residue was dissolved in $50 \mu \mathrm{l}$ of acetonitrile; $10 \mu \mathrm{l}$ was injected on HPLC as described above. Total concentration was estimated from peak area ratios. The detection limit, using $80 \mu \mathrm{l}$ plasma was $30-50 \mathrm{ng} / \mathrm{ml}$.

The ratio of the R-and $\mathbf{S}$-enantiomers was estimated by the procedure of Banfield and Rowland (1983). Briefly, $20 \mu \mathrm{l}$ of a solution of dicyclohexane-carbodiimide $(10 \mathrm{mg} / \mathrm{ml}$ in acetonitrile) and $20 \mu \mathrm{l}$ of a solution of $\mathrm{N}$-carbobenzyloxy-L-proline $(10 \mathrm{mg} / \mathrm{ml}$ in acetonitrile) were added to the remaining $40 \mu \mathrm{l}$ of extract.

The reaction was completed ovemight at $40^{\circ} \mathrm{C}$. The diastereomeric esters were seperated by straight phase chromatography using a Chromspher Si column ( $3 \times 100 \mathrm{~mm})$ and mixtures of hexane-THF and acetic acid as eluting solvent. The esters of the R-and S-enantiomers were completely separated, with the esters of the S-enantiomers eluting first. The concentrations of the individual enantiomers in a sample were calculated from the R/S ratio and the total concentration.

\section{Partition coefficients:}

The partition coefficients of the warfarin analogues for the n-octanol water system at $\mathrm{pH}$ 7.4 was estimated as follows. To $1 \mathrm{ml} 0.1 \mathrm{M}$ phosphate buffer, p.H 7.4, saturated with $\mathrm{N}$ octanol, was added $20 \mu \mathrm{g}$ of the compound $\left(20 \mu \mathrm{l}\right.$ of a $1 \mathrm{mg} \mathrm{ml}^{-1} \mathrm{pH} 8-10$ aqueous stock 
solution). Three $0.3 \mathrm{ml}$ samples were equilibrated with $0.3 \mathrm{ml} \mathrm{n}$-octanol saturated with buffer by shaking for $30 \mathrm{~min}$. The concentrations in the aqueous phase were assayed by HPLC.

\section{Plasma protein binding:}

Plasma protein binding was determined by equilibrium dialysis. Rat plasma pooled from six rats was used. Dialysis bags (diameter $6.4 \mathrm{~mm}$ ) were filled with $1 \mathrm{ml}$ plasma containing $15 \mu \mathrm{g}$ of the racemate. Dialysis was performed against $4 \mathrm{ml}$ of $0.066 \mathrm{M}$ phosphate buffer, $\mathrm{pH}$ 7.4, containing $0.1 \%$ sodium azide in screw stoppered $5 \mathrm{ml}$ flasks. The flasks were gently tumbled overnight at room temperature $\left(22^{\circ} \mathrm{C}\right)$. Assay of the enantiomers in the buffer compartment and the plasma compartment were performed as described above.

\section{Animal experiments:}

Male Wistar rats, 250-300 g, were used and had free access to labfood and water. Under light ether anesthesia, the rats were fitted with a catheter (PE-10) in the left femoral artery. The catheter exteriorized in the neck. The animals were allowed to recover at least two days before use. The warfarin analogues, as racemates $(1 \mathrm{mg} / \mathrm{ml}$ saline, $\mathrm{pH} 7-8)$, were administered subcutaneously in $2 \mathrm{mg} / \mathrm{kg}$ amounts. Blood samples, $200 \mu \mathrm{l}$, were taken at regular times and collected on $22 \mu \mathrm{l} 0.1 \mathrm{M}$ trisodium citrate in Eppendorf cuvettes. Plasma was prepared immediately and stored at $-20^{\circ} \mathrm{C}$ until analyzed.

\section{Determination of blood clotting activity:}

Blood clotting activity was measured by the thrombotest assay (Nycomed, Oslo, Norway) and was expressed as \% of control prothrombin complex activity (\%PCA). Briefly, $50 \mu \mathrm{l}$ citrated plasma was diluted with $50 \mu \mathrm{l}$ Michaelis buffer, then $100 \mu \mathrm{l}$ of a prewarmed solution of Thrombotest reagent was added (Nycomed. Oslo, Norway). After preincubation at $37^{\circ} \mathrm{C}$ for 1 minute the clotting process was started by the addition of $100 \mu \mathrm{l} \mathrm{of} \mathrm{a} 0.033 \mathrm{M}$ calcium dichloride solution. Clotting time was assayed automatically with a LC-78 coagulometer (Lode Instruments, Groningen, the Netherlands). Clotting time was converted to \% PCA from a calibration curve obtained from various dilutions of pooled plasma from control rats.

\section{Pharmacokinetic analyses:}

The plasma half-life $\mathrm{t}^{1} / 2$, was estimated from the terminal elimination phase by linear regression. The area under the plasma concentration-time curve was calculated by the trapezoidal rule with the addition of the extrapolated part: $A U C_{t}+C_{t} t^{1} / 2 / n 2$, where $A U C_{t}$ is the area from $\mathrm{t}=0$ to the last concentration $\mathrm{C}_{1}$ estimated. Total plasma clearance $\mathrm{Cl}$, assuming complete absorption of the dose D, was calculated by D/AUC, the apparent volume of distribution Varea by $\mathrm{Cl}_{1} \mathrm{I}^{1} / 2 / \mathrm{n} 2$. The pharmacokinetic constants for the unbound fraction were obtained by correcting for the protein binding; e.g. $\mathrm{Cli}=\mathrm{Cl} / \mathrm{fu}$ is the clearance of the unbound fraction (intrinsic clearance).

\section{Statistical evaluation:}

Enantiomeric differences were tested for their significance by two-tailed paired t-tests. 
TABLE 2.1: $\mathrm{pKa}$ and $\log \mathrm{P}$ constants of ring-substituted warfarins

\begin{tabular}{|l|c|c|c|c|}
\hline Compound & $\mathbf{p K a}$ & $\log \mathbf{P}$ & $\log \mathbf{P x}-\log \mathrm{Ph}$ & $\Pi \mathbf{X}$ \\
\hline Warfarin & 5.0 & 1.20 & 0.00 & 0.00 \\
\hline 4'-nitro & 5.0 & 0.98 & -0.22 & -0.28 \\
\hline 3'-nitro & 4.9 & 0.92 & -0.28 & -0.28 \\
\hline 4'-cyano & n.d. & 0.64 & -0.56 & -0.57 \\
\hline 4'-chloro & 4.9 & 2.03 & 0.83 & 0.71 \\
\hline 3'-chloro & 5.0 & 2.00 & 0.80 & 0.71 \\
\hline 2'-chloro & 5.1 & 2.02 & 0.82 & 0.71 \\
\hline 4'-bromo & 5.0 & 2.24 & 1.04 & 0.86 \\
\hline 3'-bromo & n.d. & 2.24 & 1.04 & 0.86 \\
\hline 4'-methyl & 4.9 & 1.71 & 0.51 & 0.56 \\
\hline 3'-methyl & n.d. & 1.73 & 0.53 & 0.56 \\
\hline 2'-methyl & n.d. & 1.92 & 0.72 & 0.56 \\
\hline 4'-methoxy & 5.1 & 1.25 & 0.05 & -0.02 \\
\hline 3'-methoxy & 5.0 & 1.20 & 0.00 & -0.02 \\
\hline 2'-methoxy & 5.2 & 1.59 & 0.39 & -0.02 \\
\hline
\end{tabular}

pKa and $\log \mathrm{P}$ values were determined as described in the method section. n.d., not determined
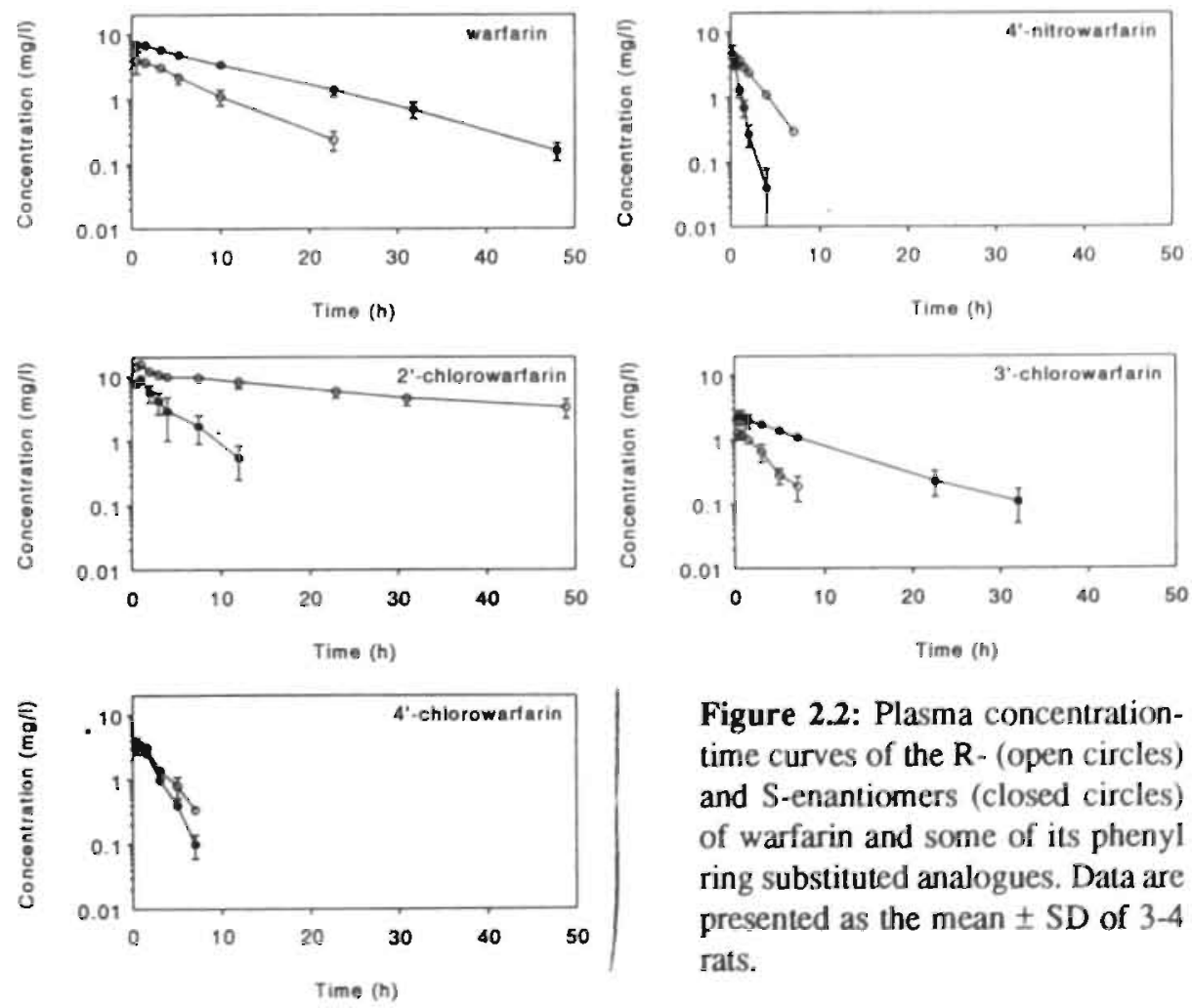

Figure 2.2: Plasma concentrationtime curves of the R- (open circles) and S-enantiomers (closed circles) of warfarin and some of its phenyl ring substituted analogues. Data are presented as the mean \pm SD of 3-4 rats. 
TABLE 2.2: Pharmacokinetic constants of ring substituted R/S warfarins in the rat.

\begin{tabular}{|c|c|c|c|c|c|}
\hline Analogue & & It/ (b) & AUC $(\mu \mathrm{g} / \mathrm{h} / \mathrm{mI})$ & $\mathrm{Cl}(\mathrm{m} / \mathrm{h} \cdot \mathrm{kg})$ & Vareal $(\mathrm{m} / \mathrm{kg})$ \\
\hline \multirow[t]{2}{*}{ H } & $\mathrm{R}$ & $4.75 \pm 0.29 * *$ & $32.0 \pm 4.0^{\circ \cdots}$ & $32.3 \pm 4.2^{\circ *}$ & $215 \pm 14.7^{\circ}$ \\
\hline & s & $8.75 \pm 0.43$ & $92.2 \pm 4.3$ & $10.9 \pm 0.5$ & $135 \pm 0.6$ \\
\hline \multirow[t]{2}{*}{$4 \cdot \mathrm{NO} 2$} & $\mathrm{R}$ & $1.70 \pm 0.10^{* *}$ & $12.6 \pm 0.7^{* *}$ & $80.1 \pm 4.6^{\circ *}$ & $193 \pm 4.3$ \\
\hline & S & $0.45 \pm 0.05$ & $3.5 \pm 0.2$ & $288.6 \pm 21.0$ & $184 \pm 7.2$ \\
\hline \multirow[t]{2}{*}{$3-\mathrm{NO} 2$} & $\mathrm{R}$ & $2.9 \pm 0.3^{*}$ & $22.4 \pm 33^{\circ *}$ & $49.0 \pm 6.6^{\circ}$ & $195 \pm 15$ \\
\hline & s & $5.2 \pm 0.8$ & $47.9 \pm 8.6$ & $26.2 \pm 6.5$ & $167 \pm 19$ \\
\hline \multirow[t]{2}{*}{ 4-CN } & $\mathbf{R}$ & $7.8 \pm 0.76^{\bullet}$ & $39.2 \pm 3.2 *$ & $25.9 \pm 2.2 \cdots$ & $295 \pm 54^{*}$ \\
\hline & s & $0.97 \pm 0.17$ & $7.1 \pm 1.5$ & $156 \pm 37$ & $197 \pm 8$ \\
\hline \multirow[t]{2}{*}{$4^{4}-\mathrm{Cl}$} & $\mathrm{R}$ & $1.96 \pm 0.14^{* *}$ & $11.9 \pm 1.4$ & $88.0 \pm 9.3$ & $239 \pm 11^{*}$ \\
\hline & s & $1.22 \pm 0.07$ & $10.4 \pm 1.4$ & $103 \pm 14$ & $176 \pm 38^{\circ}$ \\
\hline \multirow[t]{2}{*}{ 3'. Cl } & $\mathbf{R}$ & $2.47 \pm 0.07$ & $5.3 \pm 0.1^{* *}$ & $190 \pm 3.7^{* *}$ & $669 \pm 13^{\bullet \bullet}$ \\
\hline & $\mathrm{s}$ & $7.8 \pm 1.4$ & $25.4 \pm 4.2$ & $41.3 \pm 6.2$ & $436 \pm 7$ \\
\hline \multirow[t]{2}{*}{$2^{\prime}-\mathrm{Cl}$} & R & $28.3 \pm 5.9 \bullet$ & $455 \pm 10^{* *}$ & $2.4 \pm 0.4^{\cdots *}$ & $89 \pm 1.4^{\bullet}$ \\
\hline & s & $3.5 \pm 1.0$ & $42.5 \pm 12.2$ & $27.1 \pm 0.3$ & $116 \pm 6.1$ \\
\hline \multirow[t]{2}{*}{$4 \cdot-\mathrm{Br}$} & $\mathbf{R}$ & $2.58 \pm 0.17^{\star \bullet}$ & $30.5 \pm 4.4^{\circ}$ & $34.4 \pm 5.7^{\cdots \cdots}$ & $124 \pm 122$ \\
\hline & s & $1.30 \pm 0.14$ & $14.4 \pm 1.4$ & $70.7 \pm 7.5$ & $128 \pm 1.7$ \\
\hline \multirow[t]{2}{*}{$3-B r$} & $R$ & $1.66 \pm 0.13^{* *}$ & $7.5 \pm 0.3^{* *}$ & $132.5 \pm 5.5^{* *}$ & $214 \pm 14$ \\
\hline & $\mathrm{S}$ & $8.16 \pm 0.35$ & $45.2 \pm 1.8$ & $22.2 \pm 0.9$ & $259 \pm 16$ \\
\hline \multirow[t]{2}{*}{ 4-CH3 } & $R$ & $1.43 \pm 0.13$ & $9.1 \pm 0.6^{*}$ & $111.0 \pm 6.6^{*}$ & $226 \pm 0.8^{* *}$ \\
\hline & $\mathrm{s}$ & $1.62 \pm 0.12$ & $15.4 \pm 1.1$ & $65.7 \pm 4.4$ & $152 \pm 8.8$ \\
\hline \multirow[t]{2}{*}{$3^{\prime}-\mathrm{CH}_{3}$} & $\mathrm{R}$ & $1.56 \pm 0.14^{\cdots}$ & $8.8 \pm 0.6 * *$ & $114 \pm 8.0^{* *}$ & $252 \pm 10.2^{*}$ \\
\hline & $s$ & $73 \pm 27$ & $57.8 \pm 16$ & $21.6 \pm 5.8$ & $17 \pm 6$ \\
\hline \multirow[t]{2}{*}{ 2'- $\mathrm{CH} 3$} & $\mathbf{R}$ & $11.0 \pm 1.5^{* *}$ & $112.2 \pm 16^{* 0}$ & $9.0 \pm 1.2^{* *}$ & $140 \pm 1^{\circ}$ \\
\hline & s & $3.4 \pm 0.12$ & $25.6 \pm 4.9$ & $40.6 \pm 7.8$ & $194 \pm 30$ \\
\hline \multirow[t]{2}{*}{ 4-OCH3 } & $R$ & $1.51 \pm 0.2$ & $143 \pm 1.5$ & $71.3 \pm 6.8$ & $149 \pm 5^{\circ}$ \\
\hline & $\mathrm{s}$ & $1.64 \pm 0.2$ & $18.8 \pm 1.8$ & $54.3 \pm 5.6$ & $121 \pm 4$ \\
\hline \multirow[t]{2}{*}{$3 \cdot 0 \mathrm{OH} 3$} & $R$ & $29 \pm 0.2 * *$ & $16.4 \pm 1.8^{*}$ & $62.5: 6.4^{*}$ & $258 \pm 25^{*}$ \\
\hline & $\mathrm{s}$ & $6.0 \pm 0.14$ & $46.4 \pm 5.0$ & $22.0 \pm 2.3$ & $188 \pm 16$ \\
\hline \multirow[t]{2}{*}{$2 \cdot \mathrm{OCH}_{3}$} & $\mathbf{R}$ & $16.0 \pm 0.0^{* *}$ & $177 \pm 13^{* *}$ & $5.7 \pm 0.4^{* *}$ & $130 \pm 4.7^{\star *}$ \\
\hline & $\mathrm{s}$ & $2.5 \pm 0.3$ & $16.3 \pm 1.4$ & $62.2 \pm 5.4$ & $215 \pm 7$ \\
\hline
\end{tabular}

Data are the mean \pm SEM of 3-4 rats. * and ** significant difference between enantiomers $P<0.05$ and $P<0.01$ respectively. 


\subsection{RESULTS:}

The warfarin analogues investigated, are listed in table 2.1 together with some physicochemical parameters. The pKa values of the compounds did not differ greatly, ranging between 4.8 and 5.1, indicating no influence of the substituents on the acidity of the 4-hydroxy group of the coumarin nucleus. For warfarin and 4'-nitrowarfarin (acenocoumarol), our data are in agreement with those of Van der Giesen (1982).

The partition coefficient varied with the lipophilicity of the substituent. Except for 2'methoxywarfarin, the correlation of $\log \left(\mathrm{P}_{\mathrm{x}} / \mathrm{P}_{\mathrm{H}}\right)$ with Hansch's $\Pi x$ parameter was good indicating that the substituents did not alter the molecular conformation in such a manner that deviations of the additivity of the fragmental lipophilicity occur (Hansch and Leo, 1979).

The pharmacokinetic constants of the warfarin analogues are presented in table 2.2 and for illustration, some examples of the impact of substituents on the plasma elimination are shown in figure 2.2. Table 2.3 presents the plasma protein binding of the compounds as well as the pharmacokinetic constants of the unbound fraction, i.e. the clearance (intrinsic clearance) and the volume of distribution. Intrinsic clearances of the enantiomers of the phenyl ring substituted warfarin analogues are higher than the intrinsic clearances of the enantiomers of warfarin itself. E.g. the intrinsic clearances of S-4'-nitro- and S-4'-bromowarfarin are more than 30 times higher than the intrinsic clearance of S-warfarin; for the R-enantiomers, substitution of the 3'-hydrogen by a bromo group enhances the intrinsic clearance about 33 fold. In addition, phenyl ring substitution has drastic effects on the enantioselectivity of the intrinsic clearances. The intrinsic clearance of R-warfarin is 1.4 times higher than that of $S$ warfarin. 3'-Substituted warfarins show a similar pattem of enantioselectivity with $\mathrm{R} / \mathrm{S}$ ratios ranging from 1.3 (3'-nitrowarfarin) to 2.9 (3'-bromowarfarin). In contrast, for the 2 '-methoxyand 2'-chloro- analogues the intrinsic clearances of the S-enantiomers are 3.2 and 1.8 times higher than those of the R-enantiomers. For 2 -methylwarfarin, there is no difference between the enantiomers. Also in the case of 4'-nitro-, 4'-cyano, 4'-chloro- and 4'-bromowarlarin, the intrinsic clearances of the S-enantiomers are 1.7 to 9 times than the intrinsic clearances of the R-enantiomers. For 4'-methyl-and 4'-methoxywarfarin, no difference between the enantiomers is observed.

Phenyl ring substitution also has clear effects on the stereochemistry of the plasma protein binding (table 2.3) of the warfarin analogues. The plasma protein binding of warfarin, the 3'. and the 4 '-substitued warfarins is 1.1 (4'-bromowarfarin) to 2.4 ( $3^{\prime}$-chlorowarfarin) times stronger for the $S$-enantiomers and this stereoselectivity appears to be somewhat higher for the 3 '- than for the 4'- substituted analogues. 2'-Substitution however, inverses this stereoselectivity: the R-enantiomers are bound 3 (2'-methoxywarfarin) to 6 ( $2^{\prime}$-chlorowarfarin) times stronger than the S-enantiomers.

Considering plasma protein binding, there is a significant correlation between $\log \mathrm{P}$ and $\log$ (bound/free); $R: \log B / F=0.377 \log P+1.626, r=0.711 ; p<0.01(n=12) S: \log B / F=0.380$ $\log P+1.752, r=0.797: p<0.01 \quad(n=12)$. N.B.: the 2 -substituted derivatives have not been included in the correlations because their mechanisms of interaction with plasma proteins may be different, i.c. inversion of binding stereoselectivity (table 2.3 ). 
TABLE 2.3: Plasma protein binding ${ }^{a}$ and pharmacokinetic constants ${ }^{b}$ of the unbound fraction of substituted warfarins in the rat.

\begin{tabular}{|c|c|c|c|c|}
\hline Analogue: & & fu (\%) & CV/fu (1/h.kg) & Varea/fu (1/kg) \\
\hline \multirow[t]{2}{*}{$\mathbf{H}$} & $R$ & $2.26=0.06 *$ & $1.4=0.1^{*}$ & $9.5=1.7$ \\
\hline & s & $1.12=0.03$ & $1.0 \pm 0.1$ & $12 \pm 0.3$ \\
\hline \multirow[t]{2}{*}{ 4'-NO2 } & $R$ & $1.22 \pm 0.06 * *$ & $6.6 \pm 0.5 *$ & $16 \pm 1.6$ \\
\hline & s & $0.94 \pm 0.04$ & $31 \pm 2.6$ & $20 \pm 1.2$ \\
\hline \multirow[t]{2}{*}{$3 \cdot \mathrm{NO}_{2}$} & $R$ & $0.64 \pm 0.01 *$ & $7.6 \pm 1.0$ & $30 \pm 2.4$ \\
\hline & s & $0.44 \pm 0.02$ & $6.0 \pm 1.5$ & $38 \pm 4.7$ \\
\hline \multirow[t]{2}{*}{$4^{2} \cdot \mathrm{CN}$} & $R$ & $1.16 \pm 0.05 *$ & $2.2 \pm 0.2 *$ & $25 \pm 4.8$ \\
\hline & s & $0.83 \pm 0.04$ & $19 \pm 27$ & $24 \pm 1.5$ \\
\hline \multirow[t]{2}{*}{ 4.Cl } & $R$ & $0.77=0.06 *$ & $11=1.5^{\circ}$ & $31=2.8$ \\
\hline & s & $0.55 \geq 0.04$ & $19 \pm 2.9$ & $32 \geq 7.3$ \\
\hline \multirow[t]{2}{*}{ 3.Cl } & $R$ & $0.72 \pm 0.07 *$ & $26 \pm 2.6 \%$ & $93 \pm 9.2 *$ \\
\hline & s & $0.30 \div 0.03$ & {$[4=2.6$} & $145 \pm 15$ \\
\hline \multirow[t]{2}{*}{$2 \cdot C$} & $R$ & $0.14 \div 0.02 *$ & $1.7 \pm 0.4 *$ & $62 \pm 8.9 *$ \\
\hline & $\mathrm{s}$ & $0.91 \pm 0.12$ & $3.0 \pm 0.1$ & $13 \pm 0.3$ \\
\hline \multirow[t]{2}{*}{ 4. $-\mathrm{Br}$} & $R$ & $0.24 \pm 0.02$ & $14 \pm 2.6^{*}$ & $51 \pm 6.6$ \\
\hline & $\mathrm{s}$ & $0.22 \pm 0.01$ & $32 \pm 3.7$ & $59 \pm 2.8$ \\
\hline \multirow[t]{2}{*}{$3 \cdot \mathrm{Br}$} & $R$ & $0.29 \pm 0.01 *$ & $46 \pm 25 *$ & $108 \pm 8.0^{* *}$ \\
\hline & $\mathrm{s}$ & $0.14 \pm 0.01$ & $16 \pm 1.3$ & $181 \pm 17$ \\
\hline \multirow[t]{2}{*}{$4^{\prime} \cdot \mathrm{CH}_{3}$} & $R$ & $0.57 \pm 0.01 *$ & $20 \pm 0.9$ & $40=1.7$ \\
\hline & $\mathrm{s}$ & $0.40 \pm 0.01$ & $17 \pm 1.2$ & $38 \pm 2.4$ \\
\hline \multirow[t]{2}{*}{$3^{\prime}-\mathrm{CH}_{3}$} & $R$ & $0.64 \pm 0.10^{* *}$ & $18 \pm 3.1^{\cdots}$ & $39 \pm 6.4^{*}$ \\
\hline & S & $0.32 \pm 0.02$ & $6.6 \div 1.8$ & $56 \pm 4.0$ \\
\hline \multirow[t]{2}{*}{$2^{\prime} \cdot \mathrm{CH} 3$} & $\mathbf{R}$ & $0.29 \pm 0.03 *$ & $3.1=0.5$ & $39 \pm 4.0^{*}$ \\
\hline & s & $1.14 \pm 0.02$ & $3.6 \pm 0.7$ & $17 \pm 2.6$ \\
\hline \multirow[t]{2}{*}{ 4. $-\mathrm{OCH} 3$} & $R$ & $0.79 \pm 0.04 *$ & $9.0=1.0$ & $19 \pm 1.2$ \\
\hline & s & $0.60 \pm 0.04$ & $9.1 \pm 0.1$ & $20=1.5$ \\
\hline \multirow[t]{2}{*}{$3 \cdot-\mathrm{OCH}_{3}$} & $R$ & $0.87 \pm 0.06 * *$ & $7.2 \pm 0.1 \%$ & $30 \pm 3.5$ \\
\hline & $\mathrm{s}$ & $0.66 \pm 0.05$ & $3.3 \pm 0.4$ & $28 \pm 33$ \\
\hline \multirow[t]{2}{*}{$2^{\prime} \cdot \mathrm{OCH} 3$} & $R$ & $0.20 \pm 0.02 *$ & $2.9 \pm 0.3 * *$ & $65 \pm 6.9 . *$ \\
\hline & $\mathrm{s}$ & $0.69 \geq 0.03$ & $9.0 \pm 0.9$ & $31=1.7$ \\
\hline
\end{tabular}

"The unbound fractions fu are the mean \pm S.E.M. of 4 estimates in pooled rat plasma. "Unbound hepatic clearance and unbound appareni volume of distribution are calculated from the data of table 2.2. ** significant difference between enantiomers $\mathrm{P}<0.01{ }^{*}$ significant difference between enantiomers $\mathrm{P}<0.05$. 
A

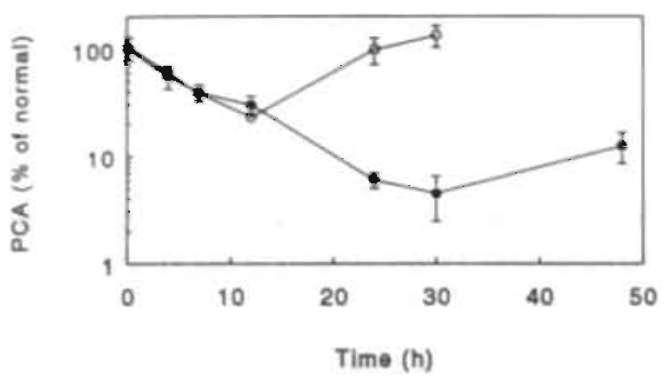

$\mathbf{B}$

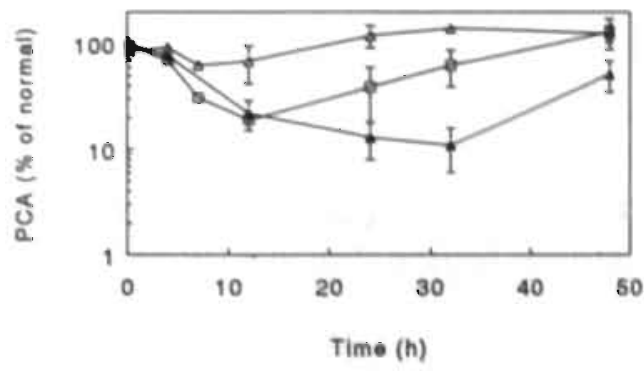

Figure 2.3: The response of the plasma prothrombin complex activity (PCA) in the experiments described in figure 2.2. A: warfarin (closed circles): 4'-nitrowarfarin (open circles); B: 2'chlorowarfarin(open triangles); 3 -chlorowarfarin (closed triangles) 4' chlorowarfarin (open squares)

All compounds affected the blood clotting activity (trombotest value). Figure 2.3 shows the effect of responses of the compounds of which the kinetics are given in figure 2.2. Compared to racemic 4'-nitrowarfarin, the effect of racemic warfarin is more initense and longer lasting, consistent with a longer residence time of the latter. The same can be argued for racemic 3 'chlorowarfarin in comparison to the other chloro-substituted analogues (figure 2.3B). Remarkably, 2'-chlorowarfarin, notwithstanding the long half-life of the R-enantiomer. showed only weak anticlotting activity. This suggests the intrinsic activity of R-2'-chlorowarfarin to be weak. Also, the other 2'-substituted warfarins showed weak activity. As the change in prothrombin complex activity (PCA) following the administration of the racemic compounds is a function of the individual enantiomeric phamacokinetics and phamacodynamics, a comparative quantitative evaluation of the effects of the racemates is not possible from our experiments.

\subsection{DISCUSSION:}

This study, presenting a series of warfarin analogues, was performed to establish the influence of substituents on pharmacokinetics. prompted by the observation that the introduction of a 4'-nitro group (acenocoumarol) greatly enhances the (metabolic) clearance of both the enantiomers, enhances the enantioselectivity of the elimination in man, and reverses the enantioselectivity of elimination in the rat (Godbillon et al, 1981; Thijssen et al, 1985, 1986). The data for R/S-warfarin and R/S-4'-nitrowarfarin are comparable to those obtained in single enantiomer studies, indicating the absence of mutual interactions. This has also been observed in man (Banfield et al, 1983; Toon et al, 1986; Gill et al, 1988).

As the warfarin analogues have in common a relatively high lipophilicity (table 2.1) and a high plasma protein binding (table 2.3), it is reasonable to assume their elimination, like warfarin and 4'-nitrowarfarin, to be solely by hepatic metabolism. With this assumption the warfarin analogues tested can be classified as low clearance drugs, i.e. their plasma clearance is much less than the liver blood flow. 
Therefore, their plasma pharmacokinetics are determined by plasma protein binding and intrinsic hepatic clearance (Wingard et al, 1978; Roland and Tozer, 1980). This study shows both parameters to be determining factors for the stereoselective pharmacokinetics of the compounds. The differences between the enantiomers in protein binding appear consistent with the differences observed for Varea, e.g. for all the racemates it holds that the enantiomer having the highest protein binding shows the lowest Varea and the highest peak concentration. However, there was no significant correlation between the protein binding and Varea : $r=0.166$ and $-0.32(p<0.05)$ for the R-and S-enantiomers, respectively.

In comparison with warfarin, the introduction of substituents greatly enhanced the intrinsic clearance, and in most cases also enhanced the stereoselectivity of the intrinsic clearance. A general stereochemical pattem in intrinsic clearance is evident; $S>R$ for the $4^{\prime}$ substituted and $2^{\prime}$-substituted derivatives, and $\mathrm{R}>\mathrm{S}$ for the $3^{\prime}$-substituted. The largest differences between the enantiomers are observed for 4'-cyano, 4'-nitrowarfarin and 3'bromowarfarin. (table 2.3). Warfarin and 4'-nitrowarfarin have been shown to be eliminated by biotransformation, which mainly involves hydroxylation of the coumarin structure (Fasco et al, 1976; Pohl et al, 1976: Dieterle et al, 1977; Toon et al, 1986; Thijssen and Baars, 1987). With the exception of the methoxy and probably the methyl derivatives (see later), this will probably also be true for the warfarin analogues we studied. If this is true this would imply that phenyl ring substitution has clear effects on the rate and stereoselectivity of hydroxylation on the coumarin site of these compounds. In addition, the diversity of P450 isozymes expressing a broad spectrum of binding and reaction selectivity (Testa, 1988) may play a role in the differences observed between the analogues. To test these hypotheses the in vitro metabolism of warfarin and 4'-nitrowarfarin (acenocoumarol), has been studied in greater detail as will be discussed in the next chapters. The absence of stereoselectivity in the intrinsic clearance of $4^{\prime}$-methoxy and $4^{\prime \prime}$-methylwarfarin is probably due to the fact that their main routes of metabolism, i.e. O-demethylation for 4'-methoxy-warfarin and methyl hydroxylation for 4'-methyl are not stereoselective (own observations). For some compounds, the intrinsic clearance greatly exceeded the liver plasma flow (about $21 \mathrm{~h}^{-1} \cdot \mathrm{kg}^{-1}$; Daemen et al, 1989) of the rat. The strong protein binding, however, makes them low clearance drugs.

Remarkably, depending upon the position of the substituent inversions in the enantioselectivity of the plasma protein binding are observed. Warfarin and the 4'- and 3'substituted analogues showed greater plasma protein binding for the S-enantiomer, but the opposite was true for the 2'-substituted analogues. Furthermore, the ratio in the enantioselective binding was high for the 2'-substituted warfarins. Recent studies, using stop-flow techniques, have presented evidence for a three-step process in the warfarin-albumin interaction, a rapid association followed by a rate-limiting translocation of the drug to a binding site inside a $\mathrm{U}$-shaped cleft where the final binding complex is formed (Bos et al. 1989). The restricted rotation of the ortho-substituted phenyl ring would favor the positioning 
of the R-configuration in that cleft: The stronger binding of the S-enantiomers of warfarin and 4'-nitrowarfarin to rat plasma protein has been shown with ratios for unbound fraction of about 1.6 (Yacobi and Levy, 1977) and 1.1 (Thijssenet al, 1985). In human plasma S-warfarin binding is stronger (Yacoby and Levy, 1977). For 4'-nitrowarfarin, human plasma protein binding has been reported to posses the opposite enantioselectivity i.e. the binding of the $\mathbf{R}$ enantiomer is stronger than that of the S-enantiomer (Gill et al, 1988). This has also been reported for immobilized human plasma albumin: the greater binding was observed for $\mathrm{S}$ warfarin and for R-acenocoumarol (Fitos et al, 1989). Binding to $\alpha_{1}$-acid glycoprotein has been reported for some drugs to have opposite stereoselectivity compared to albumin (Walle et al, 1983" Fitos et al, 1989). However, as the 4-hydroxycoumarins are weak acids, the contribution of $\alpha_{1}$-acid glycoprotein, which binds mainly cationic drugs, will be of minor importance (Urien et al, 1986).

The Varea of the unbound fraction for some compounds suggests stereoselective tissue. binding. However, as the distribution volumes of the analogues are small 10-30\% of the body mass (Table 2.2), and mainly occupy the album in space, the stimulated unbound distribution volume is merely the result of the mathematical operation (Rowland and Tozer. 1980). The 3'-chloro derivative might be an exception; Varea values observed of 669 and $436 \mathrm{ml} \mathrm{kg}^{-1}$ for the $\mathrm{R}$ - and $\mathrm{S}$-enantiomers, respectively. We have no explanation for these relatively high distribution volumes.

In summary, the study affirms stereoselectivity in plasma protein binding and in intrinsic hepatic clearance to be determining factors in the enantioselective pharmacokinetics of low clearance drugs. For the warfarin analogues, the stereoselectivity in both processes was up to a factor 3-4 for protein binding and 8-9 for the intrinsic metabolic clearance. Small structural changes, i.e. the position of the substituent, may invert the stereoselectivity. The Jatter observations shows that care should be taken in predicting the enantiomer specific phamacokinetics of a racemate from data of closely related racemates. 


\subsection{REFERENCES:}

Arièns, E.J., 1984, Stereochemistry, a basis for sophisticated nonsense in pharmacokinetics and clinical pharmacology. Eur. J. Clin. Pharmacol. 26: 663-558.

Banfield, C., and Rowland, M.., 1983, Stereospecific high-performance liquid chromatographic analysis of warfarin in plasma. J. Pharm. Sci. 72; 921-924.

Banfield, C., O'Reilly, R., Chan, E., and Rowland, M., 1984, Phenylbutazone-warfarin interaction in man: further stereochemical and metabolic considerations. Clin. Pharmacol. Ther. 16: 669-675.

Bos, O.J.M., Fischer, M.J.E., Wilting, J., and Janssen, L.H.M., 1989, Mechanism by which warfarin binds to human serum albumin. Biochem. Pharmacol. 38: 1979-1984.

Breckenridge, A.M., Orme, M., Wessling. H., Lewis, R.J., and Gibbons, R., 1973, Pharmacokinetics and pharmacodynamics of the enantiomers of warfarin in man. Clin. Pharmacol. 15:424-430.

Bush, E., and Trager, W.F., 1983, High-yield synthesis of warfarin and its phenolic metabolites: new compounds. I. Pharm. Sci. 72: 830-831.

Daemen, M.J.A.P., Thijssen, H.H.W., Van Essen, H., Vervoort-Peters, H.T.M., Prinzen, F.W.. Struijker Boudier, H.A.J., and Smits, J.F.M., 1989, Liver blood flow measurement in the rat. J.P harmacol. Meth. 21: 287-297.

Dieterle, W., Faigle. J.W., Sulc, M., and Theobald, W., 1977, Biotransformation and pharmacokinetics of acenocoumarol (Sintrom). Eur. J. Clin. Pharmacol. 11: 367-375.

Evans, A.M.,Nation, R.L., Sansom. L.N.. Boehner,F., and Somogyi, A.A., 1988, Stereoselective drug dispostion: potential for misinterpreation of drug disposition data. Br. I. clin Pharmacol. 26: 771-780.

Fasco, M.J., Baker, F.D., and Fenton, J.W., 1976. Warfarin: stereochemical aspects of its metabolism by rat liver microsomes. Biochem. Pharmacol. 25: 2153-2162.

Fitos, I.. Visy. J.. Magyar. A., Kajtar. J., and Simonyi. M., 1989, Inverse stereoselectivity in the binding of acenocoumarol to human serum albumin and to $\alpha-1$ acid glycoprotein. Biochem. Pharmacol. 38: 2259-2262.

Gill. T.S., Hopkins, K.J., and Rowland. M.. 1986, Stereospecific assay of nicoumalone: application to pharmacokinetic studies in man. Br. J. clin. Pharmacol. 25: 591-598

Godbillon. J., Richard, J.. Gerardin. H.. Meinertz. T. Kasper . W., and Jachnchen, E.. 1981, Pharmacokinetics of the enantiomers of acenocoumarol in man. Br. J. clin. Pharmacol. 5:621629.

Hansch. C., and Leo, A., Substitution constants for correlation analysis in chemistry and biology. Wiley Intersic New York. 1979.

Heimark, L.D., and Trager. W.F.. 1984. The preferred solution conformation of warfarin at the active site of cytochrome $\mathrm{P} 450$ based on the CD spectra in octanol/water mode system. J. Med. Chem. 27: 1092-1095.

Pohl, L.H. Bales, R., and Trager. W.F., 1976, Warfarin: stereochemical aspects of its metabolism in vivo in the rat. Res. Comm. Chem. Pathol. 15: 233-255.

Rowland. M., and Tozer. T.N., Clinical pharmacokinetics. eds Lea and Fegiber, Philedelphia, 1980.

Testa, B., 1988, Substrate and product stereoselectivity in monooxygenase-mediated drug activation and inactivation. Biochem. Pharmacol. 37: 85-92.

Thijssen. H.H.W.. and Baars, L.G.M., 1987, The biliary excretion of acenocoumarol in the rat: stereochemical aspects. J. Pharm. Pharmacol. 39: 655-657. 
Thijssen, H.H.W., Baars, L.G.M. and Drittij-Reijnders, MJ., 1985, Stereoselective aspects in the pharmacokinetics and pharmacodynamics of acenocoumarol and its amino and acetamido derivatives in the rat. Drug Metab. Dispos. 13: 593-597.

Thijssen, H.H.W., Janssen, G.M.J., and Baars, L.G.M., 1986, Lack of effect of cimetidine on pharmacodynamics and kinetics of single oral dose of R-and S-acenocoumarol. Eur. J. Clin. Pharmacol. 30:619-623.

Toon, S., Lon, L.K., Gibaldi, M., Trager, W.F.,O'Reilly, R.A., Motley, C.H., and Goulart, D.A., 1986. The warfarin-sulfinpyrazone interaction: stereochemical considerations. Clin Pharmacol. Ther. 39: 15-24.

Tucker, G.T., and Lennard, M.S., 1990, Enantiomer-specific pharmacokinetics. Pharmacol. Ther. 45: 309-329.

Urien, S., Albengres, E., Pinquier, J-L, and Tillement J-P., 1986, Role of $\alpha$-1-acid glycoprotein, albumin, and non-esterified fatty acids in serum binding of apazone and warfarin. Clin. Pharmacol. Ther. 39: 683-689.

Van der Giesen, W.F., Physicochemical behaviour of some 4-hydroxycoumarins, especially the binding of warfarin to human serum albumin. Ph.D.-thesis, University of Utrecht, The Netherlands. 1982

Walle, U.K., Walle, T., Bai, S.A., and Olanoff, L.S., 1983, Stereoselective binding of propranolol to human plasma, $\alpha-1$ acid glycoprotein and albumin. Clin. Pharmacol. Ther. 34: 718-723.

Walle, T., and Walle, U.K., 1986, Pharmacokinetic parameters obtained with racemates. TIPS 7: 155-158.

West, D., Preis, S., Schroeder, and C.H., Link, K.P., 1961, Studies on the 4-hydroxycoumarins. XVII. The resolution and absolute configuration of warfarin. J. Am.Chem. Soc. 83: 2676-2679.

Wingard, L.B., O'Reilly, R.A., and Levy G., 1978, Pharmacokinetics of warfarin enantiomers: a search for intrasubject correlations. Clin. Pharmacol. Ther. 23: 212-217.

Yacobi, A., and Levy, G., 1974, Comparative pharmacokinetics of coumarin anticoagulants. XII. Pharmacokinetics of the warfarin enantiomers in the rat. J. Pharmacokin. Biopharm. 2: $239-255$.

Yacobi, A., and Levy, G., 1977, Protein binding of warfarin enantiomers in serum of humans and rats. J. Pharmacokin. Biopharm. 5: 123-131. 


\section{CHAPTER 3:}

\section{COMPARISON OF THE RAT LIVER MICROSOMAL METABOLISM OF THE ENANTIOMERS OF WARFARIN AND 4'-NITROWARFARIN (ACENOCOUMAROL).}

\subsection{ABSTRACT:}

Rat liver microsomal metabolism of the enantiomers of warfarin and acenocoumarol has been studied. The enantiomers of both compounds are hydroxylated mainly at the 6-and 7-positions. Acenocoumarol enantiomers are much better substrates for cytochromes P450 than the corresponding warfarin enantiomers: $\mathrm{Km}$ values for the 6- and 7-hydroxylations are 2 to 19 times lower for R-and Sacenocoumarol than for warfarin.

Formation of the 6-, 7-, and 8- hydroxy metabolites of warfarin is stereoselective for the: Renantiomer (the R/S ratio of the total intrinsic clearance is about 3). $4^{\prime}$-Hydroxylation was not stereoselective. In contrast, formation of acenocoumarol metabolites is stereoselective for the Senantiomer (the S/R ratio of the total intrinsic clearance is about 3).

The P450 inducers phenobarbitone and methylcholanthrene and the inhibitor cimetidine show different effects on the in virro metabolism of the enantiomers of both compounds. Antibodies raised 10 $\mathrm{P} 4502 \mathrm{C} 6$ and $2 \mathrm{C} 1 \mathrm{i}$, as well as antibodies raised to the $\mathrm{P} 4503 \mathrm{~A}$ subfamily inhibit warfarin and acenocoumarol metabolism not only to different extents, but stereo- and regiochemical differences of the antibody inhibitable $\mathrm{P} 450^{\circ}$ 's are also observed. $\mathrm{P} 450^{\circ}$ 's of the $2 \mathrm{C}$ sublamily in microsomes from phenobarbitone treated rats primarily catalyse the 7-hydroxylation of R-warfarin but show no or very litle 6- and 8-hydroxylase activity. P450 2C isozymes catalyse the 6-, 7- and 8-hydroxylation of acenocoumarol non stereoselectively or with a slight preference for the S-enantiomer:

From these data it is concluded that the kinetic differences between warfarin and acenocoumarol enantiomers can partily be explained by the diversity of isozymes involved in the metabolism of both compounds. Substitution at the phenyl ring of warfarin has major effects on the regio-and stereoselectivity of P450 isozymes and on the spectrum of isozymes that contribute to the metabolism of the 4hydroxycoumarins.

Adapled from: Xenobiotica 21:295-307, 1991, J J.R. Hermans, and H.H.W. Thijssen.

\subsection{INTRODUCTION:}

In the use of a racemic drug knowledge of the metabolism and disposition of both enantiomers is of great importance (Williams and Lee, 1985: Eichelbaum. 1988: Testa .1988). Enantiomers may not only follow different metabolic routes but may also interact differently when administered together with other drugs (Lewis et al, 1974; Williams and Lee, 1985 : Eichelbaum. 1988; Testa, 1988).

The oral anticoagulants warfarin and acenocoumarol (4'-nitrowarfarin) are administered as racemates. Despite their strong structural relationship, acenocoumarol and warfarin display sharp differences in their pharmacokinetics i.e. acenocoumarol enantiomers in both 
Figure 3.1: The structure of warfarin, acenocoumarol, and warfarin metabolites.

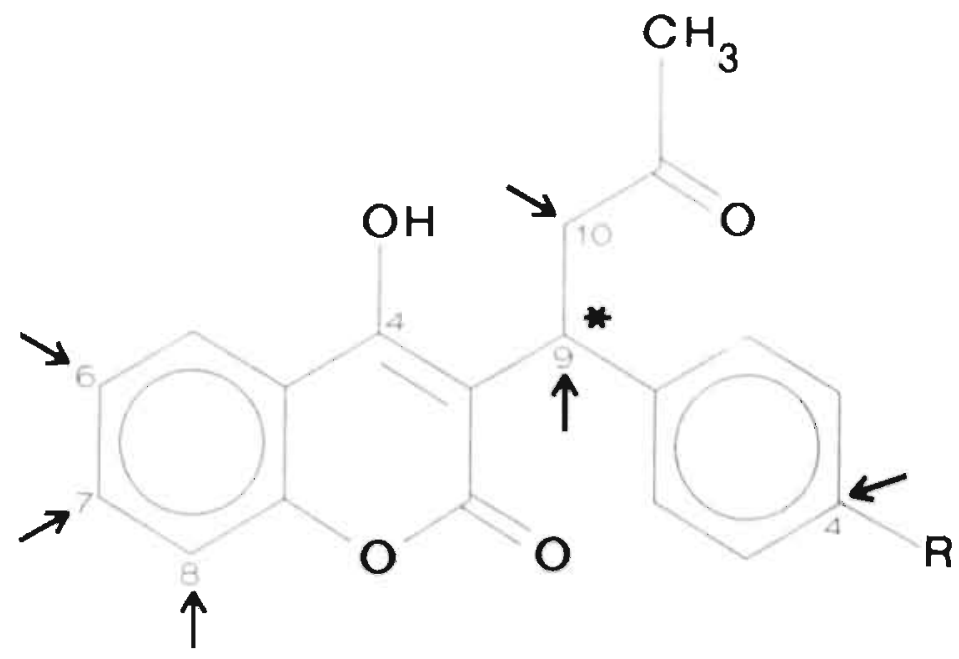

$\mathrm{R}=\mathrm{H}$ : warfarin; $\mathrm{R}=\mathrm{NO}_{2}$ : acenocoumarol. The arrows indicate sites of hydroxylation of warfarin by cytochrome P450. The dehydro metabolite possesses a double bond between C-9 and C-10.

man and rat are eliminated faster than warfarin enantiomers (Yacobi and Levy, 1974; Thijssen et al, 1985: Kelly and O Malley, 1979; Thijssen et al, 1986; chapter 2). Furthermore, differences in the stereochemical course of warfarin and acenocoumarol clearance are observed. In the rat, R-warfarin is eliminated faster than S-warfarin (Yacobi and Levy, 1974: chapter 2), whereas for acenocoumarol the opposite is true: S-acenocoumarol is eliminated faster than the R-enantiomer (Thijssen et al, 1985; chapter 2).

These differences cannot be attributed simply to differences in the plasma protein binding of warfarin and acenocoumarol enantiomers since the unbound fraction of the R-enantiomers of both warfarin and acenocoumarol is greater than the unbound fraction of the $S$-enantiomers (Yacobi and Levy, 1977; Thijssen et al, 1985, also see chapter 2).

For warfarin, multiple metabolic routes have been described in both rats and man (figure 3.1): hydroxylation at the coumarin moiety (6-, 7-, and 8 -hydroxylation), the phenyl moiety (4'-hydroxylation), aliphatic hydroxylation (9- (benzyl), 10-hydroxylation, formation of dehydro-warfarin) and ketone reduction. Several of these routes show stereoselectivity and have been observed in vivo and in vitro (Trager et al, 1970; Fasco et al, 1976; Pohl ct al, 1976 : Powell et al, 1977 : Rettie et al, 1989).

In the rat, the main metabolite of $\mathrm{R}$-warfarin is the 7-hydroxy metabolite (7-hydroxywarfarin) whereas 7- and 4'-hydroxylation are the main metabolic routes for S-warfarin (Pohl et al, 1976). In rat liver microsomes $\mathrm{R}$-warfarin is predominantly hydroxylated to 6hydroxywarfarin and 7-hydroxywarfarin whereas $\$$-warfarin is hydroxylated to 4 -, 6- and 7-hydroxywarfarin (Fasco et al, 1976: Pohl et al, 1977). 
In the rat, acenocoumarol enantiomers are hydroxylated at the 6- and 7-positions (Thijssen and Baars, 1987). To our knowledge, the in vitro metabolism of the enantiomers of acenocoumarol has not been described before.

In chapter 5 stereochemical aspects of the in virro ketone reduction of warfarin, acenocoumarol and 4'-chlorowarfarin in several animal species, will be described and it will be shown that this metabolic route cannot explain the observed pharmacokinetic differences between warfarin and acenocoumarol enantiomers in rats. In this study the liver microsomal monooxygenase-mediated metabolism of warfarin and acenocoumarol has been compared in an attempt to elucidate the mechanism of the observed pharmacokinetic differences between warfarin and acenocoumarol enantiomers. In addition, the effect of enzyme induction by phenobarbitone and methylcholanthrene and the effect of the P450 inhibitor cimetidine (Rendic et al.1983) on the metabolism of the 4-hydroxycoumarins has been investigated to determine whether the isozyme spectrum involved in the metabolism of both compounds is the same. Finally, the inhibiting effect of two monoclonal antibodies raised to cytochromes P450 2C6 and 2C11 and the P450 3A subfamily has been looked upon, since the isozymes to which these antibodies are raised are known to have warfarin hydroxylase activity (Guengerich et al, 1982).

\subsection{MATERIALS AND METHODS:}

All chemicals were of analytical grade and were obtained from Merck (Darmstadt, West Germany) unless stated otherwise.

Preparation of the $\mathrm{R}$ - and S-enantiomers of warfarin and acenocoumarol:

The respective enantiomers were isolated by the method of West et al (1961). Racemic warfarin was obtained from Sigma Chemicals (St. Louis, USA), acenocoumarol as well as 6- and 7-hydroxyacenocoumarol were a kind gift of Ciba-Geigy (Basel, Switzerland). The purity of the individual enantiomers was determined by the method of Banfield and Rowland (1984) and proved to be higher than $99 \%$ and $97 \%$ for the S- and R-enantiomers, respectively.

\section{Preparation of microsomal fractions:}

Male Wistar rats ( $300 \mathrm{gr}$ ), acclimated to $12 \mathrm{~h}$ light-dark cycle and having free access to standard lab food (SMR A 1210. Woerden, the Netherlands) and tap water, were killed by exsanguination under ether anaesthesia. Livers were perfused in situ with ice-cold saline and subsequently removed.

To obtain microsomal fractions, 4 livers were pooled and homogenized in 3 vol. ice-cold Tris-KCl-sucrose buffer, $\mathrm{pH}=7.4(0.02 \mathrm{M}$ Tris-HCl, $0.15 \mathrm{M} \mathrm{KCl}$ and $0.25 \mathrm{M}$ sucrose), using a Potter homogenizer at $1500 \mathrm{rpm}$. The homogenate was centrifuged at $10,000 \mathrm{~g}$ for $30 \mathrm{~min}$, the pellet was discarded and the supernatant was centrifuged at $110.000 \mathrm{~g}$ for $50 \mathrm{~min}$. 
The $110,000 \mathrm{~g}$ pellet was washed twice by resuspension in the original volume of Tris/ $\mathrm{KCl}$ buffer and centrifugation at $110,000 \mathrm{~g}$ for $50 \mathrm{~min}$. The final microsomal pellet was resuspended in Tris- $\mathrm{KCl}-\mathrm{NaCl}$ buffer $(0.02 \mathrm{M}, 0.15 \mathrm{M}$ and $1.0 \mathrm{M}$, respectively) to contain about $20 \mathrm{mg}$ protein per $\mathrm{ml}$ homogenate.

In the enzyme induction experiment, rats ( $\mathrm{n}=4$ in each group) were given phenobarbitone (PB: $0.1 \% \mathrm{w} / \mathrm{v}$ in drinking water for 6 days) or methylcholanthrene (MC; $25 \mathrm{mg} / \mathrm{kg}$ i.p. for 3 days). Control rats did not receive any treatment. The effect of the enzyme inducers was validated by measuring the cytochrome $\mathrm{P} 450$ content, 7-ethoxycoumarin deethylase activity and aniline p-hydroxylase activity (Rutten et al , 1987 ; Macleod et al, 1973; Greenlee and Poland, 1978). Protein content was determined by the method of Lowry (Lowry et al, 1951).

The microsomes, used in the enzyme kinetic experiment, were not from the same batch as control microsomes in the induction and inhibition experiment.

\section{Assay for warfarin and acenocoumarol metabolism:}

Microsomal fractions were incubated in the presence of an NADPH-generating system at $37^{\circ} \mathrm{C}$ for $10 \mathrm{~min}$ in test tubes. The incubation mixture consisted of $2 \mathrm{mg}$ microsomal protein in $0.2 \mathrm{mM}$ substrate, $20.2 \mathrm{mM}$ glucose 6-phosphate. $5.8 \mathrm{mM} \mathrm{MgCl}_{2}$ and $2.8 \mu$ units of glucose 6-phosphate dehydrogenase (Sigma Chemicals, St. Louis USA) and a total volume of $310 \mu \mathrm{l}$ (Tris- $\mathrm{KCl}$ buffer, $\mathrm{pH} 7.4$ ).

The enzyme kinetic parameters in control rat liver microsomes were determined at substrate concentrations ranging from 0.02 to $1.6 \mathrm{mM}$. The incubation mixtures were preincubated at $37^{\circ} \mathrm{C}$ for $2 \mathrm{~min}$; then the reaction was started by the addition of $50 \mu \mathrm{l}$ of a prewarmed $\left(37^{\circ} \mathrm{C}\right) \mathrm{NADPH}$ solution $(1.6 \mathrm{mM}$ in Tris- $\mathrm{KCl})$. In the cimetidine inhibition experiment cimetidine was added to the incubation medium in a final concentration of 1.1 $\mathrm{mM}$. Cimetidine samples were preincubated for $5 \mathrm{~min}$ at $37^{\circ} \mathrm{C}$ before the substrate and NADPH was added. Incubations of blanks, i.e. the complete reaction mixture without NADPH were run in parallel. All incubations were carried out in triplicate. The reaction was stopped after $10 \mathrm{~min}$. by the addition of $0.5 \mathrm{ml}$ ice-cold acetonitrile containing an internal standard ( $40 \mu \mathrm{g} /$ $\mathrm{ml}$ ). For warfarin metabolism, acenocoumarol was used as intemal standard, whereas for acenocoumarol metabolism warfarin was used. The mixture was centrifuged at $2500 \mathrm{~mm}$ for 5 min to precipitate the protein. The supematant was evaporated to dryness under a stream of nitrogen at $30^{\circ} \mathrm{C}$. For extraction of metabolites from the residue, $0.5 \mathrm{ml} 0.1 \mathrm{M} \mathrm{HCl}$ solution and $4 \mathrm{ml}$ of a $1: 1(\mathrm{v} / \mathrm{v})$ mixture of methylene chloride and petroleum ether (boiling range 40$60^{\circ} \mathrm{C}$ ) were added. This mixture was shaken for $10 \mathrm{~min}$ and subsequently centrifuged. The organic phase was evaporated to dryness under a stream of nitrogen at $30^{\circ} \mathrm{C}$. The residue was dissolved in $0.3 \mathrm{ml}$ of a mixture of acetonitrile and water $1: 1 \mathrm{v} / \mathrm{v}: 10-20 \mu \mathrm{l}$ was analyzed by HPLC.

The HPLC system consisted of Chromspher C18 200x3 mm (Chrompack. The Netherlands) as stationary phase and a mixture of $0,1 \%$ (aq.) acetic acid and acetonitrile $(7: 3 \mathrm{v} / \mathrm{v})$ 
Figure 3.2: Chromatograms of extracts of incubations of S-acenocoumarol and R-warfarin with PBtreated rat liver microsomes.
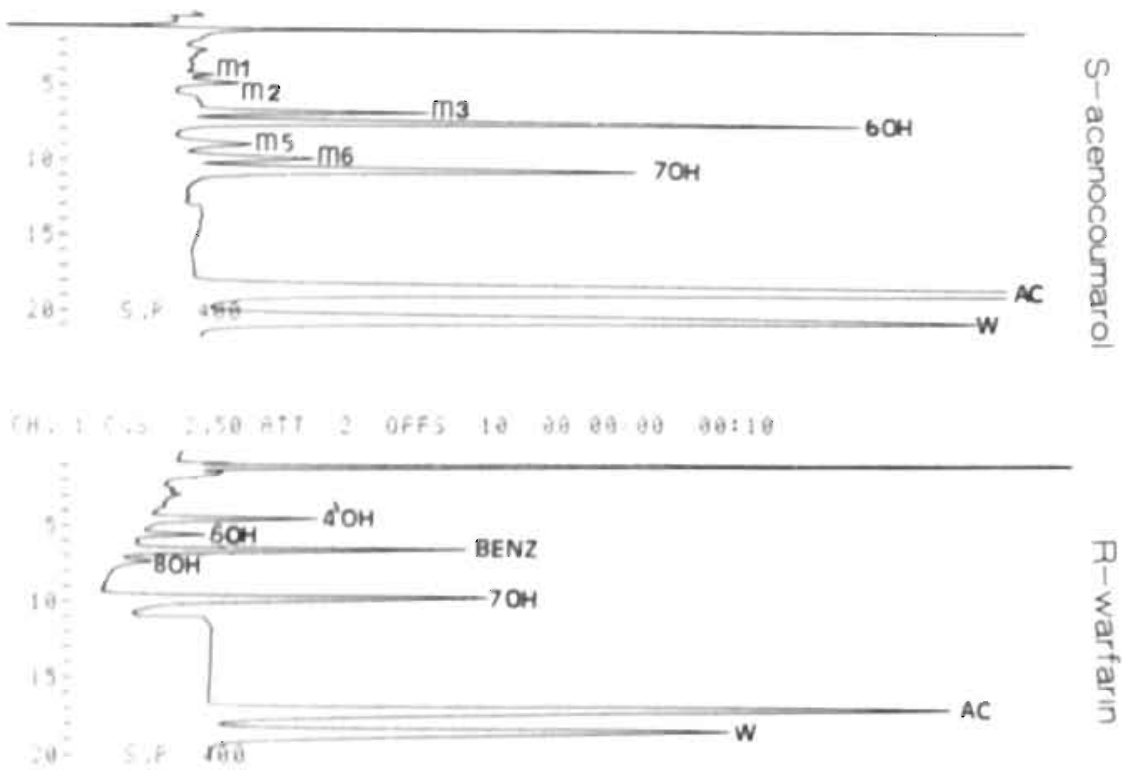

Racemic acenocoumarol was used as the internal standard for the incubation of R-warfarin. Racemic waffarin was used as the internal standard for the incubation of $\mathrm{S}$-acenocoumarol.

Extractions were performed with petroleum ether and methylene chloride.

Abbreviations: 4'OH, $6 \mathrm{OH}, 7 \mathrm{OH}, 8 \mathrm{OH}: 4$ '-, 6-, 7-, and 8-hydroxylated metabolites respectively (figure 1), benz: benzyl (9)-hydroxymetabolite. W: warfarin. AC: acenocoumarol.

brought to $\mathrm{pH} 4.76$ (ammonia) as mobile phase. The u.v. absorption at $303 \mathrm{~nm}$ was monitored on a Kratos spectroflow 783 and areas were calculated on a Hitachi D-2000 integrator. Diode array detector analysis was carried outt on a Applied Biosystems 1000S detector.

\section{Immunoinhibition of warfarin and acenocoumarol metabolism:}

Mouse monoclonal antibody raised against cytochromes $\mathrm{P} 4502 \mathrm{C} 6$ and $2 \mathrm{C} 11$ was a kind gift of Dr. Ina Goldfarb and Prof. Harry V. Gelboin from the Laboratory of Molecular Carcinogenesis, National Cancer Institute, Bethesda, Maryland, USA. Rabbit serum monoclonal antibody against the cytochrome P450 3A subfamily was a kind gift of Dr. Pierre G. Kremers (Laboratoire de Chimie Medicale, Université de Liege. Belgium). $1 \mathrm{mg}$ of microsomal protein (about $50 \mu \mathrm{l}$ ) was mixed with $500 \mu \mathrm{g}$ of antibody $(20 \mu \mathrm{l})$ and was allowed to stand for 30 minutes at room temperature, then NADPH regenerating system ( $15 \mu \mathrm{l})$ was added and samples were preincubated for 5 minutes at $37^{\circ} \mathrm{C}$ before the reaction was started by addition of substrate ( $15 \mu \mathrm{l}$ : final concentration $200 \mu \mathbf{M})$. Then, the same procedure as for normal incubations (as described above) was followed. The amount of antibody was about three times the amount needed for maximal inhibition of microsomal metabolism by the isozymes against which the antibodies were raised (own observations; Waxman et al, 1987); cross reactivity with various other isolated P450s was not apparent (Waxman et al, 1987: Kremers 1990: personal communication). 


\section{Statistical analysis of the data:}

Vmax and $\mathrm{Km}$ values were determined, by fitting the Michaelis-Menten equation to the data using the GPAD (GraphPAD Software. San Diego, USA) software package.

The effect of enzyme inducers and of the antibodies on warfarin and acenocoumarol metabolism was analysed for significance by the use of one way analysis of variance, followed by a LSD test (least significarit difference) (Sachs. 1984).

Differences in the inhibiting effect of cimetidine on warfarin and acenocoumarol metabolism between the microsomal fractions were tested for significance using a Kruskall and Wallis test (Sachs. 1984), followed by a Nemenyi test (Sachs, 1984).

Data were analysed for nomality by calculating the quotient of the range and standard deviation of the data.

Figure 3.3: Dependency of the capacity factor of the metabolites of warfarin and acenocoumarol on the $\mathrm{pH}$ of the eluent.

WARFARIN

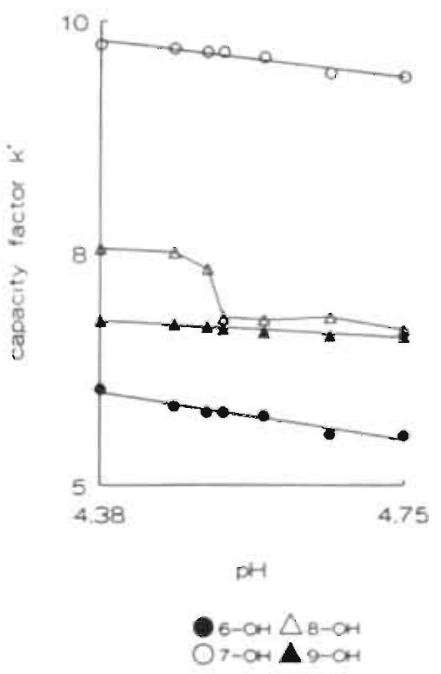

ACENOCOUMAROL

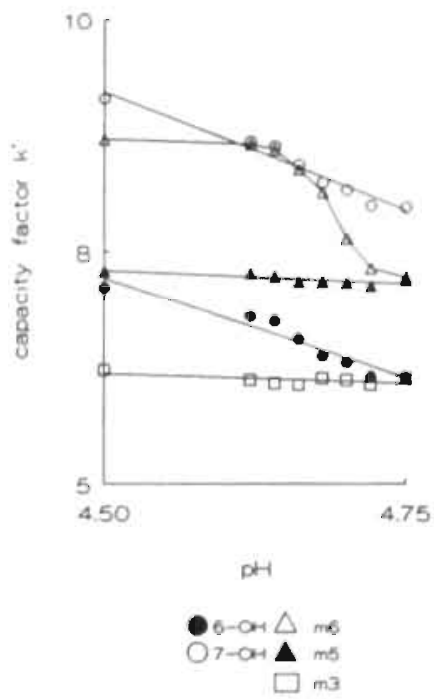

Incubations with S-acenocoumarol or R-warfarin as substrate were carried out as described.

The capacity factor $k^{\prime}$ is defined as $\left(R_{t,-m}=R_{t-1}\right) / R_{t-1}$ in which $R_{t-m}$ and $R_{t-1}$ represent the retention times of the metabolite- and solvent peaks respectively.

Capacity factors were determined using the HPLC conditions as described, except that the column was held at a constant temperature of $30^{\circ} \mathrm{C}$ and that the mobile phase consisted of a $9 / 3 \mathrm{v} / \mathrm{v}$ mixture of $0: 25$ $\% \mathrm{v} / \mathrm{v}$ aequous acetic acid and acetonitrile. The $\mathrm{pH}$ was adjusted by the addition of ammonia. 
TABLE 3.1:U.v. spectral data of warfarin, acenocoumarol and metabolites.

Warfarin

Acenocoumarol

6-Hydroxywarfarin

6-Hydroxyacenocoumarol

7-Hydroxywarfarin

7-Hydroxyacenocoumarol

8-Hydroxywarfarin

$\mathrm{m} 6$

10-Hydroxywarfarin

$\mathrm{m} 3$

9-hydroxywarfarin

$\mathrm{ms}$
213 (MX,100), 245 (MN,25), 278 (MX,50), 289 (MN,40), 302 (MX,49)

213 (MX,100), 245 (MN,38), 285 (MX,77), 292 (MN,75), 300 (MX,76)

200 (MX,100), 245 (MN,26), 278 (MX,35), 291 (MN,33), 302 (MX,34)

201 (MX,100), 245 (MN,21), 285 (broad MX,43)

202 (MX,100), $248(\mathrm{MN}, 16), 281$ (MX,42), $287(\mathrm{MN}, 40), 305$ (MX,49)

201 (MX,100), 250 (MN,21), 284 (MX,40), 287 (MN,39), 307 (MX,53)

202 (MX,100), 244 (MN,13), 267 (S,32), 278 (MX,39), 290 (MN,33), 301, (MX,36)

202 (MX,100), 241 (MN,11), 272 (S,33), 287 (MX,46), 292 (MN,45), 296 (MX,46)

205 (MX,100), 221 (BP,36), 253 (MN,13), 294 (MX,35), 301 $(\mathrm{S}, 32)$

204 (MX,100), 212 (BP,42), 242 (MN,6), 284 (MX,57), 296 $(\mathrm{S}, 54)$

202 (MX,100), 247 (MN,18), 279 (MX,33), 295 (MN,29), 302 (MX,30)

205 (MX,100), 244 (MN,6), 279 (MX,49), 295 (MN,38), 300, $(\mathrm{MX}, 39)$

Incubations of warfarin and acenocoumarol with rat liver microsomes were carried out as described in the Materials and Methods section. Extracis of these incubations were subjected to diode array detector (Applied Biosystems 1000S) analysis, using the chromatographic conditions described in the Materials and Methods section. Wavelengths are given in $\mathrm{nm}$.

MX: maximum: MN: minimum; S: shoulder; BP: bending point.Relative absorptions are given in parenthesis. 


\subsection{RESULTS:}

Figure 3.2 shows HPLC chromatograms of incubation mixtures of PB-induced rat liver microsomes with $\mathrm{R}$-warfarin and $\mathrm{S}$-acenocoumarol as substrates. For warfarin, 5 metabolites have been found (in order of retention times): 4 '- $\left(R_{1}=4.7 \mathrm{~min}\right), 6-\left(R_{t}=5.8 \mathrm{~min}\right), 9-\left(R_{t}=6.9\right.$ $\min$ ), 8- $\left(R_{t}=7.4 \mathrm{~min}\right)$ and 7-hydroxywarfarin $\left(R_{t}=10.1 \mathrm{~min}\right.$ ) (figures 3.1 and 3.2). At high substrate concentrations the formation of RR/SS alcohols, dehydro-warfarin and 10hydroxywarfarin $\left(\mathrm{R}_{\mathrm{r}}=2.3,2.8\right.$, and $3.8 \mathrm{~min}$, respectively) were also observed. For acenocoumarol, next to the 6- and 7-hydroxylated metabolites $\left(R_{t}=7.5\right.$ and $10.4 \mathrm{~min}$ respectively), 5 additional metabolites have been found, annotated as $\mathrm{m} 1, \mathrm{~m} 2, \mathrm{~m} 3, \mathrm{~m} 5$ and $\mathrm{m} 6$ $\left(R_{1}=4.1,4.8,6.7,8.6\right.$, and $9.6 \mathrm{~min}$ respectively) according to their retention times on the HPLC system used (figure 3.2).

At high substrate concentrations, the formation of alcohol $2\left(R_{1}=2.1 \mathrm{~min}\right)$ is also found. Reduction of the nitro group has not been observed. The structure of $m 1$ has been shown to be identical with dehydro-acenocoumarol by co-chromatography with the dehydroacenocoumarol synthetised by the method of Fasco et al (1978).

For tentitative identification of acenocoumarol metabolites, the u.v. spectra of warfarin and acenocoumarol metabolites (using diode array detector analysis), have been recorded and the effect of change of $\mathrm{pH}$ of the mobile phase on their retention times is determined.

The u.v. spectral data are shown in table 3.1. The data suggest a structural relation between m6 and 8-hydroxywarfarin: the spectra show a typical shoulder at 267 (8-hydroxywarfarin) and $272 \mathrm{~nm}(\mathrm{~m} 6)$ respectively. The u.v. spectrum of $\mathrm{m} 3$ shows similarities to that of $10-$ hydroxywarfarin: a typical bending point and a typical shoulder are observed at 212 and 296 $\mathrm{nm}(\mathrm{m} 3)$ and at 221 and $301 \mathrm{~nm}$ (10-hydroxywarfarin) respectively. The spectra of $\mathrm{m} 5$ and 9-hydroxywarfarin show great similarities to the spectra of their parent compounds; however, the minima at 289 (warfarin) and $292 \mathrm{~nm}$ (acenocoumarol) are shifted to $295 \mathrm{~nm}$; furthermore, the relative absorption in this region is changed for the metabolites, resulting in a substantially higher maxinum at $279 \mathrm{~nm}$ than at $300 \mathrm{~nm}$, when compared with the parent compounds.

The effect of pH of the mobile phase on the retention times of the metabolites has been established in the $\mathrm{pH}$ range of 4.40 to 4.75 as shown in figure 3.3 . In this $\mathrm{pH}$ range the retention times of the 6- and 7-hydroxylated metabolites of both warfarin and acenocoumarol show a linear decline with rising $\mathrm{pH}$. In contrast, the change in retention times of 8-hydroxywarfarin and $\mathrm{m} 6$ show an inverse sigmoid pattem (bending points at a pH of 4.57 and 4.68 respectively). The retention times of 9-hydroxywarfarin, $\mathrm{m} 3$ and $\mathrm{m} 5$ do not change drastically in this $\mathrm{pH}$ range.

Based on the u.v. spectral data and the chromatographic properties of the metabolites, $\mathrm{m} 3$, $\mathrm{m} 5$, and $\mathrm{m} 6$ are tentatively identified as 10-hydroxy-, 9-hydroxy-, and 8-hydroxyacenocoumarol. respectively. Additional support is given by the fact that incubation of rat liver microsomes with warfarin and acenocoumarol, in the presence of tert-butylperoxide resulted in the formation of two products for each substrate: in the case of warfarin, the dehydro- and 
Figure 3.4: Substrate dependency of the rates of formation of the 6- and 7-hydroxylated metabolites of warfarin and acenocoumarol enantiomers.

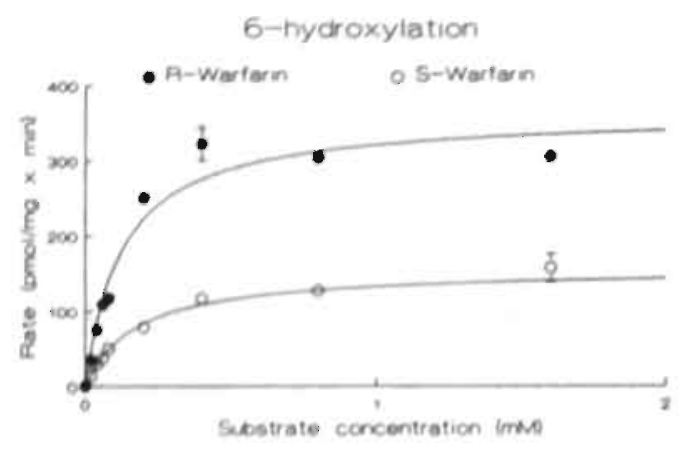

6-hydroxylation

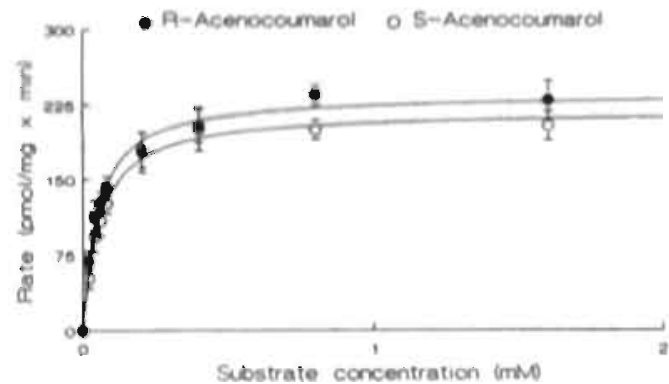

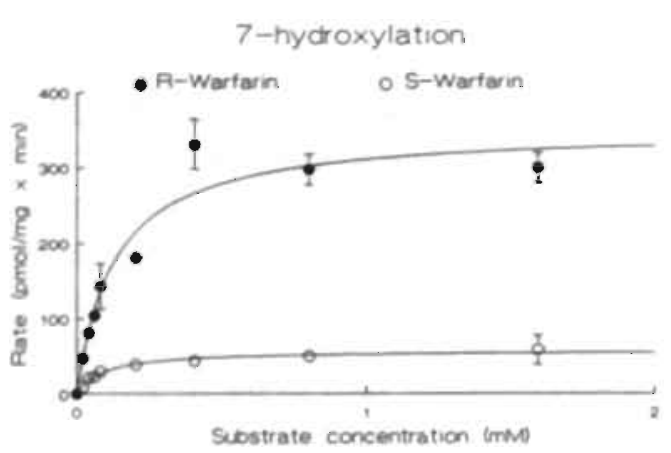

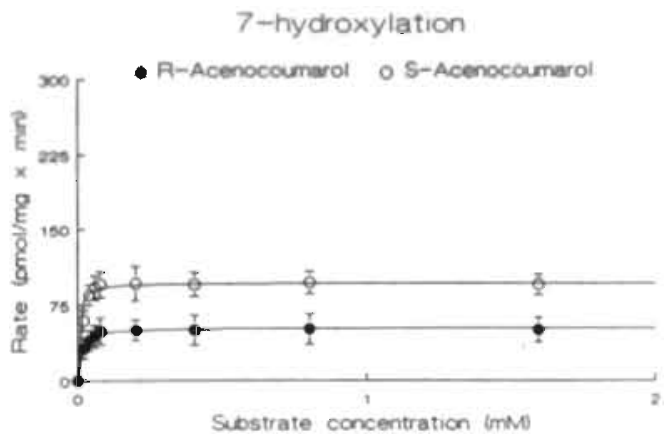

The Michaelis-Menten curve was fitted to the data by non-linear regression. Data are expressed as the mean ${ }^{*}$ SD of three incubations. Pooled liver microsomes of 4 untreated rats were used as enzyme source.

the 9-hydroxymetabolite were formed (Fasco et al, 1978), whereas for acenocoumarol $\mathrm{m} 1$ (dehydroacenocoumarol) and $\mathrm{m} 5$ (9-hydroxyacenocoumarol) were formed.

The fomation of warfarin and acenocoumarol metabolites is linear with time for at least $30 \mathrm{~min}$. Metabolite formation rates are linear with protein content in the range of 0.81012 $\mathrm{mg}$ of protein per $\mathrm{ml}$ of incubation mixture.

The formation rates of the metabolites of both warfarin and acenocoumarol as a function of substrate concentrations have been established. With the exception of the 9-hydroxy metabolites of both substrates, the formation of all metabolites follows Michaelis-Menten kinetics. V vs. [S] plots for the 6- and 7-hydroxylations are given in figure 3.4. The formation of the 8-hydroxylated metabolite of $\mathbf{R}$-acenocoumarol shows biphasic kinetics (figure 3.5), indicating two distinct enzyme systems. The enzyme kinetic parameters are summarized in table 3.2. The data show acenocoumarol to be a better substrate for the rat liver mixed function oxygenases than warfarin since the apparent $\mathrm{Km}$ values of acenocoumarol enantiomers are 
TABLE 3.2: Enzyme kinetic parameters of rat liver microsomal warfarin and acenocoumarol metabolite formation.

R-Warfarin

S-Warfarin

Metabolite

$\begin{array}{lllllll} & \text { Vmax } & \mathrm{Km} & \mathrm{Cli} & \mathrm{Vmax} & \mathrm{Km} & \mathrm{Cl} \\ \text { 4'-Hydroxy } & 56.3 & 134 & 403 & 46.8 & 120 & 384 \\ \text { 6-Hydroxy } & 360 & 123 & 2927 & 155 & 171 & 906 \\ \text { 8-Hydroxy } & 30.5 & 33.8 & 900 & 12.1 & 74.4 & 163 \\ \text { 7-Hydroxy } & 350 & 125 & 2800 & 57.0 & 85.6 & 666 \\ \text { total } & & & 7030 & & & 2119\end{array}$

R-Acenocoumarol

S-Acenocoumarol

Metabolite

$\begin{array}{lllllll} & \text { Vmax } & \mathrm{Km} & \mathrm{Cli} & \mathrm{Vmax} & \mathrm{Km} & \mathrm{Cli} \\ \text { 10-Hydroxy } & \text { nd } & \text { nd } & \text { nd } & 112 & 142 & 788 \\ \text { 6-Hydroxy } & 220 & 57.1 & 3853 & 237 & 50.4 & 4710 \\ \text { 8-Hydroxy } & 12.1 & 7.9 & 1532 & 27.4 & 9.8 & 2796 \\ & 15.5 & 120 & 129 * & & & \\ \text { 7-Hydroxy } & 52.2 & 10.1 & 5168 & 96.5 & 4.5 & 21444 \\ \text { total } & & & 10682 & & & 29738\end{array}$

Enzyme kinetic parameters werc determined by non-linear regression. Vmax is the maximal reaction rate ( $\mathrm{pmol} / \mathrm{mg}$ protein $\mathrm{x} \mathrm{min).} \mathrm{Apparent} \mathrm{Km}$ values are given in $\mu \mathrm{M}$, the intrinsic clearances $\left(\mathrm{Cl}_{1}\right)$ in $\mathrm{nl} / \mathrm{mg}$ protein $\mathrm{x}$ min. The totals are the sum of intrinsic clearances. nd $=$ not detected (detectable at the highest substrate concentrations only)

* The formation of the 8-hydroxy metabolite of $\mathrm{R}$-acenocoumarol was biphasic and was analyzed using an Eady-Hofstee plot (figure 3.5) and linear regression analysis.

lower than those of the corresponding warfarin enantiomers. The $\mathrm{Km}$ values for the major routes of metabolism, viz., 6- and 7-hydroxylation, are 2 to 19 times lower for acenocoumarol than for warfarin. The Vmax values of the microsomal hydroxylation reactions are 1.5- to 2fold higher for S-acenocoumarol than for S-warfarin. The opposite is true for the R-enantiomers. 
Figure 3.5: Eady-Hofstee plot of the rate of formation of the 8-hydroxylated metabolite of the Renantiomer of acenocoumarol.

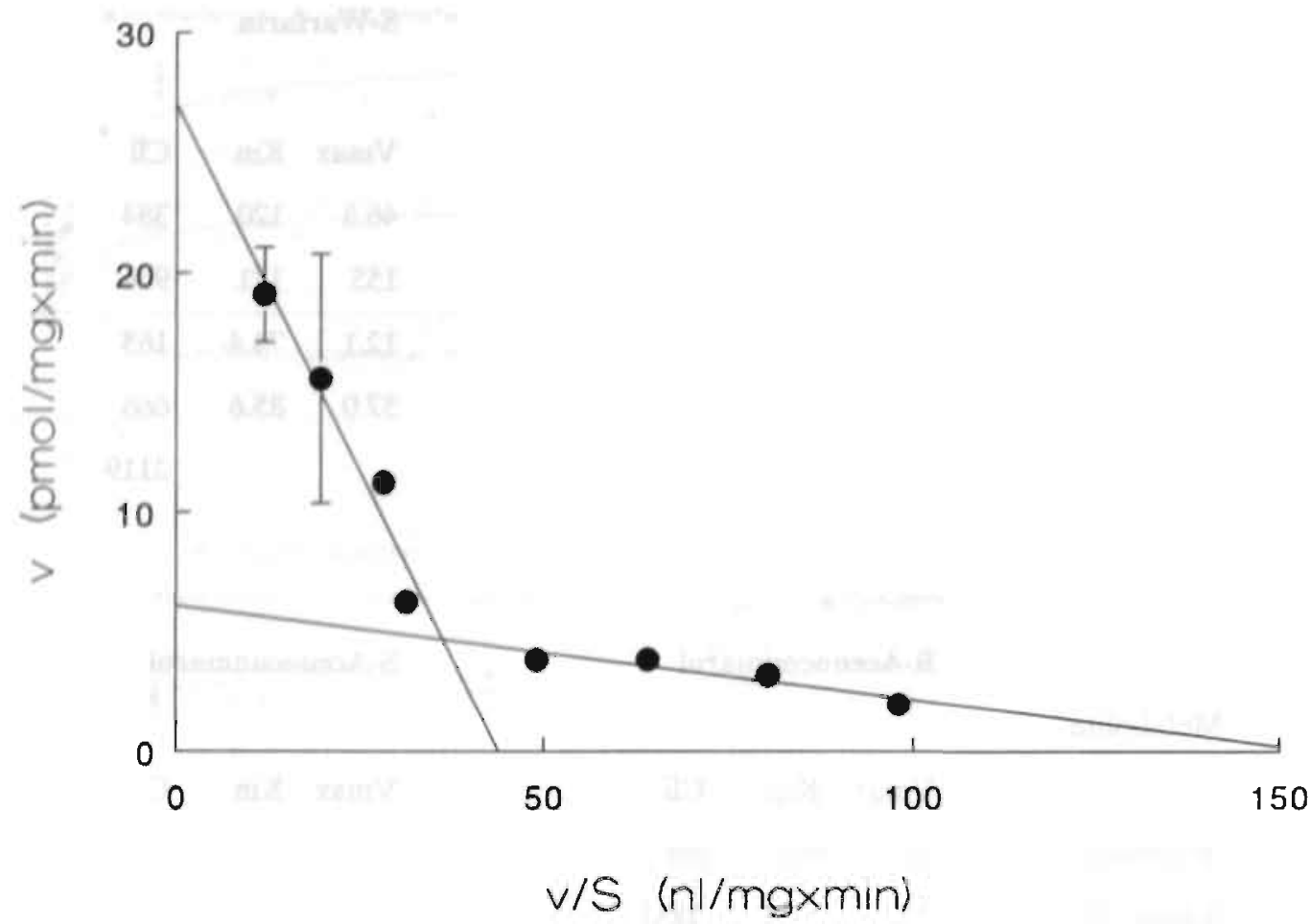

Data are expressed as the mean of 3 incubations : error bars indicate SD values. In the experiment pooled liver microsomes of 4 control rats were used.

The total (in vitro) intrinsic clearance of $\mathrm{R}$-acenocoumarol is about 1.5 times the intrinsic clearance of $\mathrm{R}$-warfarin. The difference in the total clearances is far more pronounced for the S-enantiomers: the total intrinsic clearance of S-acenocoumarol is 15 times higher than the intrinsic clearance of S-warfarin.

Conceming substrate stereoselectivity, the data clearly show the hydroxylation of the coumarin site (10 6-, 7-, and 8-hydroxywarfarin) to be stereoselective for the R-enantiomer of warfarin (the intrinsic clearances being 3 to 5 times higher for the R-enantiomer). In the case of acenocoumarol. stereoselectivity for the $S$-enantiomer is observed (S/R ratios of the intrinsic clearances being 1.5 to 4). The phenyl hydroxylation (at the 4 "position) of warfarin is not stereoselective.

To establish whether the isozyme spectrum involved in warfarin and acenocoumarol metabolism is the same, the effeci of some enzyme inducers and the P450 inhibitor cimetidine has been investigated. 
TABLE 3.3: The effect of treatment with phenobarbitone (PB) or methylcholanthrene (MC) on the metabolism of warfarin and acenocoumarol enantiomers by rat liver microsomal prepararations.

\begin{tabular}{lllll}
\multicolumn{5}{c}{ Warfarin } \\
Metabolite & \multicolumn{1}{c}{ UT\# } & \multicolumn{1}{c}{ PB } & \multicolumn{1}{c}{ MC } \\
\hline 6-Hydroxy & R & $95.3 \pm 1.2$ & $12.0 \pm 0.9^{*}$ & $22.7 \pm 21.1^{*}$ \\
& S & $18.9 \pm 3.9$ & $18.6 \pm 0.7$ & $7.0 \pm 1.2^{*}$ \\
7-Hydroxy & R & $55.3 \pm 14.7$ & $128.2 \pm 7.6^{*}$ & $69.8 \pm 17.3$ \\
& S & $40.5 \pm 6.4$ & $15.2 \pm 3.2^{*}$ & $28.7 \pm 1.7$ \\
8-Hydroxy & R & $7.2 \pm 0.1$ & $7.9 \pm 1.4$ & $11.2 \pm 0.1^{*}$ \\
& S & $7.9 \pm 0.1$ & $6.0 \pm 1.4$ & nd * \\
9-Hydroxy & R & $43.3 \pm 3.2$ & $75.5 \pm 2.2^{*}$ & $23.4 \pm 11.0$ \\
& S & $11.7 \pm 2.2$ & $48.4 \pm 1.1^{*}$ & $9.0 \pm 2.7$
\end{tabular}

Acenocoumarol

\begin{tabular}{lllll} 
Metabolite & & UT\# & \multicolumn{1}{c}{ PB } & \multicolumn{1}{c}{ MC } \\
\hline 6-Hydroxy & $\mathrm{R}$ & $135.8 \pm 5.4$ & $375.4 \pm 11.9^{*}$ & $185.1 \pm 17.6^{*}$ \\
& $\mathrm{~S}$ & $117.6 \pm 3.9$ & $263.8 \pm 27.8^{*}$ & $168.4 \pm 4.7^{*}$ \\
7-Hydroxy & $\mathrm{R}$ & $39.4 \pm 1.8$ & $80.6 \pm 1.1^{*}$ & $51.5 \pm 2.6^{*}$ \\
& $\mathrm{~S}$ & $114.2 \pm 7.2$ & $147.8 \pm 12.9$ & $127.8 \pm 13.2$ \\
8-Hydroxy & $\mathrm{R}$ & $6.4 \pm 5.4$ & $39.4 \pm 2.2^{*}$ & $\mathrm{nd}$ \\
& $\mathrm{S}$ & $13.2 \pm 3.1$ & $40.3 \pm 3.8^{*}$ & $14.7 \pm 3.6$ \\
9-Hydroxy & $\mathrm{R}$ & $8.9 \pm 8.9$ & $40.5 \pm 14.3$ & $4.3 \pm 3.4$ \\
& $\mathrm{~S}$ & $14.0 \pm 1.8$ & $33.0 \pm 4.6^{*}$ & $11.0 \pm 2.2$
\end{tabular}

Data are expressed as pmol of metabolite formed $/ \mathrm{min}$ per $\mathrm{mg}$ of protein, and are themean \pm SD of 3 incubations (pooled liver microsomes of 4 rats in each group), \# UT: microsomes from untreated rats.

* significantly different from untreated rat liver microsomes $\mathrm{P}<0.001$ (ANOVA. LSD).

nd $=$ not detectable. 
The effect of the enzyme inducers phenobarbitone (PB) and methylcholanthrene (MC) on the in vitro warfarin and acenocoumarol metabolism is shown in table 3.3. PB-treated rat liver microsomes show significantly higher rates of formation $(\mathrm{P}<0.001)$ of 9 -hydroxywarfarin for both enantiomers. The 6-hydroxylation of $\mathrm{R}$-warfarin is lowered by $\mathrm{PB}$ treatment $(\mathrm{P}<0.001)$. whereas the 6-hydroxylation of S-warfarin is not affected by PB treatment. A clear difference between enantiomers in the response to PB treatment is seen in the formation of 7 hydroxywarfarin. which is significantly enhanced for the R-enantiomer but depressed for the S-enantiomer $(\mathrm{P}<0.001)$.

For both acenocoumarol enantiomers, PB-treated rat liver microsomes show significantly $(\mathrm{P}<0.001)$ higher rates of formation of 6-hydroxy and 8-hydroxyacenocoumarol, whereas 7hydroxylation is enhanced for R-acenocoumarol only. The opposite is true for the 9-hydroxylation, which is induced by PB for S-acenocoumarol only. In general, PB treatment has a greater enhancing effect on the rates of formation of metabolites of acenocoumarol than of warfarin.

Microsomes from MC-treated rats generally show lower rates of formation of warfarin metabolites than control rat liver microsomes, which is significant for the 6-hydroxylation of $\mathrm{R}$ - and $\mathrm{S}$-warfarin and the 8-hydroxylation of the S-enantiomer. In contrast, the 8-hydroxylation of $\mathrm{R}$-warfarin is significantly induced $(\mathrm{P}<0.001)$ by $\mathrm{MC}$ pretreatment.

Unlike warfarin metabolism, the rates of formation of acenocoumarol metabolites are not depressed by treatment with MC but are enhanced or not affected. The 6-hydroxylation of Rand $\mathrm{S}$-acenocoumarol, as well as the 7-hydroxylation of R-acenocoumarol is significantly enhanced by $\mathrm{MC}(\mathrm{P}<0.001)$.

Table 3.4 summarizes the effect of cimetidine on microsomal warfarin and acenocoumarol metabolism for the various microsomal preparations. The data are expressed as \% inhibition. As shown. the effect of cimetidine is dependent on the substrate and on the microsomal source used. e.g. the metabolism of S-warfarin is inhibited to a greater extent than the metabolism of R-warfarin. This effect is most pronounced for 6-and 7-hydroxywarfarin. The formation of the 6-hydroxymetabolite of S-warfarin is inhibited to a lesser extent in MC microsomes than in control microsomes $(\mathrm{P}<0.01)$.

The inhibition of acenocoumarol metabolism by cimetidine does not show a general stereoselective pattem. Like warfarin. the extent of inhibition of acenocoumarol metabolism by cimetidine is dependent on the microsomal source used. The formation of 7- and 8hydroxyacenocoumarol for both enantiomers is inhibited to a significantly lesser extent in $\mathrm{PB}$-treated than in control microsomes. In contrast. inhibition of the formation of the 6hydroxymetabolite of R-acenocoumarol in PB-treated microsomes is significantly greater $(\mathrm{P}<0.01)$.

In order to obtain more detailed information on the nature and selectivity of the isozymes being involved in wartarin and acenocoumarol metabolism , the effect of two monoclonal 
TABLE 3.4: Inhibition of rat liver microsomal metabolism of warfarin and acenocoumarol enantiomers by cimetidine.

\section{Warfarin}

\begin{tabular}{lllll} 
Metabolite & & UT & \multicolumn{1}{c}{ PB } & MC \# \\
\hline 6-Hydroxy & R & $57 \pm 11$ & $45 \pm 13$ & $62 \pm 13$ \\
& S & $92 \pm 19$ & $74 \pm 7$ & $4 \pm 3 *$ \\
7-Hydroxy & R & $45 \pm 13$ & $65 \pm 12$ & $23 \pm 12$ \\
& S & 100 & $95 \pm 8$ & 100 \\
8-Hydroxy & R & 100 & 100 & 100 \\
& S & $1^{\prime} 100$ & 100 & nd \\
9-Hydroxy & R & $54 \pm 19$ & $33 \pm 11$ & $63 \pm 13$ \\
& S & $92 \pm 22$ & $26 \pm 16$ & 100
\end{tabular}

\section{Acenocoumarol}

\begin{tabular}{lllll} 
Metabolite & & \multicolumn{1}{c}{ UT } & \multicolumn{1}{c}{ PB } & MC\# \\
\hline 6-Hydroxy & R & $79 \pm 6$ & $95 \pm 3^{*}$ & $79 \pm 8$ \\
& S & $82 \pm 10$ & $78 \pm 8$ & $86 \pm 9$ \\
7-Hydroxy & R & $87 \pm 10$ & $55 \pm 9^{*}$ & $67 \pm 22$ \\
& S & $93 \pm 10$ & $38 \pm 10^{*}$ & $85 \pm 18$ \\
8-Hydroxy & R & 100 & $57 \pm 9^{*}$ & nd \\
& S & 100 & $33 \pm 13^{*}$ & 100 \\
9-Hydroxy & R & $58 \pm 11$ & $12 \pm 8$ & $5 \pm 3^{*}$ \\
& S & $86 \pm 7$ & $74 \pm 5$ & $100^{*}$
\end{tabular}

Incubation mixtures were preincubated with cimetidine (final concentration $1.1 \mathrm{mM}$ ) at 37 ${ }^{\circ} \mathrm{C}$ for $5 \mathrm{~min}$ before the substrate (final concentration $0.2 \mathrm{mM}$ ) was added.

The data are expressed as the percentage inhibition (mean of 3 incubations) $\pm S D$ (pooled microsomes $n=4$ in each group).

\# UT $=$ untreated, $\mathrm{PB}=$ phenobarbitone, $\mathrm{MC}=$ methylcholanthrene.

* significantly different from untreated rat liver microsomes $\mathrm{P}<0.0$ \% (Kruskall and Wallis. Nemenyi test).

$\mathrm{nd}=$ not detectable without inhibitor . 
TABLE 3.5: The effect of the monoclonal antibody against $\mathrm{P} 4502 \mathrm{C} 6 / 2 \mathrm{C} 11$ on rat liver microsomal warfarin and acenocoumarol metabolism.

\begin{tabular}{|c|c|c|c|c|c|c|}
\hline Substrate & \multicolumn{3}{|c|}{ R-WARFARIN } & \multicolumn{3}{|c|}{ S-WARFARIN } \\
\hline metabolite & UT & PB & $\mathrm{MC}$ & UT & PB & $\mathrm{MC}$ \\
\hline 4'hydroxy & $18 \pm 4$ & $25 \pm 4^{*}$ & $15 \pm 2$ & $7 \pm 2$ & $14 \pm 4$ & $26 \pm 4 *$ \\
\hline 6-hydroxyf & $-3 \pm 4$ & $-11 \pm 3$ & $-5 \pm 4$ & $-5 \pm 3$ & $4 \pm 7$ & $5 \pm 4$ \\
\hline 7-hydroxy & $22 \pm 5^{*}$ & $44 \pm 4^{*}$ & $-1 \pm 5$ & $26 \pm 1^{*}$ & $45 \pm 6^{*}$ & $10 \pm 11$ \\
\hline 8-hydroxy & $-70 \pm 10^{\bullet}$ & $-61 \pm 8^{*}$ & $-56 \pm 12^{*}$ & $-21 \pm 2^{*}$ & $-19 \pm 3^{*}$ & nd \\
\hline 9-hydroxyf & $22 \pm 4^{*}$ & $44 \pm 3^{*}$ & $-2 \pm 7$ & $12 \pm 5$ & $6 \pm 8$ & $-5 \pm 9$ \\
\hline Substrate & \multicolumn{3}{|c|}{ R-ACENOCOUMAROL } & \multicolumn{3}{|c|}{ S-ACENOCOUMAROL } \\
\hline metabolite & UT & $\mathrm{PB}$ & $\mathrm{MC}$ & UT & PB & MC \\
\hline 6-hydroxy & $-3 \pm 8$ & $14 \pm 1^{*}$ & $4 \pm 7$ & $19 \pm 1 *$ & $17 \pm 1 *$ & $28 \pm 9^{*}$ \\
\hline 7-hydroxy & $16 \pm 1^{*}$ & $30 \pm 1^{*}$ & $24 \pm 2 *$ & $18 \pm 1^{*}$ & $30 \pm 2^{*}$ & $30 \pm 6^{*}$ \\
\hline 8-hydroxy & $46 \pm 12^{*}$ & $31 \pm 1^{*}$ & nd & $27 \pm 9^{*}$ & $32 \pm 5^{*}$ & $13 \pm 4$ \\
\hline 9-hydroxy & $0 \pm 9$ & $4 \pm 1$ & $2 \pm 3$ & $-4 \pm 9$ & $11 \pm 5$ & $1 \pm 5$ \\
\hline
\end{tabular}

Data are expressed as mean \% inhibition \pm SD. Positive values imply an inhibition, negative values imply an enhancement. UT, PB. MC, microsomes from untreated. phenobarbitone treated and methylcholanthrene treated rats ( $n=4$ per group) respectively.

* Significant inhibition. $\mathrm{P}<0.025$, ANOVA, LSD

antibodies raised against P450 isozymes, has been investigated. Antibody $2 \mathrm{C}$ was raised against $\mathrm{P} 4502 \mathrm{C6} / \mathrm{Ci}$, whereas antibody $3 \mathrm{~A}$ was raised against the $\mathrm{P} 450$ 3A subfamily. These P450's are known to have warlarin hydroxylase activity (Guengerich et al, 1982). Table 3.5 shows the effect of monoclonal antibody $2 \mathrm{C}$ on warfarin and acenocoumarol metabolism in various rat liver microsomal iractions. Antibody $2 \mathrm{C}$ inhibits the 7 -hydroxylation of $\mathrm{R}$ - and $\mathrm{S}$-warfarin in microsomes from untreated or $\mathrm{PB}$ treated rats $(\mathrm{P}<0.025)$ but not in microsomes from MC treated rats. The extent of inhibition does not appear to be different for $\mathrm{R}$ - and $\mathrm{S}$-warfarin but is higher in PB microsomes than in control microsomes. The 9 hydroxylation in control and PB microsomes appears to be stereoselectively inhibited for R$(P<0.025)$ but not $\mathbf{S}$-warfarin. In contrast, the 8-hydroxylation of warfarin is enhanced about 1.6 fold for the R- and 1.2 fold for the $S$-enantiomer $(\mathrm{P}<0.025$ in both cases $)$, in microsomes where this metabolite was found under normal (without antibody) conditions. This may be due to a decrease of competition of the 8-hydroxylase with P450 2C6 and 2C11 towards the P450 reductase or to a prevention of isozyme complexation (Kaminsky and Guengerich. 1985). 
TABLE 3.6 The effect of the monoclonal antibody against the P450 $3 \mathrm{~A}$ subfamily on rat liver microsomal warfarin and acenocoumarol metabolism.

\begin{tabular}{|c|c|c|c|c|c|c|}
\hline Substrate & \multicolumn{3}{|c|}{ R-WARFARIN } & \multicolumn{3}{c|}{ S-WARFARIN } \\
\hline metabolite & UT & PB & MC & UT & PB & MC \\
\hline 4'hydroxy & $8 \pm 2$ & $13 \pm 1^{*}$ & $9 \pm 6$ & $10 \pm 3$ & $3 \pm 6$ & $15 \pm 3$ \\
\hline 6-hydroxy & $-3 \pm 5$ & $18 \pm 8$ & $-24 \pm 14$ & $4 \pm 4$ & $42 \pm 4^{*}$ & $-30 \pm 16$ \\
\hline 7-hydroxy & $-12 \pm 9$ & $-10 \pm 7$ & $-19 \pm 9$ & $9 \pm 6$ & $30 \pm 6^{* *}$ & $-13 \pm 7$ \\
\hline 8-hydroxy & $5 \pm 5$ & $2 \pm 1$ & $64 \pm 20^{*}$ & $12 \pm 1^{*}$ & $-1 \pm 3$ & nd \\
\hline 9-hydroxy & $-8 \pm 5$ & $-9 \pm 9$ & $2 \pm 2$ & $1 \pm 4$ & $-10 \pm 4$ & $-13 \pm 10$ \\
\hline Substrate & R-ACENOCOUMAROL & S-ACENOCOUMAROL \\
\hline metabolite & UT & PB & MC & UT & PB & MC \\
\hline 6-hydroxy & $5 \pm 8$ & $23 \pm 2^{*}$ & $26 \pm 6^{*}$ & $1 \pm 5$ & $-6 \pm 1$ & $-6 \pm 1$ \\
\hline 7-hydroxy & $2 \pm 1$ & $-3 \pm 1$ & $5 \pm 1$ & $19 \pm 5^{*}$ & $-7 \pm 1$ & $19 \pm 1^{*}$ \\
\hline 8-hydroxy & $-9 \pm 5$ & $0 \pm 1$ & nd & $4 \pm 2$ & $3 \pm 4$ & $-9 \pm 4$ \\
\hline 9-hydroxy & $35 \pm 1^{*}$ & $30 \pm 2^{*}$ & $14 \pm 10$ & $-7 \pm 9$ & $19 \pm 4^{*}$ & $16 \pm 5$ \\
\hline
\end{tabular}

Data are expressed as mean $\%$ inhibition \pm SD. Positive values imply an inhibition, negative values imply an enhancement. UT. PB, MC, microsomes from untreated, phenobarbitone treated and methylcholanthrene treated rats ( $n=4$ per group) respectivcly.

* Significant inhibition, $\mathrm{P}<0.025$, ANOVA, LSD

In the case of acenocoumarol, the 7-hydroxylation is significanlly $(\mathrm{P}<0.025)$ inhibitcd by antibody $2 \mathrm{C}$ in all microsomes in a non-stereoselective manner. In contrast, the 6-hydroxylation of $\mathrm{S}$-acenocoumarol is inhibited in all microsomes, whercas the 6-hydroxylation of the R-enantiomer is inhibited in PB microsomes only. The 8-hydroxylation of R-and Sacenocoumarol is inhibited in microsomes from untreated and $\mathrm{PB}$ trealcd rats $(\mathrm{P}<0.025)$.

The effect of antibody $3 \mathrm{~A}$ is shown in table 3.6. Antibody $3 \mathrm{~A}$ inhibits the 8 -hydroxylation of $\mathrm{R}$-warfarin in $\mathrm{MC}$ microsomes and of S-warfarin in control microsomes significantly. In addition the 6-and 7-hydroxylation of S-warfarin in PB trealed microsomes is inhibited by this antibody $(\mathrm{P}<0.025)$.

In the case of R-acenocoumarol, the 6-hydroxylation in $\mathrm{PB}$ and $\mathrm{MC}$ microsomes and the 9-hydroxylation in control and $\mathrm{PB}$ microsomes is inhibited by antibody $3 \mathrm{~A}(\mathrm{P}<0.025)$. The 7-hydroxylation of $\mathrm{S}$-acenocoumarol is inhibited by antibody $3 \mathrm{~A}$ in $\mathrm{MC}$ microsomes only, whereas the 9-hydroxylation of S-acenocoumarol is inhibited in $\mathrm{PB}$ microsomes only $(\mathrm{P}<0.025)$. 
Figure 3.6: Estimated formation rates of warfarin and acenocoumarol metabolites by cytochromes P450 2C6 and 2C11 in microsomes from untreated, phenobarbitone treated and methylcholanthrene treated rats.

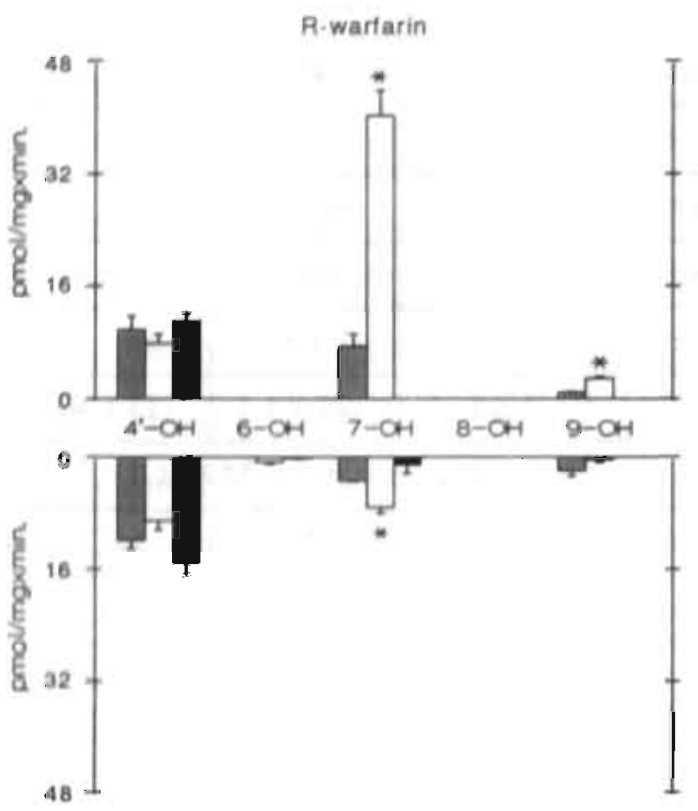

S-warfarin

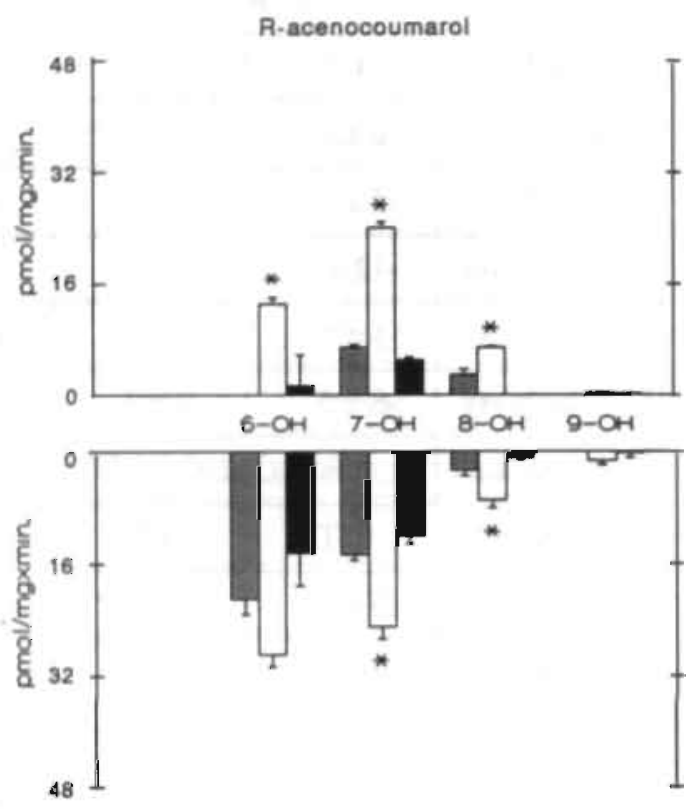

S-acenocoumarol

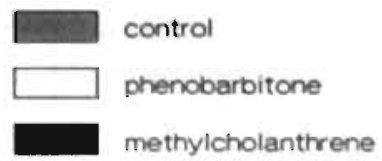

Data are expressed as the mean of three incubations; error bars indicate SD values.

4'-OH, 6-OH, 7-OH, 8-OH, 9-OH indicate metabolites hydroxylated at the 4'-, 6-, 7-, 8-, and 9 positions.

Tables 3.5 and 3.6 give a good indication of the relative contribution of the $\mathrm{P} 450$ 's that are inhibitable by antibodies $2 \mathrm{C}$ and $3 \mathrm{~A}$ to warfarin and acenocoumarol metabolism, but provide no information on the stereo- and regioselectivity and inducibility of these isozymes. Therefore, the absolute decrease of metabolite formation rates by antibody $2 \mathrm{C}$ and $3 \mathrm{~A}$, which represents the hydroxylase activity of $\mathrm{P} 450$ isozymes that are inhibited by the antibodies is given in figures 3.6 and 3.7 . 
Figure 3.7: Estimated formation rates of warfarin and acenocoumarol metabolites by cylochromes P450 from the $3 \mathrm{~A}$ subfamily in microsomes from untreated, phenobarbitone treated and methylcholanthrene treated rats.

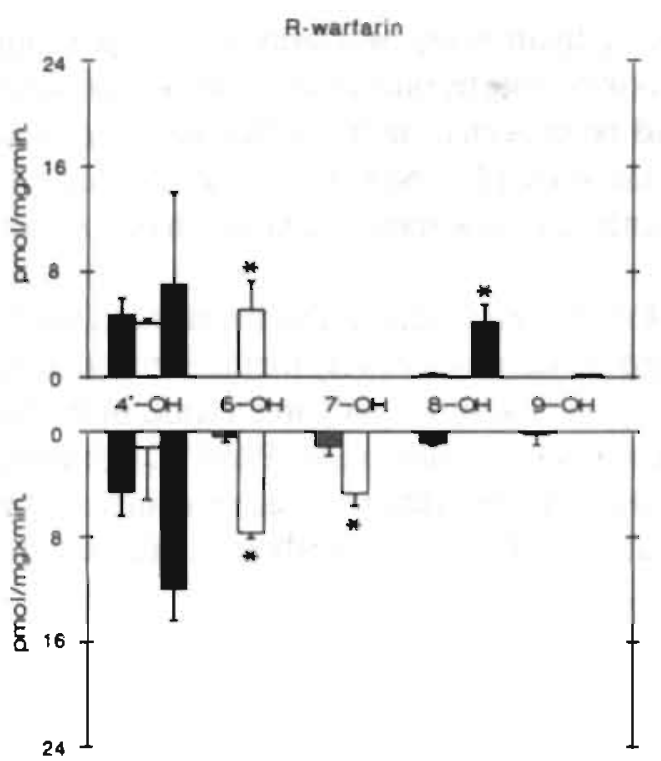

S-warlarin

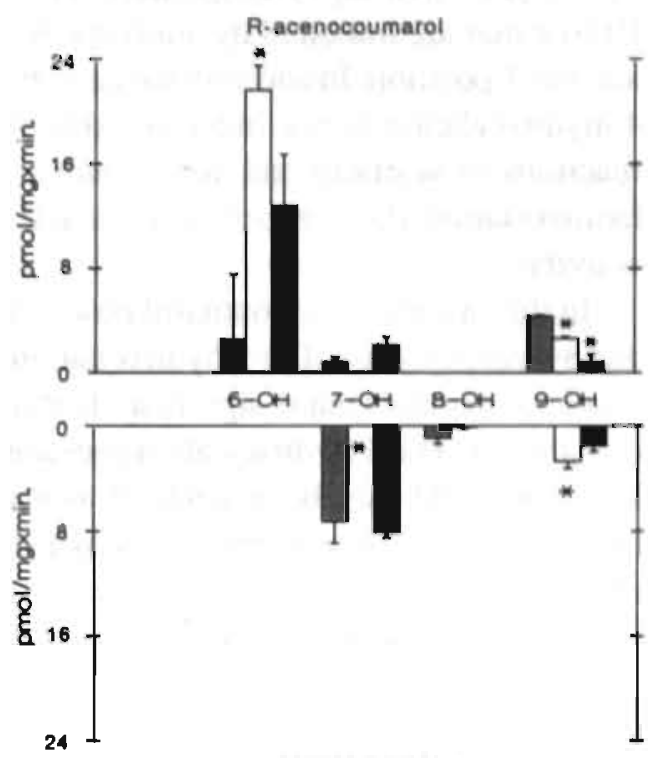

S.acenocoumarol

control

phenobarbitone

methylcholanthrene

Data are expressed as the mean of three incubations; error bars indicate SD values.

4'-OH, 6-OH, 7-OH, 8-OH, 9-OH indicate metabolites hydroxylated at the 4'-, 6-, 7-, 8-, and 9 positions.

Figure 3.6 clearly shows that there are stereo- and regioselective differences in the metabolism of warfarin and acenocoumarol by P450's that are inhibited by antibody $2 \mathrm{C}$. $\mathrm{P} 4502 \mathrm{C} 6$ is reported to be phenobarbitone inducible and to have warfarin 7-hydroxylase activity (Guengerich et al, 1982), whereas P450 2C11, a (rat) male specific, constitutive 
testosterone 16 $\alpha$-hydroxylase (Nebert and Gonzalez, 1987) primarily shows warfarin 4'hydroxylase activity (Guengerich et al, 1982). Consistent with these findings we found that $\mathrm{P} 450$ 's that are inhibited by antibody $2 \mathrm{C}$ are able to hydroxylate warfarin at the 4 ' position and the 7 -position. In addition the latter reaction is inducible by phenobarbitone, whereas the $4^{\prime}$-hydroxylation is not induced. Also, as would be expected, none of the hydroxylation reactions of warfarin and acenocoumarol is induced by MC. Next to warfarin 4'- and 7hydroxylation, the members of the rat $\mathrm{P} 4502$ 2C subfamily show some warfarin 9-hydroxylase activity.

In the case of acenocoumarol however, rat P4502C isozymes are also involved in the 6and 8-hydroxylation. The 6-hydroxylation is carried out stereoselectively for the S-enantiomer in all microsomes but is significantly induced by phenobarbitone only in the case of the $R$ enantiomer. The 8-hydroxylation does not appear to be stereoselective for $\mathrm{P} 4502 \mathrm{C}$ isozymes and is induced by PB. In contrast to warfarin, the 7-hydroxylation of acenocoumarol by antibody $2 \mathrm{C}$ inhibitable isozymes, which is induced by $\mathrm{PB}$, does not show a clear stereoselectivity.

Figure 3.7 shows the regio- and stereoselectivity of cytochrome P450 isozymes that are inhibited by the monoclonal antibody raised against the P450 3A subfamily. The rat (liver) cytochrome P450 3A subfamily consists of at least two isozymes, 3A 1 and 3A2, that are inducible by pregnenolone 16@ carbonitrile and to a lesser extent by PB (Nebert and Gonzalez, 1987, Nebert et al, 1991). P450 3Al is shown to have 4'-hydroxylase activity (Guengerich et al 1982). Information on the catalytic activity of P450 3A2 towards warfarin enantiomers is not known. However, human P450 isozymes from the $3 \mathrm{~A}$ subfamily have been shown to have 10- and 4'-hydroxylase activity along with some S-warfarin 7- and 6hydroxylase activity (Rettie et al, 1992). Since antibody 3A was raised against P450's from the $3 \mathrm{~A}$ subfamily, P450 $3 \mathrm{~A} 1$ as well as P450 $3 \mathrm{~A} 2$ will be inhibited by this antibody. Figure 3.7 shows that $\mathrm{P} 450$ 's of the $3 \mathrm{~A}$ subfamily appear to be involved in the 4'-hydroxylation of warfarin in all microsomes; this reaction does not appear to be induced. P450 3A isozymes carry out the 6-hydroxylation of both warfarin enantiomers in PB microsomes. In contrast, P450 isozymes that are inhibited by antibody $3 \mathrm{~A}$ conduct the 7-hydroxylation of S-warfarin but not R-warfarin: this reaction is induced by PB. In addition P450 3A isozymes possess some warfarin 8 -hydroxylase activity.

In sharp contrast to warfarin. $\mathrm{P} 450$ 's $3 \mathrm{~A}$ catalyse the 6-hydroxylation of only the Renantiomer of acenocoumarol in PB and MC microsomes. In addition, these P450 isozymes conduct the 7-hydroxylation of acenocoumarol in a stereoselective manner for the $\mathrm{S}$ enantiomer incontrol and in MCmicrosomes but, contrary to warfarin. not in PB microsomes. Finally, some 9-hydroxylase activity is observed. 


\subsection{DISCUSSION:}

The aim of this study was to elucidate the mechanism behind the remarkable differences between the clearances of R- and S-warfarin and R- and S-acenocoumarol. Enzyme kinetics of the various metabolic routes rather than rates of formation were studied because the established parameter $\mathrm{Vmax} / \mathrm{Km}$ is more appropriate for comparison with in vivo clearance data (Rane et al., 1977). This approach was recently also applied by Rettie et al (1989) to compare the in vitro and in vivo metabolism of warfarin in man.

The study shows the in vitro metabolism of acenocoumarol to involve the same metabolic reactions as warfarin, except for the 4 '-hydroxylation, i.e. hydroxylation occurs at the coumarin moiety at the 6-.7-, and 8-positions and at C9 (benzyl-hydroxy) and $\mathrm{ClO}$ (figure 3.1). However, the enantiomers of acenocoumarol appear to be better substrates for these reactions; the apparent $\mathrm{Km}$ values are 2 (6-hydroxylation of R-acenocoumarol) to 19 (7hydroxylation of the S-enantiomer) times lower (table 3.2).

The lower $\mathrm{Km}$ value clearly is the main factor determining the higher intrinsic clearance of the metabolism of the enantiomers of acenocoumarol vs warfarin, which is in accordance with the in vivo observations (see chapter 2 ). Also in agreement with the in vivo observations is the fact that the in vitro clearance of warfarin is stereoselective for the R-enantiomer, whereas the in vitro clearance of acenocoumarol shows stereoselectivity for the $\mathrm{S}$-enantiomer.

In several studies it has been shown that the hydroxylations of warlarin enantiomers can be catalysed by various cytochrome P450 isozymes (Guengerich et al, 1982 ; Kaminsky et al, 1984 ; Kaminsky, 1989). Also for the 4-hydroxycoumarin, phenprocoumon, the involvement of various P450 isozymes has been suggested (Wheeler et al. 1981). Likewise this will probably also hold for the enantiomers of acenocoumarol. The question then arises whether the set of P450 isozymes involved in the hydroxylations of R-and S-warfarin will catalyse the hydroxylations of R-and S-acenocoumarol to the same extent. The inhibition study with the P450 inhibitor (Rendic et al, 1983; Hoensch et al, 1985: Miners et al, 1988) cimetidine shows that the 7-hydroxylation in control microsomes is almost completely inhibited by cimetidine for $\mathrm{R}$-acenocoumarol, but only partly for $\mathrm{R}$-warfarin, despite the higher $\mathrm{Km}$ value of the latter. This may indicate that different $\mathrm{P450}$ isozymes are involved in the metabolism of warlarin and acenocoumarol. The induclion and inhibition study also points in that direction. For instance, the 6-hydroxylation of $\mathrm{R}$-warfarin is lowered by $\mathrm{PB}$ and $\mathrm{MC}$, whereas the 6-hydroxylation of $\mathrm{R}$-acenocoumarol is enhanced by $\mathrm{PB}$ and $\mathrm{MC}$. Also, the 6-hydroxylation of $\mathrm{R}$-acenocoumarol is inhibited by cimetidine to a greater extent in PB-treated microsomes than in control microsomes; this is not the case for R-warfarin. For the other metabolic routes, differences between warfarin and acenocoumarol in response to PB and $\mathrm{MC}$ treatment, and to inhibition (of induced microsomes vs. control microsomes) by cimctidine, can also be observed (tables 3.2 and 3.3). Taken together, these data strongly indicate that some of the differences in the metabolism of warfarin and acenocoumarol can be attributed to the diversity of enzymes involved in the major metabolic pathways of these substances; i.e. the cytochrome $\mathrm{P} 450$ isozymes involved in the (coumarin) hydroxylations of $\mathrm{R}$ - and S-warfarin 
may not catalyse the same reactions for R-and S-acenocoumarol and vice versa, or to only minor extents.

Additional evidence for this hypothesis is provided by the immuno-inhibition experiments. P450's of the 2C and 3A subfamily are clearly involved in the metabolism of both 4-hydroxycoumarins but show a different stereo- and regioselectivity in the coumarin hydroxylation of warfarin and that of acenocoumarol (figures 3.6 and 3.7). E.g. P450 2C isozymes are able to hydroxylate acenocoumarol but not warfarin at the 6-position. On the other hand the contribution (table 3.5) of $\mathrm{P} 4502 \mathrm{C}$ isozymes to the 7-hydroxylation of warfarin in PB and control microsomes appears to be greater than that of acenocoumarol, whereas the opposite is true in MC microsomes. The P450 3A subfamily conducts the 6 . hydroxylation of warfarin in a non-stereoselective manner but shows high stereoselectivity for the R-enantiomer of acenocoumarol; S-acenocoumarol does not appear to be hydroxylated at the 6-position by these isozymes. The relative contribution of $\mathrm{P} 4503 \mathrm{~A}$ isozymes in the 6hydroxylation of S-warfarin in PB microsomes is about twice as high as in the 6-hydroxylation of the R-enantiomers of warfarin and acenocoumarol (table 3.6).

These examples demonstrate that 1) cytochrome P450 isozymes are involved in the metabolism of the enantiomers of warfarin and acenocoumarol to different extents 2) even if the same (sets of) isozymes are looked upon, both substrates are hydroxylated with different stereo- and regioselectivity. This indicates that the phenyl ring of warfarin is highly involved in the interaction with the apoprotein and that the substituents additionally determine selectivity towards cytochrome $\mathrm{P} 450$ isozymes.

The 4-hydroxycoumarin phenprocoumon, like acenocoumarol also shows stereoselective (in vitro) metabolism for the S-enantiomer (Wheeleret al, 1981). Heimark and Trager (1985), in explaining this discrepancy with warfarin, suggested that the $\mathrm{R}$-enantiomer of warfarin has the possibility to mimick the S-enantiomer of phenprocoumon by hemiketal formation (Valente and Trager. 1978). However, this may not be the mechanism since acenocoumarol displays the same stereoselectivity as phenprocoumon, despite its ability to form similar hemiketals as warfarin. In our opinion, the discrepancy between phenprocoumon and warfarin can be explained better by the diversity of cytochrome $\mathrm{P} 450$ isozymes involved in the metabolism of these compounds.

In conclusion, the study gives additional support for the viewpoint that various cytochrome P450 enzymes are involved in the regio- and stereoselectivity of the hydroxylation of R-and $\mathrm{S}$-warfarin. Furthermore, the study indicates that similar hydroxylations of acenocoumarol may be catalysed by enzymes different from those transforming warfarin. This observation complicates studies aimed at the investigation of structure-biotransformation relationships. 
Banfield, C., and Rowland, M., 1984, Stereospecific fluorescence high-performance liquid chromatographic analysis of warfarin and its metabolites in plasma and urine.J.P harm.Sci.73: 13921396.

Beaune, P.H., Kremers, P.G., Kaminsky, L.S., de Graeve, J., Albert, A., and Guengerich, F.P.,1986, Comparison of monoxygenase activities and cytochrome P450 isozyme concentrations in human liver microsomes. Drug Metab. Dispos. 14: 437-442.

Eichelbaum, M., 1988, Pharmacokinetic and phamacodynamic consequences of stereoselective drug metabolisn in man. Biochem. Pharmacol, 37: 93-96.

Fasco, M.J., Baker, F.D., and Fenton, J.W., 1976, Warfarin- stereochemical aspects of its metabolism by rat liver microsomes. Biochem. Pharmacol.. 25: 2153-2162.

Fasco, M.J., Dymerski, P.P., Wos, J.D., and Kaminsky. L.S., 1978, A new warfarin metabolite: structure and function. J. Med. Cherm. 21: 1054-1059.

Greenlee, W.F., and Poland, A., 1978, An improved assay of 7-ethoxycoumarin O-deethylase activity: induction of hepatic enzyme activity in $\mathrm{C} 57 \mathrm{BL} / 6 \mathrm{~J}$ and $\mathrm{DBA} / 2 \mathrm{~J}$ mice by phenobarbital, 3-methylcholanthrene and 2,3,7,8-tetrachlorodibenzo-p-dioxin. J. Pharmacol.Exp. Ther. 205: 596-605.

Guengerich, F.P., Dannan, G.A., Wright, S.T., Martin, M.V., and Kaminsky, L.S., 1982, Purification and characterization of microsomal cytochrome P-450s. Xenobiotica 12: 701-716.

Heimark, L.D., and Trager, W.F., 1985, Stereoselective metabolism of conformational analogue of warfarin by B-naphtoflavone-inducible cytochrome P-450. J. Med. Chem. 28: 503-506.

Hoensch, H.P., Hutzel, H., Kirch, W., and Ohnhaus, E.E., 1985, Isolation of human hepatic microsomes and their inhibition by cimetidine and ranitidine. Eur. J. Clin. Pharmacol.

29:199-206.

Kaminsky, L.S..1989, Warfarin as a probe of cytochromes P-450 function. Drug Metab. Rev, 20: $479-487$,

Kaminsky, L.S., Dunbar, D.A., Wang, P.P., Beaune, P., Larrey, D., Guengerich, F.P., Schnellemann. R.G., and Sipes, I.G., 1984, Human hepatic cytochrome P-450 composition as probed by in vitro microsomal metabolism of warfarin. Drug Metab. Dispos. 12: 470-477.

Kaminsky, L.S., and Guengerich F.P., 1985, Cytochrome P-450 isozyme/isozyme functional interactions and NADPH-cytochrome P-450 reductase concentrations as factors in microsomal metabolism of warfarin. Eur. J. Biochem. 16: 479-489.

Kelly, J.G., and O'Malley, K., 1979, Clinical phanmacokinetics of oral anticoagulants.

Clin. Pharmacokin. 4: 1-15.

Lewis, R.J., Trager, W.F., Chan, K.K., Breckenridge, A., Orme, M., Garland, M., and Schary, W., 1974, Warfarin. Stereochemical aspects of its metabolism and the interaction with phenylbutazone. J. Clin. Invest. 53: 1607-1617.

Lowry, O.H., Rosebrough, N.J.. Farr, A.L., and Randall, R.J., 1951, Protein measurement with the Folin phenol reagent. J. Biol. Chem. 193: 265-275.

Macleod S.M., Renton K.W.. and Eade N.R., 1973, Post mortem characteristics of the hepatic microsomal drug oxidizing enzyme system. Chem.-Biol. Interact. 7: 29-37.

Miners, J.O., Smith, K.J., Robson, R.A., McManus. M.E., Veronese M.E., and Birketl. D.J., 1988. Tolbutamide hydroxylation by human liver microsomes. Biochem. Pharmacol. 37: 1137-1144.

Nebert, D.W., and Gonzalez. F.J. 1987, P450 genes: structure, evolution, and regulation.

Ann. Rev. Biochem. 56: 945-993. 
Nebert, D.W., Nelson, D.R., Coon, M.J., Estabrook, R.W., Feyereisen, R., Fujii-Kuriyama, Y., Gonzalez, F., Guengerich, F.P., Gunsalus, I.C., Johnson, E.F., Loper, J.C., Sato, R., Waterman, M.R., and Waxman, D.J., 1991, The P450 superfamily: update on new sequences, gene mapping, and recommended nomenclature. DNA Cell Biol. 10: 1-14,

Pohl, L.H., Bales, R., and Trager, W.F., 1976, Warfarin: stereochemical aspects of its metabolism in vivo in the rat. Res. Comm. of Chem. Pathol. Pharmacol. 15: 233-255.

Pohl, L.R., Ponter, W.R., and Trager, W.F., 1977, Stereochemical biotransformation of warfarin as a probe of the homogeneity and mechanism of microsomal hydroxylases. Biochem. Pharmacol. 26: 115-120.

Powell, M.L., Pope, B., Elmer, G.W., and Trager, W.F., 1977, Biliary excretion of warfarin metabolites and their metabolism by rat gut flora. Life Sci. 20: 171-178.

Rane A., Wilkinson G.R., and Shand D.G., 1977, Prediction of hepatic extraction ratio from in vitro measurement of intrinsic clearance. J. Pharmacol. Exp. Ther. 200: 420-424.

Rendic, S., Kajfez, F., and Ruf, H-H, 1983, Characterization of cimetidine, ranitidine, and related siruciures' interaction with cytochrome P-450. Drug Metab. Dispos. 11: 137-142.

Rettie, A.E., Eddy. C., Heimark, L.D., Gibaldi, M., and Trager, W.F., 1989. Characteristics of warfarin hydroxylation by human liver microsomes. Drug Metab. Dispos. 17: 265-270.

Rettie. A.E., Korzekwa, K.R., Kunze, K.L., Lawrence, R.F., Eddy C.G., Aoyama, T., Gelboin, H.V., Gonzalez, F.J., and Trager, W.F., 1992, Hydroxylation of warfarin by human cDNAexpressed cytochrome P-450: A role for cytochrome P-4502C9 in the etiology of (S)-warfarin-drug interactions. Chem. Res. Tox. 5: 54-59,

Rutten, A.J.J.L., Flake, H.E., Catsburg, J.F., Topp. R., Blaauboer, B.J., v. Holsteijn, I.. Doom. L., and v. Leeuwen, F.R.X., 1987, Interlaboratory comparison of total cy tochrome P-450 and protein determinations in rat liver microsomes. Arch. Toxicol. 61: 27-35.

Sachs, L., 1984, Angewandte Statistik, sixth edition, pp 381-426, Berlin : Springer-Verlag.

Testa, B., 1988. Substrate and product stereoselectivity in monooxygenase-mediated drug activation and inactivation. Biochem. Pharmacol. 37: 85-92.

'Thijssen. H.H.W... and Baars, L.G.M.. 1987. The biliary excretion of acenocoumarol in the rat: stereochemical aspects. J. Pharmac. Pharmacol. 39: 655-657.

Thijssen. H.H.W., Baars, L.G.M., and Drittij-Reijnders, M.J., 1985, Stereoselective aspects in the pharmacokinetics and pharmacodynamics of acenocoumarol and its amino and acetamido derivatives in the rat. Drug Metah. Dispos. 13: 593-597.

Thijssen. H.H.W., Jansen. G.M.J., and Baars, L.G.M., 1986, Lack of effect of cimetidine on pharmacodynamics and kinetics of single oral doses of $\mathrm{R}$ - and $\mathrm{S}$ - acenocoumarol. Eur. J. Pharmacol. 30: $619 \cdot 623$.

Trager. W.F., Lewis. R.J., and Garland. W.A.. 1970. Mass spectral analysis in the identification of human metabolites of warfarin. J. Med. Chem. 13: 1196-1204.

Valente. E.J., and Trager, W.F., 1978. Anomalous chiroptical properties of warfarin and phenprocoumon. J. Med. Chem. 21: 141-143.

Waxman. D.J.. Lapenson, D.P.. Park, S.S., Attisano, C., and Gelboin. H.V., 1987, Monoclonal antibodies inhibitory to rat hepatic cytochromes $\mathrm{P}-450: \mathrm{P}-450$ form specificities and use as probes for cytochrome P-450 dependent steroid hydroxylations. Mol. Pharmacol. 32: 616-624.

West, B.D.. Preis, S.. Schroeder. C.H., and L.ink. K.P., 1961, Studies on the 4-hydraxycoumarins. XVIl. The resolution and absolute configuration of warfarin. Biochem. Pharmacol. 83: $2676-2679$. 
Wheeler, C., Trager, W.F., and Porter, W.R., 1981, Stereochemical aspects of the metabolism of phenprocoumon in rat liver microsomes. Biochem. Pharmacol. 30: 1785-1790.

Williams, K., and Lee, E., 1985, Importance of drug enantiomers in clinical pharmacology. Drugs 30: 333-354.

Yacobi, A., and Levy, G., 1974, Pharmacokinetics of the warfarin enantiomers in rats. $J$. Pharmacokin. Biopharm. 2: 239-255.

Yacobi, A., and Levy, G., 1977, Protein binding of warfarin enantiomers in serum of humans and rats. J. Pharmacokin. Biopharm. 5: 123-131. 


\section{CHAPTER 4:}

\section{COMPARATIVE BIOTRANSFORMATION OF WARFARIN ANALOGUES IN HUMAN LIVER MICROSOMES: 4'-SUBSTITUTION MODIFIES CYTOCHROME P450 ISOZYME SELECTIVITY.}

\subsection{ABSTRACT:}

Human liver microsomal metabolism of warfarin and acenocoumarol (4'- nitrowarfarin) has been studied. The effect of cimetidine, propafenone, and sulfaphenazole on their metabolism has been investigated in microsomes from 5 subjects.

For S-warfarin, formation of the 7-hydroxy metabolite is the main metabolic route; 6-hydroxylation and SS-alcohol formation are relatively minor routes. $50 \%$ of the metabolic clearance of R-warfarin is due to 6-hydroxylation, the other $50 \%$ mainly to 4 - and 7 -hydroxylation. The enantioners of acenocoumarol are hydroxylated at the 7-and 6-position.

Acenocoumarol is a better substrate for human liver cytochromes P450 than warfarin itself. This is due to differences in $\mathrm{Km}$ values that are 4.5 to 23 times lower for $\mathrm{R}$-acenocoumarol and 5 to 28 times lower for $\mathrm{S}$-acenocoumarol. Human liver microsomal warfarin and acenocoumarol metabolism is stereoselective for the $\mathrm{S}$-enantiomer: the $\mathrm{S} / \mathrm{R}$ ratio of the intrinsic clearances is about 3 for warfarin and about 30 for acenocoumarol.

The 6- and 7-hydroxylation rates of the R-enantiomer correlate significantly with those of the Senantiomer for acenocoumarol but not for warfarin. The 6- and 7-hydroxylation of S-acenocoumarol do not correlate with the 6-and 7-hydroxylation of S-warfarin. The same is true for the. 6-hydroxylation of the R-enantiomers, but not for the 7-hydroxylation of the R-enantiomers, which correlates significantly.

Cimetidine partly inhibits the 6-and 7-hydroxylation of only the R-enantiomers of warfarin and acenocoumarol up to $40 \%$. Propafenone inhibits the 6- and 7-hydroxylation of acenocoumarol nonstereoselectively up to $40 \%$. In contrast, only the 7-hydroxylation of R-warfarin is inhibited by propafenone to about $40 \%$. Sulfaphenazole stereoselectively inhibits the 7-hydroxylation of Swarfarin almost completely and in some microsomal samples also inhibits the 6-hydroxylation of S-warfarin toabout $50 \%$. In contrast, sulfaphenazole inhibits the 7-hydroxylation of both acenocoumarol enantiomers, and the 6-hydroxylation of the S-enantiomer up to about $75 \%$. In all these cases, sulfaphenazole has similar Ki values. This may indicate the involvement of P450 isozymes of the 2C subfamily in the 6-and 7-hydroxylation of S-warfarin and S-acenocoumarol as well as in the 7hydroxylation of R-acenocoumarol. However, the lack of a correlation between warfarin and acenocoumarol hydroxylation as well as the differential effect of the inhibitors tested, indicates that the set of P450 isozymes metabolizing warfarin is not identical to that metabolizing acenocoumarol.

The results suggest that the phenyl group of warfarin is involved in the interaction with the P450 binding sites and that ring substitution additionally discriminates for particular isozymes of this class of enzymes.

Submitted for publication (1992). J.J.R. Hermans and H.H.W. Thijssen, 


\subsection{INTRODUCTION:}

The oral anticoagulants warfarin and acenocoumarol (the 4'-nitro analogue of warfarin) are administered as racemates. Although structurally related, warfarin and acenocoumarol display great differences in theirpharmacokinetics. In man, the enantiomers of acenocoumarol are eliminated much faster than the enantiomers of warfarin. In addition, the ratio of elimination of the $\mathrm{S}$ - over the $\mathrm{R}$-enantiomer of acenocoumarol is much more pronounced (the S/R ratio is about 10 versus 1.5 for warfarin) (Thijssenet al 1986; Kelly and O' Malley, 1979). E.g. elimination half lifes are about 35-58 and 24-33 hours for S- and R-warfarin (Kelly and O'Malley, 1979), whereas elimination half lifes of S- and R-acenocoumarol are 0.5-1 and 810 hours (Thijssen et al, 1986). Since both 4-hydroxycoumarins are eliminated by biotransformation, the pharmacokinetic differences may be explained by disparity in the metabolism of these compounds. The enantiomers of warfarin have been shown to follow different metabolic routes in man (Lewis et al, 1974; Banfield et al, 1983; Toon et al, 1987). The S-enantiomer is mainly hydroxylated to form 7-hydroxywarfarin, whereas R-warfarin is mainly reduced to its RS alcohol and hydroxylated at the 6-position. The enantiomers of acenocoumarol are hydroxylated at the 7-and, to a lesser extent, the 6-position to form 7-or 6-hydroxyacenocoumarol respectively (Thijssen et al, 1986).

In previous studies from this laboratory, it was shown that substitution at the phenyl ring of warfarin has a great impact on the pharmacokinetics and the stereoselectivity thereof in the rat (Thijssen et al, 1985; chapter 2). As shown in chapter 2, substitution of the 4'-hydrogen did not only enhance the intrinsic clearance but also led to a marked inversion of the stereoselectivity for the S-enantiomers. In contrast, 3'-subtituted warfarins were cleared stereoselectively for the R-enantiomers. In chapter 3 , using rat livermicrosomes, it was found that warfarin and acenocoumarol follow similar metabolic routes but with $\mathrm{Km}$ values that are 2 to 20 times lower for acenocoumarol. Furthermore, based on the differential effects of enzyme inducers, the P450 inhibitor cimetidine, and P450 antibodies, it was stated that the kinetic differences between warfarin and acenocoumarol can be partly attributed to the involvement of different sets of P450 isozymes in the metabolism of both 4-hydroxycoumarins. To study whether this is also true in man, the human liver microsomal metabolism of warfarin has been compared with that of its 4'-nitro analogue (acenocoumarol). Furthermore, the effect on the human liver microsomal metabolism of warfarin and acenocoumarol of three drugs (cimetidine, propafenone, and sulfaphenazole) has been described. The aspecific P450 inhibitor cimetidine was chosen since it is known to decrease the clearance of the Renantiomer of warfarin in man (Choonara et al, 1986). Sulfaphenazole, because this compound is reported to be a potent inhibitor of human liver cytochrome $\mathrm{P} 4502 \mathrm{C} 9$ mediated S-warfarin 7-hydroxylation (Rettie et al, 1991). Propafenone was chosen because, although this compound is shown to decrease the clearance of warfarin in man (Kates et al, 1987), information on stereochemical aspects is still lacking.

The results show that, as in rat, 4'-substituted warfarins in humans are metabolized by different, but probably overlapping sets of liver P450 iso\%ymes. 


\subsection{MATERIALS AND METHODS:}

Racemic warfarin and racemic propafenone (as the $\mathrm{HCl}$ salt) were obtained from Sigma Chemicals (St. Louis, USA), Acenocoumarol as well as 6- and 7-hydroxyacenocoumarol were a kind gift of Ciba-Geigy (Basel. Switzerland). Cimetidine was from Smith, Kline and French Laboratories (Welwyn Garden City, UK). Sulfaphenazole was kindly provided by Dr. Vree (Dept. Clin. Pharmacy, Univ. Hospital, Nijmegen, the Netherlands). All other chemicals were of analytical grade and were obtained from Merck (Darmstadt, West Germany) unless stated otherwise.

Warfarin and acenocoumarol enantiomers were prepared as described in chapter 2 .

\section{Preparation of microsomal fractions:}

Human liver samples (table 4.1) were obtained from kidney donors (I,II, and V) or were obtained post mortem (III, and IV). The use of human liver for the study had the approval of the Ethics Committee of the University Hospital. Liver samples were stored at $-80^{\circ} \mathrm{C}$ until processing. Data on liver sample sources are shown in table 4.1. Microsomes were prepared as described in chapter 3. The final microsomal pellet was resuspended in Tris- $\mathrm{KCl}-\mathrm{NaCl}$ buffer $(0.02 \mathrm{M}, 0.15 \mathrm{M}$ and $1.0 \mathrm{M}$. respectively; $\mathrm{pH}=7.4)$ to contain about $20 \mathrm{mg}$ protein per mil homogenate.

\section{Assay for warfarin and acenocoumarol metabolism:}

The assay of warfarin and acenocoumarol metabolism was conducted essentially as previously described in chapter 3. Microsomal fractions were incubated in the presence of a NADPH-generating system at $37^{\circ} \mathrm{C}$ for $15-60 \mathrm{~min}$ in test tubes. The incubation mixture consisted of 0.5 to $1.0 \mathrm{mg}$ microsomal protein, substrate. $7.4 \mathrm{mM}$ glucose 6-phosphate, 2.4 $\mathrm{mM} \mathrm{MgCl}$, and $1.0 \mu$ unit of glucose 6-phosphate dehydrogenase, $0.5 \mathrm{mM} \mathrm{NADPH}$, and 2. mM NADP+.

Metabolite formation rates and the inhibitor effect for the various microsomal preparations were determined at substrate concentrations of $25 \mu \mathrm{M}$ and $100 \mu \mathrm{M}$ and incubation times of 30 and 60 minutes for acenocoumarol and warfarin enantiomers respectively. Inhibitor concentrations were $25 \mu \mathrm{M}$ (sulfaphenazole), $100 \mu \mathrm{M}$ (propafenone), and $1000 \mu \mathrm{M}$ (cimetidine). Before the reactions were started by addition of substrate, complete reaction mixiures, containing microsomes. NADPH-generating system and inhibitor (or an equal volume of buffer in the controls) were preincubated for 15 minutes at $37^{\circ} \mathrm{C}$.

The enzyme kinetic parameters of the metabolism of acenocoumarol enantiomers by liver microsomes were determined at substrate concentrations ranging from 1 to $250 \mu \mathrm{M}$ and an incubation time of 15 minutes. The enzyme kinetic parameters of warfarin metabolism were determined at substrate concentrations of 25 to $800 \mu \mathrm{M}$ (R-enantiomer) and 2.5 to $400 \mu \mathrm{M}$ (S-enantiomer) and an incubation time of 30 minutes. Incubation mixtures were preincubated for 15 minutes at $37^{\circ} \mathrm{C}$ before starting the reaction by the addition of substrate.

Determination of $\mathrm{Ki}$ values and types of inhibition were tested at R/S acenocoumarol concentrations of 2.5-25 $\mu \mathrm{M}$. S-warfarin concentrations of $50-400 \mu \mathrm{M}$, and R-warfarin 
concentrations of $100-400 \mu \mathrm{M}$. Inhibitor concentrations ranged from $1-25 \mu \mathrm{M}$ for sulfaphenazole, $25-250 \mu \mathrm{M}$ for propafenone, and 50-600 $\mu \mathrm{M}$ for cimetidine.

The metabolites were analyzed by HPLC as described in chapter 3. Protein content was determined by the method of Lowry et al (1951). Cytochrome P450 content was determined by the DT-difference method as described by Rutten et al (1987). 7-Ethoxycoumarin deethylase and aniline-p-hydroxylase activity was determined as described by Greenlee and Poland (1978) and Macleod et al (1973).

\section{Statistical analysis of the data:}

$V \max$ and $\mathrm{Km}$ values were determined by fitting the Michaelis-Menten equation to the data using the GPAD (GraphPAD Software, San Diego, USA) software package. Ki values and inhibition mechanisms were determined by the use of Dixon plots and double reciprocal plots respectively. The effect of the inhibitors on the 6- and 7-hydroxylation of warfarin and acenocoumarol was tested for significance by the use of a oneway ANOVA and least significant differences (LSD) were calculated. Spearman rank correlation coefficients were tested for significance by transformation to the Students t-distribution (Sachs, 1984).

TABLE 4.1: Information on the subjects from which liver samples were obtained.

$\begin{array}{lllll}\text { Code } & \text { Sex } & \text { Age } & \text { Death cause } & \text { Drug History } \\ \text { I } & \text { male } & 52 & \text { Traffic accident } & \\ \text { II } & \text { male } & 18 & \text { Traffic accident } & \\ \text { III } & \text { female } & 36 & \text { Subarachnoidal bleeding } & \\ \text { IV } & \text { female } & 61 & \text { Brain damage } & \text { Alcohol abuse } \\ \text { V } & \text { male } & 57 & \text { Brain tumour } & \text { Propranolol }\end{array}$

TABLE 4.2: Cytochrome P450 content, 7-ethoxycoumarin- (7-EC-) deethylase activity, and aniline-p- (An-p-) hydroxylase activity in the human liver microsomal preparations used.

$\begin{array}{lccr}\text { Code } & \begin{array}{c}\text { [P450] } \\ (\mathbf{n m o l} / \mathrm{mg})\end{array} & \begin{array}{c}\text { 7-EC-deethylase } \\ (\mathbf{n m o l} / \mathrm{mg} \times \mathrm{min})\end{array} & \begin{array}{r}\text { An-p-hydroxyl } \\ (\mathrm{nmol} / \mathrm{mg} \times \text { }\end{array} \\ \text { I } & 0.45 \pm 0.07 & 0.24 \pm 0.01 & 2.1 \pm 0.6 \\ \text { II } & 0.45 \pm 0.15 & 0.14 \pm 0.01 & 2.5 \pm 0.3 \\ \text { III } & 0.74 \pm 0.06 & 0.21 \pm 0.01 & 1.1 \pm 0.6 \\ \text { IV } & 0.40 \pm 0.12 & 0.21 \pm 0.01 & 1.5 \pm 0.4 \\ \text { V } & 0.51 \pm 0.13 & 0.22 \pm 0.04 & 2.0 \pm 0.8\end{array}$

Data are expressed as the mean \pm SD of three determinations. Cytochrome P450 content is given in nmol per mg microsomal protein. Enzyme activities are expressed as nmol of product formed per minute per mg microsomal protein. 


\subsection{RESULTS:}

Standard parameters of the human liver samples are shown in table 4.2. The obtained values are in the range of data reported in other studies (Beaune et al, 1986).

In order to obtain information on the relative contribution of the metabolites formed from warfarin and acenocoumarol the enzyme kinetic parameters $\mathrm{Vmax}, \mathrm{Km}$, and intrinsic formation clearances (Cli) have been determined for sample I (table 4.3). Next to the metabolites shown in table 4.3, small amounts of the 10-hydroxy metabolites, and the RRand RS-alcohols are found. Remarkably, in contrast to 8-hydroxyacenocoumarol, only small amounts of 8-hydroxywarfarin are found. The 9-hydroxy- and dehydro metabolites of acenocoumarol are only detected in small amounts at the highest substrate concentrations.

Table 4.3 shows that the Vmax values of the metabolite formation rates are 1.5 (4: hydroxywarfarin) to 24 (6-hydroxywarfarin) times higher for R-warfarin than for S-warfarin, except for the dehydro- metabolite. Apart from 4'-hydroxylation, $\mathrm{Km}$ values are 1.4 (9. hydroxywarfarin) to 65 (7-hydroxywarfarin) times higher for R-warfarin.

Based on intrinsic clearances, the formation of 7-hydroxywarfarin and dehydrowarfarin is stereoselective for the $\mathrm{S}$-enantiomer, since the intrinsic clearances are 14 and 10 times higher for S-warfarin. The 4'- and 6-hydroxylation of warfarin appear non-stereoselective, whereas 9-hydroxylation is stereoselective for $\mathbf{R}$-warfarin (intrinsic clearance 2.2 -fold that of $\mathbf{S}$ warfarin).

For acenocoumarol, Vmax values of the 6- and 8-hydroxylation are about 4 times higher for the R-enantiomers, whereas the Vmax value of the 7-hydroxylation is about 2.3 times higher for the S-enantiomer. The $\mathrm{Km}$ values of $\mathrm{R}$-acenocoumarol are 14 (8-hydroxy metabolite) to 120 (7-hydroxy metabolite) times higher than those of S-acenocoumarol.

If intrinsic clearances are considered, the formation of the acenocoumarol metabolites is stereoselective for the S-enantiomer. Intrinsic clearances are 3.5 (8-hydroxyacenocoumarol) to 36 (7-hydroxyacenocoumarol) times higher for S- than for R-acenocoumarol.

From table 4.3, it is clear that the overall microsomal metabolism of warfarin and its 4'nitro analogue is stereoselective for the S-enantiomer. However, the S/R ratio of the total intrinsic clearance is much higher for acenocoumarol (with a $S / R$ ratio of about 30) than for warfarin ( $S / R$ about 3.5). Furthermore, the total intrinsic clearances of the enantiomers of acenocoumarol are considerably higher than those of the corresponding warfarinenantiomers. Intrinsic clearances of R- and S-acenocoumarol are 9 and 80 times higher than those of Rand S-warfarin. The main reason for this is that the $\mathrm{Km}$ values of the acenocoumarol enantiomers are about 5-28 times lower than those of the enantiomers of warfarin itself.

Next to differences in total intrinsic clearances and in stereochemistry, there are clear differences in the regioselectivity. For S-warfarin, 7-hydroxylation is by far the most important metabolic route that accounts for about $70 \%$ of intrinsic clearance, whereas 6hydroxylation (about $10 \%$ of intrinsic clearance) and formation of the SS alcohol (about 10 $\%$ of intrinsic clearance) are relatively minor routes. In contrast, in the case of R-warfarin, formation of the 6-hydroxy metabolite accounts for $50 \%$ of total metabolic clearance. 
TABLE 4.3: Enzyme kinetics of the human liver (sample I) microsomal metabolism of the enantiomers of warfarin and acenocoumarol.

\begin{tabular}{|c|c|c|c|c|}
\hline R-WARFARIN & $\begin{array}{l}V_{\max } \\
(\mathrm{pmol} / \mathrm{mg} \text { gumin) }\end{array}$ & $\underset{(\mu \mathrm{M})}{\mathrm{Km}}$ & $\begin{array}{l}\mathrm{Cli}^{*} \\
\text { (nl/mgxmin) }\end{array}$ & $\begin{array}{l}\mathrm{Cli}_{\text {(\% total) }} \\
\text { (\% }\end{array}$ \\
\hline 4'-hydroxy & 3.76 & 370 & 10.2 & 20.9 \\
\hline 6-hydroxy & 13.8 & 585 & 23.6 & 48.5 \\
\hline 7-hydroxy & 2.94 & 336 & 8.8 & 18.1 \\
\hline 9-hydroxy & 18.7 & 3277 & 5.7 & 11.7 \\
\hline dehydro- & 2.4 & 3619 & 0.4 & 0.8 \\
\hline total \# & & & 48.7 & 100 \\
\hline S-WARFARIN & $\begin{array}{l}\text { Vmax } \\
\text { (pmol/mgxmin) }\end{array}$ & $\begin{array}{l}\mathrm{Km} \\
(\mu \mathrm{M})\end{array}$ & $\begin{array}{l}\mathrm{Cli} \\
\text { (n1/ngxmin) }\end{array}$ & $\begin{array}{l}\text { Cli } \\
\text { (\% total) }\end{array}$ \\
\hline $4^{\prime}$-hydroxy & 2.71 & 371 & 7.3 & 4.4 \\
\hline 6-hydroxy & 0.55 & 30 & 18.3 & 11.0 \\
\hline 7-hydroxy & 0.62 & 5.2 & 120 & 71.9 \\
\hline 9-hydroxy & 0.41 & 159 & 2.6 & 1.6 \\
\hline dehydro- & 9.79 & 2444 & 4.0 & 2.4 \\
\hline SS-alcohol & 5.01 & 340 & 14.7 & 8.8 \\
\hline total & & & 167 & 100 \\
\hline R-ACENOCOUMAROL & $\begin{array}{l}\text { Vmax } \\
\text { (pmol/mgxmin) }\end{array}$ & $\begin{array}{l}\mathrm{Km} \\
(\mu \mathrm{M})\end{array}$ & $\begin{array}{l}\mathrm{Cli} \\
\text { (nl/mgxmin) }\end{array}$ & $\begin{array}{l}\text { Cli } \\
\text { (\% total) }\end{array}$ \\
\hline 6-hydroxy & 20.6 & 131 & 157 & 35 \\
\hline 7-hydroxy & 3.4 & 14.4 & 236 & 52.6 \\
\hline 8-hydroxy & 2.2 & 39.4 & 55.8 & 12.4 \\
\hline total & & & 449 & 100 \\
\hline S-ACENOCOUMAROL & $\begin{array}{l}V \max \\
\text { (pmol/mgxmin) }\end{array}$ & $\mathrm{Km}_{(\mu \mathrm{M})}$ & $\begin{array}{l}\mathrm{Cli} \\
\text { (nل/mgxmin) }\end{array}$ & $\begin{array}{l}\text { Cli } \\
\text { (\% total) }\end{array}$ \\
\hline 6-hydroxy & 4.97 & 1.11 & 4477 & 33.7 \\
\hline 7-bydroxy & 7.95 & 0.93 & 8548 & 64.3 \\
\hline 8-hydroxy & 0.56 & 2.83 & 198 & 1.5 \\
\hline SS-alcohol & 27.0 & 394 & 69 & 0.5 \\
\hline total & & & 13292 & 100 \\
\hline
\end{tabular}

'Intrinsic clearance $\mathrm{Cli}=\mathrm{Vmax} / \mathrm{Km}$ "total= sum of Cli's 
The other $50 \%$ are accounted for by formation of the 7-, 4'-, and 9-hydroxy metabolites.

For R- and S-acenocoumarol, 7-hydroxylation accounts for 53 and $64 \%$ of the total metabolic clearance, whereas 6-hydroxylation accounts for about $35 \%$.

Since the 6-and 7-hydroxylation appear to be the main metabolic routes of warfarin and acenocoumarol in human liver microsomes, the other experiments were mainly focussed on these reactions. Figures 4.1 and 4.2 show the rates of the 6- and 7-hydroxylation of both warfarin and acenocoumarol enantiomers in 5 human liver microsomal samples.

Figure 4.1: Rates of formation of the 6-hydroxy metabolites of the enantiomers of warfarin (left) and acenocoumarol in 5 human liver microsomal preparates.
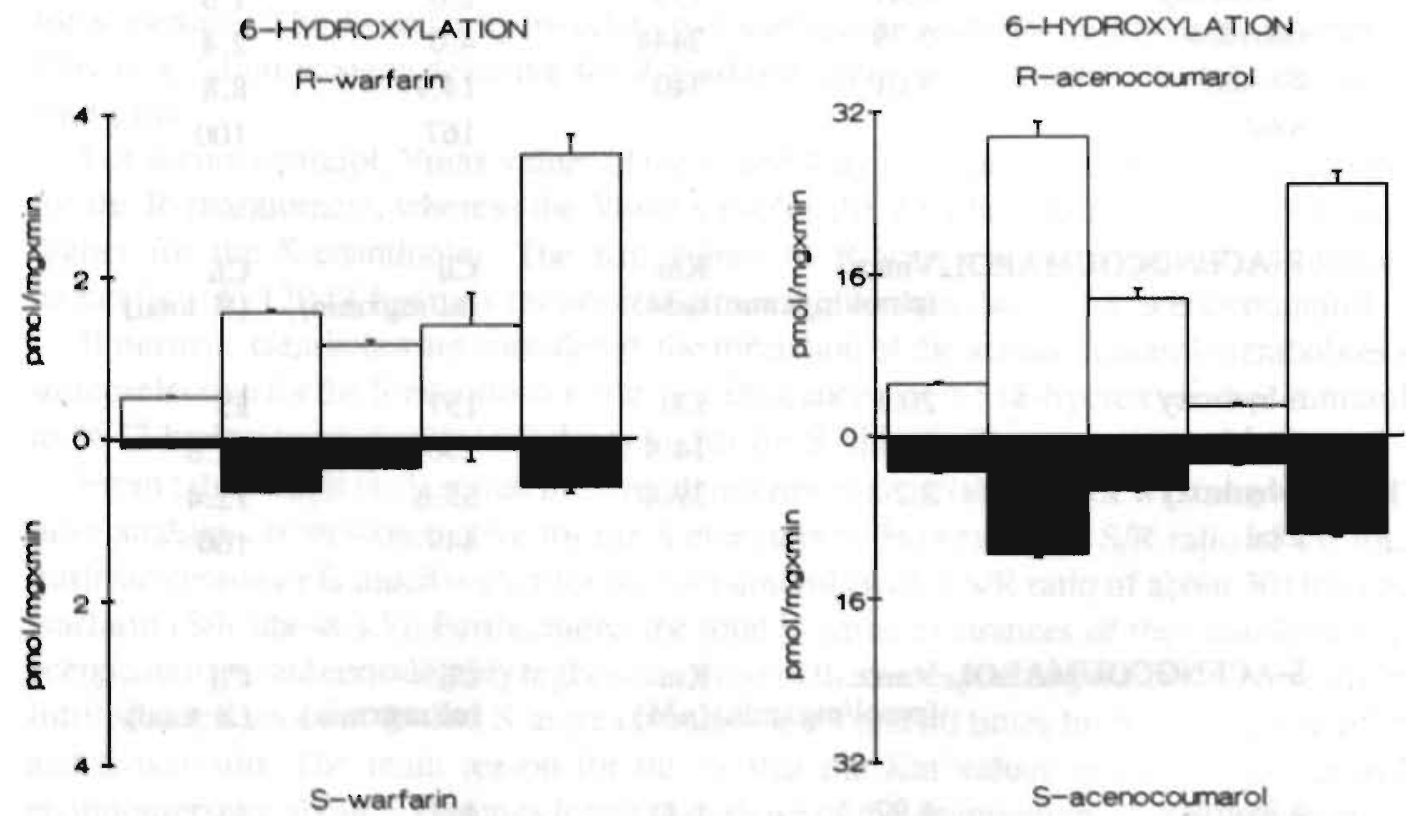

Data are expressed as the mean (pmol metabolite/ $\mathrm{mg}$ protein $\mathrm{x}$ min) $\pm \mathrm{SEM}$ of two incubations. The five sets of bars represent microsomal fraction I (left) to $\mathrm{V}$ (right).

Open bars: R-enantiomers; cross hatched bars: S-enantiomers. 
Figure 4.2: Rates of formation of the 7-hydroxy metabolites of the enantiomers of warfarin (left) and acenocoumarol in 5 human liver microsomal preparates.

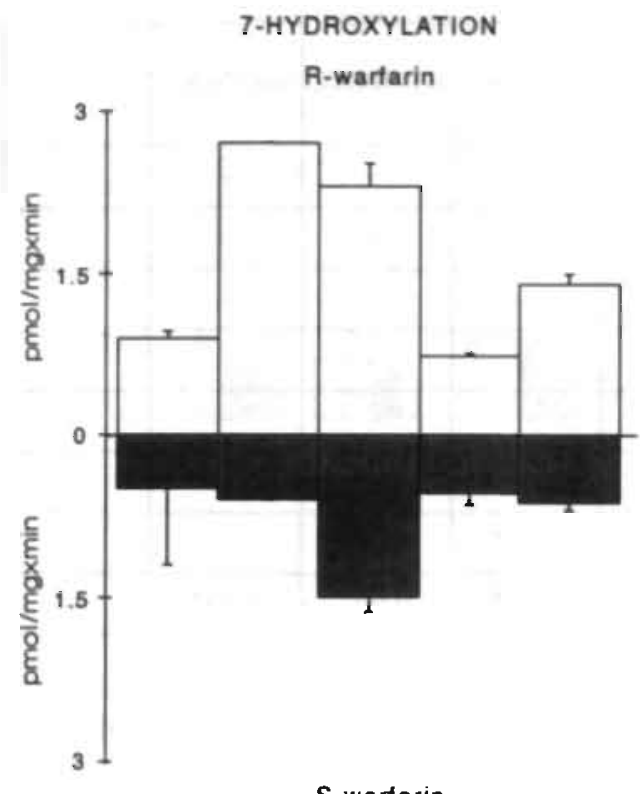

S-wartarin

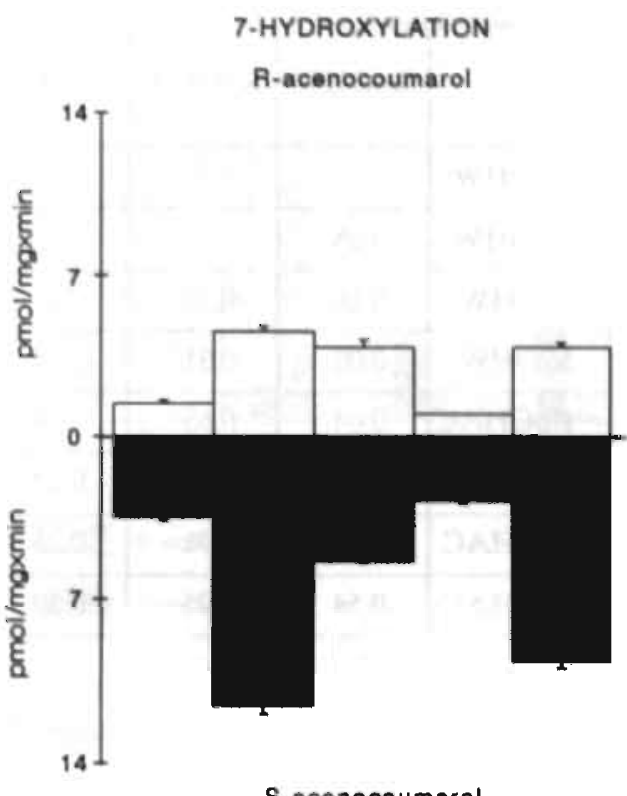

S.acenocoumarol

Data are expressed as the mean rate (pmol metabolite/ $\mathrm{mg}$ protein $\mathrm{x}$ min) $\pm S E M$ of two incubations. The five sets bars of represent microsomal fraction I (left) to V (right).

Open bars: R-enantiomers; cross hatched bars: S-enantiomers.

The formation rates of 6-hydroxywarfarin ranged 7 -fold $(0.5$ to $3.5 \mathrm{pmol} / \mathrm{mg} x \mathrm{~min}$.) for $\mathrm{R}$ warfarin and 11 fold for S-warfarin $(0.12$ to $1.3 \mathrm{pmol} / \mathrm{mg}$ protein $\mathrm{x}$ min.) among the microsomal preparations. The 6-hydroxylation of R-acenocoumarol ranged 10 fold ( 3 to 30 $\mathrm{pmol} / \mathrm{mg} \mathrm{x} \mathrm{min),} \mathrm{whereas} \mathrm{that} \mathrm{of} \mathrm{S-acenocoumarol} \mathrm{ranged} \mathrm{only} 4$-fold (3 to $12 \mathrm{pmol} / \mathrm{mg} \mathrm{x}$ $\mathrm{min}$ ). The 6-hydroxylation rate of both 4-hydroxycoumarins is higher for the $\mathrm{R}$ - than for the S-enantiomers at the substrate concentrations chosen. This is probably due to the higher $\mathrm{V}$ max values of the R-enantiomers (table 4.3). However, during therapy, blood levels range from 1 to $10 \mu \mathrm{M}$ for warfarin (Holford, 1986) and from 60 to $600 \mathrm{nM}$ for acenocoumarol (Thijssen et al, 1988). The concentration of the unbound drugs will be even lower. Therefore, intrinsic clearances rather than Vmax values will give an indication of the metabolic profile in vivo, since in this parameter, differences in $\mathrm{Km}$ values are accounted for.

The 7-hydroxylation of all substrates appears to be less variable among the microsomes than the 6-hydroxylation. Formation rates of the 7-hydroxy metabolite range 3 to 4 fold. 7Hydroxylation rates are generally lower for the S-enantiomer of warfarin $(0.5$ to $1.5 \mathrm{pmol} /$ $\mathrm{mg} \mathrm{x} \mathrm{min)} \mathrm{than} \mathrm{for} \mathrm{the} \mathrm{R-enantiomer} \mathrm{(} 0.7$ to $2.8 \mathrm{pmol} / \mathrm{mg} \mathrm{x} \mathrm{min}$ ). The opposite is true for acenocoumarol (7-hydroxylation rates vary from 1.1 to $4.5 \mathrm{pmol} / \mathrm{mg} \mathrm{xmin}$. for Racenocoumarol versus 4.2 to $13.8 \mathrm{pmol} / \mathrm{mg} \mathrm{x} \mathrm{min}$. for the S-enantiomer). 
TABLE 4.4: Correlation matrix of the 6- and 7-hydroxy metabolite formation rates of R-and $\mathrm{S}$-warfarin and -acenocoumarol in human liver microsomes from 5 subjects.

\begin{tabular}{|c|c|c|c|c|c|c|c|c|}
\hline & R6OHW & R7OHW & S6OHW & S7OHW & R6OHAC & R7OHAC & S6OHAC & S7OHAC \\
\hline R6OHW & -- & - & - & - & - & - & - & - \\
\hline R7OHW & 0.05 & - & - & - & -- & - & -- & - \\
\hline S6OHW & 0.16 & -0.37 & - & - & - & - & - & - \\
\hline S7OHW & 0.08 & 0.31 & -0.37 & - & - & - & -- & - \\
\hline R6OHAC & 0.64 & 0.65 & -0.24 & 0.03 & - & - & - & - \\
\hline R7OHAC & 0.45 & $0.90^{*}$ & 0.12 & 0.41 & $0.92^{*}$ & - & -- & - \\
\hline S6OHAC & 0.59 & 0.71 & 0.20 & 0.06 & $0.99^{*}$ & $0.89^{*}$ & - & - \\
\hline S7OHAC & 0.54 & 0.75 & 0.30 & 0.01 & $0.99^{*}$ & $0.90^{*}$ & $0.99^{*}$ & -- \\
\hline
\end{tabular}

'significant correlation $\mathrm{P}<0.025$, as determined by transformation to the Student'st-distribution.

TABLE 4.5:Inhibitor type and Ki values of the inhibition of the human liver (sample I) microsomal 6- and 7-hydroxylation of the enantiomers of warfarin and acenocoumarol by sulfaphenazole, cimetidine, and propafenone.

Inhibitor

Sulfaphenazole

Cimetidine

Propafenone

Inlibitor

Sultaphenazole

Cimetidine

Propafenone

\section{6-OH-WARFARIN}

Corap. $45 \%$

Mixed $40 \%$

R- $\quad 472 \pm 1.03$

S. n.i.

R- n.i.

S- a.i.

6-OH-ACENOCOUMAROL

R. n.i.

S. $\quad 1.3 \pm 0.3$

R- $1938 \pm 328$

S- n.i.

R- $563 \pm 97$

S= $\quad 670 \pm 170$

\section{7-OH-WARFARIN}

n.i.

$0.5 \pm 0.3 \quad$ Comp. $95 \%$

$1780 \pm 667 \quad$ Mixed $35 \%$

n.i.

$131 \pm 22 \quad$ Mixed $40 \%$

n.i.

7-OH-ACENOCOUMAROL

$\begin{array}{ll}1.0 \pm 0.4 & \text { Comp. 70\% } \\ 1.2 \pm 0.4 & \text { Comp. 80\% } \\ 223 \pm 25 & \text { Comp. 40\% } \\ & \end{array}$

$23.1 \pm 22 \quad$ Mixed $40 \%$

$236 \pm 79 \quad$ Mixed $40 \%$

Ki values are given as mean (in $\mu \mathrm{M}) \pm$ standard deviation calculated from all intersections of the obtained lines in Dixon plots. n.i., no inhibition as determined by one-way ANOVA. Comp., indicates competitive inhibition. Mixed, indicates mixed type inhibition.

Types of inhibition were determined from double reciprocal plots. Percentages indicate the maximal inhibition at the lowest substrate and highest inhibitor concentrations used. 
Figure 4.3; Inhibition of the 6- (above) and 7-hydroxylation of the enantiomers of warfarin and acenocoumarol by sulfaphenazole, propafenone, and cimetidine.

6-Hydroxylation

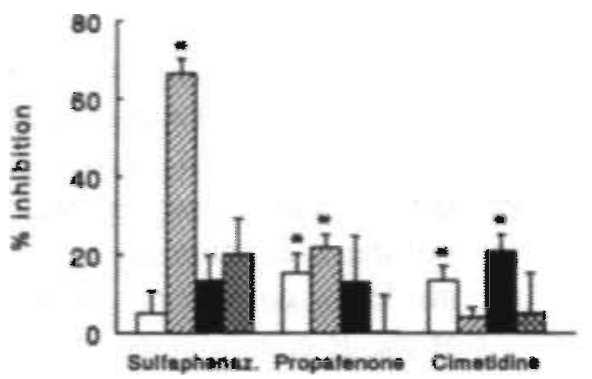

7-Hydroxylation

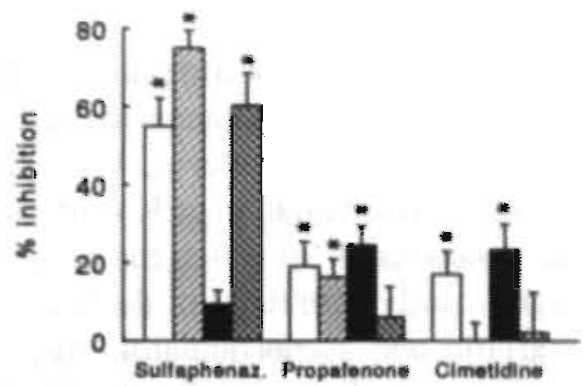

Inhibitor concentrations were : sulfaphenazole : $25 \mu \mathrm{M}$, propafenone: $100 \mu \mathrm{M}$, and cimetidine 1000 $\mu \mathrm{M}$. The concentration of warfarin and acenocoumarol enantiomers were 100 and $25 \mu \mathrm{M}$ respectively. Data are expressed as the mean $\pm \mathrm{SE}$ of 5 human microsomal samples. * Indicates a significant inhibition: $\mathrm{P}<0.05$, ANOVA, LSD.

Figure 4.4: Dixon plots of the inhibition of the human liver (sample I) microsomal 7-hydroxylation of S-acenocoumarol by sulfaphenazole (graph A) and R-acenocoumarol by cimetidine and propafenone (graphs B and C).

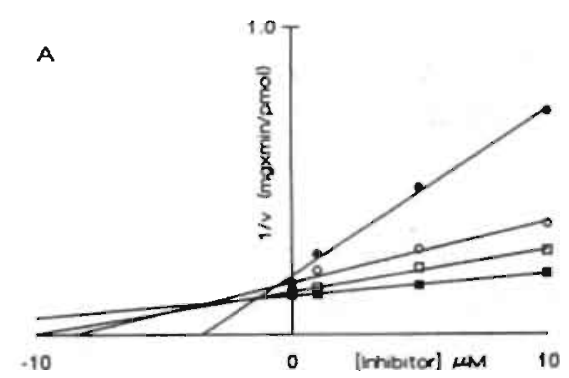

Substrate concentrations were 2.5 (closed circles), 5.0 (open circles), 10 (open squares). and $25 \mu \mathrm{M}$ (closed squares) respectively. The inhibitor concentration (the $\mathrm{X}$-axis) is given in $\mu \mathrm{M}$. The $\mathrm{Y}$ axis represents the reciprocal value of metabolite formation rates ( $\mathrm{mgxmin} / \mathrm{pmol}$ ). Lines were fitted using the least squares method.
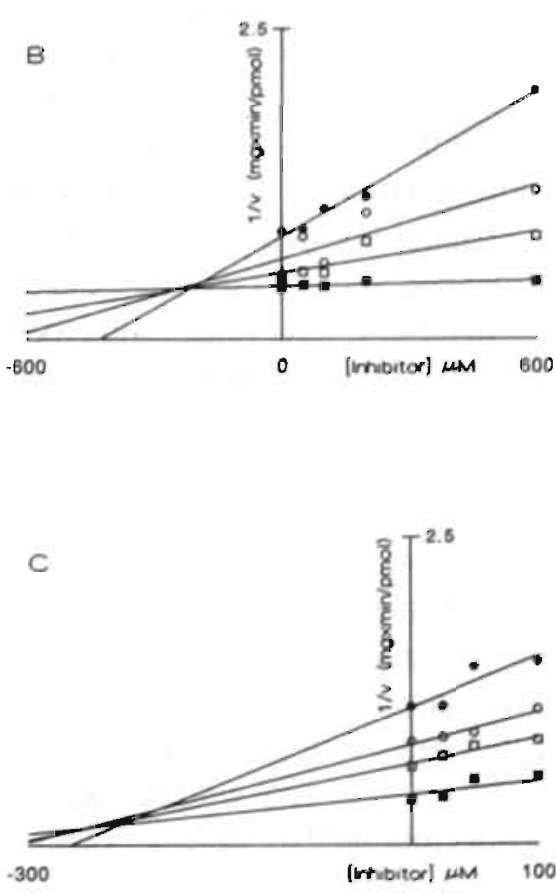
Table 4.4 shows a correlation matrix of the 6- and 7-hydroxylation rates of warfarin and acenocoumarol enantiomers in the human liver microsomes. If the correlations between the enantiomers are considered, there appears to be no clear relationship (table 4.4) between the 6- and 7-hydroxylation of R-warfarin with those of S-warfarin. This is in sharp contrast to acenocoumarol for which the 6- and 7-hydroxylation rates of the R-enantiomer correlate significantly with those of the S-enantiomer $(\mathbf{P}<0.025)$. Considering correlations between warfarin and acenocoumarol, only the 7-hydroxylations of the R-enantiomers correlate significantly $(\mathrm{P}<0.025)$. For the other reactions, there is no correlation between warfarin and acenocoumarol.

Finally, a significant correlation between the 6- and 7-hydroxylation within and between the enantiomers of acenocoumarol is observed $(\mathrm{P}<0.025)$. In contrast, these reactions do not correlate for warfarin.

The effect of sulfaphenazole, propafenone and cimetidine on the 6- and 7-hydroxylation of warfarin and acenocoumarol enantiomers by the various microsomal preparations is shown in figure 4.3. These data are presented as the mean $\%$ inhibition \pm SE. Sulfaphenazole inhibits the 6-hydroxylation of S-acenocoumarol $(\mathrm{P}<0.05)$ about $65 \%$ but has no effect on the 6-hydroxylation of R-acenocoumarol or of R-and S-warfarin. However,in the case of the 6hydroxylation of S-warfarin, there was considerable variation in the effect of sulfaphenazole, the inhibition ranging from 0 (sample V) to $50 \%$ (sample II). The rate of 7-hydroxylation is decreased significantly $(P<0.05)$ by sulfaphenazole for $R$ - and $S$-acenocoumarol (about 55 and $75 \%$ ) and for S- (about $60 \%$ ) but not R-warfarin.

Propafenone significantly $(\mathrm{P}<0.05)$ inhibits the formation of the 6- and 7-hydroxy metabolites of R- and S-acenocoumarol about $15-20 \%$. In the case of warfarin, only the 7hydroxylation of the $\mathrm{R}$-enantiomer is inhibited $(\mathrm{P}<0.05)$ about $25 \%$.

Cimetidine depresses $(\mathrm{P}<0.05)$ the 6- and 7-hydroxylation of $\mathrm{R}$-warfarin (about $25 \%$ ) and R-acenocoumarol (about 15 and $20 \%$ ) but not of the S-enantiomers.

In table 4.5. Ki values and types of inhibition of the three inhibitors for their effect on the 6- and 7-hydroxylation of warfarin and acenocoumarol are given for sample I. However, these data should be interpreted with care since the hydroxylation reactions are probably carried out by multiple P450 isozymes, some of which may not be influenced by the inhibitors. Therefore (although estimated from the linear parts of Dixon plots as shown in figure 4.4). Ki values may be overestimated, and quasi mixed type inhibition may actually be a combination of competitive inhibitions. In fact, all inhibitions appeared to be partial (with the exception of the inhibition of the 7-hydroxylation of S-warfarin by sulfaphenazole). For that reason, the maximal inhibition (in \%) at the lowest substrate and highest inhibitor concentration is given. Sulfaphenazole appears to be a competitive inhibitor of the 7-and 6hydroxylation of S-warfarin with similar $\mathrm{Ki}$ values $(0.6$ and $0.7 \mu \mathrm{M})$. The 7-hydroxylation is fully inhibited by this compound, the 6-hydroxylation to $45 \%$. In the case of acenocoumarol, 
sulfaphenazole competitively inhibits the 7-hydroxylation of both enantiomers and the 6hydroxylation of the S-enantiomer with approximately similar $\mathrm{Ki}$ values $(1.0-1.3 \mu \mathrm{M})$ and maximal inhibitions (70-80 \%).

Cimetidine appears to be a mixed type inhibitor of the 6- and 7-hydroxylation of $\mathbf{R}$ warfarin but with different $\mathrm{Ki}$ values (472 and $1780 \mu \mathrm{M}$ respectively). In the case of $\mathrm{R}$-acenocoumarol, cimetidine is a mixed type inhibitor of the 6-hydroxylation (up to $35 \%$, $\mathrm{Ki}=1938 \mu \mathrm{M}$ ) but a competitive inhibitor of the 7-hydroxylation (up to $40 \%, \mathrm{Ki}=223 \mu \mathrm{M}$ ).

Propafenone is a mixed type inhibitor of the 7-hydroxylation of $\mathrm{R}$-warfarin $(\mathrm{Ki}=131 \mu \mathrm{M})$ and of R-and S-acenocoumarol (Ki's of 231 and $236 \mu \mathrm{M}$ ) and these reactions are inhibited up to $40 \%$. Propafenone also is a mixed type inhibitor of the 6-hydroxylation of R- and Sacenocoumarol with $\mathrm{Ki}$ values of 563 and $670 \mu \mathrm{M}$ and maximal inhibitions of 40 and $30 \%$.

\subsection{DISCUSSION:}

Warfarin enantiomers are often used as a probe for cytochromes P450 (Guengerich et al, 1982; Bcaunc et al, 1986: Kaminsky, 1989). Various P450 isozymes, displaying different regio- and stereoselectivities, have been shown to be involved in the metabolism of warfarin (Guengerich et al, 1982; Rettie et al, 1992). The variety of P450 isozymes involved in warfarin metabolism is evident if the variable stereoselectivity of pharmacokinetic interactions of other drugs with warfarin is considered. Stereoselective impairment of the clearance of only the R-enantiomer (Choonara et al, 1986; Toon et al, 1987; Sutfin et al, 1989; Abemethy et al, 1991), or only the S-enantiomer (Lewis et al, 1974; O'Reilly, 1976; O'Reilly, 1980; O'Reilly, 1982; Banfield et al, 1983) has been described, as well as non-stereoselective interactions (O'Reilly et al, 1987). All of these interactions have been attributed to inhibition of the metabolism of warfarin.

In previous studies we found that substitution at the phenyl ring of warfarin drastically changes the pharmacokinetics and the stereoselectivity there of in the rat (Thijssen et al, 1985; chapter 2). 4'-Substitution greatly enhances the intrinsic clearances with a general preference for the S-enantiomer. E.g. substitution of the 4' hydrogen by a nitro-, cyano-, bromo- or chloro- group enhances the intrinsic clearances of the S-enantiomers 19 to 32 fold but enhances the intrinsic clearances of the R-enantiomers only 2 to 20 fold, as compared to warfarin. As a result the $\mathrm{R} / \mathrm{S}$ enantiomeric ratio of 1.5 for warfarip itself is shifted to 0.2-0.4 for the 4 '-substituted analogues.

This study shows that the 4 -substituent also higly influences the metabolic clearance of warfarin derivatives in human liver microsomes. The enantiomers of acenocoumarol, the 4'nitro analogue of warfarin, display higher intrinsic clearances than the corresponding enantiomers of warfarin itself. The main reason for this is that the $\mathrm{Km}$ values are 5 to 28 times 
lower for acenocoumarol than for warfarin. In addition, the stereoselectivity for the Senantiomer is much more pronounced for acenocoumarol. Interestingly, for 4 '-chlorowarfarin, we also found that the microsomal metabolic clearance is much higher ( 12 and 120 fold for the $\mathbf{R}$ - and S-enantiomers) than that of warfarin, and that the $\mathrm{S} / \mathrm{R}$ ratio is 10 times higher (own observations).

The observed pattems of warfarin and acenocoumarol clearance are in good agreement with those found in vivo. However, the clearances of the R-enantiomers may possibly be underestimated because ketone reduction, an important metabolic route of R-warfarin, is not dealt with, since the enzymes responsible for this reaction are located in the cytosol (as will be discussed in chapters 5 and 6 ).

As stated above, disparity in affinities of the 4-hydroxycoumarins towards human liver monooxygenases is the main reason of the differences in the metabolic clearances between the enantiomers of warfarin and acenocoumarol. In this respect, the human system behaves similarly as the rat. Different affinities to monooxygenases may arise because of the physicochemical properties of the substrates and because of the diversity of P450 isozymes involved in their metabolism. Figure 4.3 as well as table 4.5 show clear differences in the effect of inhibitors on the 6- and 7-hydroxylation of acenocoumarol vs warfarin enantiomers. E.g., the 7-hydroxylation of R-acenocoumarol but not of R-warfarin is inhibited by sulfaphenazole. The 7-hydroxylation of S-acenocoumarol but not S-warfarin is inhibited by propafenone. The 6-hydroxylation of R-and S-acenocoumarol but not of R- and S-warfarin is inhibited by propafenone. These differences indicate that the isozymes catalysing the hydroxylation of warfarin at the 6-and 7-position do not catalyse these reactions to the same extent for acenocoumarol, although there will be some overlap. The lack of a clear relationship between the 6-hydroxylation of the enantiomers of warfarin and the corresponding acenocoumarol enantiomers and the absence of any correlation between the 7-hydroxylation of S-warfarin and $\mathrm{S}$-acenocoumarol in the various microsomal preparations (table 4.4) further supponts this.

Recently, Rettie et al (1992), in testing various cDNA expressed human liver cy tochromes P450 for regio- and stereoselective hydroxylation of warfarin enantiomers, found that cylochrome $\mathrm{P} 4502 \mathrm{C} 9$ is a 7-hydroxylase of S-warfarin. In contrast, $\mathrm{R}$-warfarin. which also binds to this enzyme with a relatively high affinity, is not metabolized by this enzyme (Kunze et al, 1991: Rettie et al, 1992). This P450, which is inhibited by sulfaphenazole. was stated to be responsible for the bulk of $\mathrm{S}$-warfarin clearance. 'The enzyme was also shown to catalyse the 6-hydroxylation of S-warfarin and in human liver microsomes a correlation between the 6-and 7-hydroxylation of S-warianin was observed (Rettie et al, 1992). However, we found that the 6-hydroxylation of S-warfarin could be only partially inhibited by sulfaphenazole in some liver samples and we did not find a correlation between the 6- and 7-hydroxylation of S-warfarin. This apparent contradiction may be explained by the fact that at least two 
enzymes catalyse this reaction (Rettie et al, 1989), so that the ratio at which these enzymes are present (which may show some geografic differences) determines the actual effect of sulfaphenazole and the (lack of) correlation. In agreement with Rettie et al (1992), we find the 7-hydroxylation of S-but not R-warfarin to be inhibited by sulfaphenazole. Interestingly, sulfaphenazole inhibits the 7-hydroxylation of both R-and S-acenocoumarol. In addition, the 6-hydroxylation of S- but not of R-acenocoumarol is inhibited by sulfaphenazole. Furthermore, we found the 8-hydroxylation of $\mathrm{R}$ - but not $\mathrm{S}$-acenocoumarol to be inhibited $(\mathrm{Ki}=0.6$ $\mu \mathrm{M}$; data not shown). The similar Ki values would suggest these acenocoumarol hydroxylations to be carried out by the same enzyme as the 7-hydroxylation of S-warfarin. On the other hand, the acenocoumarol hydroxylation rates do not correlate with S-warfarin 7-hydroxylation. even if the data are corrected for the non-sulfaphenazole inhibitable parts. This would suggest that the hydroxylation of acenocoumarol, which is inhibited by sulfaphenazole, cannot (completely) be ascribed to cytochrome P450 2C9. The P450 2C subfamily is very complex and its isozymes often are structurally very similar (Nebert et al, 1991; Srivastava et al, 1991). E.g. it has been shown that tolbutamide is hydroxylated by at least three structurally very similar P450 isozymes 2C8-C10 (Relling et al, 1990; Srivastava et al, 1991) and that tolbutamide hydroxylation can be completely inhibited by sulfaphenazole (Miners $\mathrm{et}$ al, 1988). Although P450 2C8 has not been shown to conduct hydroxylation of warfarin at the coumarin ring (Rettie et al, 1992), it may well be that this isozyme or other P450s of the 2C sublamily, have this catalytic activity towards acenocoumarol. This would imply that the phenyl ring of warfarin plays an important role in the binding and in the orientation of the coumarin towards these $\mathrm{P} 450$ isozymes. With this respect, it is interesting to note that antibodies raised against rat liver $\mathrm{P} 4502 \mathrm{C}$ isozymes showed differential effects on the stereoand regioselectivity of warfarin and acenocoumarol hydroxylations by rat liver microsomes (chapter 3), which also indicates adifferent binding and orientation of the 4-hydroxycoumarins.

The fomation of the main metabolite of propafenone, 5-hydroxypropafenone, has been shown to be carried out by the polymorphic cytochrome P4502D6. This may give rise to the idea that P450 2D6 catalyses the coumarin hydroxylations of warfarin and acenocoumarol since the 6-and 7-hydroxylation of both acenocoumarol enantiomers and the 7-hydroxylation of R-warfarin are inhibited by propafenone. However, the $\mathrm{Km}$ value of propafenone for the formation of the 5-hydroxy metabolite is about $2 \mu \mathrm{M}$ (Kroemer et al, 1989), whereas the $\mathrm{Ki}$ values determined in this study vary from 130 to $670 \mu \mathrm{M}$. Therefore, it is very unlikely that P450 2D6 is involved in the metabolism of warfarin or acenocoumarol.

Cimetidine, an aspecific P450 inhibitor (Knodell et al, 1991) is known to decrease the in vivo clearance of the R-enantiomer of warfarin (Choonara et al, 1986) and acenocoumarol (Gill et al, 1989). For warfarin, this has been attributed to inhibition of the 6-hydroxylation and to a lesserextent of the 7-hydrox ylation (Niopias et al, 1991), which is in accordance with the data in table 4.5 (lower $\mathrm{Ki}$ value of the 6-hydroxylation). The 6-hydroxylation of $\mathrm{R}$ - 
warfarin has been shown to be carried out by cytochrome P450 1A2 (Wang et al, 1983; Rettie et al, 1992). The Ki value we found for the inhibition of this reaction by cirnetidine is in good agreement with the Ki value that this substance has for purified cytochrome P450 1A2 (Knodell et al, 1991), whereas this is not the case for the 6-hydroxylation of R-acenocoumarol, possibly indicating the involvement of a different (set of) isozyme(s). In the case of acenocoumarol, cimetidine decreases the clearance of the $\mathbf{R}$-enantiomer only if a relatively high dose of this drug is applied (Thijssen et al, 1986; Gill et al, 1989). The data in table 4.3 and 4.5 offer an explanation for this phenomenon, since the $\mathrm{Km}$ over Ki ratios are lower for acenocoumarol than for warfarin, which implies that at equal substrate and inhibitor concentrations the extent of inhibition will be lower for acenocoumarol than for warfarin.

This study demonstrates once again that small differences, in the structure of drugs can completely change their pharmacokinetics and the stereoselectivity thereof. Since a small structural change may have implications on the relative contribution of P450 isozymes in the metabolism of 4-hydroxycoumarins, differences in interactions may occur. Furthermore, ring substituted warfarin analogues may serve as probes in exploring subtle differences between the isozymes of the $\mathrm{P} 4502 \mathrm{C}$ subfamily. 


\subsection{REFERENCES:}

Abernethy, D.R., Kaminsky, L.S., and Dickinson, T.H., 1991, Selective inhibition of warfarin metabolism by diltiazem in humans. J. Pharmacol. Exp. Ther. 257: 411-415.

Banfield, C., O'Reilly, R., Chan, E., and Rowland, M., 1983, Phenylbutazone-warfarin interaction in man: further stereochemical and metabolic considerations. Br. J. clin. Pharmacol. 16: 669. 675 .

Beaune, P.H., Kremers, P.G., Kaminsky, L.S., de Graeve, J., Albert, A., and Guengerich, F.P., 1986. Comparison of monooxygenase activities and cytochrome $\mathrm{P} 450$ isozyme concentrations in human liver microsomes. Drug Melab. Dispos. 14: 437-442.

Choonara, I.A., Cholerton, S., Haynes, B.P., Breckenridge, A.M., and Park, B.K., 1986, Stereoselective interaction between the R-enantiomer of warfarin and cimetidine. Br.J. clin. Pharmacol. 22: 729-732.

Gill, T.S., Hopkins, KJ., Bottomley, J., Gupta, S.K., and Rowland M., 1989, Cimetidine-nicoumalone interaction in man: stereochemical considerations. Br.J. clin. Pharmacol. 27: 469-474.

Greenlee, W.F., and Poland, A., 1978, An improved assay of 7-ethoxycoumarin deethylase activity: induction of hepatic enzyme activity in $\mathrm{C} 57 \mathrm{BL} / \mathrm{J} 6$ and DBA/2J mice by phenobarbital, 3 . methylcholanthrene, and 2,3,7,8,-tetrachlorodibenzo-p-dioxin.J. Pharmacol.Exp. Ther.205: 596-605.

Guengerich, F.P., Dannan, G.A., Wright, S.T., Martin, M.V., and Kaminsky, L.S., 1982, Purification and characterization of microsomal cytochrome P450s. Xenobiotica 12: 701-716.

Holford, N.H.G., 1986, Clinical pharmacokinetics and pharmacodynamics of warfarin: understanding the dose-effect relationship. Clin. Pharmacokin. 11: 483-504.

Kaminsky, L.S., 1989, Warfarin as a probe of cylochromes P450 function. Drug Metab. Rev, 20: 479-487.

Kates. R.E., Yee, Y-G, and Kirsten, A.B., 1987. Interaction between warlarin and propafenone in healthy volunteer subjects. Clin. Pharmacol. Ther. 42: 301-311.

Kelley, J.G.. and O'Mallcy. K., 1979. Clinical pharmacokitics of oral anticoagulants. Clin. Pharmacokin. 4: 1-15.

Kroemer, H.K., Mikus, G., Kronbach, T., Meyer, U.A., and Eichelbaum M., 1989, in vitro characterization of the human cytochrome $\mathrm{P} 450$ involved in polymorphic oxidation of propafenone. Clin. Pharmarol. Ther. 45: 28-33.

Knodell, R.G.. Browne, D.G., Gwozdz, G.P., Brian, W.R., and Guengerich, F.P., 1991, Differential inhibition of human livercytochromes P450 by cimetidine. Gastroenterology 101: 1680-1691.

Kunzc, K.L., Eddy, A.C., Gibaldi, M., and Trager, W.F., 1991, Metabolic enantiomeric interactions: the inhibition of human (S)-warfarin-7-hydroxylase by (R)-warfarin. Chirality 3: 24-29.

Lewis, R.J., Trager, W.F., Chan, K.K., Breckenridge, A., Orme, M., Rowland, M., and Schary, W., 1974, Warfarin: Stereochemical aspects of its metabolism and the interaction with phenylbutazone. J. Clin. Invest. 53: 1607-1617.

Lowry, O.H., Rosebrough, N.J., Farr, A.L., and Randall, R.J., 195I, Protein measurement with the Folin phenol reagent. J. Biol. Chem. 193: 265-275.

Macleod, S.M., Renton, K.W., and Eade N.R., 1973, Post mortem characteristics of the hepatic microsomal drug oxidizing enzyme system. Chem.-Biol. Int. 7: 29-37. 
Miners, J.O., Smith, K.J., Robson, R.A., McManus, M.E., Veronese, M.E., and Birkett, D.J., 1988. Tolbutamide hydroxylation by human liver microsomes. Biochem. Pharmacol. 37: 11371144.

Nebert, D.W., Nelson, D.R., Coon, M.J., Estabrook, R.W.,Feyereisen, R. Fuji-Kuriyama, Gonzalez, F.J., Guengerich, F.P., Gunsalus, I.C., Johnson, E.F., Loper, J.C., Sato, R.. Waterman, M.R., and Waxman, D.J., 1991, The P450 superfamily: update on new sequences, gene mapping. and recommended nomenclature. DNA Cell Biol., 10: 1-14.

Niopias, I., Toon, S., and Rowland, M., 1991, Further insight into the stereoselective interaction beIween warfarin and cimetidine in man. Br. J. clin. Pharmacol., 32: 508-511.

O'Reilly, R.A., 1976, The stereoselective interaction of warfarin and metronidazole in man. New Engl. J. Med., 295: 354-357.

O'Reilly, R.A., 1980, Stereoselective interaction of trimethoprim-sulfamethoxazole with the separated enantiomorphs of racemic warfarin in man. New Engl. I. Med., 302: 33-35.

O'Reilly. R.A., 1982, Stereoselective interaction of sulphinpyrazone with racemic warfarin and its separated enantiomorphs in man. Circulation 65: 202-207.

O'Reilly, R.A., Trager, W.F., Rettie, A.E., and Goulart, D.A., 1987, Interaction of amiodarone with racemic warfarin and its separatedenantiomorphs in humans. Clin. Pharmacol. Ther.42: 290294.

Relling, M.V., Aoyama, T., Gonzalez, F.J., and Meyer, U.A., 1990, Tolbutamide and mephenytoin hydroxylation by human cytochrome P450s in the CYP2C subfamily.J.P harmacol. Exp.Ther. 252: $442-447$.

Rettie, A.E., Eddy, A.C., Heimark, L.D., Gibaldi, M., and Trager, W.F., 1989. Characteristics of warfarin hydroxylation catalyzed by human liver microsomes. Drug Metab. Dispos. 17: 265 270.

Rettie, A.E., Korzekwa, K.R., Kunze. K.L. Lawnence, R.F.. Eddy. A.C., Aoyama. T., Gonzalez, F.J., Gelboin, H.V., and Trager, W.F., 1991. Wariarin hydroxylation catalyzed by human P-450's expressed in HepG2 cells (abstract). ISSX. 3th Int. Meeting, 1991.

Retlic, A.E., Korrekwa. K.R., Kinze. K.L. Lawrence, R.F., Eddy. A.C.. Aoyama. T., Gonzalez, F.J., Gelboin. H.V., and Trager. W.F., 1992. Hydroxylation of warfarin by human cDNA expressed cytochrome P450: A role for P450 $2 \mathrm{C9}$ in the etiology of (S)-warfarin-drug interactions. Chem. Res. Tox. 5: 54-59,

Rutien, A.J.J.L., Flake, H.E., Catsburg, J.F., Topp. R., Blatauwboer, B.J., v. Holsteijn, I., Doorn, L., and v. Leenwen. F.R.X.. 1987. Interlaboratory comparison of total cytochrome P450 and protein determinations in rat liver microsomes. Arch. Toxicol. 61: 27-35.

Sachs, L. 1984, Angewandte statistik, 6ih edn. pp 298-342, and pp 381-426. Berlin, Springer Verlag. Srivastava, P.K., Yun, C-H. Beaune, P.H., Ged, C., and Guengerich. F.P., 1991, Separation of human liver microsomal iolbutamide hydroxylase and (S)-mephenytoin 4'-hydroxylase cytochrome P-450 enzymes. Mol. Pharmacol.. 41: 69-79.

Sutfin, T., Balmer, K., Bostroem, H., Eriksson, S., Hoeglund,P., andPaulsen, O., 1989, Stereoselective interaction of omeprazole with warfarin in healthy men. Ther. Drug Mon. 11: 176-184. 
Thijssen, H.H.W., Baars, L.G.M., and Drittij-Reijnders, M.J., 1985, Stereoselective aspects in the pharmacokinetics and pharnacodynamics of acenocoumarol and its amino- and acetamido derivatives in the rat. Drug Metab. Dispos. 13: 593-597.

Thijssen, H.H.W., Hamulyak, K., and Willigers, H., 1988, 4-Hydroxycoumarin oral anticoagulants: pharmacokinetics-response relationship. Thromb. Haemost, 60: 35-38.

Thijssen, H.H.W., Jansen, G.M.J., and Baars, L.G.M., 1986, Lack of effect of cimetidine on pharmacodynamics and kinetics of single oral doses of R-and S-acenocoumaroll. Eur. J.Pharmacol. $30619-623$.

Toon, S., Hopkins, K.J., Garstang, F.M., Aarons, L., Sedrnan, A., and Rowland M., 1987. Enoxacinwarfarin interaction: pharmacokinetic and stereochemical aspects. Clin. Pharmacol. Ther. 42: $33-41$.

Wang.P.P., Beaune, P., Kaminsky, L.S., Dannan, G.A., Kadlubar, F.F., Lanrey, D., and Guengerich, F.P., 1983, Purification and characterization of six cytochrome P450 isozymes from human liver microsomes. Biochem. 22: 5375-5385. 


\section{CHAPTER 5:}

\section{THE IN VITRO KETONE REDUCTION OF WARFARIN AND ANALOGUES. SUBSTRATE STEREOSELECTIVITY, PRODUCT STEREOSELECTIVITY AND SPECIES DIFFERENCES.}

\subsection{ABSTRACT:}

The in vitro metabolic ketone reduction of warfarin and its analogues acenocoumarol (4'nitrowarfarin) and 4"-chlorowarfarin has been investigated using microsomal and cytosolic fractions of several species. Both subcellular fractions show reductase activity, which is NADPH dependent. The cytosolic fractions of most species, exhibit a clear substrate- and product stereoselectivity, i.e., the R-enantiomer is preferred as a substrate to be reduced mainly to the S-alcohol. In the rat, phenobarbitone and methylcholanthrene induce the cytosolic ketone reductase activity 5 to 11 fold and 3 to 7.5 fold respectively.

The microsomal fractions also show substrate- and product stereoselectivity. Contrary to the cytosolic fractions however, a general pattem of substrate and productstereoselectivity among species is not observed. Rat liver microsomes show practically no reductase activity. Phenobarbitone and methylcholathrene treatment appear to have no, or very little effect on the rat liver microsomal reductase activity.

Substitution of the 4'-hydrogen of warfarin results in a change of reduction rates, and in some cases even in a change of substrate- and product stereoselectivity.

Prelog 's rule for product stereoselectivity of metabolic ketone reduction, does not always agree with the data presented here.

Adapted from: Biochem. Pharmacol. 38: 3365-3370, 1989. J.I.R.Hermans, and H.H.W. Thijssen,

\subsection{INTRODUCTION:}

Reduction of aldehydes or ketones to their corresponding alcohols plays a role in the metabolism of both endogenous (e.g. glucuronic acid, steroids) and exogenous compounds (e.g. p-nitrobenzaldehyde, daunorubicine, metyrapone, etc.) in various species (Bachur. 1976: Felsted el al, 1977; Wermuth et al, 1977; Ahmed et al, 1979; Sawada and Hara, 1978: Sawada et al, 1980). The enzymes, responsible for this type of reaction are found in microsomal and cytosolic fractions of various tissues (Bachur, 1976: Sawada and Hara, 1978: Ahmed et al, 1979; Sawada et al, 1981: Maser, 1988; Lee et al, 1988), but mainly in the liver.

The in vivo ketone reduction of the acetonyl side-chain of the oral anticoagulant warfarin to its alcohols in man was first described by Trager et al (1970). As warfarin possesses a stereocentre, two optically active enantiomers exist: the $\mathbf{R}(+)$-enantiomer and its antipode 
the S(-)-enantiomer. Therefore, from racemic warfarin, four diastereomeric alcohols (figure 5.1) have been separated, alcohol 1 being the RS- or SR-alcohols and alcohol 2 being the RRof SS-alcohols (Chan et al, 1972).

The in vivo and in vitro metabolic reduction of warfarin in the rat and in man proved to be stereoselective for both substrate preference and product formation (Chan et al, 1972; Lewis et al, 1974; Pohl et al, 1974; Moreland and Hewick, 1975; Pohl et al, 1976) In in vitro systems, both species prefer the R-enantiomer as a substrate, reducing it mainly to the RSalcohol. S-warfarin is mainly reduced to the SS-alcohol. In vivo, in man, ketone reduction is an important metabolic route for R-warfarin, which is reduced to the RS alcohol but only a minor route for S-warfarin, which is reduced to the SS alcohol (Lewis et al, 1974). In the rat, ketone reduction is only a minor metabolic route for both warfarin enantiomers, but contrary to what is found in vitro, the in vivo reduction is stereoselective for the $\mathrm{S}$-enantiomer which is mainly reduced to the SS-alcohol (Pohl et al, 1974).

The 4'-nitro analogue of warfarin, acenocoumarol, has also been shown to be reduced to its alcohols in man (Dieterle et al 1977). However, information on the stercochemistry of its metabolic ketone reduction is absent.

Warfarin analogues display great differences in the phamacokinetics of their enantiomers (chapter 2; Thijssen et al, 1985; Thijssen et al, 1986). Therefore, the stereochemical course of the acetonyl side chain reduction of warfarin, acenocoumarol and 4'-chlorowarfarin has been studied, using subcellular fractions of several species. Also, the effect of enzyme induction (in rats) has been looked upon. As the diastereomeric alcohols of warfarin can be quantitated easily by HPLC (Fasco et al, 1979), the enantiomers of warfarin analogues represent interesting tools for the investigation of substrate- as well as product stereoselectivity of metabolic ketone reduction.

Figure 5.1: The structure of the warfarin analogues and the corresponding alcohols. $-R=H$ : warfarin, $-\mathrm{R}=\mathrm{NO}_{2}$ : acenocoumarol; - $\mathrm{R}=\mathrm{CL}$ : 4'-chlorowarfarin.
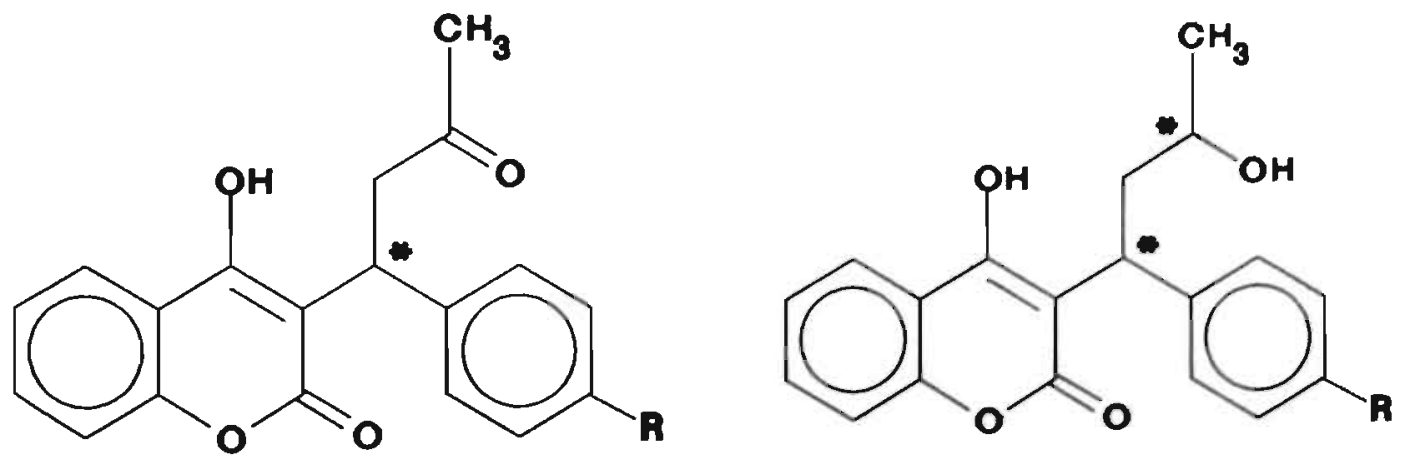


\subsection{MATERIALS AND METHODS:}

All chemicals were of analytical grade and were obtained from Merck (Darmstadt, Gernany) unless stated otherwise.

\section{Preparation of microsomal and cytosolic fractions:}

Livers of the (female) bovine ( $n=1)$, pig $(n=1)$, horse $(n=1)$ and sheep $(n=2)$ were obtained from the regional abattoir and stored on ice immediately. Rat livers ( $\mathrm{n}=4$; male Wistar rats) and rabbit $(\mathrm{n}=2)$ livers were removed directly after the animals were killed (by bleeding to death under ether anesthesia).

Human liver was obtained via the department of Pathology of the Academic Hospital Maastricht (The Netherlands), with the approval of the Ethics Committee, from autopsy of a 36 years old female that died of brain damage.

If more livers from one species were used, these livers were pooled for preparation of microsomal and cylosolic fractions. Livers were homogenized in 3 vol. of ice-cold Tris, 0.15 $\mathrm{M} \mathrm{KCl}$ and $0.25 \mathrm{M}$ sucrose, brought to $\mathrm{pH} 7.4$ with $6 \mathrm{~N} \mathrm{HCl}$ solution), using a potter at 1500 $\mathrm{rpm}$. The homogenate was then centrifuged at $10,000 \mathrm{~g}$ for $30 \mathrm{~min}$. The pellet was discarded and the supernatant was centrifuged at $110,000 \mathrm{~g}$ for $50 \mathrm{~min}$. The $110,000 \mathrm{~g}$ supematant was used as the cytosolic fraction in the ketone reduction assay. The $110,000 \mathrm{~g}$ pellet was washed twice by resuspension in the original amount of Tris/ $\mathrm{KCl}$ buffer, then homogenized and centrifuged at $110,000 \mathrm{~g}$ for $50 \mathrm{~min}$. The final microsomal pellet was resuspended in Tris/ $\mathrm{KCl} / \mathrm{NaCl}(0.02 \mathrm{M}, 0.15 \mathrm{M}$ and $1.0 \mathrm{M}$, respectively) to contain about $20 \mathrm{mg}$ of protein per $\mathrm{ml}$ homogenate. Rats were induced by phenobarbitone $0.1 \% \mathrm{w} / \mathrm{v}$ in drinking water for 6 days; $\mathrm{n}=4$ ) or by methylcholanthrene ( $25 \mathrm{mg} / \mathrm{kg}$ i.p. for 3 days; $\mathrm{n}=4$ ). The effect of administration of enzyme inducers was tested, measuring cytochrome P450 content and 7ethoxycoumarin deethylase activity.

The protein content of the fractions was determined by the method of Lowry et al (20) using bovine serum albumin as standard. All fractions were stored at $-80^{\circ} \mathrm{C}$ until used in the assay.

\section{Preparation of the $\mathbf{R}$ - and S-enantiomers of warfarin and its analogues:}

The respective enantiomers were isolated by the method of West et al (21). Racemic warfarin was obtained from Sigma Chemical Co. (St. Louis, MO, USA). 4'-chlorowarfarin was from Aldrich Chemicals and acenocoumarol was a gift from Ciba-Geigy (Basel, Switzerland).

Purity of the enantiomers was tested by the formation of their t-BOC-L-proline diastereomers (22) and subsequent analysis by HPLC(Lichrosorb $\mathrm{Si}$ 60; n-hexane/ethylacetate/ methanol $75 / 25 / 0.2$ ). The purity of the enantiomers was higher than $97 \%$. 


\section{Assay for the ketone reduction:}

Microsomal and $110,000 \mathrm{~g}$ fractions were incubated in $55 \times 11 / 12$ test tubes for $10 \mathrm{~min}$ at $37^{\circ} \mathrm{C}$ at aerobic conditions. The incubation mixture contained (in Tris $/ \mathrm{KCl}, \mathrm{pH}=7.4$, final vol. $360 \mu \mathrm{l}$ ): $110 \mu \mathrm{l}$ microsomal or supernatant fraction, $0.2 \mathrm{mM}$ substrate, $1.6 \mathrm{mM}$ NADPH, 20.2 $\mathrm{mM}$ glucose-6-phosphate (G-6-P), $5.8 \mathrm{mM}$ magnesium chloride, and $2.8 \mathrm{M}$ units of G-6-P dehydrogenase (Sigma).

The reaction mixture was preincubated at $37^{\circ} \mathrm{C}$ for $2 \mathrm{~min}$; then, the substrate was added. The reaction was stopped after $10 \mathrm{~min}$. by the addition of $500 \mu \mathrm{l}$ ice-cold acetonitrile, containing an internal standard. Warfarin was used as internal standard for the assay of acenocoumarol and 4'-chlorowarfarin; acenocoumarol was used as the intemal standard for the assay of warfarin. The mixture was centrifuged at $2500 \mathrm{rpm}$ for $5 \mathrm{~min}$ to precipitate the protein. The supematant was evaporated under a stream of nitrogen at $37^{\circ} \mathrm{C}$. To the residue $0.5 \mathrm{ml} 0.1 \mathrm{~N} \mathrm{HCl}$ solution was added and the warfarin analogues and their alcohols were extracted with $4 \mathrm{ml}$ of a $1 / 1(\mathrm{v} / \mathrm{v})$ mixture of petroleum ether and methylene chloride. The organic phase was evaporated to dryness at $37^{\circ} \mathrm{C}$ under a stream of nitrogen. The residue was taken up in $1 / 1(\mathrm{v} / \mathrm{v})$ mixture of acetonitrile and water and was analyzed by HPLC. Blank incubations were run in parallel; all incubations were carried out in triplicate.

The HPLC system consisted of Chromspher C-18 (200x3 mm. Chrompack, The Netherlands) as the stationary phase and a mixture of $0.1 \%$ acetic acid and acetonitrile $(7 / 3$ $\mathrm{v} / \mathrm{v}$ brought to $\mathrm{pH} 4.76$ with ammonia) as the mobile phase. UV absorption at $303 \mathrm{~nm}$ was measured on a Kratos spectroflow 783 and areas were calculated on Hitachi D-2000 integrator.

\section{Identification of the alcohols:}

The alcohols of the warfarin analogues were synthetized for reference purposes by reduction with sodium-boronhydride in methanol (Pohl et al, 1974). The alcohols were purified by the use of a two-dimensional thin-layer (silica) chromatography system. In the first dimension, the non-reduced warfarin analogue was separated from the diastereomeric alcohols, using a mixture of acetone and dichlorethane $(90 / 10 \mathrm{v} / \mathrm{v})$ as the mobile phase. The diastereomers in the second dimension, using diethylether/acetic acid $(99 / 1.5 \mathrm{v} / \mathrm{v})$ as the mobile phase. On the thin-layer system, The RS/SR alcohols (therefore also called alcohol 1) travelled faster than the RR/SS alcohols (alcohol 2). On the reversed phase HPLC system, the opposite was true.

\subsection{RESULTS:}

The ketone reduction of the acetonyl side-chain of the warfarin analogues by liver microsomal fractions is presented in figure 5.2. Species differences in substrate (stereo)selectivity and differences in product stereoselectivity are apparent. 
Figure 5.2: Rate of formation of the alcohols in microsomal fractions. Formation rates are expressed as pmol of alcohol formed per min per $\mathrm{mg}$ of protein (mean $\pm \mathrm{SD}$ ).

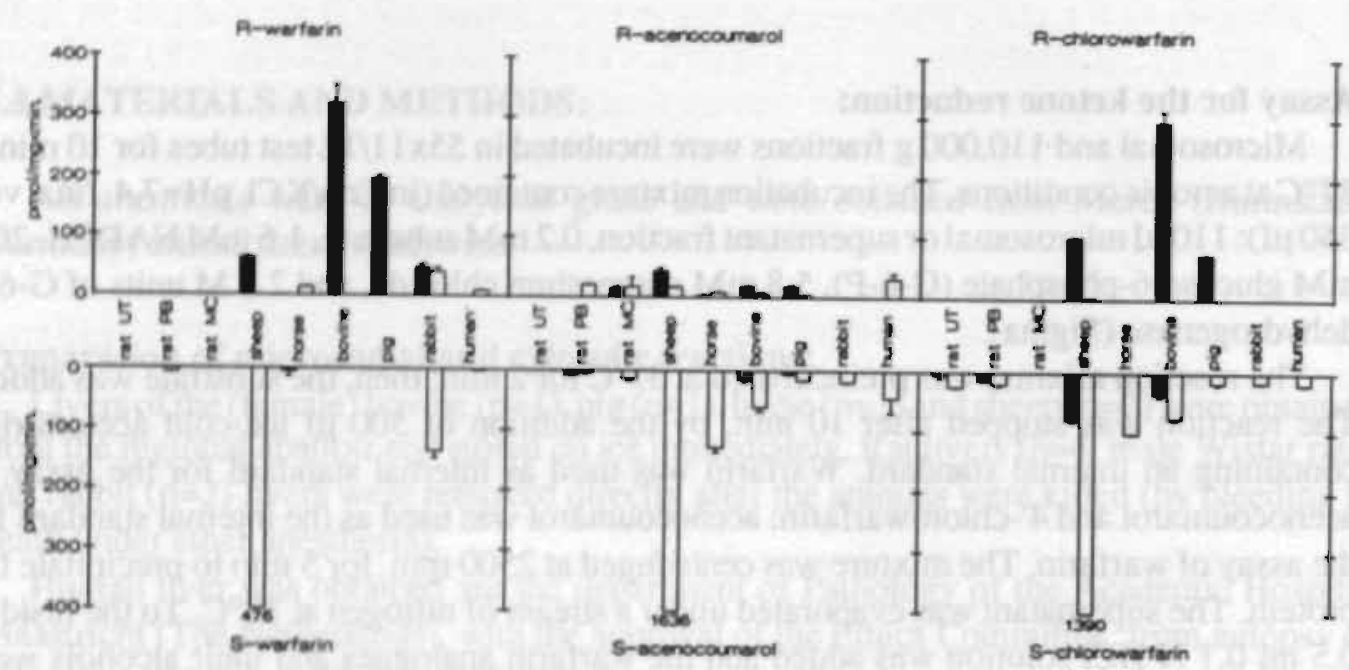

For instance, microsomes of untreated rats show practically no ketone reductase activity although minor activity is observed for S-4'-chlorowarfarin (about $30 \mathrm{pmol}$ of SS alcohol is formed per mg protein per min.). The enzyme inducers phenobarbitone (PB) and methylcholanthrene (MC) do not show a clear effect on rat liver microsomal alcohol formation rates. However, PB and MC may have some enhancing effect on the formation of the alcohols of acenocoumarol. Contrary to microsomes from untreated rats, MCmicrosomes do not show any $S-4$-chlorowarfarin reductase activity.

Liver microsomes of the other species generally show higher reductase activities. The substrate stereoselectivity varies widely, depending on the species and on the warfarin analogue. E.g., sheep microsomes show a high selectivity for the S-enantiomer of all analogues; this enantiomer is mainly reduced to the SS-alcohol. Horse microsomes also show a preference to reduce the S-enantiomers of acenocoumarol and 4'-chlorowarfarin to the S alcohols. In contrast, for warfarin, horse liver microsomes show a low reductase activity but show a preference for the R-enantiomer. Microsomal fractions of the bovine and pig show a preference for the R-enantiomer of warfarin and its 4'-chloro-analogue which is reduced to the $\mathrm{S}$ alcohol. Remarkably, $\mathrm{R}$-acenocoumarol is a poor substrate. Rabbit liver microsomes show the highest activity for warfarin, with a preference for the S-enantiomer to be reduced to the S-alcohol. Both alcohols are found for R-warfarin. Of the analogues, only the Senantiomer was reduced by rabbit microsomes, resulting in the formation of the $\mathrm{S}$-alcohols. 
Figure 5.3: Rate of formation of the alcohols in cytosolic fractions. Formation rates are expressed as pmol alcohol formed per min per $\mathrm{mg}$ of protein (mean $\pm \mathrm{SD}$ ).

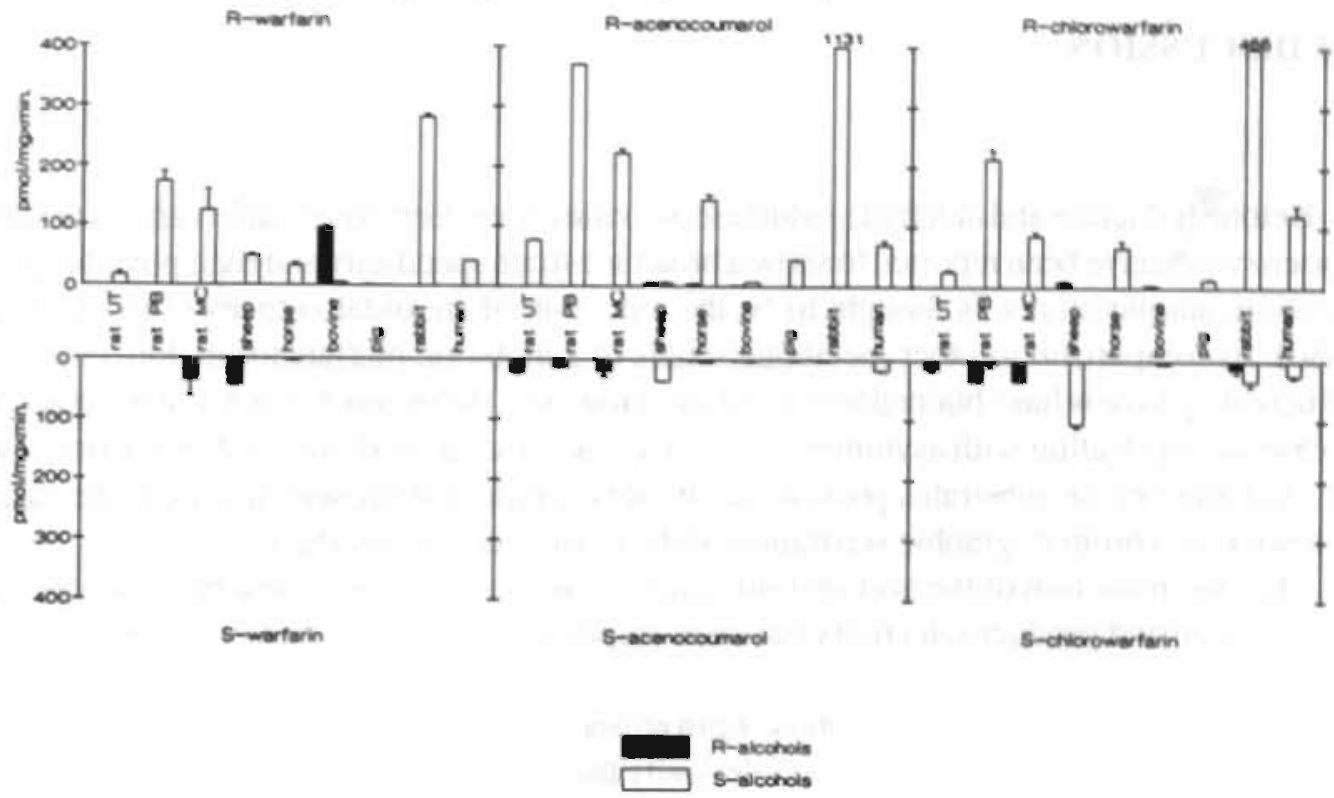

Human liver microsomes appeared to have a preference for the R-enantiomer of warfarin to form the S-alcohol. In contrast, in the case of acenocoumarol and 4'-chlorowarfarin, a preference for the S-enantiomer is observed. The products are the S-alcohols. The microsomal ketone reductases proved to be NADPH-dependent. No activity is observed when NADH, sodium dithionite or dithiothreitol (DTT) are used as reducing agents.

Figure 5.3 shows the reduction of the warfarin analogues in the cytosolic fractions. In contrast to the microsomal fractions, in all species but the sheep, there is a clear selectivity for the R-enantiomer, which is reduced to the S-alcohol: the ratios in conversion rates between the $\mathrm{R}$ - and S-enantiomers range from 2.2 (4'-chlorowarfarin in the rat) to $>1000$ (acenocoumarol in the rabbit). Inversion of the generally observed product stereoselectivity (formation of the S-alcohols) is seen for the bovine cytosolic fraction, which reduces $\mathbf{R}$ warfarin to its R-alcohol.

Inversion of the general pattem of substrate stereoselectivity (for the R-enantiomers) is observed for the sheep cytosolic fraction which shows a preference for the reduction of $S$ acenocoumarol and S-4'-chlorowarfarin to be reduced to the S-alcohols. Remarkably, $\mathrm{S}$-warfarin is reduced to the $\mathrm{R}$-alcohol by sheep cytosol.

Ketone reduction of the $\mathrm{R}$-enantiomers is higher in cytosolic fractions from PB treated (5to 11 -fold, depending on the substrate used) and $M C$ treated rats (3- to 7.4-fold) than in cytosolic fractions from untreated rats. In contrast. $\mathrm{PB}$ and $\mathrm{MC}$ treatment does not have a clear effect on the reduction of the S-enantiomers.

In general, ketone reductase activity is higher for the warfarin analogues than for warfarin itself; in most cases, acenocoumarol is the best substrate. The cytosolic ketone reductases proved to be NADPH-dependent, although small activity (10-20\% of NADPH at $1 \mathrm{mM}$ ) is observed with NADH as cosubstrate. Microsomal and cytosolic fractions, denaturated by the addition of acetonitrile do not show any reductase activity. 


\subsection{DISCUSSION:}

Ketone reductase and aldehyde reductase activities have been observed in various tissues. The enzymes have been reported to show a broad substrate specificity and their physiological function, among others, is thought to be the reduction of steroidal ketones (Sawada et al, 1980). In comparison to other metabolic routes of xenobiotic biotransformation, carbonyl reduction up to now has obtained less attention. However, the stereochemistry of the reaction in case we are dealing with asymmetric ketones makes the study of this system worthwhile. By studying ketone substrates possessing chirality, product stereoselectivity can be easily followed by chrematographic separation of the diastereomeric products.

Ketone reduction of the acetonyl side-chain of warfarin has been described before and the substrate and product selectivity has been emphasized in vivo (Chan et al, 1972; Lewis et al, 1974; Pohl et al, 1976) and in vitro (Moreland and Hewick, 1975). The present results are in agreement with these studies showing in rat and human liver cytosolic fraction substrate preference for R-warfarin and product selectivity for the S-alcohol. With the exception of the sheep, liver cytosolic ketone reductase of the other species also show a substrate preference for the R-enantiomer leading to the formation of the S-alcohol. This may suggest a possible interspecies relationship of the reductases. The order of sensitivity is generally $R$ acenocoumarol $>$ R-4'-chlorowarfarin $>$ R-warfarin. Moreland and Hewick (1975) have reported the substrate preference for $R$-warfarin of the ketone reductase activity in human and rat liver and kidney cytosolic fraction to be a matter of affinity rather than Vmax. Referring to the apparent interspecies relationship of the cytosolic activities, it is likely that this observation also holds for the acenocoumarol and 4'-chlorowarfarin substrates.

In agreement with the observation of Moreland and Hewick (1975), we found the cytosolic ketone reductase activity to be sensitive for inducing agents.

Next to the cytosolic fraction, liver microsomes also exhibit ketone reductase activity. Substrate preference and product stereoselectivity are different from that of the cytosol. Solubilization of the microsomal enzyme did not change these features (own observations), excluding the possibility that the stereoselectivity is an environmental (microsomal membranes) phenomenon. Therefore, these data indicate the microsomal and cytosolic reductases to be different enzyme systems.

In enzymatic ketone reduction, product stereoselectivity is a well-known phenomenon (Prelog. 1964: Roerig et al, 1976: Kabuto et al, 1978: Prelusky et al, 1982). In studying the reduction of ketones by bacteriological systems. Prelog (1964) formulated a rule to predict the configuration of the resulting alcohol. If a ketone is projected in plane with the large group at the left. the resulting alcohol predominantly will have the configuration with the hydroxyl group above the plane (figure 5.4). Prelusky et al (1982), by studying the in vivo and in vitro reduction of some selected arylalkyl ketones in rabbits and rats affirmed the validity of Prelog's rule. For the warfarin analogues, the rule would imply the formation of the RS- and SS-alcohols from the R-and S-enantiomers, respectively. In the cytosolic systems, this 

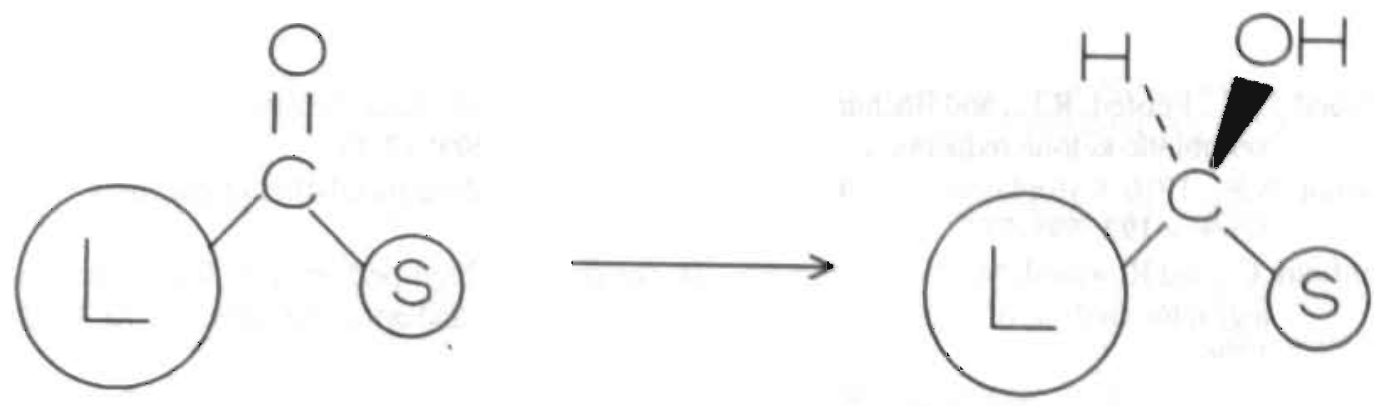

generally appears to be true for the R-, but not for the S-enantiomers (figure 5.3). For the microsomal systems, the S-, but less the R-enantiomers foilow the rule (figure 5.2). Taking our findings together, one might raise the question whether Prelog's rule is valid for predicting product stereoselectivity of mammalian ketone reductases.

Attaching a meaning to the differences in reductase activities between the species is difficult. For human, bovine, pig and horse, only one liver could be used. This implies that for these species the data presented here are only indicative for species differences as intraspecies variation cannot be ruled out. Furthermore, Moreland and Hewick (1975) showed the recovery of R-warfarin reductase activity from rat liver to decrease with post-mortem time. Only rat and rabbit livers were obtained immediately after death of the animals and the livers were perfused in situ with ice-cold saline before excision. Livers from the slaughter house were processed about 1-2 hr after death. The human liver was removed $3 \mathrm{hr}$ after death. However. except for the human liver, all livers were put directly on ice to minimize loss of enzymatic activity. Reduction rates in both rat and human cytosolic fractions in our study are higher than in the study presented by Moreland and Hewick (1975).

Our in vitro data on warfarin ketone reduction in man are in accordance with the in vivo observations, i.e. the formation of the RS-alcohol mainly. This appears also to be the case for acenocoumarol, and therefore. the data would suggest that this metabolic route is not responsible for the great differences in pharmacokinetics between $\mathrm{R}$ - and $\mathrm{S}$-acenocoumarol in man. The fact that $\mathrm{R}$-acenocoumarol is reduced faster by the cytosolic reductases than $\mathrm{R}$ warfarin may however contribute to differences in the elimination rate of the $\mathrm{R}$-enantiomers of these 4-hydroxycoumarins.

In conclusion, although it is claimed that ketone reductases have a broad substrate specificity, there is a clear substrate stereoselectivity. Also, striking substituent dependencies are observed, suggesting the involvement of the benzyl moiety of the warfarin analogues in the reaction mechanism. In the next chapter (chapter 6 ) experiments with partially purified rabbit liver cytosolic warfarin reductases will be described. 


\subsection{REFERENCES:}

Ahmed, N.K.. Felsted, R.L., and Bachur NR, 1979, Comparison and characterization of mammalian xenobiotic ketone reductases. J. Pharmacol. Exp. Ther. 209: 12-19.

Bachur, N.R., 1976, Cytoplasmic aldo-keto reductases: a class of drug metabolizing enzymes. Science 192: 595-597.

Banfield, C., and Rowland, M., 1984, Stereospecific fluorescence high-performance liquid chromatographic analysis of warfarin and its metabolites in plasma and urine.J.Pharm. Sci 73: 1392 1396.

Chan, K.K., Lewis, R.L., and Trager, W.F., 1972, Absolute configurations of the four warfari alcohols. J. Med. Chem. 15: 1265-1270.

Dielerle. W. Faigle, J.W., Sulc, M. Theobald. W, 1977, Biotransformation and pharmacokinetics of acenocoumarol (Sintrom). Eur. J. Clin. Pharmacol. 11: 367-375.

Fasco, M.J., Cashin, M.J., and Kaminsky, L.S., 1979, A novel method for the quantitation of warfarin and its metabolites in plasma. J. Liq. Chrom. 2: 565-575.

Felsted R.L.. Richter, D.R., and Bachur, N.R., 1978, Rat liver aldehyde reductase. Biochem. Pharmacol. 26: $1117-1124$.

Kabuto, K.. Imuta, M., Kempner, E.S., and Ziffer, H., 1978, Product stereospecificity in the microsomal reductions of hydroaromatic ketones. J. Org. Chem. 43: 2357-2361.

Lee, V.H.L. Chien, D-S, and Sasaki, H., 1988, Ocular ketone reductase distribution and its role in the metabolism of ocularly applied levobunolol in the pigmented rabbit. J. Pharmacol. Exp. Ther. 246: 871-877.

Lewis, J., Trager, W.F..Chan, K.K., Breckenridge, A., Orme, M., Rowland, M., and Schary, W.,1974. Warfarin, stereochemical aspects of metabolism and the interaction with phenylbutazone. $J$ Clin. Invest. 53: 1607-1617.

Lowry, O.H.. Rosebrough. N.J.. Farr, A.L.. and Randall, R.J., 1951, Protein measurement with the Folin phenol reagent. J. Biol. Chem. 193: 265-275.

Maser, E., 1988. Partial purification and characterization of the microsomal metyrapone reductase. Naunyn Scimmiedeberg's Arch. Pharmacol. 337 (suppl): R 10.

Moreland. A.T.. and Hewick. D.S. 1975. Studies on a ketone reduclase in human and ral liver and kidney soluble fraction using warfarin as a substrate. Biochem. Pharmacol. 24: 1953-1957.

Pohl, R.L.. Bales, R., and Trager. W.F. 1974, Warfarin: stereochemical aspects of its metabolism in vivo in the rat. Res. Comm. in Chem. Pathol. Pharmacol. 15: 233 -255.

Pohl, R.L., Nelson, S.D., Porter, W.R., and Trager, W.F.. 1976, Warfarin: stereochemical aspects of its metabolism by rat liver microsomes. Biochem. Pharmacol. 25: 2153-2162.

Prelog. V.. 1964, Specification of the stereospecificity of some oxidoreductases by diamant lattice sections. Pure Appl. Chem. 9: 119-130.

Prelusky, D. B., Coutts. R.T., and Pasutto. T.M.. 1982, Stereospecific metabolic reduction of ketones. I. Pharm. Sci. 71: 1390-1393.

Roerig. S. Fujimoto, J.M.. Wang. R.I.H. Pollock. S.H.. and Lange, D., 1976. Preliminary characterization of enzymes for reduction of naloxone and naltrexone in rabbit and chicken liver. Drug Metab. Dispos. 5: 53-58. 
Sawada, H., and Hara, A., 1978, Studies on the metabolism of bromazepam. Reduction of 2-(2-amino-5-bromobenzoyl)pyridine, a metabolite of bromazepam in the rabbit, rat, and guinea pig. Drug Metab. Dispos. 6: 205-212.

Sawada, H., Hara, A., Nakayama, T., Kato, F., 1980. Reductases for aromatic aldehydes and ketones from rabbit liver. J. Biochem. 87: 1153-1165.

Sawada, H., Hara, A., Hayashibara, M., Nakayama, M.. Usui, T., and Saeki, T., 1981, Microsomal reductase for aromatic aldehydes and ketones in guinea pig liver. Purification, characterization and functional relationship to hexose-6.phosphate dehydrogenase.J. Biochem. 90: 1077-1085.

Thijssen, H.H.W., Baars, L.G.M, and Drittij-Reijnders, M.J., Stereoselective aspects in the pharmacokinetics and pharmaco-dynamics of acenocoumarol and its amino- and acelamido derivatives in the rat. Drug Metab. Dispos. 13: 593-597, 1985

Thijssen, H.H.W. Janssen, G.W.J, and Baars, L.G.M., 1986, Lack of effect of cimetidine on pharmacodynamics and kinetics of single oral doses of R-and S-acenocoumarol. Eur.J. Clin. Pharmacol. 30: 619-623.

Trager, W.F., Lewis. J., and Garland, W.A., 1970, Mass spectral analysis in the identification of human metabolites of warfarin. Med. Chem. 13: 1196-1204.

Wermuth, B., Muench, J.D.B, and Von Wartburg. J.. 1977, Purification and properties of NADPH dependent aldehyde reductases from human liver. J. Biol. Chem. 252: 3821-3828.

West, D., Preis, S., Schroeder, C.H., and Link K,P, 1961, Studies on the 4-hydrox ycoumarins. XVII. The resolution and absolute configuration of warfarin. J. Am. Chem. Soc.83: 2676- 2679. 


\section{CHAPTER 6:}

\section{STEREOSELECTIVE ACETONYL SIDE CHAIN REDUCTION OF WARFARIN AND ANALOGUES: PARTIAL CHARACTERIZATION OF TWO CYTOSOLIC CARBONYL REDUCTASES.}

\subsection{ABSTRACT:}

The reductase activity mediating the ketone reduction of the acetonyl side chain of warfarin and analogues has been partially purified from rabbit liver cytosol. The reductase activity is resolved in two different fractions, $\mathrm{A}$ and $\mathrm{B}$, by DEAE-Sephacel chromatography. Both fractions reduce the acetonyl group of warfarin analogues with marked substrate- (Renantiomers) as well as product stereoselectivity (alcohols of the S-configuration). The reductases are NADPH dependent, which is absolute for fraction $B$. The enzyme kinetics of the R-enantiomers of warfarin and three 4'- derivatives (4'-nitro-, 4'-chloro-, and 4'methoxywarfarin) has been investigated. In contrast to fraction $B$, fraction $A$ is sensitive in its $\mathrm{Km}$ for 4' substitution: the $\mathrm{Km}$ values of 4 - nitro- and chloro- analogues are about 6 times lower than the $\mathrm{Km}$ values of the 4'- methoxy-analogue or warfarin itself. On the other hand, the $V \max$ values of fraction $A$ are all in the range of about 1 to $2 \mathrm{nmol} / \mathrm{mgxmin}$, whereas the Vmax values of fraction B vary from about 1 (4'-methoxywarfarin) to 12 (the $4^{x}$-nitroanalogue). The intrinsic activities $(\mathrm{Vmax} / \mathrm{Km})$ of both enzymes show the sane rank order: 4 '-nitro $>4$ '-chloro $>4$ '-methoxy = warfarin.

Warfarin reductase activity of both enzymes is not inhibited by pyrazole, sodiumbarbitone or dicoumarol but strongly inhibited by quercetin, indomethacin, furosemide. and prostaglandin E2 (PGE2). In addition. fraction $A$ is inhibited by menadione and androsterone: fraction B is inhibited by estrone. Various compounds were tested as substrates for these enzyme fractions. Menadione, haloperidol, glyceraldehyde, and estrone are substrates for iraction $\mathrm{A}$ but not for $\mathrm{B}$. In contrast. androsterone is a (weak) substrate for fraction B only. p-Nitrobenzaldehyde, p-nitroacetophenone, and PGE2 are reduced by both enzymes. The $\mathrm{Km}$ values for the latter substrate agree well with the Ki values that PGE2 has as (competitive) inhibitor of R-4'-nitrowarfarin reduction by both enzyme fractions. The product from PGE2 reduction by both enzyme fractions is prostaglandin $F 2 \alpha$.

The highly stereoselective acetonyl side chain reduction of warfarin analogues by rabbit liver cytosol is carried out by at least two enzymes. Endogenous substrates for both enzymes may be prostaglandins and steroids. 


\subsection{INTRODUCTION:}

In man, the oral anticoagulant warfarin is extensively metabolised by hydroxylation reactions as well as reduction of the acetonyl side chain (Lewis et al, 1974). About 15-20\% of an oral dose of warfarin is recovered as the alcohols produced by side chain reduction. Also for the warfarin analogue acenocoumarol (4'-nitrowarfarin) ketone reduction occurs (Dieterle et al, 1977).

Since warfarin possesses a chiral centre and ketone reduction introduces a second, reduction of the acetonyl group will result in the formation of two pairs of diastereomeric alcohols: alcohol 1, being the RS/SR alcohols, and alcohol 2, the RR/SS alcohols (Chan et al, 1972). In man, ketone reduction is more important for the R-enantiomer than for the Senantiomer of warfarin, and the alcohols formed are mainly in the RS- or SS-configuration (Lewis et al, 1974; Moreland and Hewick, 1975), demonstrating that the enzymes involved. show substrate- and product stereoselectivity.

Carbonyl reductases are a class of enzymes which are present in a great variety of species and tissues. These enzymes are able to reduce carbonyl groups of numerous xenobiotics as well as of endogenous compounds (Ahmed et al, 1979; Felsted and Bachur, 1980; Lee et al, 1988; Inaba et al, 1989; Iwata et al, 1990).

Carbonyl reduction has been shown to be involved in various inactivation processes of toxic compounds e.g. quinones (Wermuth et al, 1986), and drugs e.g. warfarin (Lewis at al, 1974; Moreland and Hewick, 1975). Also, the alcohols formed, may be pharmacologically active, as is the case for the alcohols of adriamycin (Loveless et al, 1978), naloxone (Roerig et al, 1976), and pentoxifylline (Ward and Clissold, 1987), thereby prolongating the pharmacological effect of the mother compound. Furthermore. a compound may be activated by this metabolic pathway: this is the case for the carcinogenic compound aflatoxin Bl (Wong and Hsieh, 1978) and may probably also be the case for keto-metabolites of 3-methylcholanthrene (Myers et al, 1989).

Next 10 its role in the metabolism of xenobiotics, carbonyl reduction plays an important role in the synthesis, interconversion and biodegradation of steroids (Pietruszko and Chen, 1976), prostaglandins (Hara et al, 1982), bile acids (Kudo et al, 1990), vitamin A (Fellsted and Bachur, 1980), glucuronic acid (Felsted and Bachur, 1980). elc.

In chapter 5 we showed the reduction of the acelonyl group of warfarin and some of its 4'- derivatives to be carried out by microsomal, as well as cytosolic NADPH dependent reductases. The cytosolic reductase activity was shown to exert a strong substrate- as well as product stereoselectivity (similar to that observed in vivo in man) and was shown to be present in a variety of species. In order to investigate this stereoselective metabolic pathway of warfarin in more detail, the cytosolic enzymes, responsible for this metabolic pathway have been partially purified and an attempt has been made for characterization. The kinetics of various 4 ' - substituted warfarin analogues have been determined. Rabbit liver was used as the reductase source. 


\subsection{MATERIALS AND METHODS:}

p-Nitroacetophenone, p-nitrobenzaldehyde, and haloperidol were obtained from Janssen (Beersse, Belgium). The prostaglandins E2 and F2 $\alpha$ were from Upjohn (Crawly, USA). All other chemicals were of analytical grade and were obtained from Merck (Darmstadt, Germany) unless stated otherwise.

\section{Isolation of enantiomers and identification of the alcohols:}

Warfarin was obtained from Sigma Chemicals (St Louis, MO), 4'-chlorowarfarin was from Aldridge Chemicals, and 4'-nitrowarfarin was a gift from Ciba-Geigy (Basel, Switserland). 4'-Methoxywarfarin was synthetised as described in chapter 2.

Enantiomers were isolated by the method of West et al (1961). Purity of the enantiomers was tested by HPLC as described in chapter 2 and was higher than $98.5 \%$. Alcohols were identified by TLC as described in chapter 5 .

\section{Purification of the reductases:}

All purification steps were carried out at $0^{\circ} \mathrm{C}$. 200 grams of (male) rabbit liver, obtained from the local poultry, were homogenized in $300 \mathrm{ml}$ of buffer $A(10 \mathrm{mM}$ sodium phosphate buffer, $\mathrm{pH}=6.2$, containing $1 \mathrm{mM}$ dithiothreitol (DTT) and $1 \mathrm{mM}$ EDTA) using a Potter homogenizer at $1500 \mathrm{rm}$. The homogenate was centrifuged at $10,000 \mathrm{x} \mathrm{g}$ for $30 \mathrm{~min}$. Subsequently, the supematant was centrifuged for $50 \mathrm{~min}$ at $110,000 \mathrm{x} \mathrm{g}$ to obtain the cytosolic fraction.

The cytosolic fraction was passed through a short $(10 \times 1.0 \mathrm{~cm})$ Biorex $T-70$ (sodium form, 200-400 mesh, obtained from Biorad, Veenendaal, the Netherlands) column, preequilibrated with buffer $A$, to remove hemoglobin (to avoid this protein to decrease flow rates of the next steps by aggregation). The reductase activity was not absorbed.

The $\mathrm{pH}$ of the effluent was brought to 7.5 by gradual addition of $0.1 \mathrm{M}$ ammonia. Ammonium sulphate was added to $40 \%$ saturation and the solution was stirred for $30 \mathrm{~min}$. during which the $\mathrm{pH}$ was kept constant. The mixture was centrifuged at $10,000 \mathrm{xg}$ for $10 \mathrm{~min}$. To the supernatant, ammonium sulphate was added to obtain a solution of $80 \%$ saturation. This fraction was stirred, kept at a pH of 7.5, and after 30 min centrifuged at $10,000 \mathrm{x} \mathrm{g}$ for $10 \mathrm{~min}$.

The $40-80 \%$ precipitate was dissolved in a minimal volume buffer B ( $10 \mathrm{mM}$ sodium phosphate buffer $\mathrm{pH}=7.5$. containing $1 \mathrm{mM}$ DTT) and subjected to gelfiltration on a Sephadex G-100 (Pharmacia fine chemicals, Uppsala, Sweden) column $(100 \times 2.6 \mathrm{~cm})$ equilibrated with buffer $B$. Elution was carried out with buffer $B$ at a flow rate of $10 \mathrm{ml} / \mathrm{h}$. Fractions of $5 \mathrm{ml}$ were collected and tested for reductase activity and protein content.

Active fractions from the G-100 step were pooled and applied to a DEAE Sephacel (Pharmacia fine chemicals, Uppsala, Sweden) column $(40 \times 5.0 \mathrm{~cm})$ equilibrated with buffer B. After application, the column was washed with 21 of buffer B. Elution was carried out at a flow rate of $100 \mathrm{ml} / \mathrm{h}$ using a linear $\mathrm{NaCl}$ gradient by gradual mixing of buffer $\mathrm{B}$ (1 l) with a $500 \mathrm{mM} \mathrm{NaCl}$ solution in buffer $\mathrm{B}(11) .8 \mathrm{ml}$ fractions were collected and tested for activity 
and protein content. This chromatographic step revealed two distinct active fractions (denoted as fraction A and B).

These fractions were concentrated by ammonium sulphate precipitation (at $95 \%$ saturation) as described above. The precipitates of both fractions were dissolved in a minimal volume of buffer $\mathrm{C}(10 \mathrm{mM}$ sodium phosphate buffer, $\mathrm{pH}=7.2$, containing $2 \mathrm{mM} \mathrm{DTT})$ and were desalted on short $(5 \times 1.5 \mathrm{~cm})$ Sephadex G-25 columns equilibrated with buffer $C$.

The concentrated, desalted fracions were applied to a hydroxy-appatite column $(12 \times 1.0$ $\mathrm{cm}$ ) equilibrated with buffer $\mathbf{C}$. Under these circumstances the reductase activity of fraction A was recovered in the void volume of the column. The reductase activity of fraction B was eluted from the hydroxy-appatite column using a linear sodium phosphate gradient by gradual mixing of $200 \mathrm{ml}$ buffer $\mathrm{C}$ with $200 \mathrm{ml}$ of a $150 \mathrm{mM}$ sodium phophate solution, $\mathrm{pH}=7.2$, containing $2 \mathrm{mM}$ DTT. $5 \mathrm{ml}$ fractions were collected and tested for reductase activity.

The active fractions from this final step were pooled, and diluted with phosphate buffer to yield solutions containing $1 \mathrm{mg}$ protcin/ $\mathrm{ml}$ in $50 \mathrm{mM}$ sodium phosphate buffer. These solutions were used as enzyme fractions $A$ and $B$ in the experiments described. The fractions were stored at $-80^{\circ} \mathrm{C}$ until use. No loss of activity, due to storage, was observed. All experiments described, were carried out using fractions $\mathrm{A}$ and $\mathrm{B}$ from one single preparation.

\section{Assay for the alcohol formation of warfarin and analogues:}

During the purification procedure, fractions were tested for warfarin reductase activity as described in chapter 5 .

Enzyme kinetic studies and the inhibitor studies were carried out almost similarly but there. were some minor modifications. The complete reaction mixture consisted of $20 \mu \mathrm{l}$ of enzyme fraction, substrate, NADPH. 7.0 mM MgCl2, $25 \mathrm{mM}$ glucose-6-phosphate (G-6-P) and 3.4 $\mu$ units G-6-P-dehydrogenase (Sigma Chemicals, St Louis MO) in a total volume of $60 \mu \mathrm{l}$. For determination of $\mathrm{Vmax}$ and $\mathrm{Km}$ values of warfarin and analogues the NADPH concentration was $1.0 \mathrm{mM}$; substrate concentrations were varied from 0 to $2.5 \mathrm{mM}$ In the kinetic mechanistic study NADPH was varied from 0 to $1(0) \mu \mathrm{M}$, at R-nitrowarfarin concentrations of $0.125,0.25,0.50$, and $1.00 \mathrm{mM}$. Substrate- and product stereoselectivity was determined at an NADPH concentration of $1.0 \mathrm{mM}$ and a substrate concentration of $2.5 \mathrm{mM}$. In the inhibition experiment, the inhibitor concentration was $1.0 \mathrm{mM}$, except for quercetin $(0.1$ $\mathrm{mM}), \mathrm{R}$-nitrowarfarin was used as a substrate at $0.5 \mathrm{mM}$. Inhibitors were either dissolved in Tris/ $/ \mathrm{KCl}$ buffer or in $1.5 \%$ ethanol in Tris/KCl buffer. The final concentration of ethanol did not exceed $0.5 \%$; reductase activity was not influenced by this concentration of ethanol.

The complete reaction mixture, without the enzyme, was preincubated for $2 \mathrm{~min}$ at $37^{\circ} \mathrm{C}$. The reaction was started by the addition of the prewarmed enzyme fractions. After 15-25 min of incubation at $37^{\circ} \mathrm{C}$, the reaction was stopped by the addition of $0.5 \mathrm{ml} 0.1 \mathrm{~N}$ sodium-acetate buffer $\mathrm{pH}=4.5$. $20 \mu \mathrm{l}$ of intemal standard (at $1.2 \mathrm{mM}$ solution of nitrowarfarin or warfarin, 
depending on the substrate used) was added and was extracted with $2 \mathrm{mI}$ of a $1 / 1$ ( $\mathrm{v} / \mathrm{v}$ ) mixture of petroleum-ether/methylene chloride. The organic phase was evaporated to dryness under a stream of nitrogen at $37^{\circ} \mathrm{C}$. The residue was taken up in $0.30 \mathrm{ml}$ of a $1 / 1$ mixture of acetonitrile and water. $20 \mu \mathrm{I}$ was used for assay on HPLC.

The mobile phase of the HPLC system used consisted of a $3 / 7(\mathrm{v} / \mathrm{v})$ mixture of acetonitrile and $0.1 \%(\mathrm{v} / \mathrm{v})$ acetic acid. The $\mathrm{pH}$ of the eluent was 4.76 (adjusted with ammonia) for the assay of warfarin and nitrowarfarin alcohols and 5.10 (adjusted with ammonia) for the assay of chlorowarfarin and methoxywarfarin alcohols. The stationary phase consisted of Chromspher C-18 (Chrompack, the Netherlands). Column dimensions were $200 \times 3 \mathrm{~mm}$ for the assay of warfarin and nitrowarfarin alcohols and $100 \times 3 \mathrm{~mm}$ for the assay of methoxywarfarin and chlorowarfarin alcohols. The flow rate was $1.5 \mathrm{ml} / \mathrm{mnin}$. The absorbance at $303 \mathrm{~nm}$ was recorded.

Enzyme kinetic parameters were obtained by direct fitting the Michaelis-Menten equation to the data using the software package GPAD (GraphPAD Software, San Diego, CA).

\section{Other assays:}

Protein content was determined by the method of Lowry et al (1951). The reduction of other substrates was assayed as follows: $20 \mu \mathrm{l} \mathrm{enzyme} \mathrm{fraction} \mathrm{was} \mathrm{incubated} \mathrm{with} \mathrm{substrate}$ $(1 \mathrm{mM})$ and $\mathrm{NADPH}(1 \mathrm{mM})$ a $37 \mathrm{C}$ for 30 minutes. The reaction was stopped by the addition of $0.5 \mathrm{ml} 0.1 \mathrm{M}$ sodium-acetate buffer $\mathrm{pH}=4.5$. These mixtures were centrifuged at $1500 \mathrm{rmm}$ for 1 minute. The supernatant was used to determine the amount of oxidised NADPH spectrofotometrically. Appropriate blancs were run in parallel. This method was validated by determining the amount of alcohols of R-nitrowarfarin. p-nitrobenzaldehyde and pnitroacetophenone on HPLC (using the same column and eluent as for R-nitrowarfarin but measuring the absorption at $280 \mathrm{~nm}$ ) and comparing it with the amount of oxidized NADPH as described above.

\subsection{RESULTS:}

Purification results are given in table 6.1. Quick processing of the fractions was found to be necessary since warfarin reductase activity appeared to be inactivated rapidly (a decrease of activity of about $40 \%$ was observed after 12 hours of storage at $0^{\circ} \mathrm{C}$ ).

DEAE-Sephacel chromatography revealed two distinct fractions of warfarin reductase activity (figure 6.1). Fraction A eluted from the column at a $\mathrm{NaCl}$ concentration of about 0.1 $\mathrm{M}$ : fraction B cluted at a concentration of about $0.2 \mathrm{M}$. Fraction $\mathrm{A}$ was not absorbed by hydroxy-appatite, whereas fraction B was absorbed and eluted at a sodium phosphate concentration of about $50 \mathrm{mM}$. At this stage, the specific activity was enlarged 92 - and 240 fold for enzyme fraction A and B respectively at recoveries of 6 and $17 \%$. Altempts for further purification of the reductases appeared troublesome because of the rapid loss of reductaseactivity at this stage of purification. 


\begin{tabular}{|c|c|c|c|c|c|c|}
\hline \multicolumn{2}{|l|}{ Fraction } & $\begin{array}{l}\text { Total activity } \\
\text { (nmol/min) }\end{array}$ & $\begin{array}{c}\text { Total protein } \\
\text { (g) }\end{array}$ & $\begin{array}{l}\text { Specific activity } \\
\text { (pmol/mgxmin) }\end{array}$ & $\begin{array}{l}\text { Purification } \\
\text { (fold) }\end{array}$ & $\begin{array}{c}\text { Recovery } \\
(\%)\end{array}$ \\
\hline \multicolumn{2}{|l|}{ Cytosol } & 691 & 26.8 & 26 & .- & 100 \\
\hline \multicolumn{2}{|l|}{ Biorex T-70 } & 636 & 19.7 & 32 & 1.3 & 92 \\
\hline \multicolumn{2}{|c|}{ Amm sulf prep. $75 \% \mathrm{~s}$. } & 572 & 10.9 & 53 & 2.0 & 83 \\
\hline \multicolumn{2}{|l|}{ Sephadex G-100 } & 531 & 6.7 & 79 & 3.1 & $\pi$ \\
\hline \multirow[t]{2}{*}{ DEAE-Sephacel } & A & 90 & 0.5 & 180 & 7.0 & 13 \\
\hline & B & 155 & 0.2 & 775 & 30 & 21 \\
\hline \multirow[t]{2}{*}{ Hydroxy-appatite } & A & 47 & 0.02 & 2350 & 92 & 6 \\
\hline & B & 125 & 0.02 & 6250 & 240 & 17 \\
\hline
\end{tabular}

Figure 6.1: DEAE fractionation pattern of the rabbit liver cytosolic warfarin reductases.

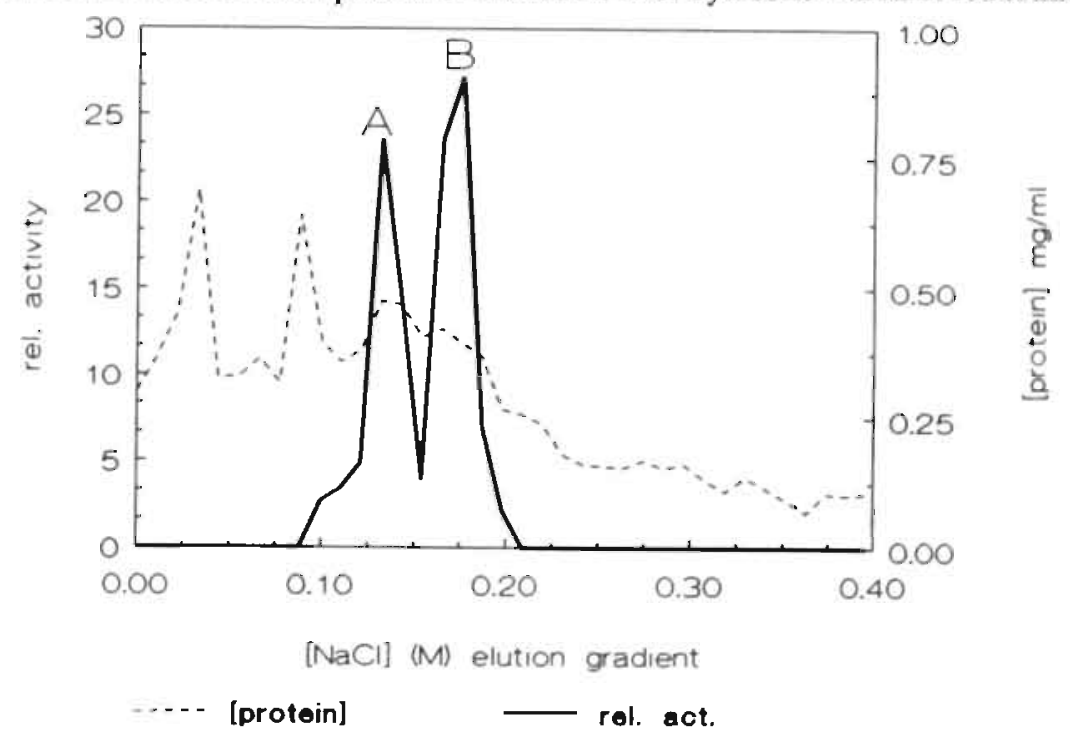

Chromatography was carried out as described in the materials and methods section. The fractions are annotated $\mathrm{A}$ and $\mathrm{B}$ in order of their elution from the DEAE sephacel column.

The obtained enzyme fractions prefer NADPH as a cofactor for reduction of the acetonyl side chain of warfarin. NADPH is obligatory for fraction B. whereas fraction A shows 15 times lower reduction rates if NADH instead of NADPH is used. Reduction rates were linear with time and the amount of enzyme added. Even at high alcohol- (up to $5 \mathrm{mM}$ ) and NADP* concentrations, the reversed reaction (oxidation of the alcohols to the corresponding ketones) was not observed for both fractions. 
TABLE 6.2: Substrate- and product stereoselectivity of the reduction of the acetonyl group of 4 -substituted warfarins by the rabbit liver cytosolic fractions.

$\begin{array}{lll}\text { FRACTION A } & \text { S-alcohols } & \text { R-alcohols } \\ \text { R-warfarin } & 8.60 \pm 1.21 & 0.10 \pm 0.02 \\ \text { R-nitrowarfarin } & 17.50 \pm 0.52 & 0.34 \pm 0.01 \\ \text { R-chlorowarfarin } & 9.40 \pm 0.52 & 0.14 \pm 0.03 \\ \text { R-methoxywarfarin } & 13.00 \pm 0.61 & 0.65 \pm 0.04 \\ & & \\ \text { S-warfarin } & \text { nd } & \text { nd } \\ \text { S-nitrowarfarin } & 0.97 \pm 0.08 & \text { nd } \\ \text { S-chlorowarfarin } & 0.78 \pm 0.06 & \text { nd } \\ \text { S-methoxywarfarin } & \text { nd } & \text { nd }\end{array}$

$\begin{array}{lll}\text { FRACTION B } & \text { S-alcohols } & \text { R-alcohols } \\ \text { R-warfarin } & 16.00 \pm 1.77 & 0.10 \pm 0.01 \\ \text { R-nitrowarfarin } & 102.00 \pm 6.63 & 2.26 \pm 0.17 \\ \text { R-chlorowarfarin } & 62.00 \pm 2.19 & 6.20 \pm 0.19 \\ \text { R-methoxywarfarin } & 11.25 \pm 0.91 & 0.67 \pm 0.08 \\ & & \\ \text { S-warfarin } & 0.47 \pm 0.05 & \text { ad } \\ \text { S-nitrowarfarin } & 5.18 \pm 0.21 & \text { nd } \\ \text { S-chlorowarfarin } & 1.12 \pm 0.21 & 0.39 \pm 0.14 \\ \text { S-methoxywarfarin } & 2.62 \pm 0.28 & \text { nd }\end{array}$

Alcohol formation was assayed as described in the methods section at substrate concentrations of $2.5 \mathrm{mM}$ and a NADPH concentration of $1.0 \mathrm{mM}$. Data are expressed as nmol alcohol formed per $10 \mathrm{~min}$ per $\mathrm{mg}$ protein and are the mean of 3 incubations \pm standard deviations. nd: not detected 
Both enzyme fractions display a high degree of substrate- and product stereoselectivity in reducing the acetonyl side chain of warfarin and analogues (table 6.2). The R-enantiomers of all warfarin analogues are clearly preferred as substrate over the $\mathrm{S}$-enantiomers (R/S ratios of alcohol formation rates are 15 to $>250$ and 5 to 35 for fraction $A$ and $B$ respectively). For both the $\mathrm{R}$ - and $\mathrm{S}$-enantiomers the alcohols produced are mainly in the S-configuration. RSalcohol formation rates were 20 to 86- (fraction A) and 10 to 160 (fraction B) times higher than RR alcohol formation rates. Formation of the SR alcohol could only be observed for enzyme fraction B, using S-4'-chlorowarfarin as substrate. Since the product of S-warfarin analogues (the SS-alcohols) is easily separable by HPLC from the main product of the Renantiomers (the RS-alcohols) we were able to discover that the S-enantiomers of the warfarin analogues are no or only very weak inhibitors of the reduction of the R-enantiomers (less than $5 \%$ inhibition at 15 fold excess of S-vs R-).

The kinetic parameters of the $\mathrm{S}$-alcohol formation of the R-enantiomers of four warfarin analogues are shown in table 6.3. The $V$ max values of enzyme fraction $A$ range from about 1 to $2 \mathrm{nmol} / \mathrm{mg}$ protein $x$ min. The Vmax values of enzyme fraction $B$ are more variable for the warfarin analogues; they range from about 1.3 (4'-methoxywarfarin) to about $12 \mathrm{nmol} /$ mgxmin (4'-nitrowarfarin).

TABLE 6.3: Enzyme kinetic parameters of both carbonyl reductase fractions for the formation of RS alcohols using various warfarin 4 '-derivatives as a substrate

\begin{tabular}{lccccccc} 
SUBSTRATE & \multicolumn{3}{c}{ ENZYME FRACTION A } & \multicolumn{3}{c}{ ENZYME FRACTION B } \\
& Vmax & Km & Cli & Vmax & Km & Cli \\
& & & & & & & \\
& 1.33 & 1.34 & 1.0 & 1.75 & 0.41 & 4.3 \\
R-warfarin & 1.92 & 0.22 & 8.7 & 11.6 & 0.35 & 33 \\
R-nitrowarfarin & 1.02 & 0.23 & 4.4 & 6.90 & 0.28 & 25 \\
R-chlorowarfarin & 2.04 & 1.46 & 1.4 & 1.28 & 0.34 & 3.8 \\
R-methoxywarfarin & & & & &
\end{tabular}

Enzyme kinetic parameters were obtained by direct fitting of the Michaelis-Menten equation to the data (alcohol-formation rates were measured at 8 different substrate concentrations ranging from 0-2.5 mM; incubations were carried out in triplicate). Incubations were carried out as described in the Materials and Methods section. Vmax values are expressed as nmol $\mathrm{RS}$-alcohol/mg xmin. $\mathrm{Km}$ values are given in $\mathrm{mM}$. Cli: intrinsic clearance ( $\mathrm{Vmax} / \mathrm{Km})$ in $\mu \mathrm{l} /$ mg protein $x$ min.) 
In contrast, the $\mathrm{Km}$ values of enzyme fraction A appear to be more sensitive for 4'substitution than the $\mathrm{Km}$ values of enzyme fraction $\mathrm{B}: \mathrm{Km}$ 's of fraction $\mathrm{A}$ are about 6 times lower for nitrowarfarin $(0.22 \mathrm{mM})$ and chlorowarfarin $(0.23 \mathrm{mM})$ than for warfarin $(1.34$ $\mathrm{mM}$ ) and methoxywarfarin $(1.46 \mathrm{mM})$ whereas the $\mathrm{Km}$ values of fraction $\mathrm{B}$ for the analogues are in the same range $(0.3$ to $0.4 \mathrm{mM})$.

Based on the intrinsic clearances $(\mathrm{Vmax} / \mathrm{Km})$ it is clear that the R-enantiomers of nitrowarfarin and chlorowarfarin are far better substrates for both reductases than the Renantiomers of warfarin and methoxywarfarin.

The kinetics of the cofactor NADPH have been studied at four different substrate concentrations (figure 6.2). The four obtained lines intersect in the second and third quadrant respectively for enzyme fraction B and A respectively. This pattern is consistent with an ordered sequential or a quasi equilibrium random mechanism, both of which are not uncommon for carbonyl reducing enzymes (Felsted and Bachur, 1980). The 'real' $\mathrm{Km}$ values for NADPH, calculated from (linear) replots are 4 (fraction $A$ ) and $9 \mu \mathrm{M}$ (fraction B).

Figure 6.2: Double reciprocal plots of R-nitrowarfarin reduction by fraction A (left) and B at various NADPH and R-nitrowarfarin concentrations.
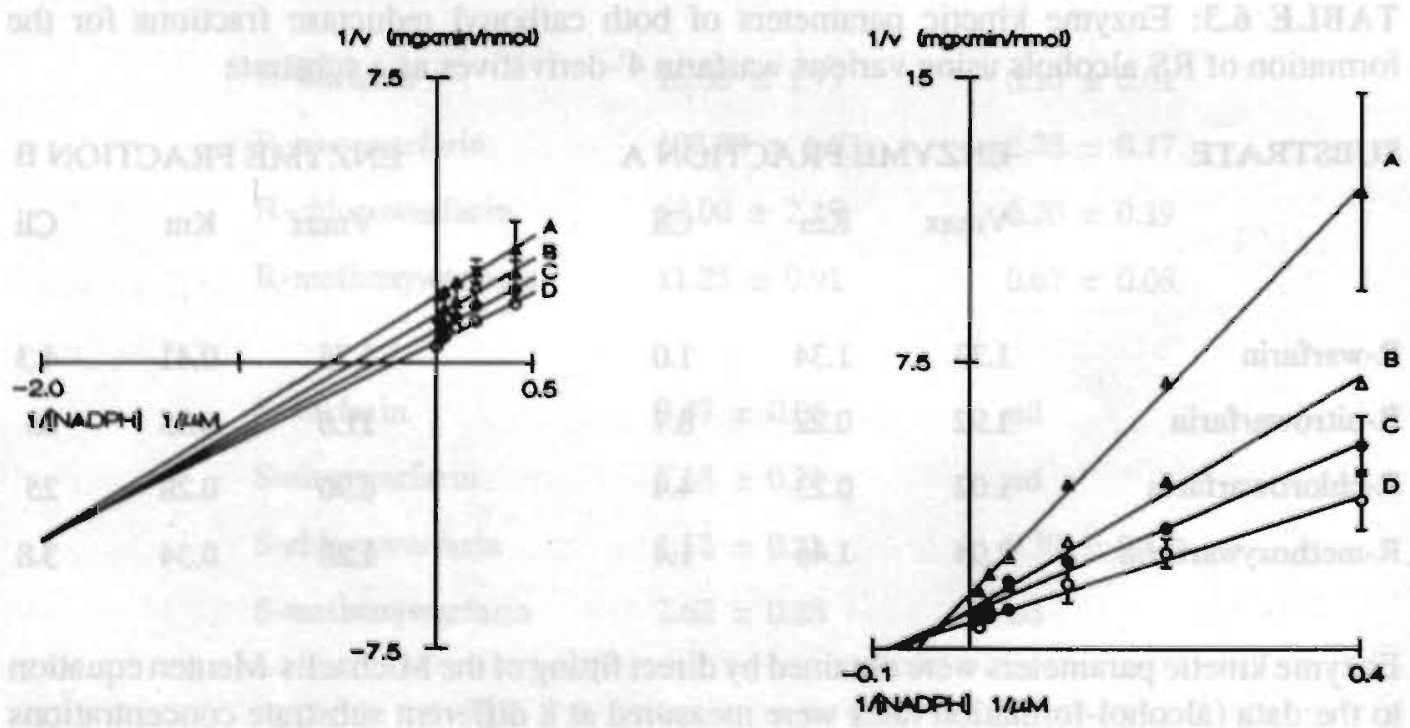

Data are the mean \pm SD from 3 incubations.

A: [R-nitrowarfarin] $=125 \mu \mathrm{M}, \mathrm{B}:[\mathrm{R}$-nitrowarfarin $]=250 \mu \mathrm{M}, \mathrm{C}:[\mathrm{R}$-nitrowariarin $]=500 \mu \mathrm{M}$.

D: [R-nitrowarfarin] $=1000 \mu \mathrm{M}$ 
TABLE 6.4: The effect of some selected inhibitors on rabbit liver cytosolic R-warfarin reductases.

Inhibitor \% inhibition (SD)

Fraction A

Fraction B

Pyrazole

14 (10)

4(2)

Sodium-barbitone

2 (3)

0 (1)

Quercetin

88 (2)

88 (1)

Dicoumarol

4 (1)

$5(1)$

DL-Glyceraldehyde

$20(3)$

4 (4)

$\mathrm{HgC12}$

99 (1)

95 (1)

Furosemide

98 (1)

$45(5)$

Indomethacin

75 (1)

87 (1)

Prostaglandin E2

$62(5)$

78 (4)

Estrone

7 (2)

30 (4)

Androsterone

$40(6)$

Menadione

74 (4)

$3(5)$

Haloperidol

$12(5)$

$1(3)$

Metyrapone

4 (3)

$3(1)$

Data are expressed as the mean $\pm \mathrm{SD}$ of 3 incubations. The inhibitor concentration was 1.0 $\mathrm{mM}$, except for quercetin (used at a concentration of $0.1 \mathrm{mM}$ ). R-nitrowarfarin was used as substrate at a concentration of $0.5 \mathrm{mM}$. The cofactor (NADPH) concentration was $1.0 \mathrm{mM}$. Incubations were carried out as described in the text.

In order to characterize both warfarin reductases, the effect of some selected inhibitors has been investigated. The results are summarized in table 6.4. Pyrazole (an alcohol dehydrogenase inhibitor), sodium barbitone (an aldehyde reductase inhibitor), and dicoumarol (a DTdiaphorase inhibitor) show no inhibiting effect on both reductases. In contrast, the flavonoid quercetine, indomethacin, furosemide and prostaglandin E2 (PGE2) are potent inhibitors of both reductase fractions. Menadione, androsterone and to a lesser extent DL-glyceraldehyde inhibit fraction A but not fraction B. Estrone decreases this reaction for reductase B but not for reductase A. Mercuri-chloride inhibits both enzymes completely. This may point to the presence of essential thiol groups. 
TABLE 6.5: Reduction rates of both reductase fractions using various substrates.

\author{
NADPH oxidized (nmol/mgrmin) \\ mean (SD)
}

$\begin{array}{lll}\text { Substrate } & \text { Fraction A } & \text { Fraction } \\ \text { R-Nitrowarfarin } & 1.5(0.7) & 8.5(0.5) \\ \text { p-Nitroacetophenone } & 22(1.5) & 6.1(0.5) \\ \text { p-Nitrobenzaldehyde } & 14(2.1) & 22.5(4.3) \\ \text { Prostaglandin E2 } & 3.2(0.5) & 1.2(0.1) \\ \text { Menadione } & 33(0.4) & \text { nd } \\ \text { Metyrapone } & \text { nd } & \text { nd } \\ \text { Haloperidol } & 3.5(0.5) & \text { nd } \\ \text { Androsterone } & \text { nd } & 0.8(0.1) \\ \text { Estrone } & 0.6(0.1) & \text { nd } \\ \text { DL-Glyceraldehyde } & 3.0(0.1) & \text { nd }\end{array}$

Data are expressed as the mean (SD) of 3 incubations.

nd: not detectable

Various compounds were tested as substates for both reductase fractions (table 6.5). As shown, p-nitrobenzaldehyde and p-nitroacetophenone are relatively rapidly reduced by both fractions. Menadione, is rapidly reduced by reductase A, but is no substrate for reductase B. The same holds true for DL-glyceraldehyde, estrone, and haloperidol. In contrast androsterone is a (weak) substrate for reductase B.

The diagnostic drug metyrapone, which is shown to be reduced by quercitrin sensitive cytosolic reductases (next to a microsomal barbiturate sensitive reductase) (Maser and Netter, 1991), appears to be no substrate for both enzyme fractions.

PGE2 is reduced by both enzyme fractions. Since this compound also is a clear inhibitor of the reduction of R-nitrowarfarin by both reductase fractions, the kinetics of PGE2 reduction and the inhibition kinetics of $R$-nitrowarfarin reduction have been studied in some detail. PGE2 reduction follows Michaelis-Menten kinetics (figure 6.3). Vmax values are 3.6 and $1.6 \mathrm{nmol} / \mathrm{mgxmin}$. for fraction $A$ and $B$ respectively. $\mathrm{Km}$ values are 0.14 and $0.16 \mathrm{mM}$. Extracts from 1 hour incubations of both enzyme fractions with PGE2 and NADPH were analyzed on HPLC, as described by Terragno et al (1981). Next to the substrate peak, an additional peak was detected, which co-eluted with prostaglandin $F 2 \alpha$ (data not shown).

The inhibition of R-nitrowarfarin reduction by PGE2 appears to be of the competitive type (figure 6.4) with Ki values of $0.14 \mathrm{mM}$ (fraction A) and $0.15 \mathrm{mM}$ (fraction B). 


\subsection{DISCUSSION:}

In chapter 5, we showed warfarin reductase activity to be present in liver microsomes and cytosol of various species. In contrast to the microsomal fractions, the cytosolic fractions showed a general pattem of substrate- and product stereoselectivity among species, which was not different for the warfarin analogues tested. Predominantly, the R-enantiomers of 4'substituted warfarins were reduced to the S-alcohols. In the present study we were able to resolve the cytosolic NADPH dependent warfarin reductase activity from rabbit liver into two distinct fractions by the use of DEAE-Sephacel chromatography (table 6.1).

Although the two reductase fractions both exhibit the same substrate- (for the Renantiomers) as well as product stereoselectivity ( $S$-alcohols), substitution at the 4 ' position of warfarindifferently affects the kinetics of both fractions (table 6.3). Kinetic differences are also observed for the cofactor NADPH at various R-nitrowarfarin concentrations (figure 6.2). These observations, in addition with the observed differences in the substrate and inhibitor profile (tables 6.4 and 6.5 ), make it unlikely that warfarin reduction by the resolved fractions is in fact carried out by one single enzyme, being present in two electrical or oligomeric states. Both reductases are not inhibited by sodium-barbiturate but strongly inhibited by quercetin and should therefore be classified as ketone reductases rather than aldehyde reductases (Ahmed et al, 1979). However, although having been purified on their ability to reduce the ketonic group of warfarin, both enzymes are able to reduce carbonyl groups from a variety of compounds among which are the quinone menadione, DL-glyceraldehyde (fraction A only), p-nitrobenzaldehyde, and some ketones. The ability of ketone reductases to reduce carbonyl groups, other than ketonic groups is not uncommon for this class of enzymes (Felsted and Bachur, 1980). Therefore, the term ketone reductase appears to be rather inconsequent for these enzymes, as has been previously also stated by Wermuth et al (1981). and could perhaps better be replaced by the tem barbiturate insensitive/flavonoid sensitive carbonyl reductase.

From the physiological compounds tested, PGE2 and the steroids androsterone (fraction $B$ only) and estrone (fraction A only) are reduced by the reductases. The $\mathrm{Km}$ values for PGE2 reduction ( 0.14 and $0.16 \mathrm{mM}$ for fractions $A$ and $B$ respectively) are in the same order of magnitude as the Ki values ( 0.14 and $0.15 \mathrm{mM}$ respectively) that PGE2 exhibits as inhibitor of R-nitrowarfarin reduction. In addition, angiotensin I, which has been shown to activate PGE2 reductases (Lee and Levine, 1975), was able toenhance the reduction of R-nitrowarfarin by enzyme fraction $B$ slightly ( 1.4 fold) but significantly $(\mathrm{P}<0.01$, $\mathrm{t}$-test), by increasing the affinity of the enzyme for NADPH (own observations). Furthermore indomethacin and furosemide. known prostaglandin reductase inhibitors (Chang and Tai, 1981; Wermuth 1981), strongly inhibit the alcohol formation of R-nitrowarfarin by both fractions (table 6.4). Therefore, prostaglandins and possibly steroids may perhaps be physiological substrates for both reductases. The $\mathrm{Km}$ values we found for the reduction of PGE2 are in the range of $\mathrm{Km}$ values that were reported previously for NADPH dependent prostaglandin 9-keto-reductases 
in several species ( 0.08 to $0.32 \mathrm{mM}$ ) (Lee et al 1975; Stone and Hart, 1975; Lin and Jabarak 1978; Chang and Tai, 1981; Wermuth, 1981; Hara et al, 1982; Iwata et al, 1989). Whether the interaction of therapeutical doses of warfarin or its analogues with the NADPH dependent 9-keto-reduction of prostaglandins may have physiological implications is unlikely, since the conversion of PGE2 and the formation of prostaglandin F2 a can be carried out via altemative and more efficient routes (Lands, 1979).

NADPH dependent reductases, having the ability to reduce the 9-keto-group of prostaglandins were initially studied because of their prostaglandin convertase activity (Lee and Levine, 1975; Hassid and Levine, 1977; Lin and Jarabak, 1978). Later, it became clear that these enzymes may not (only) serve as prostaglandin convertases, but may (also) play an important role in the detoxification of ketones, aldehydes and quinones ( $L$ in and Jabarak. 1978; Chang and Tai, 1981: Wermuth et al, 1986). This appears to be also true for the rabbit liver cytosolic enzyme fractions described in this chapter.

Reduction of prochiral ketones results in the introduction of a chiral centre in the secondary alcohol that is produced. Carbonyl reductases are known to exert product stereoselectivity (Roerig at al, 1976; Felsted and Bachur, 1980; Prelusky et al, 1982; Falgueyret et al, 1990; de Carvallo et al, 1991). By using pure enantiomers as a substrate for ketone reducing enzymes, product stereoselectivity can be easily studied since the diastereomeric alcohols are separable by simple chromatographic procedures. This may be useful since product stereoselectivity may indirectly give an indication of the orientation of the substrate when bound to the metabolizing enzyme. In this respect, the enantiomers of warfarin (or its analogues) may be interesting substrates. 


\subsection{REFERENCES:}

Ahmed, N.K., Felsted, R.L., and Bachur, N.R., 1979, Comparison and characterization of mammalian xenobiotic ketone reductases. J. Pharmacol. Exp. Ther. 209: 12-19.

Chan, K.K., Lewis, R.L., and W.F. Trager, 1972, Absolute configurations of the four warfarin alcohols. J. Med. Chem. 15: 1265-1270.

Chang, D.G-B., and Tai, H-H, 1981 Prostaglandin 9-ketoreductase/type II 15-hydroxyprostaglandin dehydrogenase is nol a prostaglandin specific enzyme. Biochem. Biophys. Res. Comm.

101: 898-904.

de Carvallo, M., Okamoto, M.T., Moran, P.J.S., and Rodrigues, J.A.G., 1991, Baker's yeast reduction of $\alpha$-haloacetophenones. Tetrahedron 47: 2073-2080.

Dieterle, W., Faigle, J.W., Sulc, M., and Theobald, W., 1977. Biotransíormation and pharmacokinetics of acenocoumarol (Sintrom). Eur. J. Clin. Pharmacol. 11: 367-375.

Falgueyret, J-P. Leblanc, Y., and Riendeau, D., 1990. Stereoselective carbonyl reductases from rat skin and leukocyte microsomes converting 12-ketoeicosatetraenoic acid to 12 (S)-HETE. FEBS lell. 262: 197-200.

Felsted, R.L.., and Bachur, N.R., 1980, Mammalian carbonyl reductases. Drug Metab. Rev. 11: 1-60.

Hara, A., Deyashiki, Y., Nakagawa, M., Nakayama, T., and Sawada, H., 1982, Isolation of proteins. with carbonyl reductase activity and prostaglandin 9-keto-reductase activity from chicken kidney. J. Biochem. 92: 1753-1762.

Hassid, A., and Levine, L., 1977, Multiple molecular forms of prostaglandin 15-hydroxy-dehydrogenase and 9-ketoreductase in chicken kidney. Prostaglandins 13: 503-516.

Inaba, T., and Kovacs, J., 1989. Haloperidol reductase in human and guinea pig livers. Drug Metab. Dispos. 17: 330-333.

Iwata, N., Inazu, N., and Satoh. T., 1989, The purification and properties of NADPH-dependent carbonyl reductases from rat. d. Biochem. 105: 556-564.

Iwata, N., Inazu. N., and Satoh. T., 1990. Immunological and enzymological localization of carbonyl reductase in ovary and liver of various species. I. Biochem. 107: 209-212.

Kudo, K., Amuro. Y., Hada, T., and K. Higashino, 1990. Purification and properties of 3cx-hydroxysteroid dehydrogenase as a 3 -keto bile acid reductase from human liver cytosol. Biochim. Biophys. Acra 1046: 12-18.

Lands. W.E.M., 1977. The biosynthesis and metabolism of prostaglandins. Ann. Rev. Physiol. 41: 633-652.

Lee, V.H.L.. Chien, D-S, and Sasaki, H., 1988, Ocular ketone reductase distribution and its role in the metabolism of ocularly applied levobunolol in the pigmented rabbit.J.Pharmacol. Exp. Ther. 246: $871-878$.

Lee, S.C. and Levine. L., 1975. Purification and regulatory properties of chicken heart prostaglandin E 9-ketoreductase. J. Biol. Chem. 250: 4549-4555.

Lewis, J., Trager, W.F., Chan, K.K. Breckenridge, A., Orme, M., Rowland, M., and Schary, W.. Wartarin. 1974, stereoselective aspects of its metabolism and the interaction with phenylbutazone. I.clin.Invest. 53: 1607-1617 
Lin, Y-M, and Jabarak, J., 1978, Isolations of two proteins with 9-ketoprostaglandin reductase and NADP-linked 15-hydroxy-prostaglandin dehydrogenase activities and studies on their inhibition. Biochem. Biophys.Res.Comm. 81: 1227-1233.

Loveless, H., Arena, E., Felsted, R.L., and Bachur, N.R., 1978, Comparative mammalian metabolism of adriamycin and daunorubicin. Cancer Res. 38: 593-596.

Lowry, O.H., Rosebrough, N.J., Farr, A.L., and Randall R.J., 1951, Protein measurement with the Folin phenol reagent. J. Biol.Chem. 193: 265-275.

Maser, E., and Netter, K.J., 1991, Reductive metabolism of metyrapone by a quercitrin-sensitive ketone reductase in mouse liver cytosol. Biochem. Pharmacol.41: 1595-1599.

Moreland, T.A., and Hewick, D.S., 1975. Studies on a ketone reductase in human and rat liver and kidney soluble fraction using warfarin as a substrate. Biochem. Pharmacol. 24: 1953-1957.

Myers, S.R., Blake, J.W., and Flesher, J.W., 1989, Metabolism of 3-methylcholanthrene in rat liver cytosol. Chem.-Biol. Int. 71: 393-401.

Pietruszko, R., and Chen, F.F, 1976 Aldehyde reductase from rat liver is a $3 \alpha$-hydroxysteroid dehydrogenase. Biochem. Pharmacol. 25: 2721-2725.

Prelusky, DB., Coutts, R.T., abd Pasutto, F.M., 1982, Stereospecific metabolic reduction of ketones. J. Pharmac. Sci. 71: 1390-1393.

Roerig, S., Fujimoto, J.M., Wang. R.I.H., Pollock, S.H., and Lange, D., 1976, Preliminary characterization of enzymes for reduction of naloxone and naltrexone in rabbit abd chicken liver.

Drug Metab. and Dispos. 4: 53-58.

Stone K.J., and Hart, M., 1975, Prostaglandin-E2-9-ketoreductase in rabbit kidney. Prostaglandins 10: $\quad$ 273-288.

Terragno, A., Rydzik, R., and Terragno, N.A., 1981, High performance liquid chromatography and UV detection for the separation and quantitation of prostaglandins. Prostaglandinss 21: 101-112.

Ward, A., and Clissold, S.P., 1987. Pentoxifylline. A review of its pharmacodynamic and pharmacokinetic properties, and its therapeutic efficacy. Drugs 34: 50-97.

Wermuth, B., Purification and properties of an NADPH-dependent carbonyl reductase from human brain. Relationship to prostaglandin 9-ketoreductase and xenobiotic ketone reductase.J. Biol. Chem. 256: 1206-1213.

Wermuth, B., Platts, K.L., Seidel, A., and Oesch, F., 1986. Carbonyl reductase provides the enzymatic basis of quinone detoxification in man. Biochem. Pharmacol. 35: 1277-1282.

West, D., Preis, S., Schroeder, C.H., and Link, K.P., 1961, Studies on the 4-hydroxycoumarins. XVII. The resolution and absolute configuration of warfarin. J. Am.Chem. Soc. 83: 2676-2679.

Wong. Z.A., and Hsieh, D.P.H., 1978. Aflatoxicol: major aflatoxin B1 metabolite in rat plasma. Science 200: 325-327. 


\section{GENERAL DISCUSSION}

\subsection{THE BASIS OF THE PHARMACOKINETIC DIFFERENCES OF THE ENAN- TIOMERS OF WARFARIN AND ACENOCOUMAROL:}

The awareness of the fact that stereoisomers may behave differently in biological systems has been growing rapidly in the past decades. One of the reasons is that new techniques in the synthesis and isolation of pure stereoisomers as well as enantioselective analytical procedures have become available. Also, various authors pointed to the importance of analyzing differences that stereoisomers may exert in biological systems (Ariëns et al, 1983; Ariëns, 1984; Simonyi, 1984, Drayer, 1988; Evans et al, 1988; Williams, 1989). That this field is gaining more and more attention is demonstrated by the fact that in 1989 a journal (Chirality) has beenlaunched which specifically deals with the subject of stereoisomerism in pharmacology and toxicology.

Warfarin is an example of a chiral drug whose enantiomers differ in their pharmacokinetics as well as in interactions with other drugs (see chapter 1). The 4'-nitro analogue of warfarin, acenocoumarol possesses completely different pharmacokinetic properties than warfarin. The enantiomers of acenocoumarol are not only eliminated faster than those of warfarin, but also marked stereochemical differences are observed as has been discussed in chapter 1 . Substitution of the 4'-hydrogen of warfarin by an amino or acetamido group was also shown to have a great impact on the rate of elimination as well as on the stereoselectivity there of (Thijssen and Baars, 1983; Thijssen et al, 1985). This may point to an important role of the phenyl ring of warfarin in determining the stereochemical course of its pharmacokinetics. Therefore, we studied the pharmacokinetics of various phenyl ring substituted warfarin analogues in the rat (chapter 2). Next to effects on (stereoselective) protein binding, phenyl ring substitution does not only enhance the intrinsic clearances but also has a clear effect on the stereoselectivity thereof. Generally, of the 2'- and 4'-substituted analogues, the intrinsic clearances of the $\mathrm{S}$-enantiomers are higher than the intrinsic clearances of the $\mathrm{R}$-enantiomers, whereas the opposite is observed for the 3'-substituted analogues. In an attempt to reveal the mechanism of the differences between warfarin analogues. we compared the in vitro biotransformation of warfarin with that of acenocoumarol. This compound was chosen since acenocoumarol, like warfarin, is widely used as oral anticoagulant, but studies on its in vitro biotransformation have not yet been conducted.

The experiments described in this thesis show that the stereoselectivity and the rate of the oxidative metabolism differ greatly for warfarin and acenocoumarol, despite the fact that apart from 4'-hydroxylation, warfarin and acenocoumarol are hydroxylated at the same positions. In chapter 3, it was shown that the rat liver microsomal metabolism of warfarin is stereoselective for the $\mathrm{R}$-enantiomer, whereas that of acenocoumarol is stereoselective for the S-enantiomer. In contrast, in human liver microsomes (chapter 4 ) the metabolism of both compounds is stereoselective for the S-enantiomer, but the difference between the enan- 
tiomers is far more pronounced for acenocoumarol than for warfarin. In addition, in both rat liver and human liver microsomes, the metabolic clearance of acenocoumarol (chapters 3 and 4) greatly exceeds that of warfarin, due to the lower $\mathrm{Km}$ values of acenocoumarol towards monooxygenases. These differences between warfarin and acenocoumarol are qualitatively in agreement with the observed differences in the intrinsic clearances between these compounds in vivo (Yacobi and Levi, 1974; Kelly and O'Malley, 1979; Thijssen et al, 1985; Thijssen et al, 1986; Holford, 1986; chapter 2) and the results obtained for warfarin metabolism agree well with previous studies that were conducted on the microsomal metabolism of warfarin (Pohl et al, 1976a; Rettie et al, 1989).

Since it is known that the enantiomers of warfarin are metabolized by a variety of cytochrome P450 isozymes in man and in the rat (Fasco et al, 1976; Pohl et al, 1977. Guengerich et al , 1982, Wang et al, 1983; Kaminsky et al, 1985, Rettie et al, 1992), the question arose whether the same set of isozymes is involved in the microsomal metabolism of both 4-hydroxycoumarins. Experiments with enzyme inducers as well as with the cytochrome P450 inhibitor cimetidine showed that in the rat this is probably not the case (chapter 3) since the metabolism of warfarin and acenocoumarol is differently affected. Immuno-inhibition experiments revealed that rat liver microsomal P450 isozymes of the 2C and $3 \mathrm{~A}$ subfamilies possess hydroxylase activity towards both 4-hydroxycoumarins. However, marked differences in the regio- and stereoselectivity of these P450 isozymes are observed for both compounds, indicating that the 4-hydroxycoumarins are differently oriented to the catalytic site of the cytochromes P450. For instance, if coumarin ring hydroxylation is considered, $\mathrm{P} 450$ isozymes of the $2 \mathrm{C}$ subfamily only catalyse the hydroxylation of warfarin at the 7-position. In the case of acenocoumarol however, these isozymes catalyse the hydroxylation at the 6-, 7-, and 8-positions. This also shows that at least a part of the coumarin hydroxylations of the enantiomers of warfarin and acenocoumarol is catalyzed by different enzymes.

Similarly, in human liver microsomes warfarin and acenocoumarol also appear to be metabolized by different sets of isozymes. Cytochrome $\mathrm{P} 4502 \mathrm{C} 9$ has been shown to be a Swarfarin 7-hydroxylase which accounts for the main part of the metabolic clearance of S-warfarin (Rettie et al, 1992). R-warfarin was shown to be no substrate for this cytochrome P450 isozyme. Consequently, sulfaphenazole, a specific competitive inhibitor of cytochromes P450 2C8-C10 (Guengerich, 1992), inhibits the 7-hydroxylation of S- but not of R-warfarin in human liver microsomes (chapter 4). However, in the case of acenocoumarol the 7-hydroxylation of both enantiomers and the 6-hydroxylation of S-acenocoumarol is inhibited by sulfaphenazole up to $70 \%$. This proves that contrary to warfarin, a substantial part of the metabolic clearance of R-acenocoumarol in man is due to P450 isozymes of the $2 \mathrm{C}$ subfamily. 
Furthermore, we showed that the (sulfaphenazole inhibitable) acenocoumarol hydroxylations do not correlate with the 7-hydroxylation of S-warfarin. This may indicate that different members of the human liver cytochrome P450 2C subfamily are involved in the coumarin hydroxylations of warfarinand acenocoumarol. The differenteffect of the inhibitor propafenone on the metabolism of the 4-hydroxycoumarins also shows that at least a part of the metabolism of both compounds is conducted by different $\mathrm{P} 450$ isozymes.

Taken together, the experiments in chapter 3 and 4 show that the differences that warfarin and acenocoumarol show in their oxidative metabolism can (at least partly) be explained by the fact that the 4-hydroxycoumarins are metabolized by different sets of isozymes. Substitution at the phenyl ring of warfarin does not only influence the stereo-and regioselectivity of the monooxygenases but also determines which isozymes metabolize the 4-hydroxycoumarin.

Another metabolic pathway of warfarin is reduction of its acetonyl side chain to its diastereomeric alcohols (Lewis et al, 1974. Banfield, 1974). The reductive route has been shown to be of only minor importance in the biotransformation of warfarin in the rat (Pohl et al, 1976b). The reason for this is that the intrinsic clearance of the formation of the alcohols is relatively low as compared to the hydroxylated metabolites of warfarin (Pohl et al, 1976a; Moreland and Hewick, 1975). In man however, formation of the diastereomeric alcohols is an important metabolic route for R- but not S-warfarin and product stereoselectivity for the formation of the $S$-alcohol is observed (Lewis et al, 1974; Banfield et al, 1983). In agreement with Moreland and Hewick (1975), we found that the R-warfarin reducing reductase activity is mainly located in the cytosol (chapter 5); the rat and human liver microsomal reduction of warfarin and acenocoumarol, appeared to be of only minor importance in the metabolic clearance of the 4-hydroxycoumarins. Contrary to liver microsomal fractions, a general pattem of substrate-(reduction of the R-enantiomers) and product stereoselectivity (formation of the S-alcohols) is observed in the liver cytosolic fractions of various species. This stereoselectivity is not different for the 4'-substituted warfarin analogues tested. Acenocoumarol and chlorowarfarin were shown to be reduced faster by the cytosolic fractions than warfarin itself. In chapter 6 , we showed that in rabbit liver cytosol, the acetonyl side chain reduction of warfarin analogues is conducted by at least two carbonyl reductases having a similar subsirate (R-enantiomers) and product ( $\mathrm{S}$-alcohols) stereoselectivity. These enzymes appear to be related. based on their similar inhibitor pattern. For both enzymes, acenocoumarol and 4'-chlorowarfarin are better substrates than warfarin or its 4'-methoxy analogue. However, the basis of the different intrinsic activities of the enzymes towards the 4hydroxycoumarins is different. In the case of carbonyl reductase fraction A. the 4-hydroxycoumarins possess different $\mathrm{Km}$ values but similar Vmax values. In the case of carbonyl reductase fraction $\mathrm{B}$, the differences in the intrinsic activities between the substrates are a matter of their different Vmax values. 
Thus, allthough the cytosolic ketone reduction of warfarin and its analogues is conducted with similar stereoselectivity, differences between the 4-hydroxycoumarins exist in the rate of reduction of the $\mathrm{R}$-enantiomers. This may probably contribute to the differences in the rate of elimination of the R-enantiomers of warfarin and acenocoumarol.

In conclusion, the differences that warfarin and acenocoumarol show in the rate and stereoselectivity of their intrinsic clearances, can largely be explained by the differences of the enantiomers of these 4-hydroxycoumarins in the rate of their metabolism. These metabolic differences can be ascribed to the fact that the 4-hydroxycoumarins are able to interact with a variety of metabolizing enzymes possessing different stereochemical and physico-chemical demands. The stereoselectivity of these enzymes and their contribution to the clearance of the warfarin analogue is influenced by substitution at the phenyl ring.

\subsection{COMPLEXITY OF ENANTIOMERIC DIFFERENCES}

The experiments described in this thesis clearly show that differences between enantiomers in biological systems are due to a combination of their different three-dimensional structures and the variety of biomolecules with which they can or cannot interact. For a chiral compound, the overall stereoselectivity of its effect will be determined by the stereochemical demands of the biomolecules with which the compound interacts, as well as the contribution of these biomolecules in the resulting effect.

Clearly, predicting the stereoselectivity of the overall effect will be more difficult if the amount of biomolecules, with which enantiomers interact is large. In addition, larger interindividual and interspecies differences can be expected. However, even the interaction of enantiomers with only one biomolecule is more complex than originally stated by Easson and Stedman (1933). Although their 3-point attachement model (also see the introduction section) proved its value in the explanation of various enantiomeric ligand-receptor interactions (Ruffolo et al, 1983), the model has some limitations as has been discussed by Testa (1990):

1) The model only gives a qualitative description but no quantitative information (on e.g. eudismic ratios).

2) Only attractive, not repulsive interactions (e.g. steric hindrance) between receptors and ligands are dealt with.

3) The model only deals with the binding of ligands, not with their intrinsic activities.

To obtain insight in the factors that determine the different interaction of enantiomers with biomolecules, quantitative structure-activity studies using the biomolecules in a purified homogeneous form should be performed. Nevertheless, this only provides information on the interaction of chiral compounds with one type of biomolecule. Clearly, extrapolation to more complex systems, where the enantiomers interact with a wider range of biomolecules (and 
may therefore show differences in their pharmacokinetics, as well as in the effects they may exert) will be a difficult matter.

Taken together, the difficulties of predicting the effects of racemates in biological systems, validate the statement of Ariëns $(1983,1984,1987,1991)$ that racemic drugs, should in fact be condidered as mixtures of two different drugs, despite the similar physico-chemical properties of the enantiomers.

\subsection{ENANTIOMERS AS TOOLS IN BIOMEDICAL SCIENCE:}

The fact that enantiomers interact differently with biomolecules, but have similar physicochemical properties, makes them useful experimental tools in biomedical sciences (Williams, 1989).

Because enantiomers possess similar physico-chemical properties, but often show large differences in their interaction with recepiors, the distomer of a chiral drug may serve as a tool to investigate whether a certain type of receptor is involved in certain effects of the drug. For instance, the effects of the $\beta$-adrenoceptor blocking agent propranolol that are associated with its membrane stabilizing properties do not show stereoselectivity, in contrast to its effects via $\beta$-adrenoceptors (Rahn, 1983; Simonyi, 1984). The absence or presence of enantiomeric differences in the effect of $\beta$-adrenoceptor blocking agents thus provides insight whether or not certain pharmacological effects are indeed mediated by $\beta$-adrenoceptors (Rahn, 1983).

Stereoselectivity in ligand-receptor interactions or in substrate-/inhibitor-enzyme interactions may give information on the orientation of the ligand, when bound to the biomolecules, and may be of help in designing more efficient ligands for a specific receptor or enzyme (Testa, 1988). For instance, the study of the regio- and stereoselective metabolism of benzo(a)pyrene, provided information of the spatial requiremenis of cytochrome P450 1Al (Jerina et al, 1985).

In the case of stereospecific active or facilitated transpon, the enantiomer which is not subjected to this type of transport may give information on the role of passive diffusion in the disposition of the drug. An example of this is methotrexate, of which the D-enantiomer has been suggested as a probe to estimate entero-hepatic cycling of the clinically used Lenantiomer (Hendel and Brodthagen, 1984).

Furthermore, the stereoselectivity in the metabolism of compounds may provide more sensitive tools for the investigation of genetic polymorphisms as is for example shown for mephenytoin: the urinary S/R ratio of this compound appears to be an equally accurate but less time consuming screening method for phenotyping (Guttendorf and Wedlund, 1992) than the classical approach (determination of the urinary ratio of the 4-hydroxy metabolite of S-mephenytoin versus unchanged S-mephenytoin). 
Finally, in enzyme catalysed reactions, in which an additional chiral element is introduced in the product, enantiomers offer the advantage that the products are diastereomeric and as such more easily separable by chromatographic procedures than the single enantiomers formed from an achiral substrate (Testa, 1986). An example is provided by the metabolic reduction of the ketone group of warfarin and analogues, as described in chapters 5 and 6.

\subsection{ENANTIOMERICALLY PURE VERSUS RACEMIC DRUGS:}

Since many chiral drugs were developed in an era in which knowledge of the differences between stereoisomers was less sophisticated and in which synthesis or isolation of pure stereoisomers was technically very difficult, if not impossible, about $25 \%$ (Ariëns, 1991) of the drugs currently marketed, are mixtures of stereoisomers. However, in the last decade, it is questioned by various authors whether or not chiral drugs should be marketed as mixtures of stereoisomers or as pure stereoisomers (Ariëns et al, 1983; Ariëns, 1984; Kumkumian, 1988; Birkett, 1989; Williams, 1989; Lennard, 1991) . Currently, no clear answer has been given to this question and the debate is still going on. Some considerations concerning the use of racemic or enantiomerically pure drugs will be put forward.

For chiral drugs various possibilities have to be considered (Ariëns, 1984):

1) The enantiomers undergo chiral inversion or racemization.

2) The enantiomers differ quantitatively in their (desired) pharmacological effect.

3) The enantiomers differ qualitatively in their pharmacological effect.

Three types of chiral inversion may occur: I) the eutomer is transformed to the distomer II) the distomer is transformed to the eutomer (e.g. NSAIDs of the arylpropionic acid type; Caldwell et al, 1988), and III) racemization.

Extensive transformation of the eutomer to the distomer does not seem desirable, especially if the eudismic ratio is high. Transformation of the distomer to the eutomer may at first sight appear to be in favor of the use of the racemate, but problems may arise since inversion may be not complete and may show large interindividual differences. Therefore, if the racemate is to be applied, therapeutic drug monitoring may be difficult, and requires thorough evaluation.

If (chemical) racemization occurs (e.g. in an acidic environment like the stomach), the application of a pure enantiomer as well as of a racemate implies that two enantiomers will enter the body. In addition, the possibility exists that the enantiomers are stable under certain conditions in parts of the body. Therefore, the fate and effects of both enantiomers should be evaluated. In general, if racemization occurs, application of a pure enantiomer will have no advantage above the racemate. This is however not always the case, as is demonstrated by arbaprostil ((15-R)-15-methyl-prostaglandin E2), which is used for the treatment of gastric 
ulcers. This stereoisomerically pure drug is an inactive prodrug. In an acidic environment it is racemized (actually epimerized) to give a mixture of the active 15-S and the inactive 15$\mathrm{R}$ form. This only occurs as the $\mathrm{pH}$ falls below 5 (Reele, 1985), and thus the amount of active drug is controlled by the gastric pH (Cox et al, 1986; Williams 1990). In this case, racemization is used for specific drug targeting of the active enantiomer.

Quantitative differences may range from extreme i.e. the distomer has very low activity ( $\beta$-adrenoceptor blocking agents; Rahn, 1983; Ruffolo, 1983) to modest i.e. the distomer is nearly as active as the eutomer (warfarin; Wingard et al, 1978; Choonara et al, 1986). If the eudismic ratio is large, the contribution of the distomer to unwanted side effects or toxicity should be evaluated. This is exemplified by $\beta 2$-adrenoceptor sympathomimetic drugs as isoprenaline, salbutamol and terbutaline that are used as bronchodilators in asthma therapy. These compounds are currently administered as racemates. Their sympathomimetic activity resides in the R-enantiomers. However, the S-enantiomers were shown to induce increased airway responsivity to histamine and leukotriene C4 (Chapman et al, 1992) and are believed to contribute substantially to the bronchospasmic hyperreactivity to inhaled allergens that is associated with the use of $\beta 2$-sympathomimetics. Therefore, Chapman et al (1992) proposed the use of only the eutomers (the R-enantiomers) in the treatment of asthma. Another example of a chiral drug for which the application of only one enantiomer would be beneficial because the enantiomers show quantitative differences is timolol. This $\beta$-adrenoceptor blocking agent is marketed as the (-) enantiomer and is (among others) used for the treatment of glaucoma. One of its disadvantages for this application is that when it is administered ocularly, the drug may enter the circulation and as a result may have (undesired) systemic effects. When applied as eye drops in humans, 15 times higher doses of $(+)$-timolol were required to elicit similar systemic effects (as assessed by inhibition of isoprenalin induced bronchodilatation) as the (-)-enantiomer (Richards and Tattersfield, 1985). However the ( + )-enantiomer is as effective as the (-)-enantiomer in the treatment of glaucoma (Keates and Stone 1984). Therefore, these authors proposed the ( + )-enantiomer as a therapeutic agent for glaucoma treatment since less systemic side effects than for (-)-timolol should be expected. On the other hand if systemic $\beta$-adrenoceptor blockade is wanted, the (-)-enantiomer could be used.

At a high eudismic ratio. even in the case that the distomer does not contribute to side effects, it should be considered that for racemic drugs a dose is required that is twice as high as that of the eutomer; in that case the distomer can be considered 'isomeric ballast' since it serves no therapeutic purpose (Arièns. 1984).

If the eudismic ratio is small and the contribution of both enantiomers to side effects is similar (or even absent), there may be also good reasons to market only one enantiomer (Birkett, 1989). The enantiomers may follow different metabolic routes and/or may be metabolized by different sets of isozymes (e.g. warfarin and acenocoumarol: chapters 3 to 6 ). 
As a result, the enantiomers may interact differently with other drugs (as has been described for warfarin: see paragraph 1.5.5 and chapter 4) and large interindividual differences in the enantiomeric plasma concentration ratios should be expected (Drayer, 1988). Clearly, therapeutic drug monitoring will be more difficult for the racemate than for one of the enantiomers (Drayer, 1988). This point of consideration is of course most important for drugs with a relatively narrow therapeutic index.

Qualitative differences between enantiomers may arise because: 1) enantiomers interact with a variety of receptors to different extents 2 ) enantiomers interact with the same receptors in a different manner (agonist-antagonist). In both cases, the pharmacological profile of the racemate may be very complex, especially if the enantiomers differ in their phamacokinetics (Mehvar, 1992) and should be evaluated carefully. Qualitative differences may concem toxicity or undesired side effects of only enantiomer. An example thereof is provided by propranolol. Its $\beta$-adrenoceptorblocking potency can be mainly attributed to the S-enantiomer. However, only the R-enantiomer depresses the conversion of thyroxine to triiodothyronine (Stochitzki et al, 1992).

On the other hand, the qualitative differences in the action of enantiomers may sometimes be beneficial since the enantiomers may have complementary or synergistic effects. Indacrinone offers an example of a drug of which the different pharmacological properties of the enantiomers may be of advantage in clinical practice. Indacrinone is a potent diuretic. In man, the (-)-enantiomer of indacrinone is a more potent natriuretic agent than the (+)-enantiomer; in contrast, both enantiomers are equipotent as uricosoric agents (Tobert et al, 1981). Tobert et al (1981) tested the effects of various combinations of the enantiomers of indacrinone and found that its therapeutic effect can be improved (i.e. diuresis without accumulation of uric acid in the plasma, a side effect of many diuretics) by giving indacrinone in an enantiomeric $(+) /(-)$ ratio of $1 / 4$.

Another, intriguing example of a drug for which the application of mixtures of stereoisomers appears to have some advantage above the application of a pure stereoisomer is labetolol. Its RR-enantiomer (dilevalol) has been introduced as a $\beta 2$-adrenoceptor blocking drug in 1990 in Japan and Portugal but has been withdrawn because of its hepatotoxicity (Lennard, 1991). Hepatotoxicity has also been reported for labetolol (a mixture of the RR, RS, SR, and SS diastereomers) but appears to be observed less frequent (Lennard, 1991). Nevertheless, because of the hepatotoxicity of its RR-diastereomer, one might argue that other $\beta 2$ adrenoceptor blocking drugs should be used in stead of labetolol.

From the above, it may be clear that for a chiral drug knowledge of the fate and effect of both enantiomers is crucial. When a decision has to be made whether or not to use a chiral drug in its racemic or enantiomerically pure form, the results of this evaluation, loge ther with 
the costs of drug production, and the desirability of the drug (e.g. for the treatment of lifethreatening diseases) should be taken into consideration (Birkett, 1989; Campbell, 1990).

At present, many chiral drugs are marketed as a racemate and as such have proved their vafue in the past (Lennard, 1992). There is however a tendency in the phamaceutical industry to prefer enantiomerically compounds when new drugs are to be produced (Campbell 1990 . Lennard, 1992). This tendency is demonstrated by the fact that in the UK in 1987 less chiral drugs were developed than in the year before and that of the chiral drugs the amount of pure enantiomers doubled (Campbell, 1990). That the issue of developing racemic or enantiomerically pure drugs has penetrated the pharmaceutical industry and is seriously dealt with may be clear from table 7.1, which is drawn from results of a questionnaire held by Cayen (1991).

Taken together, the decision whether or not to use drugs in their stereoisomerically pure form is very complex, which probably is the reason that the debate on this subject is still going on.

Indeed, enantiomers or stereoisomers should be considered different drugs but this does not necessarily imply that the use of mixtures of stereoisomers (albeit not necessarily in the ratio that is obtained from non-stereoselective synthesis) should be rejected, since in some cases the different pharmacological profile of the stereoisomers can be of advantage in therapy. In that case, mixtures of enantiomers or stereoisomers can be considered combination preparations. However, it seems reasonable to assume that the tendency to develop enantiomerically pure drugs will proceed and that the application of drugs in their racemic form (without a founded reason) will gradually disappear.

TABLE 7.1: Criteria used in the industry to market enantiomers or racemates (from Cayen, 1991):

Reasons to market enantiomers:

1 high eudismic ratio

2 the distomer is toxic

3 low therapeutic index

4 natural products are used that are already enantiomerically pure.

5 better physico-chemical properties of the enantiomers.

6 no chiral inversion (enzymatic/chemical)

7 ease of batch production

Reasons to market racemates/mixtures of stereoisomers:

1 distomer has similar pharmacological and toxicological properties

2 high therapeutic index

3 synergistic or additive pharmacological properties of the enantiomers

4 large scale synthesis or isolation of stereoisomers is cost prohibitive or inachievable (especially for multiple chiral centres)

5 life threatening indications: development of pure stereoiso mers is too time consuming. 


\subsection{REFERENCES:}

Ariēns, E.J., 1984, Stereochemistry, a basis for sophisticated nonsence in pharmacokinetics and clinical pharmacology. Eur, J. Clin. Pharmacol. 26: 663-668.

Arièns, E.J., 1991, Racemic therapeutics- ethical and regulatory aspects. Eur. J. Clin. Pharmacol. 41: 89-93.

Ariēns, E.J., Soudijn, W.. and Timmermans, P.B.M.W.M.(eds), Stereochemistry and Biological Activity of Drugs. Blackwell Scientific Publications, Oxford, 1983.

Arièns, E.J., and Wuis, E.W., 1987, Bias in pharmacokinetics and clinical pharmacology. Clin. Pharmacol. Ther. 42: 361-363.

Banfield,C.,O'Reilly, Chan, E., and Rowland, M., 1983,Phenylbutazone-warfarin interaction in man: further stereochemical and metabolic considerations. Br. J. clin. Pharmacol. 16:669-675.

Beaune, P.H., Kremers, P.G., Kaminsky, L.S., de Graeve, J., Albert, A., an Guengerich, F.P.1986 Comparison of monooxygenase activities and cytochrome P450 isozyme concentrations in human liver microsomes. Drug Metab. Dispos. 14: 437-442.

Birkett, DJ., 1989. Racemates or enantiomers: regulatory approaches. Clin. Exp. Pharmacol. Physiol. 16: 479-483.

Caldwell. J., Hutt. A.J., and Fournel-Gigleux, S., 1988, The metabolic chiral inversion and dispositional enantioselectivity of the 2-arylpropionic acids and their biological consequences.

Biochem. Pharmacol. 37: 105-114.

Campbell, D.B., 1990. Stereoselectivity in clinical pharmacokinetics and drug development.

Eur. J. Drug Metab. Pharmacokin. 15: 109-125.

Cayen, M.N., 1991, Racemic mixtures and single isomers: industrial concerns and issues in drug development. Chirality 3: 94-98.

Chapman, I.D., Buchheit, K.H., Manley, P.. and Morley, J., 1992, Active enantiomers may cause adverse effects in asthma. TIPS 13: 231-232.

Choonara, I.A.. Haynes. B.P.. Cholerton. S.. Breckenridge. A.M.. and Park. B.K., 1986. Enantioners of warfarin and vitamin K1 metabolism. Br. I. clin. Pharmacol. 22: 729-732.

Cox. J.W.. Bothwell. W.M., Pullen, R.H., Wynalda. M.A., Fitzpatrick. F.A., and Van der Lught, J.T., 1986. Plasma levels of the prodrug. arbaprostil, [(15R)-15-methylprostaglandin E2] and its active antiulcer (15S) epimer in humans after single dose oral administration. $J$. Pharm. Sci. 75: $1107-1112$.

Drayer, D.E., 1988. Problems in therapeutic drug monitoring: the dilemma of enantiomeric drugs in man. Ther. Drug Mon. 10: 1-7.

Evans. A.M.,Nation, R.L., Sansom. L.N., Bochner. F., and Somogyi. A.A., 1988. Stereoselective drug disposition: potential for misinterpretation of drug disposition data. Br. J. clin. Pharmacol. 26: $771-780$.

Easson. L.H., and Stedman. E.. 1933. Studies on the relationship between chernical constitution and physiological action. V Molecular dissymmetry and physiological activity. Biochem. J. 27: 1257-1266.

Fasco. M.J., Baker, F.D., and Fenton, J.W., 1976, Warfarin- stereochemical aspects of its metabolism by rat liver microsomes. Biochem. Pharmacol. 25: 2153-2162.

Guengerich, F.P.. 1992. Characterization of human cytochrome P450 enzymes. FASEB I. 6: 745-748. 
Guttendorf, R.J., and Wedlund, P.J., 1992, Genetic aspects of drug disposition and therapeutics. J. Clin. Pharmacol. 32: 107-117.

Hendel, J., and Brodthagen, H., 1984, Enterohepatic cycling of methotrexate estimated by the use of the D-isomer as a reference marker. Eur. J. Clin. Pharmacol. 26: 103-107.

Jerina, D.M., Sayer, J.M., Yagi, H., van Bladeren, P.J., Thakker, D.R., Levin, W., Chang. R.L., Wood, A.W.. and Conney, A.H., In: Micrososomes and Drug Oxidation, eds: Boobis, A.R.Caldwell, J., DeMatteis, F., and Elcombe, C.R., pp: 310-323, Taylor and Francis, Philadelphia, 1985. Kaminsky, L.S., Dunbar, D.A., Wang, P.P., Beaune, P., Larrey, D., Guengerich, F.P., Schnellemann, R.G., and Sipes, I.G., 1984, Human hepatic cytochrome P-450 composition as probed by in vitro microsomal metabolism of warfarin. Drug Metab. Dispos. 12: 470-477.

Kaminsky, L.S.,1989, Warfarin as a probe of cytochromes P-450 function. Drug Metab. Rev, 20: $479-487$.

Keates, E.U., and Stone, R., 1984, The effect of d-timolol on intraocular pressure in patients with ocular hypertension. Am. J. Ophihalmol. 98: 73-78.

Kelly,J.G., and O'Malley, K.O., 1979, Clinical pharmacokinetics of oral anticoagulants. Clin. Pharmacokin. 15: 1-15.

Kumkumian C.S., The use of stereochemically pure pharmaceuticals: a regulatory point of view,in: Drug Stereochemistry, Analytical Methods and Pharmacology , eds Wainer, I.W., and Drayer, D.E., pp: 299-311, New York, 1988.

Lennard, M.S., 1991, Clinical pharmacology through looking glass: reflections on the racemate vs enantiomer debate. Br.J. clin. Pharmacol. 31: 623-625.

Lewis, R.J., Trager, W.F., Chan, K.K., Breckenridge, A., Orme, M., Rowland, M., and Schary, W., 1974, Warfarin: stereochemical aspects of its metabolism and the interaction with phenylbutazone. J. Clin. Invest. 53: 1607-1617.

Mehvar, R., 1992. Stereochemical considerations in pharmacodynamic modelling of chiral drugs. $J$. Pharm. Sci. 81: 199-200.

Pohl, L.R., Bales, R., and Trager, W.F., 1976b. Warfarin: stereochemical aspects of its metabolism in vivo in the rat. Res. Comm. of Chem. Pathol. Pharmacal. 15: 233-255.

Pohl. L.H., Nelson, S.D.. Porter. W.R., Trager, W.F., Fasco, MJ., Baker, F.D., and Fenton. J.W., 1976a, Wariarin-stereochemical aspects of its metabolism by rat liver microsomes. Biochem. Pharmacol. 25: 2153-2162.

Pohl. L.R., Porter, W.R., and Trager. W.F., 1977. Stereochemical biotransformation of warfarin as a probe of the homogeneity and mechanism of microsomal hydroxylases. Biochem. Pharmacol. 26: $115-120$.

Rahn, K.H., Racemates or specific isomers: clinical practice. In: Stereochemistry and Biological Activity of Drugs. Eds: Ariëns. E.J.. Soudijn, E., and Timmermans, P.B.M.W.. pp: 103-125, Blackwell Scientific Publications, Oxford. 1983.

Reele.S.B., 1985, Gastric antisecretory activity of arbaprostil as affected by gastric pH. Dig. Dis. Sci. 30: $612-616$.

Rettie, A.E., Eddy. A.C., Heimark, L.D., Gibaldi, M., and Trager, W.F., 1989. Characteristics of warfarin hydroxylation catalyzed by human liver microsomes. Drug Metab. Dispos.

17: $265-270$. 
Rettie, A.E., Korzekwa, K.R., Kunze, K.L., Lawrence, R.F., Eddy C.G., Aoyama, T., Gelboin, H.V., Gonzalez, F.J., and Trager, W.F., 1992, Hydroxylation of warfarin by human cDNAexpressed cytochrome P-450: A role for cytochrome P-4502C9 in the etiology of (S)-warfarin-drug interactions. Chem. Res. Tox. 5: 54-59.

Richards, R., and Tatterfield, A.E., 1985. Bronchial S-adrenoceptor blockade following eyedrops of timolol and its isomer L-714,465 in normal subjects. Br. J. Pharmacol.20: 459-462.

Ruffolo, R.R., Stereoselectivity in adrenergic agonists and adrenergic blocking agents. In: Stereochemistry and Biological Activity of Drugs, Eds: Ariëns, E.J., Soudijn, E., and Timmermans, P.B.M.W., pp: 103-125, Blackwell Scientific Publications, Oxford, 1983.

Simonyi, M., 1984, On chiral drug action. Med. Res. Rev. 4: 359-413.

Stoschitzki, K., Lindner, W., Egginger, G., Brunner, F., Obermayer-Pietsch, B., Passat, A., and Klein. W., 1992, Racemic (R,S)-propranolol versus half-dosed optically pure (S)-propranolol in humans at steady state: hemodynamic effects, plasma concentrations, and influence on thyroid hormone levels. Clin. Pharmacol. Ther. 51: 445-453.

Testa, B., 1986, The chromatographic analysis of enantiomers in drug metabolism studies. Xenobiotica 16: 265-279.

Testa, B., 1990, Mechanisms of chiral recognition in pharmacology. The Easson-Stedman model revisited. Acta Pharm. Nord. 2: 137-144.

Thijssen, H.H.W., and Baars, L.G., 1983, Active metabolites of acenocoumarol: do they contribute to the therapeutic effect? Br.J. clin. Pharmacol. 16: 491-496.

Thijssen, H.H.W.. Baars, L.G.M., and Drittij-Reijnders, M.J., 1985, Stereoselective aspects in the pharmacokinetics and pharmacodynamics of acenocoumarol and its amino and acetamido derivatives in the rat. Drug Metab. Dispos. 13: 593-597.

Thijssen, H.H.W. Jansen, G.M.J., and Baars. L.G.M., 1986, Lack of effect of cimetidine on pharmacokineticsandkinetics of single oral doses of R-and S-acenocoumarol.Eur.J. Clin. Pharmacol. 30: 619-623.

Tobert, J.A.,Cirillo, V.J., Hitzenberger,G.,James, I.,Pryor,J.,Cook. T., Butinx, A., Holmes, I.B., and Lutterbeck, P.M., 1981. Enhancement of the uricosoric properties of indacrinone by manipulation of the enantiomeric ratio. Clin. Pharmacol. Ther. 29: 344-350.

Wang. P.P., Beaune. P.. Kaminsky. L.S.. Kadlubar. F.F.. Larrey, D.. and Guengerich, F.P., 1983. Purification and characterization of six cytochrome P-450 isozymes from human liver microsomes. Biochem. 22: 5375-5384.

West, B.D.. Preis, S.. Schroeder. C.H., and Link. K.P.. 1961. Studies on the 4-hydroxycoumarins. XVII. The resolution and absolute configuration of warfarin.J.Am.Chem.Soc. 83:2676-2679.

Williams, K.M.. 1989. Chirality: pharmacokinetics and pharmacodynamics in 3 dimensions. Clin. Exp. Pharmacol. Physiol. 16: 465-470.

Williams, K.M., 1990. Enantiomers in arthritic disorders. Pharmacol. Ther. 46: 273-295.

Wingard, L.B., O'Reilly, R.A., and Levy, G., 1978. Pharmacokinetics of warfarin enantiomers: a search for intrasubject correlations. Clin. Pharmacol. Ther. 23: 212-217.

Yacobi and Levy. 1974. Pharmacokinetics of the warfarin enantiomers in rats. J. Pharmacokin. Biopharm. 2: 239-255. 


\section{CHAPTER 8:}

\subsection{SUMMARY}

The fact that stereoisomers exert different effects in biology is well documented and is gaining more and more attention. Warfarin and acenocoumarol (4'-nitrowarfarin) are chiral drugs that are widely used as oral anticoagulants. In the discussion conceming chiral drugs in pharmacology, warfarin is an often cited example because of its well documented stereoselective pharmacokinetics, pharmacodynamics, and drug interactions. In this thesis, the stereochemical course of the pharmacokinetics and in vitro metabolism of warfarin has been compared with some of its phenyl ring substituted analogues. Special attention is given to acenocoumarol since it displays quite different pharmacokinetic properties than warfarin.

The pharmacokinetics of various warfarin analogues in rats is described in chapter 2. Phenyl ring substitution appeared to have a great impact on the pharmacokinetics and the stereochemistry thereof. The S-enantiomers of warfarin and its 4'- and 3'- substituted analogues were shown to be more tightly bound to plasma proteins than the R-enantiomers. The opposite was observed for the 2'-substituted analogues.

Phenyl ring substitution resulted in a higher intrinsic clearance than that of warfarin. Stereoselectivity of the intrinsic clearance was shown to depend on the position of the substituent: the intrinsic clearance of warfarin and its 3'-substituted analogues was higher for the R-enantiomers. In contrast, 2'- and 4'- substitution generally reversed this stereoselectivity.

In chapter 3, the rat liver microsomal metabolism of warfarin has been compared with that of acenocoumarol. The overall metabolism of warfarin was found to be stereoselective for the R-enantiomer, whereas that of acenocoumarol was shown to be stereoselective for the Senantiomer. In addition, the total metabolic intrinsic clearances of $\mathrm{R}$ - and $\mathrm{S}$-acenocoumarol greatly exceeded those of the enantiomers of warfarin. due to the lower $\mathrm{Km}$ values of acenocoumarol towards monooxygenases. From experiments with the P450 inducers phenobarbitone and methylcholanthrene and the cytochrome P450 inhibitor cimetidine it appeared that the spectrum of isozymes involved in the metabolism of warfarin is different from that involved in the metabolism of acenocoumarol. Experiments with antibodies raised against $\mathrm{P} 450$ isozymes of the $2 \mathrm{C}$ and $3 \mathrm{~A}$ subfamilies showed that these $\mathrm{P} 450$ s are probably involved in the metabolism of both compounds. However, their stereo- and regioselectivity. differ greatly for warfarin and acenocoumarol.

To investigate whether similarmetabolic differences between warfarin and acenocoumarol are also observed in humans, their human liver microsomal metabolism has been compared in chapter 4 . The overall metabolism of both compounds was stereoselective for the Senantiomer, but this stereoselectivity was far more pronounced for acenocoumarol. In addition. the total intrinsic clearances of the enantiomers of acenocoumarol greatly exceeded those of $\mathrm{R}$ - and $\mathrm{S}$-warfarin. As in rats, this was mainly due to the lower $\mathrm{Km}$ values of 
acenocoumarol towards the metabolizing enzymes. From experiments with P450 inhibitors, and from the lack of a correlation between the formation rates of warfarin and acenocoumarol metabolites it was concluded that, as in rats, the (stereochemical) differences in the kinetics between warfarin and acenocoumarol are at least in part attributable to the fact that the metabolism of these compounds is carried out by different combinations of P450 isozymes. This suggests that the phenyl ring of warfarin is involved in the interaction with $\mathrm{P} 450$ binding sites and that ring substituted warfarin analogues may discriminate for particular P450 isozymes.

Another metabolic route of warfarin analogues, reduction of the acetonyl side chain to the diastereomeric alcohols is described in chapters 5 and 6 . The ketone reduction of warfarin, and its 4'-nitro, and 4'-chloro analogues was investigated in microsomal and cytosolic fractions of various species (chapter 5). Ketone reduction occurred in both subcellular fractions and was shown to be NADPH dependent. In microsomes, large differences between species, as well as between the warfarin analogues were observed in alcohol formation rates and in substrate- and product stereoselectivity. No general pattem was evident. In cytosolic fractions, a general pattem of substrate- and product stereoselectivity was observed: the Renantiomers were preferred as a substrate and the alcohols formed were mainly in the S-configuration. Contrary to the microsomal reductase activity, the cytosolic reductase activity in the rat was induced by phenobarbitone and methylcholanthrene. In cytosolic fractions, acenocoumarol was generally a better substrate than 4'-chlorowarfarin which in its turn was a better substrate than warfarin.

In chapter 6 , the rabbit liver cytosolic warfarin reductase has been partially purificd and characterized. DEAE-Sephacel chromatography revealed that at least two enzymes (fractions $A$ and $B$ ) possess warfarin ketone reductase activity. Both enzymes showed similar substrate- (for the R-enantiomers) as well as product stereoselectivity (formation of the Salcohols) but were differently influenced by 4'-substitution in their kinetics. 4'-Substitution predominantly affected the $\mathrm{Km}$ values for fraction $\mathrm{A}$, whereas for fraction $\mathrm{B}$ Vmax values were affected. NADPH was the preferred cofactor, which was absolute for fraction B. Both fractions were able to reduce carbonyl groups from a variety of compounds, including prostaglandin E2 and steroids, but fraction A showed a broader substrate spectrum and was e.g. also able to reduce the quinone menadione. Both fractions were inhibited by the flavonoid quercetin, but not by sodium-barbitone.

Finally, in chapter 7, the results of this thesis, the value of enantiomers in biomedical science, and some considerations conceming the use of enantiomerically pure or racemic drugs will be discussed.

The experiments described in this PhD thesis show that the different effects of enantiomers in biological systems is not only due to the distinct 3-dimensional structure of the enantiomers, but also to the multiplicity of biomolecules with which they can (or cannot) interact. 


\subsection{SAMENVATTING}

Het feit dat stereoisomeren verschillende effecten vertonen in biologische systemen kent vele voorbeelden en begint steeds meer aandacht te krijgen. Warfarine en acenocoumarol (4:nitrowariarine) zijn chirale verbindingen die algemeen worden toegepast als orale anticoagulantia. Ten aanzien van de rol van chirale verbindingen in de farmacologie wordt warfarine vaak genoemd als voorbeeld omdat hiervan de stereochemische aspecten in de farmacokinetiek, farmacodynamiek, alsook in interacties met andere farmaca uitgebreid zijn beschreven. In dit proefschrift wordt de stereoselectiviteit van de farmacokinetiek en van het in vitro metabolisme van warfarine en enkele phenyl ring gesubstitueerde warfarine analoga met elkaar vergeleken. Hierbij wordt extra aandacht geschonken aan acenocoumarol omdat dit geneesmiddel farmacokinetisch gezien vrij sterk van warfarine verschilt.

De farmacokinetiek van enkele warfarine analoga in de rat wordt beschreven in hoofdstuk 2. Substitutie aan de phenyl ring bleek sterke effecten te hebben op de farmacokinetiek en de stereoselectiviteit hiervan. Zo bleken b.v. de S-enantiomeren van warfarine en diens 3'- en 4'- gesubstitueerde analoga sterker aan plasma eiwitten gebonden te zijn dan de R-enantiomeren. Voor de 2'- gesubstitueerde warfarine analoga bleek echter het omgekeerde het geval te zijn.

Phenyl ring substitutie leidde in alle gevallen tot een verhoging van de intrinsieke klaring. De stereoselectiviteit van de intrinsieke klaring bleek af te hangen van de positie van de substituent. De intrinsieke klaring van warfarine en zijn $3^{\prime}$ - gesubtitueerde analoga was hoger voor de R-enantiomeren. Daarentegen bleken 2'- en 4'-subtitutie i.h.a. te leiden tot een hogere intrinsieke klaring van de S-enantiomeren.

In hoofdstuk 3 wordt het rattelever microsomale metabolisme van warfarine vergeleken met dat van acenocoumarol. De totale metabole intrinsieke klaring van warfarine bleek hoger voor de R-enantiomeer te zijn, terwijl in het geval van acenocoumarol juist de S-enantiomeer het snelsi gemetabolizeerd werd. Bovendien bleek dat de intrinsieke klaring van R- en Sacenocoumarol veel hoger was dan de intrinsieke klaring van beide warfarine enantiomeren. Dit bleek met name te wijten aan de lagere $\mathrm{Km}$ waarden die acenocoumarol heeft t.o.v. het monooxygenase systeem. Experimenten met de cytochroom $\mathrm{P} 450$ inducers phenobarbital en methylcholanthreen en de P450 inhibitor cimetidine duidden erop dat het spectrum van isoenzymen dat betrokken is bij het metabolisme van acenocoumarol verschilt van dat van warfarine. Uit experimenten met antilichamen, opgewekt tegen P450's van de $3 \mathrm{~A}$ en $2 \mathrm{C}$ subfamilies, bleck dat deze $\mathrm{P} 450$ 's waarschijnlijk betrokken zijn bij het metabolisme van beide stoffen. Echter, hun stereo- en regioselectiviteit en hun relatieve bijdrage aan de totale metabole klaring bleek te verschillen voor warfarine en acenocoumarol.

Om te onderzoeken of dergelijke metabole verschillen tussen warfarine en acenocoumarol ook in de mens waargenomen worden, werd hun metabolisme in humane lever microsomen met elkaar vergeleken. Het totale metabolisme bleek voor beide stoffen stereoselectief te zijn voor de S-enantiomeer, maar deze stereoselectiviteit was veel sterker in het geval van 
acenocoumarol. Ook bleek, net als in de rat, de totale intinsieke klaring van de acenocoumaro! enantiomeren veel groter te zijn dan in het geval van R-en S-warfarine. Ook nu weer was dit te wijten aan de lagere $\mathrm{Km}$ waarden van acenocoumarol t.o.v. de metabolizerende enzymen. Uit experimenten met P450 inhibitoren, en uit het gebrek aan correlatie tussen de vormingssnelheden van de metabolieten van warfarine en acenocoumarol werd geconcludeerd dat de kinetische verschillen tussen de warfarine analoga in ieder geval deels zijn tenug te voeren op het feit dat verschillende combinaties van isoenzymen deze stoffen metabolizeren. Hieruit blijkt dat de phenyl ring van warfarine betrokken is bij de interactie met P450 bindings-plaatsen en dat phenyl ring gesubstitueerde warfarine analoga onderscheid künnen maken tussen bepaalde $\mathrm{P} 450$ isoenzymen.

Een andere metabole route van warfarine analoga is de reductie van de acetonyl zijketen waarbij diastereomere alcoholen worden gevormd. De keton reductie van warfarine, en diens 4'-nitro en 4'-chloor analoga door(lever) microsomale en cytosolaire fracties van verschillende species werd bestudeerd in hoofdstuk 5. Deze reactie werd door beide subcellulaire fracties uitgevoerd en bleek NADPH afhankelijk te zijn. In microsomen werden grote verschillen tussen de species en de warfarine analoga waargenomen wat betreft reactie snelheden alsook substraat- en product stereoselectiviteit. Een algemeen patroon werd niet waargenomen. In cytosol fracties werd er echter wel een algemeen patroon van substraat- en product stereoselectiviteit waargenomen: de R-enantiomeren werden geprefereerd als substraat en de gevormde alcoholen bleken vooral in de $S$-configuratie te zijn. De cytosolaire keton reductase activiteit bleek, in tegenstelling tot de microsomale keton reductase activiteit, in de rat geinduceerd te worden door phenobarbital en methylcholanthreen. Voorts bleek dat in de cytosolaire fracties acenocoumarol een beter substraat was dan 4'-chloorwarfarine, dat op haar beurt weer een beter substraat was dan warfarine.

In hoofdstuk 6 wordt de partiële zuivering en karakterisering beschreven van lever cytosolaire enzymen uit het konijn die de keton groep van warfarine kunnen reduceren. Uit DEAE Sephacel chromatografie bleek dat deze reactie door minstens twee enzymen wordt gecatalyseerd (fractie A en B). Beide fracties vertoonden een zelfde substraat- (voor de Renantiomeren) en product (vorming van vooral de $S$-alcoholen) stereoselectiviteit maar subtitutie van de 4'-groep van warfarine had voor beide fracties verschillende effecten op de enzym kinetiek. In het geval van fractie A bleek 4'-substitutie met name effect te hebben op de $\mathrm{Km}$ van het warfarine analogon, terwijl in het geval van fractie $\mathrm{B}$ met name de Vmax beïnvloed werd. Beide fracties waren in staat carbonyl groepen van verschillende stoffen (waaronder prostaglandine E2 en steroïden) te reduceren maar de substraat specifiteit bleek het breedst voor fractie A. Deze fractie kon b.v. ook het chinon menadion reduceren. Het flavonoid quercetine was een inhibitor van beide enzym fracties, terwijl natrium barbital geen effect had. 
In hoofdstuk 7 tenslotte, worden de resultaten van dit proefschrift, het nut vanenantiomeren als gereedschap in de biomedische wetenschappen, en enige overwegingen ten aanzien van het gebruik van racemische of zuiver enantiomere geneesmiddelen bediscussiëerd.

De experimenten die in dit proefschrift beschreven worden, laten zien dat de verschillen die waargenomen worden in de biologische effecten van enantiomeren niet alleen terug te voeren zijn op de verschillende 3-dimensionale structuur van de enantiomeren, maar ook op de veelheid van biomoleculen waarmee enantiomeren al dan niet een interactie aangaan. 


\section{CURRICULUM VITAE}

\section{J.J.R.M. (Rob) Hermans}

\section{0-Augustus 1966: Geboren te Amby}

1978-1984: Gymnasium B, Stella Maris, te Meerssen.

1984-1988: Studie Gezondheidswetenschappen (Biologische Gezondheidkunde), Rijksuniversiteit Limburg.

1988-1992: Aanstelling als AIO bij de vakgrnep Farmacologie, Rijksuniversiteit Limburg. 


\section{Lijst van publicaties:}

\section{Full papers:}

Hermans, J.J.R., and Thijssen, H.H.W., 1989, The in vitro ketone reduction of warfarin and analogues. Substrate stereoselectivity, product stereoselectivity, and species differences. Biochem. Pharmacol. 38: 3365-3370.

Verhagen, H., Fumeé, C., Schutte, B., Hemnans, J.J.R., Bosman, F.T., Blijham, G.H., ten Hoor, F., and Kleinjans, J.C.S., 1989, Butylated hydroxyanisole-induced alterations in cell kinetic parameters in rat forestomach in relation to its oxidative cytochrome P450 mediated metabolism. Carcinogenesis 10: 1947-1991.

Baars, L.G.M., Schepers, M.T., Hermans, J.J.R., Dahlmans, H.J., and Thijssen, H.H.W., 1990. Enantioselective structure-pharmacokinetic relationships of ring substituted warfarin analogues in the rat $\boldsymbol{j}$. Pharm. Pharmacol. 42: 861-866

Hageman, G., Hermans, R., ten Hoor, F., and Kleinjans, J., 1990, Mutagenicity of deep-frying fat, and evaluation of urine mutagenicity after consumption of fried potatoes. Food Chem. Toxicol. 28: 75-80.

Hermans, J.J.R., and Thijssen, H.H.W., 1991, Comparison of the rat liver microsomal metabolism of the enantiomers of warfarin and 4'-nitrowarfarin (Acenocoumarol). Xenobiotica 21: 295-307.

Hermans, J.J.R., and Thijssen, H.H.W., 1992, Stereoselective acetonyl side chain reduction of warfarin and analogs. Partial characterization of two cytosolic carbonyl reductases. Drug Metab. Dispos.20: 268-274.

Hermans, J.J.R., and Thijssen, H.H.W., Comparative biotransformation of warfarin analogues in human liver microsomes: 4'-substitution modifies cytochrome $\mathrm{P} 450$ isozyme selectivity. Submitted, 1992.

Hermans, J.J.R., and Thijssen, H.H.W., Properties and stereoselectivity of carbonyl reductases involved in the ketone reduction of warfarin and analogues. To be published (Molecular Biology and Enzymology of Carbonyl Metabolism. 4 eds Weiner. H., and Flynn T.G., New York.

Oppermann, U.C.T., Maser, E., Hermans, J.J.R., Koolmann, J., and Netter, K.J., 1992, Functional and structural homologies between vertebrate microsomal liver, procaryontic. and insect enzymes involved in steroidogenic andxenobiotic carbonyl metabolism.To be published. (I. Steriod. Biochem.) 


\section{Abstracts:}

Hageman, G., Hermans, R., and Kleinjans, J.C.S., 1987, Evaluation of mutagenic activity of deep fat fried foods. Pharm. Weekbl. Sci. Ed. 9: 353

Hermans, J.J.R.. and Thijssen, H.H.W., 1988. The in vitro reduction of the ketone group of some warfarin derivatives: stereoselectivity and species differences. Pharm.Weekbl. Sci. Ed. 10: 230.

Hermans, J.J.R., and Thijssen, H.H.W., 1989, Comparative in vitro metabolism of warfarin and acenocoumarol: stereochemical aspects. Naunyn-Schmiedeberg's Arch. Pharmacol. 335 (Suppl): R5, 20.

Hermans, J.J.R., and Thijssen, H.H.W., 1990, Partial purification of a liver cytosolic carbonyl reductase, reducing the acetonyl side chain of warfarin andderivatives.Eur. J. Pharmacol. 183: 375, P200.

Hermans, J.J.R., and Thijssen, H.H.W., 1990, Ketone reduction of warfarin and analogues: partial purification of a liver cytosolic reductase.Naunyn Schmiedeberg's Arch. Phaimacol. 341 (Suppl): R8, 30.

Oppermann, U., Maser, E., Hermans, J.J.R., Thijssen, H.H.W., Gebel. T., and Netter,K.J., 1991. Establishment of an evolutionary conserved microsomal class of liver enzymes involved in steroidogenesis and reductive xenobiotic metabolism. $3 \mathrm{th} \mathrm{Int}$. Meeting ISSX, abstract 253.

Hermans, J.J.R., and Thijssen, H.H.W., 1992, Stereochemical aspects in the inhibition of the DTT-dependent vitamin $\mathrm{K}$-epoxide reductase by the enantiomers of warfarin. Pharm. Weekbl. Sci. Ed. 14: B7. 


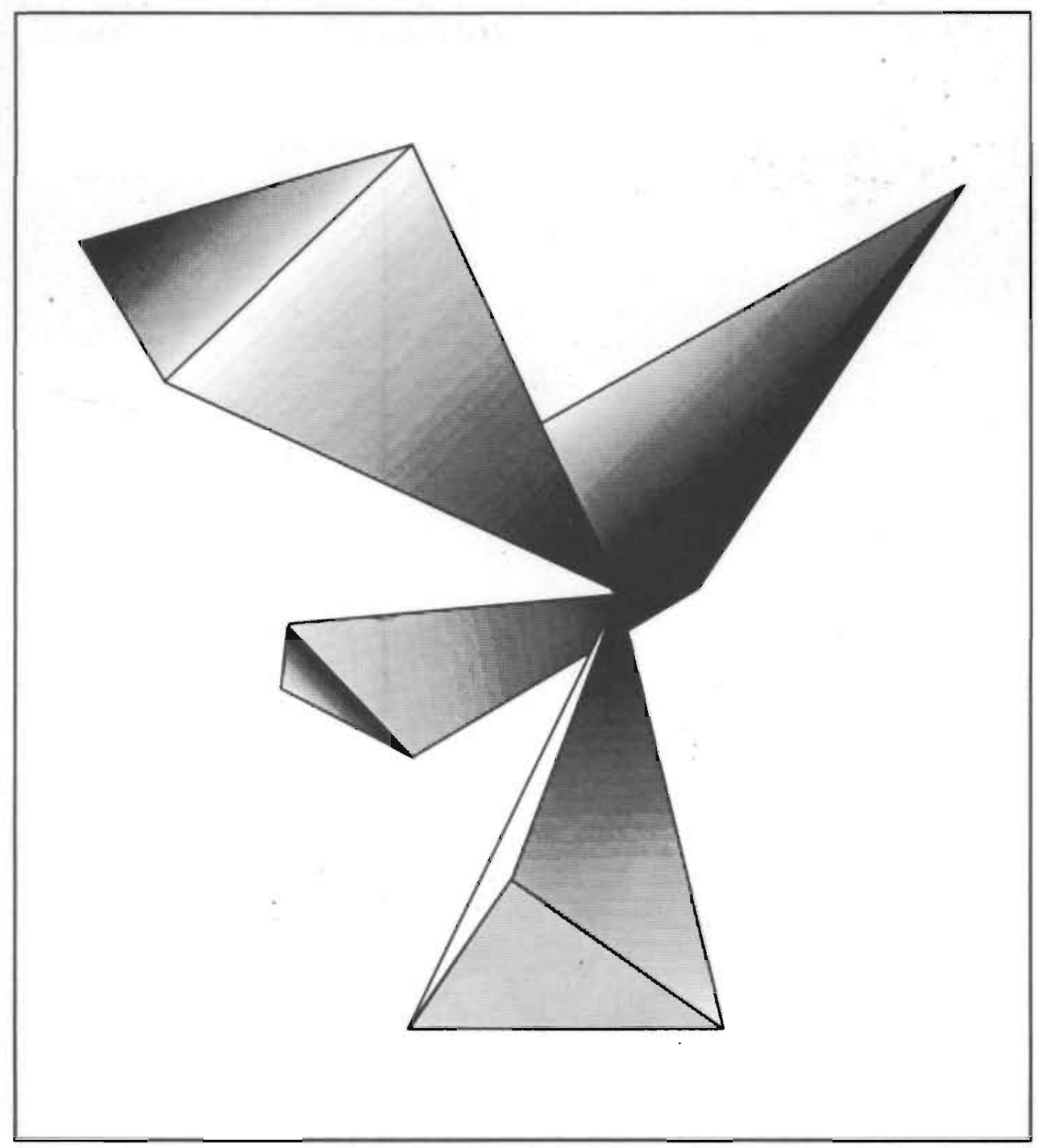

